\title{
Reclosing Transients in Standard and Premium Efficiency Induction Machines in the Presence of Voltage Unbalance
}

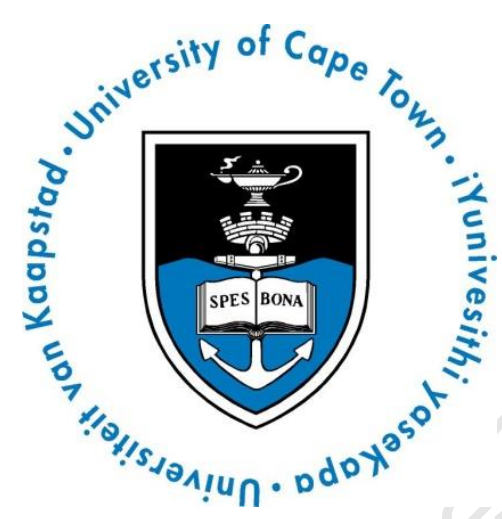

\section{Prepared by: \\ Tumelo Gabaraane GBRTUM001}

Department of Electrical Engineering

University of Cape Town

\section{Prepared for: \\ A. Prof Paul Barendse \\ Department of Electrical Engineering \\ University of Cape Town}

\section{June 2018}

Submitted to the Department of Electrical Engineering at the University of Cape Town in full fulfilment of the academic requirements for the Degree of Master of Science in Electrical Engineering.

Key Words: flux, residual voltage, induction, impedance, reclosing transients, unbalance 
The copyright of this thesis vests in the author. No quotation from it or information derived from it is to be published without full acknowledgement of the source. The thesis is to be used for private study or noncommercial research purposes only.

Published by the University of Cape Town (UCT) in terms of the non-exclusive license granted to UCT by the author. 


\section{Declaration}

I, Tumelo Gabaraane, know the meaning of plagiarism and declare that all the work in the document, save for that which is properly acknowledged, is my own. This dissertation has been submitted to the Turnitin module and I confirm that my supervisor has seen my report and any concerns revealed by such has been resolved with my supervisor. All information that is not my own has been clearly referenced. I declare that this thesis has not been presented and will not be presented to any other University or institution for any similar or other degree.

Name: $\quad$ Tumelo Gabaraane

Signature: 


\section{Acknowledgements}

I would like to give thanks to the following:

- First of all, Lord God Almighty for ALL the good He has done in my life. I continuously give Him all the glory;

- Both my parents for continually supporting me through my entire school career with their amazing love;

- My supervisor, Associate Professor Paul Barendse, for his patience and guidance throughout this entire study;

- My co-supervisor, Associate Professor Azeem Khan, for his advice and his supply of necessary material for this study;

- My friends and colleagues: Mr Jonathan Kaija, Mr Andrew Ipurale, Mr Abdullah Jabbar, Mr Alfred Waligo, Dr Oladapo Ogidi, Mr Akrama Khan, Mr Hoosein Denarvifard, Mr Mpendulo Dlamini, Mr Himal Patel, Mr Jatin Harribai and Mr Joshua Siame who have supported and assisted me greatly;

- The lab supervisor Mr Chris Wozniak for his support and advice when working in the machines lab;

- Mr Philip Titus and the technical crew for their support in setting up the machines;

- And to NRF for providing financial support 


\section{Abstract}

The impact of restarting an induction machine, while coasting, was investigated in this study. When restarting an induction machine, high peaking current and torque transients appear. As a result, possible damage to the rotor shaft could occur together with a destabilising of the power system which could lead to fluctuating supply voltage levels. This dissertation investigated the restarting of two different efficiency class induction machines and analyses how a shift in the phase between the supply voltage and the residual voltage affects the restarting transients. Previous studies have been carried out on standard efficiency induction machines, however this study aimed to compare the impact of restarting on the standard and premium plus efficiency induction machines.

The design differences between standard and energy efficient induction machines play a significant role in how these transients behave. The energy efficient machines were found to be made of higher grade lamination steel and larger sized conductors in order to reduce the stator and rotor copper losses. Using material with a higher permeability, as is the case with energy efficient machines, ensures that the machines are able to retain less residual flux at the point of disconnect than standard motors. It is for this reason that the energy efficient machines have a larger residual voltage at the point of disconnect. However, the speed of the decay of the residual flux of the standard efficiency machine is higher than the energy efficient machine and, as a result, the energy efficient machine resulted with a higher residual voltage at the $180^{\circ}$ phase shift. This leads to a larger potential difference for the energy efficient machines than the standard efficiency machines. However, the stator impedance of the energy efficient machine was established as a dominating factor in the outcome of the tests results. Energy efficient machines have a significantly lower impedance than standard efficiency machines and due to this, they are more susceptible to the detrimental effects of out-of-phase restarting.

It was important to establish a critical point when the current and torque transients are at a maximum as the motors speed is winding down. It is necessary to minimise the effects of restarting at this critical point as the resulting developed torque can be mechanically detrimental to the shaft. The residual voltage needs to be minimised dramatically to a point where the out-of-phase reclosing will not give rise to significantly high torque transients.

Additional to this study was the observation of the current and torque transients in the presence of voltage unbalance. Voltage unbalance presents a power quality issue which can potentially have a negative effect on the efficiency of an induction machine. Both machines were tested for $0 \%, 1 \%$ and $2 \%$ voltage unbalance with a focus on start-up and $180^{\circ}$ restart. In addition, voltage unbalance was introduced at the rated voltage of $400 \mathrm{~V}$ with $10 \%$ variations above and below this rating for over and undervoltage respectively. It was seen that the energy efficient machines were more vulnerable to unbalance effects due to a larger negative sequence air gap torque being developed under transient conditions. 


\section{Table of Contents}

Declaration

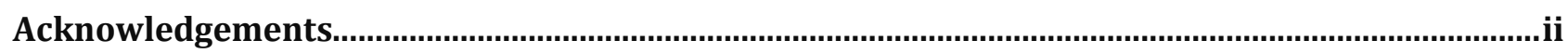

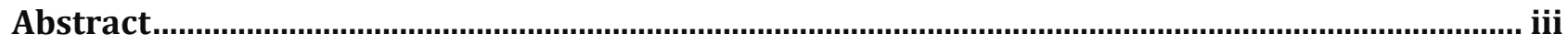

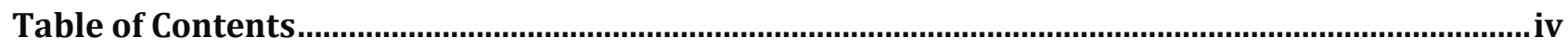

List of Figures

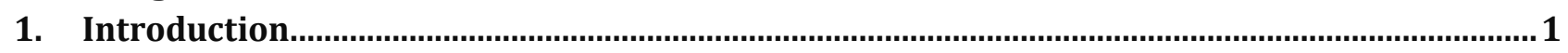

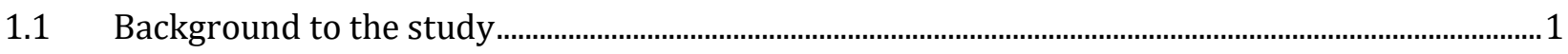

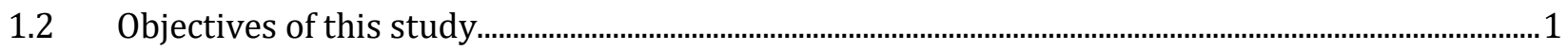

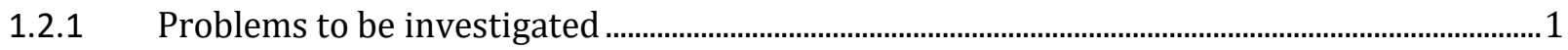

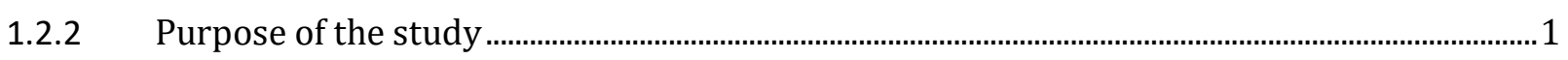

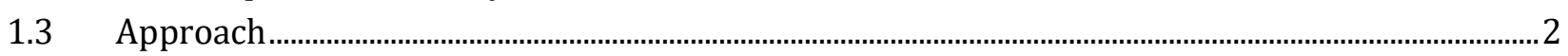

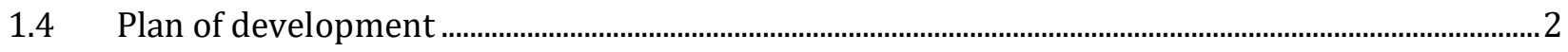

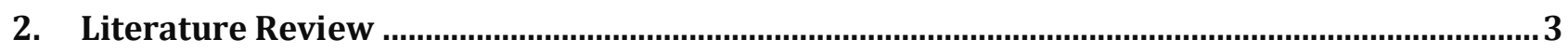

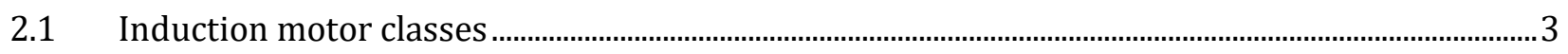

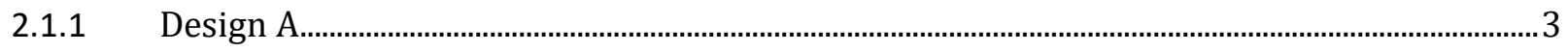

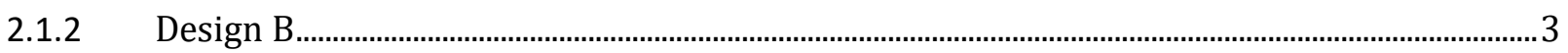

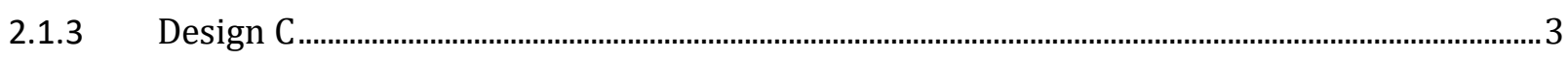

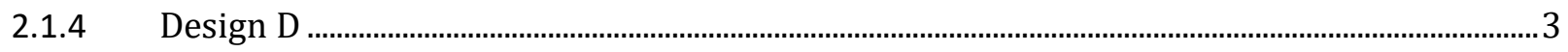

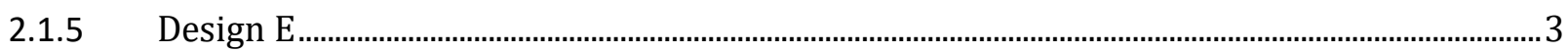

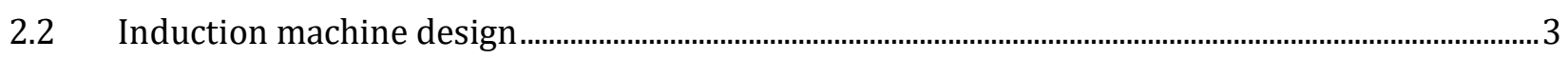

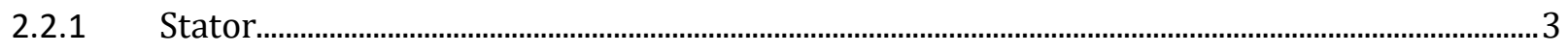

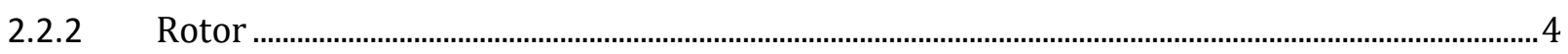

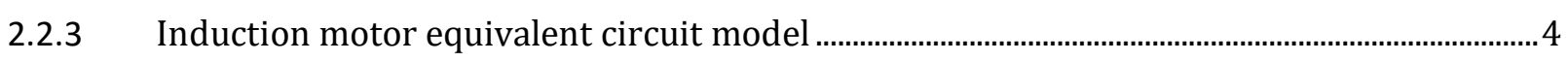

2.2.4 Principles of operation of an induction machine..........................................................................

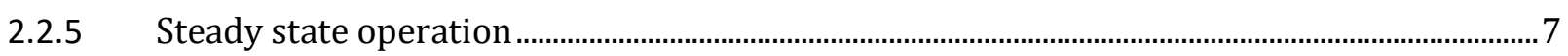

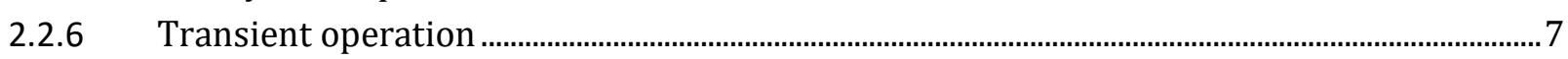

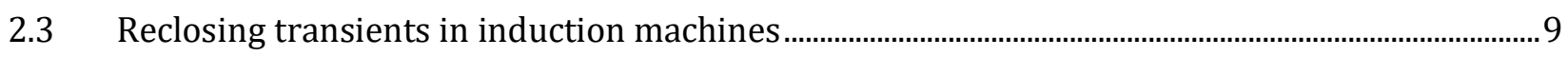

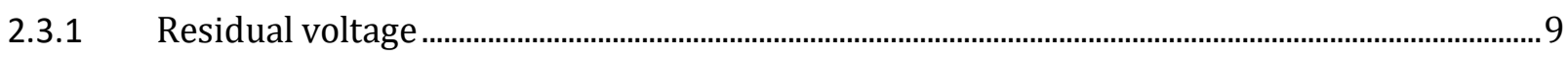

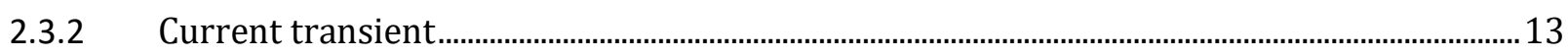

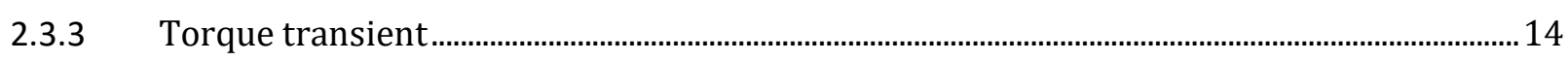

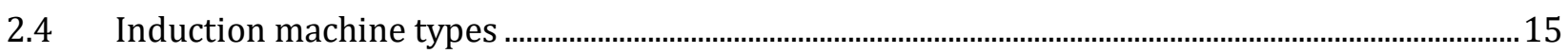

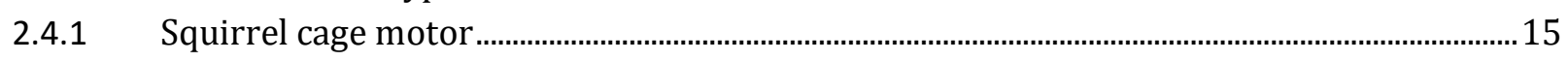

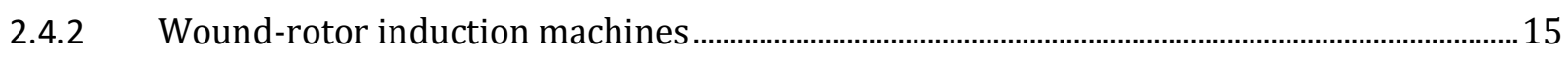

2.5 Differences between standard and energy efficient machines .......................................................... 15

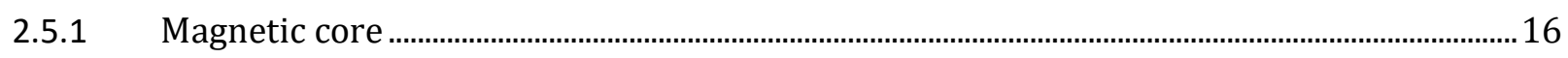

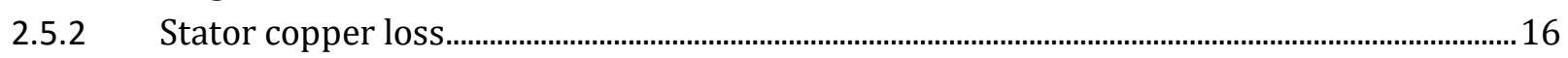

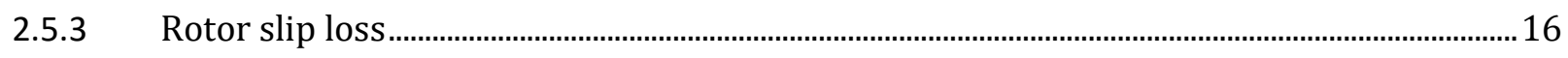

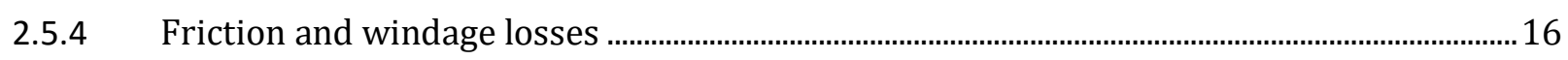

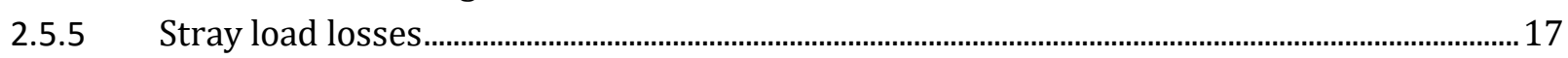

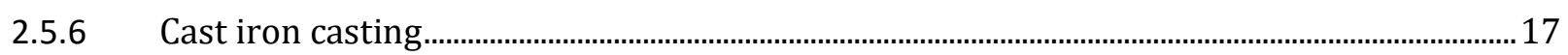

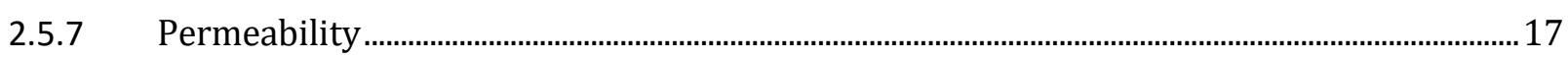

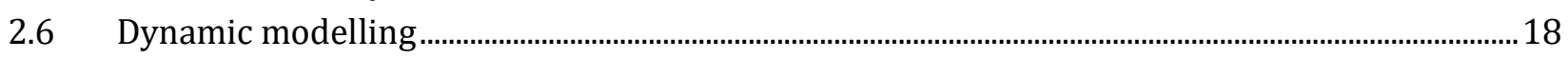

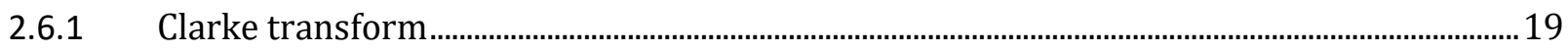

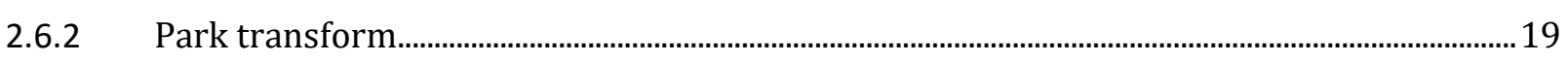

$2.7 \quad$ Voltage unbalance ....................................................................................................................... 19 
2.7.1 National electrical manufacturers association (NEMA) ..........................................................20

2.7.2 Institute of electrical and electronic engineers (IEEE) ……..................................................... 20

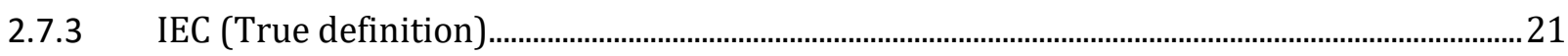

2.7.4 Per-phase equivalent circuit model.........................................................................................21

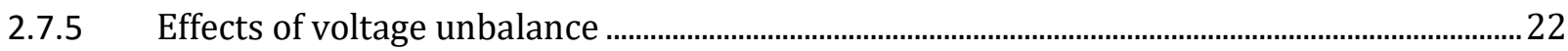

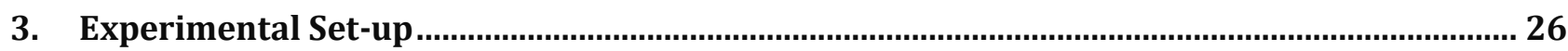

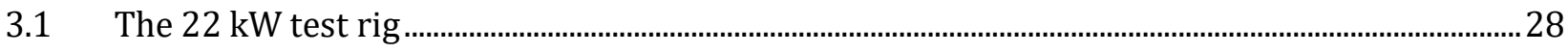

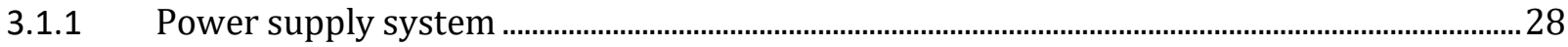

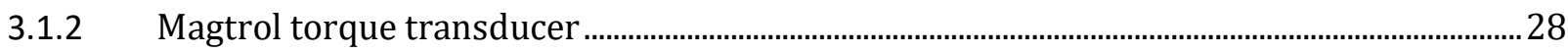

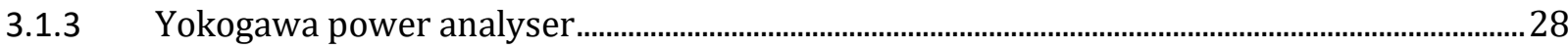

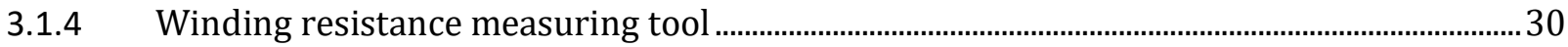

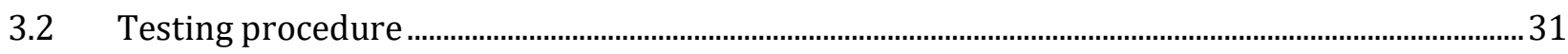

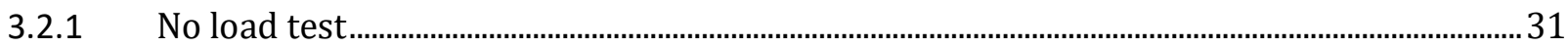

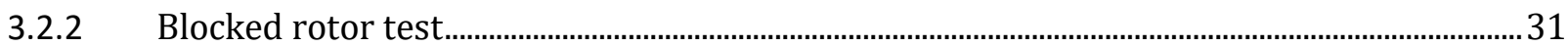

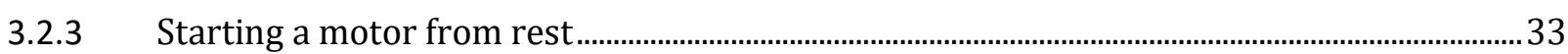

3.2.4 Restarting a motor in a coasting transient state …......................................................................33

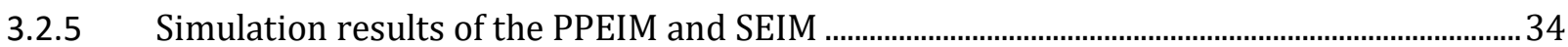

4. Validation of results and discussion of balanced induction machine transients .................. 43

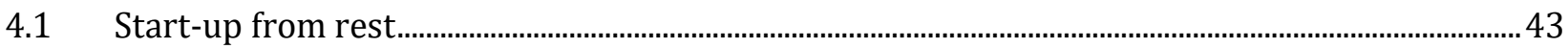

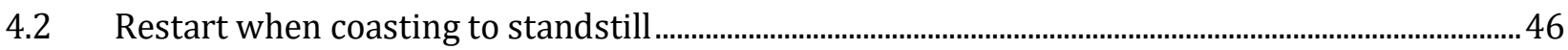

4.3 Important factors in determining restarting transients in induction machines ...........................60

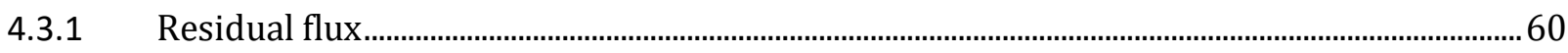

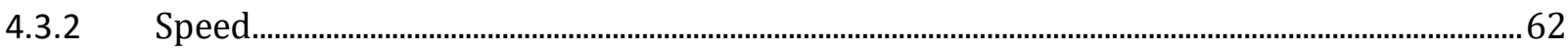

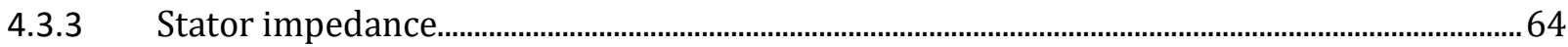

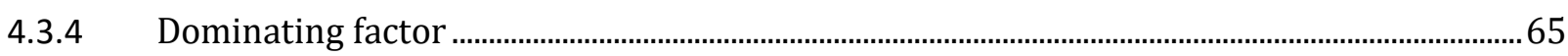

5. Impact of voltage unbalance on reclosing of SEIM and PPEIM ...............................................66

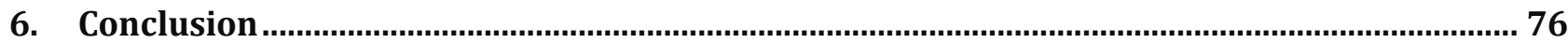

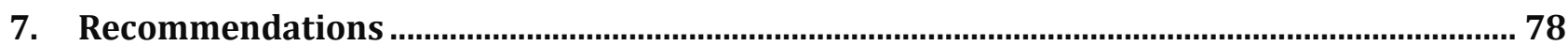

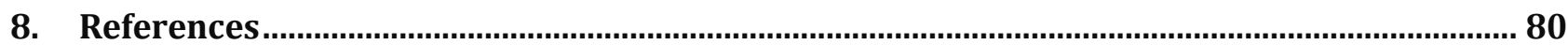

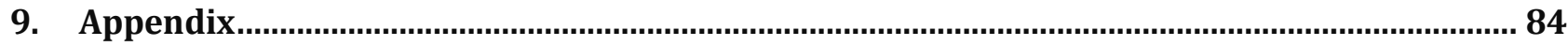

9.1 MATLAB code used to extract peak torque values...............................................................................

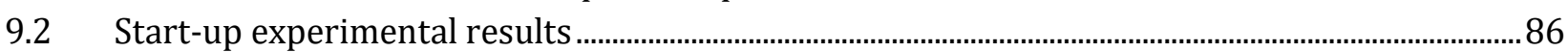

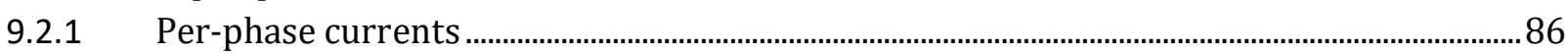

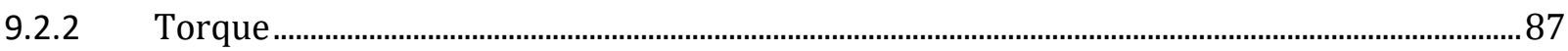

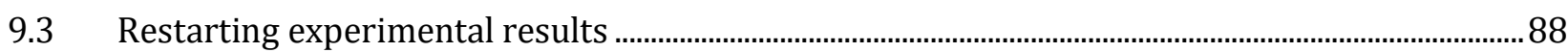

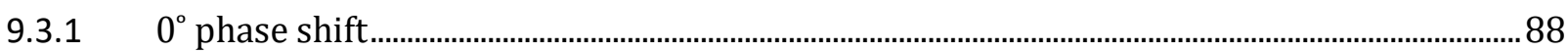

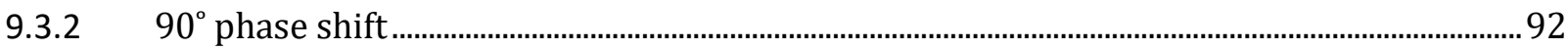

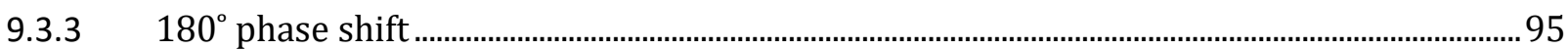




\section{List of Figures}

\section{List of Illustrations}

Figure 1: Typical stator coil configuration [6] ……...........................................................................................

Figure 2: Induction machine rotor

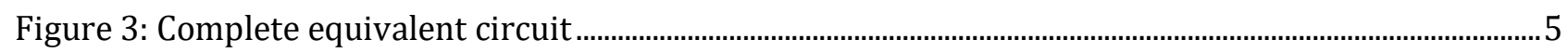

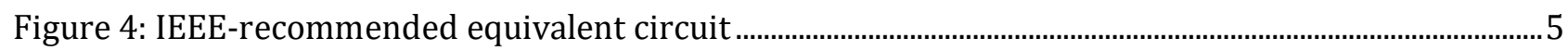

Figure 5: Per-phase stator voltage profile from Matlab SIMULINK.....................................................................6

Figure 6: Circuit connection for induction machine (Matlab SIMULINK) ..........................................................6

Figure 7: Torque-speed characteristics of different induction machines [6] .....................................................

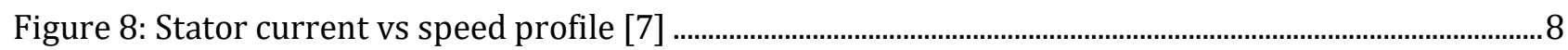

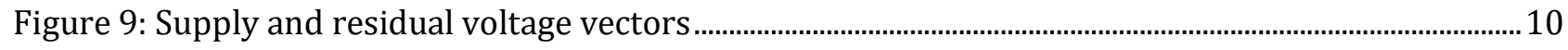

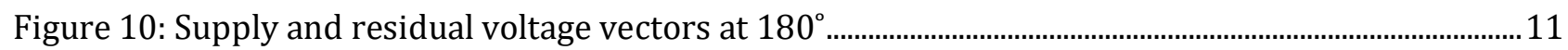

Figure 11: Residual voltage profiles after disconnect ..........................................................................................13

Figure 12: Various components of stator and rotor magnetic fields ……......................................................... 14

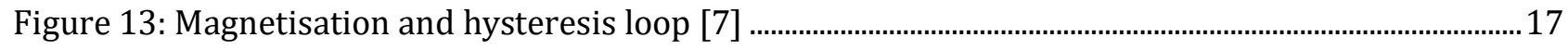

Figure 14: Per-phase positive sequence equivalent circuit [4] ……….............................................................2

Figure 15: Per-phase negative sequence equivalent circuit [4] ….................................................................2 21

Figure 16: Voltage unbalance implications in induction machines [39] ............................................................23

Figure 17: Positive and negative sequence torques under voltage unbalance [36] .......................................24

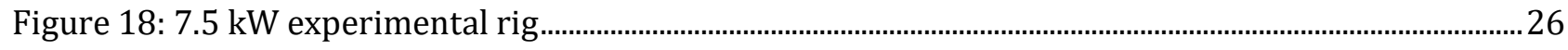

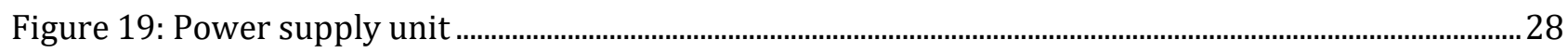

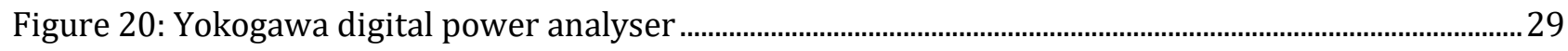

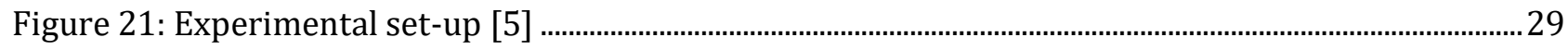

Figure 22: Galvanometer for winding resistance measurement..................................................................... 30

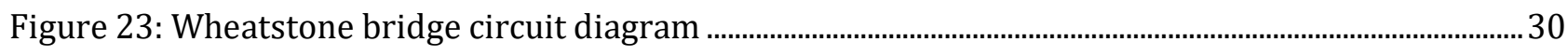

Figure 24: Stator resistance wiring arrangement........................................................................................... 31

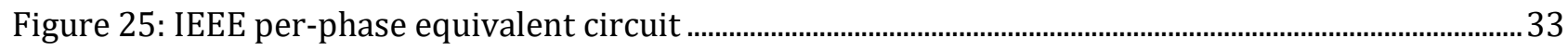

Figure 26: SIMULINK model for PPEIM and SEIM .............................................................................................. 34

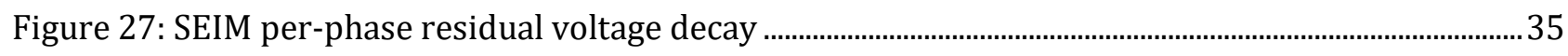

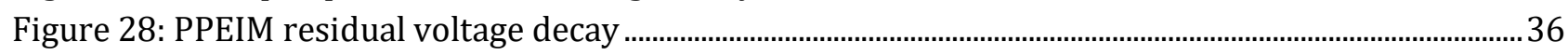

Figure 29: SEIM current transient response - 180 degrees phase shift ............................................................36

Figure 30: PPEIM current transient response - 180 degrees phase shift............................................................37

Figure 31: PPEIM SIMULINK torque \& speed transient response - 180 degrees phase shift ...................... 38

Figure 32: SEIM SIMULINK torque \& speed transient response - 180 degrees phase shift.......................... 38

Figure 33: Detailed view of SEIM rotor speed decay - 180 degrees phase shift ................................................39

Figure 34: Detailed view of PPEIM rotor speed decay - 180 degrees phase shift............................................ 40

Figure 35: Detailed view of SEIM residual voltage peak after the point of disconnect .................................. 41

Figure 36: Detailed view of PPEIM residual voltage peak after the point of disconnect.................................41

Figure 37: Rated per-phase start-up stator current ........................................................................................... 44

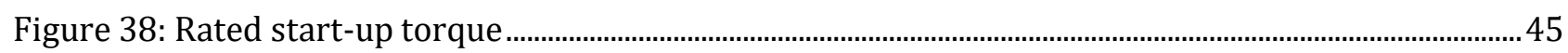

Figure 39: $0^{\circ}$ Per-phase supply voltage vs. residual voltage [SEIM] ................................................................. 47

Figure 40: Per-phase residual voltage - 0 degrees phase shift................................................................................ 48

Figure 41: Per-phase stator current - 0 degrees phase shift............................................................................ 49

Figure 42: Torque - 0 degrees phase shift …………......................................................................................... 50

Figure 43: $90^{\circ}$ Per-phase supply voltage vs. residual voltage [SEIM] ……....................................................... 51

Figure 44: Per-phase stator residual voltage - 90 degrees phase shift..............................................................52

Figure 45: Per-phase stator current - 90 degrees phase shift ............................................................................... 53 
Figure 46: Torque - 90 degrees phase shift

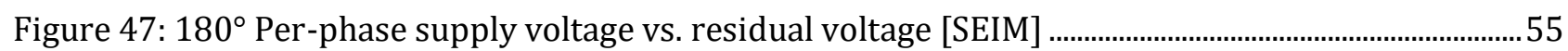

Figure 48: Per-phase residual voltage - 180 degrees phase shift (a) ................................................................. 56

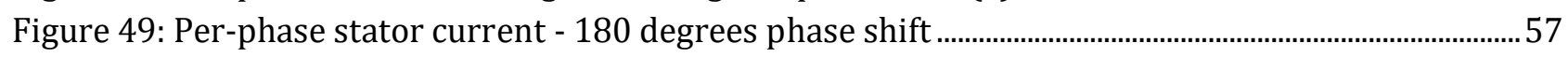

Figure 50: Torque - 180 degrees phase shift............................................................................................................58

Figure 51: Per-phase residual voltage - 90 degree phase shift (b) ....................................................................... 60

Figure 52: Per-phase residual voltage - 180 degree phase shift (b) .................................................................61

Figure 53: Speed transient - 0 degree phase shift ...................................................................................................62 62

Figure 54: Speed transient - 90 degree phase shift............................................................................................63

Figure 55: Speed transient - 180 degree phase shift.............................................................................................64

Figure 56: SEIM speed for rated voltage unbalance at 180 degrees phase shift ...........................................69

Figure 57: PPEIM speed for rated voltage unbalance at 180 degrees phase shift ...........................................69

Figure 58: SEIM torque for rated voltage unbalance at 180 degrees phase shift............................................ 70

Figure 59: PPEIM torque for rated voltage unbalance at 180 degrees phase shift ........................................ 71

Figure 60: SEIM rated, under- \& overvoltage torque comparison .......................................................................... 72

Figure 61: PPEIM rated, under- \& overvoltage torque comparison ..................................................................... 73

Figure 62: PPEIM undervoltage torque comparison between rated, $1 \%$ and $2 \%$ unbalance....................... 74

Figure 63: SEIM undervoltage torque comparison between rated, $1 \%$ and $2 \%$ unbalance ...........................75

Figure 64: Rated phase A start-up current........................................................................................................ 86

Figure 65: Rated phase B start-up current........................................................................................................... 86

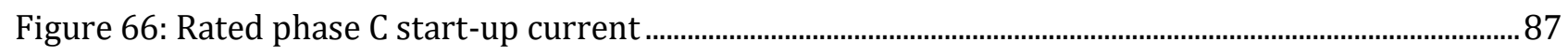

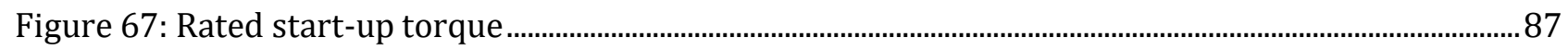

Figure 68: Phase A residual voltage - 0 degrees phase shift ............................................................................... 88

Figure 69: Phase B residual voltage - 0 degrees phase shift .................................................................................. 88

Figure 70: Phase C residual voltage - 0 degrees phase shift..................................................................................... 89

Figure 71: Phase A stator current - 0 degrees phase shift.................................................................................... 89

Figure 72: Phase B stator current - 0 degrees phase shift....................................................................................... 90

Figure 73: Phase $C$ stator current - 0 degrees phase shift...................................................................................... 90

Figure 74: Torque - 0 degrees phase shift ………….................................................................................................. 91

Figure 75: Phase A residual voltage - 90 degrees phase shift.............................................................................. 92

Figure 76: Phase B residual voltage - 90 degrees phase shift.................................................................................92

Figure 77: Phase $C$ residual voltage - 90 degrees phase shift................................................................................ 93

Figure 78: Phase A stator current - 90 degrees phase shift...................................................................................93

Figure 79: Phase B stator current - 90 degrees phase shift................................................................................... 94

Figure 80: Phase C stator current - 90 degrees phase shift.......................................................................................94

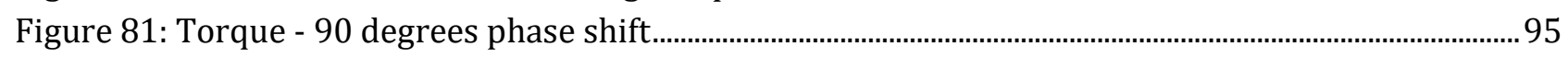

Figure 82: Phase A residual voltage - 180 degrees phase shift...............................................................................95

Figure 83: Phase B residual voltage - 180 degrees phase shift................................................................................96

Figure 84: Phase $C$ residual voltage - 180 degrees phase shift ............................................................................... 96

Figure 85: Phase A stator current - 180 degrees phase shift ................................................................................ 97

Figure 86: Phase B stator current - 180 degrees phase shift ............................................................................. 97

Figure 87: Phase C stator current - 180 degrees phase shift .................................................................................. 98

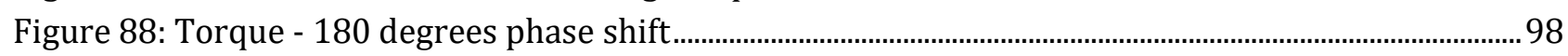




\section{List of Tables}

Table 1: SEIM and PPEIM structural characteristics.

Table 2: SEIM and PPEIM ratings for a wye connection .................................................................................... 26

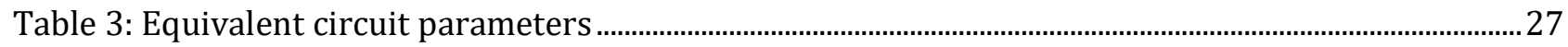

Table 4: Starting scheme and synchronous speed.............................................................................................. 27

Table 5: Induction motor base values .............................................................................................................. 43

Table 6: Factors associated with the motor design, which contribute to the spike in current and torque

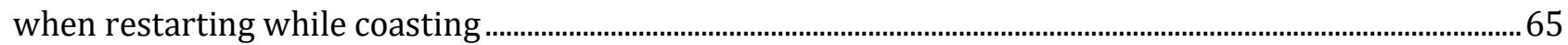

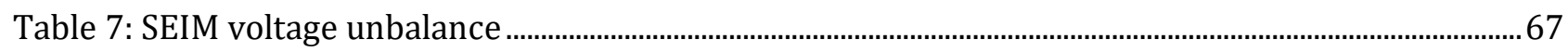

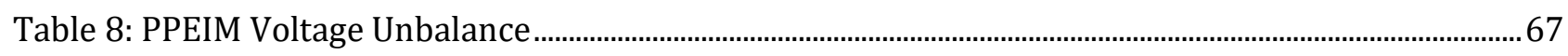




\section{Introduction}

\subsection{Background to the study}

Induction machines are widely considered the workhorse of industry due to their ruggedness and ease of use. However, an interruption to their power supply can prove to be costly. A dip in voltage can have a negative impact on the daily operation of induction machines due to large inrush currents. The length of time taken to start up the machine can also prove costly since production is halted for a prolonged period of time. Thus, the instant restarting of such machines, while coasting, is often practiced yet it leads to undesirable effects. The current and torque spikes experienced by the stator and rotor respectively can potentially exceed the rated current and torque several times, which may be destructive [1].

Previous studies have analysed the residual voltage in terms of its magnitude and phase, the stator current and torque as they are restarted before they are allowed to come to rest. At start-up, the rotor of the induction machine is locked and thus a large current is drawn as it flows only through the stator impedance [2]. This results in a current several times larger than the rated value. The same is true for the electromagnetic torque of the machine, which is produced by the peaking current. What is evident in the studies is that when a motor is restarted immediately after disconnect, it is possible to experience significantly larger inrush current and torque when compared to start-up conditions [3].

An increasing number of energy efficient motors are now being used in industry in order to realise energy savings as these machines have a higher efficiency [4]. Eskom has also introduced energy efficient motor programs which seek to incentivise industrial parties to retrofit their standard efficiency motors with energy efficient ones. The incremental improvements in efficiency of induction machines can yield large gains in energy savings and this has further fuelled the movement towards the use of energy efficient machines [4]. It is for this reason that power quality issues and restarting transients need to be tested for these machines to observe how they compare with their standard efficiency counterparts. The structural component of both machines needs to also be taken into account.

\subsection{Objectives of this study}

\subsubsection{Problems to be investigated}

The problems that are to be investigated in this study are as follows:

- The variation in magnitude and phase displacement of the residual voltage in relation to the constant supply from the point of disconnect to the point of reclosing.

- The magnitude of the torque and current spikes experienced by the standard and energy efficient machines and their possible impact.

- The power quality effect of over- and undervoltage conditions in combination with unbalance on the reclosing transients on both standard and energy efficient machines.

\subsubsection{Purpose of the study}

The main aims of this research include:

- Investigating the restarting of two different efficiency class induction machines while coasting and to analyse the various factors which influence the magnitude of the restarting transients. 
- Determining a dominating factor for the transient current and torque response in the two efficiency class machines with respect to the stator impedance, residual voltage and speed.

- Quantifying the effect of restarting the standard and energy efficient machines under the influence of voltage unbalance (in combination with overvoltage or undervoltage) on the supply side.

\subsection{Approach}

Two machines were used for the purpose of this research and these were namely the standard efficiency and premium plus efficiency induction machines which were both rated at $7.5 \mathrm{~kW}$. These motors were tested according to the IEEE 112-B international standard for testing induction machines and the tests were conducted at rated voltage, unbalanced voltage, undervoltage and overvoltage conditions for each motor. The experimental test results were analysed and interpreted in detail using MATLAB. The tests were associated with analysing the effects of restarting an induction machine as it coasted to rest. In addition, the start-up characteristics were also analysed.

The conducted experiments were limited to the $7.5 \mathrm{~kW}$ rated induction machines and were unloaded. The testing procedure was limited to a manual disconnecting and reclosing technique in order to capture data. Therefore, to assess the phase shift of the residual voltage compared to the supply, numerous, repeated tests needed to be run to obtain a good level of consistent data.

\subsection{Plan of development}

The report begins with a brief description of the background to the research before discussing the problem to be assessed as well as the purpose of the study.

It then goes on to develop the theory behind the starting up, running and restarting of induction machines as they coast towards standstill in chapter 2 . This chapter also discusses the power quality issues associated with induction machines. Previous studies are discussed as the hypothesis is continually developed for the study.

In chapter 3, the experimental set-up is outlined, which describes the necessary tools required for obtaining the appropriate results as well as the testing procedures and protocols.

This is followed by the first set of results that deal with restarting induction machines under rated balanced voltage conditions in chapter 4 . A comparison between the two efficiency classes of machines is carried out as the peak current and torque transients are analysed. This chapter also analyses the results of restarting the induction machines further by attempting to establish a dominating factor after having taken the speed, residual voltage magnitude and stator impedance into consideration in order to determine which machine is more susceptible to reclosing transients.

Chapter 5 discusses the impact of starting up and restarting induction machines under the presence of varying degrees of voltage unbalance. The effects of overvoltage and undervoltage with unbalance are also analysed.

The conclusions and recommendations for further work are discussed in chapter 6 and 7 respectively based on the findings in the study. 


\section{Literature Review}

This chapter deals with the different efficiency classifications for induction motors that are manufactured and used worldwide. It then discusses the induction motor design and its principles of operation before concentrating on the theory behind reclosing transients and their related effects. The dynamic modelling of an induction machine is discussed, and the definitions of voltage unbalance are explored as well as the implications voltage unbalance has on the power quality of the machines.

\subsection{Induction motor classes}

As a motor is started from a rest, the rotor is locked and, as a result, the motor draws high inrush currents. The restarting of an induction motor while coasting can also cause large inrush currents which can lead to large torque spikes which have the potential to damage the motor. The design of the machine will determine the peak of the inrush current and torque [5].

The NEMA standard publication no. MG 1 specifies the different types of induction motors as follows:

\subsubsection{Design A}

These machines have a normal starting torque and a high starting current. Its breakdown torque is the highest of all NEMA machines [6].

\subsubsection{Design $B$}

These machines have a normal starting torque and a low starting current and they are the most commonly sold induction machine. The reason for this popularity can be attributed to the motor's high efficiency and full-load power factor [6].

\subsubsection{Design $C$}

These machines have a high starting torque and a low starting current. The starting torque is high (higher than the previous two designs) in order for the machines to be able to handle heavy breakaway loads such as compressors and crushers [6].

\subsubsection{Design $D$}

These machines have the highest starting torque of all NEMA machines, a low starting current and a low full-load speed. The machines' high slip values make it useful for applications involving changing loads and sharply changing motor speeds e.g. energy storage in flywheels [6].

\subsubsection{Design $E$}

These machines are similar to the Design B machines yet they have a higher efficiency, higher starting currents and lower full-load currents [5], [6].

\section{$2.2 \quad$ Induction machine design}

\subsubsection{Stator}

The stator consists of several thin laminations of aluminium or cast iron which are punched together to form a hollow cylindrical core [6]. This core has slots in which coils of insulated wire are inserted. Each 
group of coils forms an electromagnet with the core it surrounds as soon as an alternating current (AC) power supply is present. The number of poles on an AC induction machine is determined by the internal connections of the stator windings which are connected directly to an external power source. Once an AC supply is provided, a rotating magnetic field is created [6]. A typical stator can be seen in Figure 1:
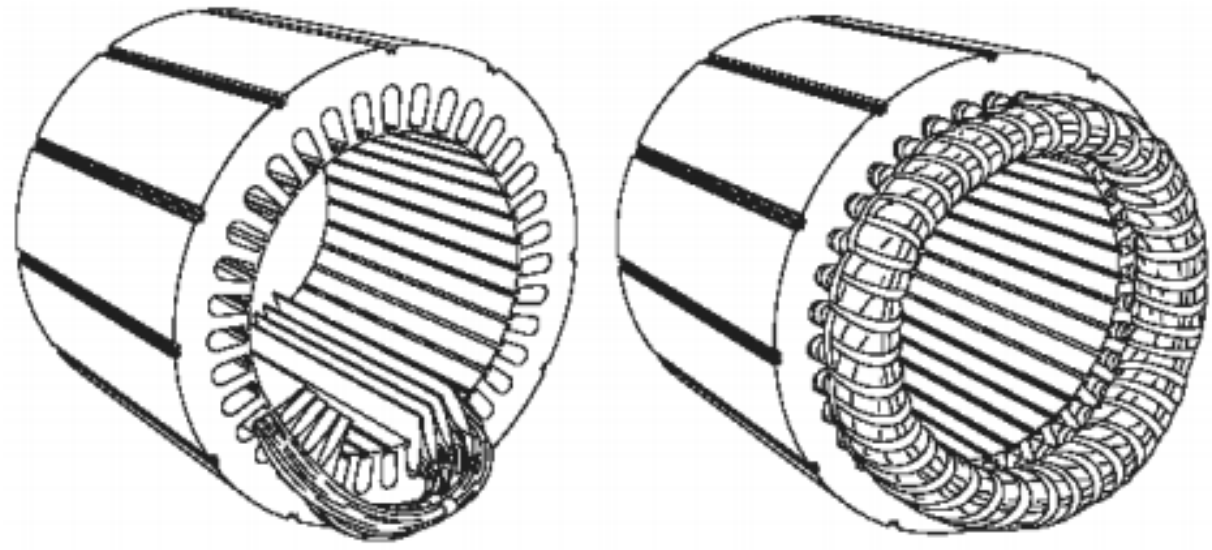

Figure 1: Typical stator coil configuration [6]

\subsubsection{Rotor}

The rotor is made up of several thin steel laminations and evenly spaced bars which are made up of aluminium or copper [6]. In a squirrel cage motor, the bars are connected mechanically and electrically by the use of rings. The rotor consists of a cylindrical laminated core with axially placed parallel slots in order to carry conductors. The rotor bars are constantly short-circuited at either end with the aid of the end rings. The rotor slots are constructed in such a way that they are orientated in a skew manner relative to the shaft. The first reason is to ensure that the machine runs quietly as the slot harmonics are reduced. The second reason is to ensure that that the locking tendency of the rotor is reduced [6]. A figure of a typical rotor configuration is shown in Figure 2:

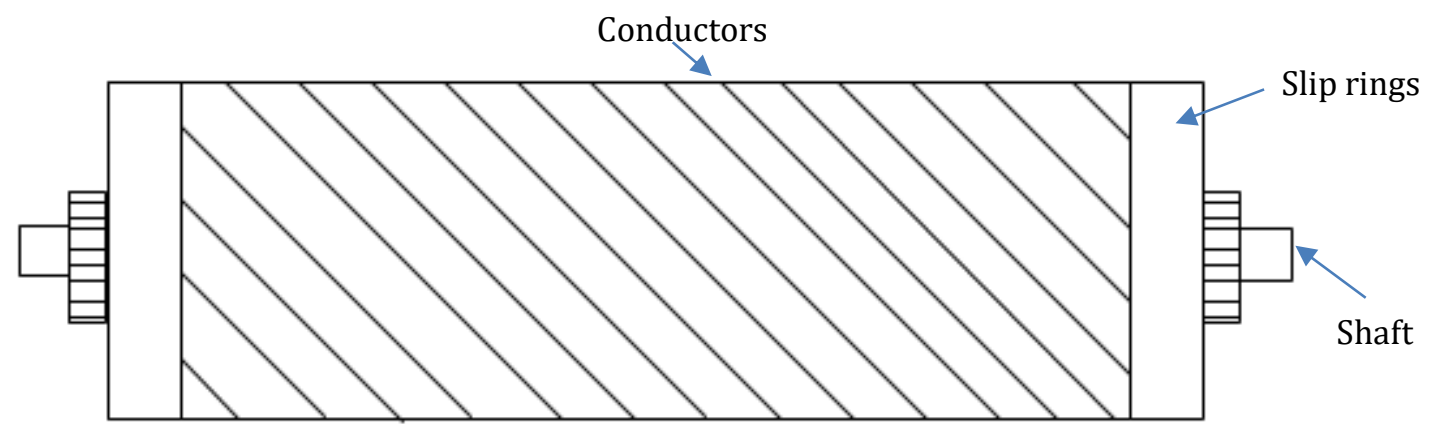

Figure 2: Induction machine rotor

\subsubsection{Induction motor equivalent circuit model}

P.C. Sen defines the induction machine equivalent circuit model that can be used to predict its performance. The stator equivalent circuit and the rotor equivalent circuit are at the same line frequency and can, hence, be combined [7]. The core loss, $R_{C}$, is shown connected in parallel with the magnetising inductance. The circuit is shown in Figure 3: 


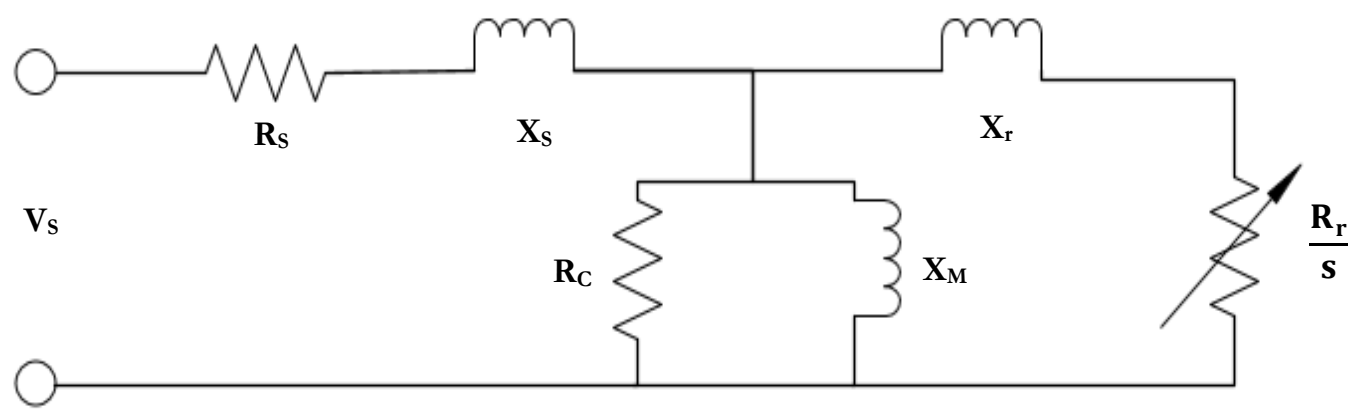

Figure 3: Complete equivalent circuit

Due to the air gap in the induction machine, the exciting current, $I_{\varnothing}$, is high and this means that the leakage reactance, $X_{s}$, is also high. IEEE recommends that the resistance, $R_{c}$, be omitted so that the core loss is combined with the windage and friction losses [7]. The resulting circuit diagram is shown in Figure 4:

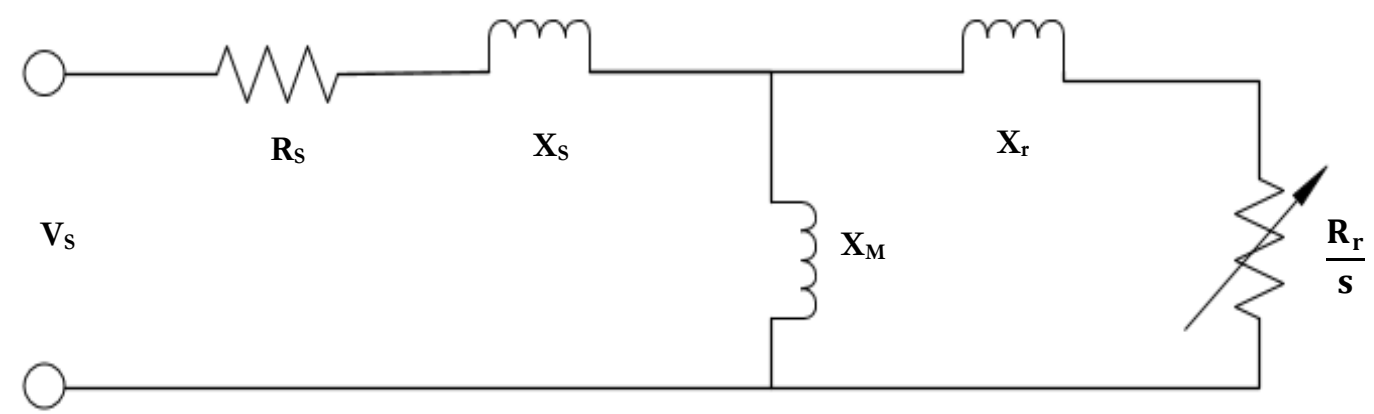

Figure 4: IEEE-recommended equivalent circuit

The input impedance is obtained by the following equation:

$$
Z_{1}=R_{S}+j X_{S}+\frac{j X_{m}\left(\frac{R_{r}}{s}+X_{r}\right)}{\frac{R_{r}}{s}+\left(j X_{m}+X_{r}\right)}
$$

The stator current is thus denoted as:

$$
I_{s}=\frac{V_{s}}{Z_{1}}
$$

\subsubsection{Principles of operation of an induction machine}

The stator windings are divided into three-phase axes (A, B and C). These axes are displaced at $120^{\circ}$ from each other and lie perpendicular to the plane in which the stator winding lies. The 3-phase winding can be connected in a star or delta configuration [8]. When an AC voltage supply is applied to the windings, they are excited and this results in a flow of three-phase currents which are displaced $120^{\circ}$ from each other. A visual representation of the $120^{\circ}$ displacement of the three-phase stator voltages is shown in Figure 5: 


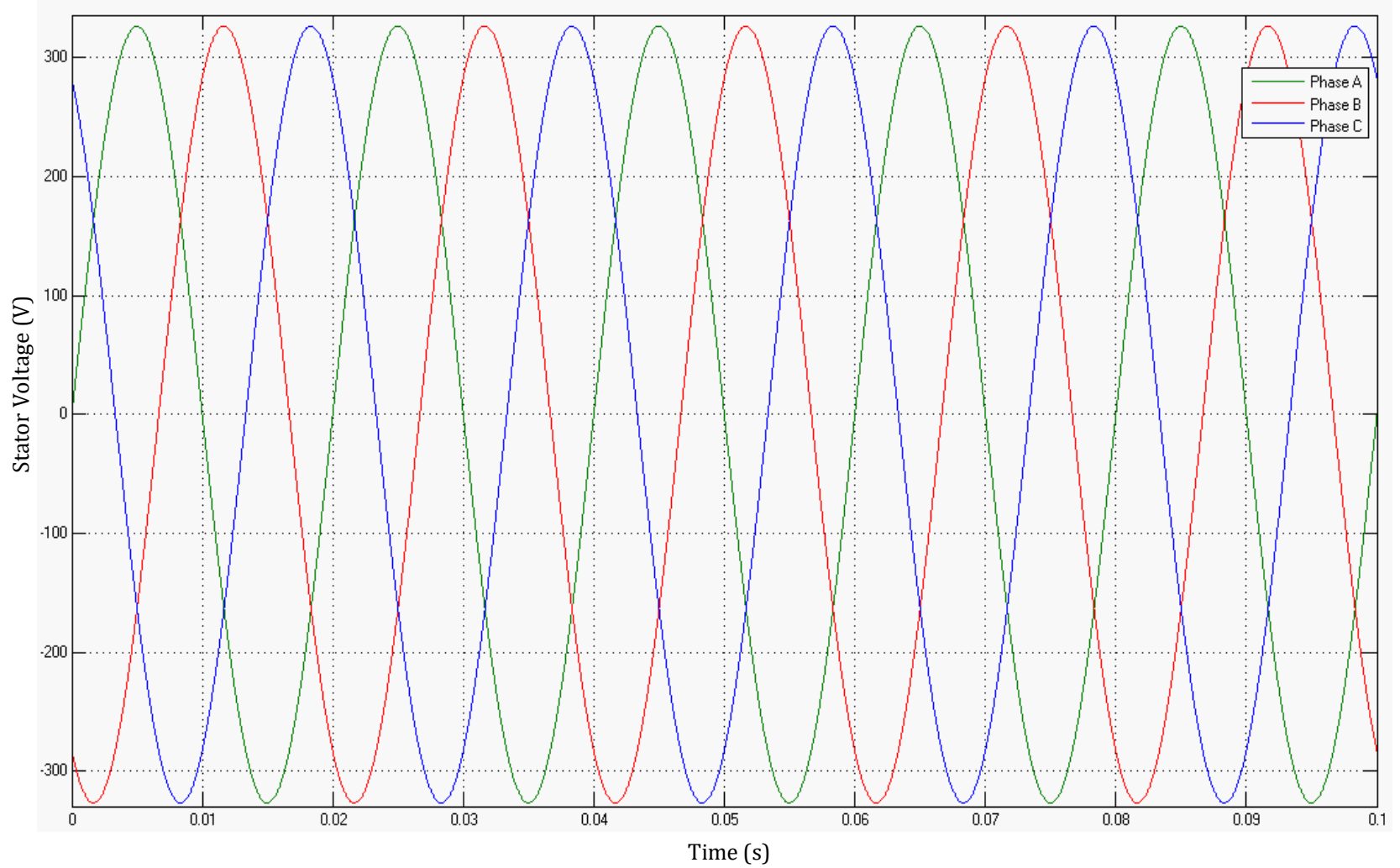

Figure 5: Per-phase stator voltage profile from Matlab SIMULINK

A basic circuit diagram of an induction machine connected to a constant voltage supply is shown in Figure 6:

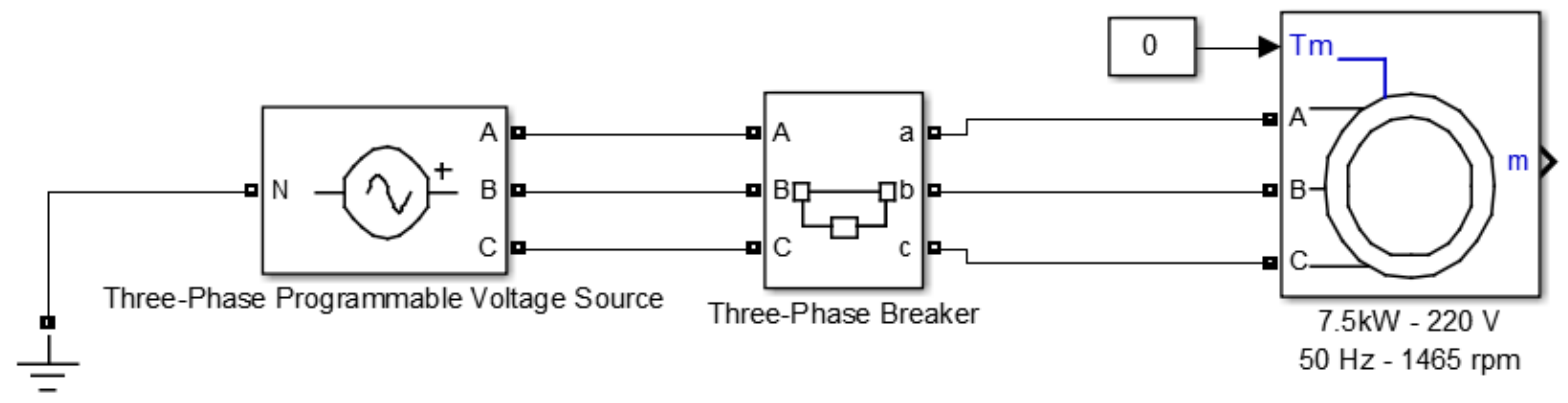

Figure 6: Circuit connection for induction machine (Matlab SIMULINK)

As current flows through a phase coil, a distributed mmf is produced as a result of the distributed stator windings. Each mmf wave can be represented by a vector along the axis of the phase winding [7]. As a result, the sum of these phase mmf waves, a rotating magnetic field is induced in the stator and in the air gap. The magnetic field that is induced in the air gap rotates at synchronous speed which is represented by the following equation:

$$
N_{s}=\frac{120 f}{p}
$$

Where $p$ is the number of poles and $f$ represents the frequency of operation. 
The rotating magnetic field in the air gap induces a voltage in the rotor windings as the flux lines cut through the rotor. The induced voltage causes an induced current to flow in the rotor windings. This results in a rotating magnetic field in the air gap due to the rotor windings.

\subsubsection{Steady state operation}

After start-up, the induction motor accelerates until it gradually reaches steady state speed due to the developed electromagnetic torque. The rotor reaches a steady state speed which is less than the synchronous speed of the rotating air gap [7]. The difference between the synchronous speed and rotor speed is called the slip, $s$, and it is determined using the equation below:

$$
s=\frac{N s-N_{r}}{N_{s}}
$$

Where $N_{s}$ is the synchronous speed and $N_{r}$ is the rotor speed.

A motor running at a speed lower than the synchronous speed (or rated frequency) is said to be running in motoring mode, while a motor running at a speed higher than the synchronous is operating in generating mode [9]. Once running at steady state, an open circuit, short circuit or changing load will introduce transients into the system which will vary according to the residual flux [10], which will be expanded on in the next section.

\subsubsection{Transient operation}

As the induction machine starts up from rest, the current and torque transients are only affected by the stator impedance and the constant supply voltage. The starting torque peak will drop slightly to a minimum torque, which is the pull-up torque. As the motor accelerates even further, the torque will then rise to a maximum value which is known as the break-down torque [6]. This torque then rapidly decreases to zero as the motor reaches its rated speed. Figure 7 depicts the torque-speed characteristics for the different types of induction machines:

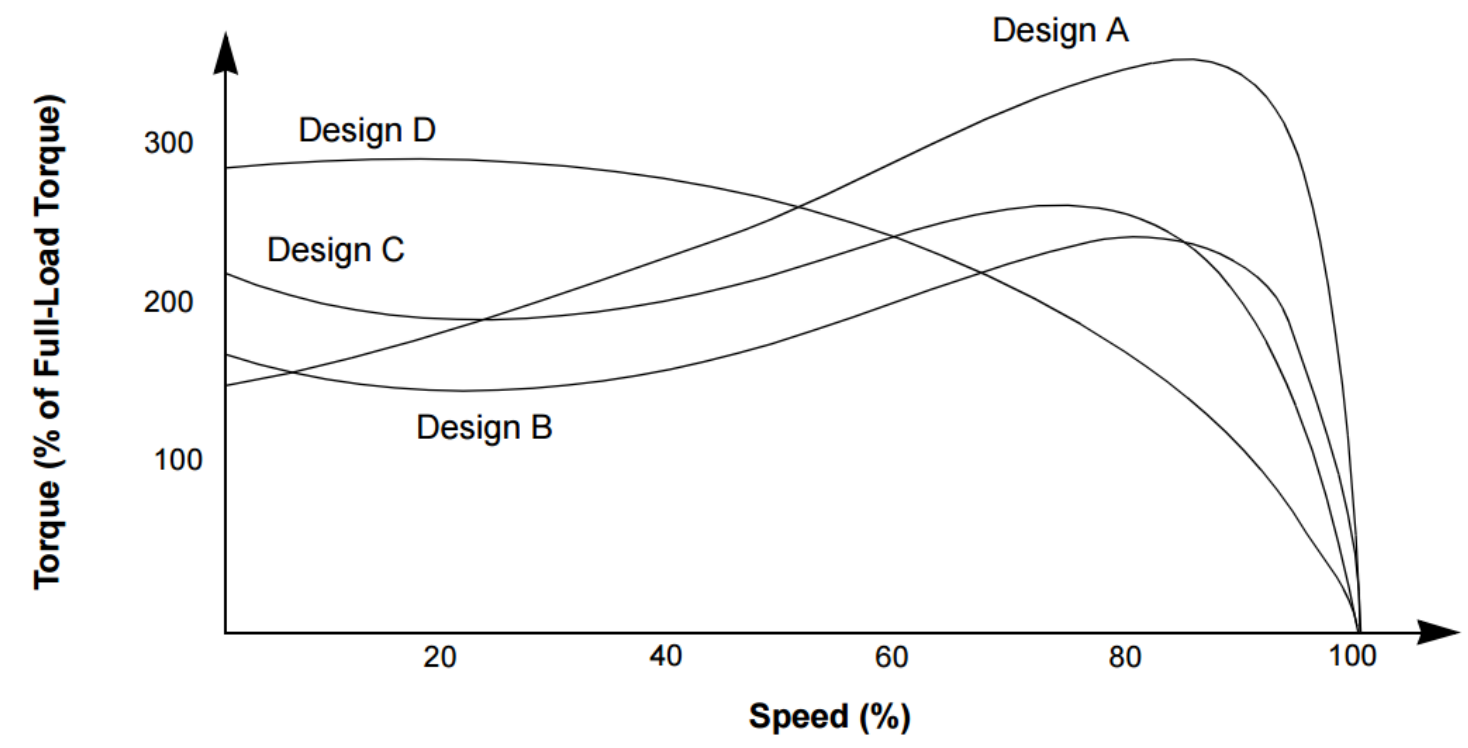

Figure 7: Torque-speed characteristics of different induction machines [6]

High starting currents are also induced as the motors stator experiences full terminal voltage. Figure 8 shows how the stator current varies with the speed of the induction machine. 


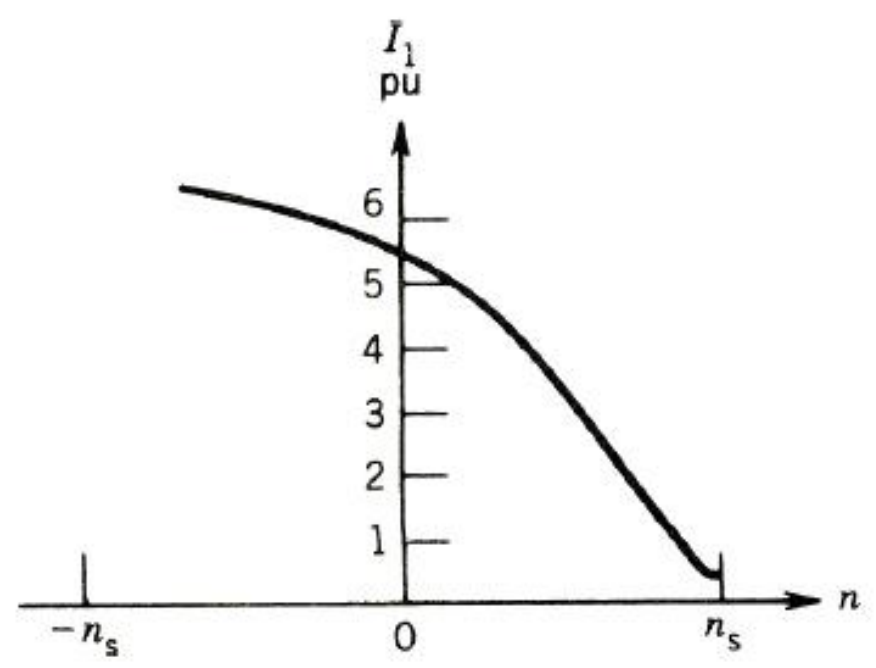

Figure 8: Stator current vs speed profile [7]

Any disconnect from the supply will lead to deceleration of the running motor. While the motor coasts towards standstill, there is a residual flux which remains in the air gap but it rapidly begins to decay. This decaying residual flux causes a residual voltage at the stator terminals which decays in magnitude and frequency as the speed decreases [11]. The residual voltage decays according to the open circuit time constant which is the time taken for the induced voltage in the stator to decay to $37 \%$ of its rated value [3].

The equation for the open circuit time constant is shown below:

$$
t_{e}=\frac{L_{s}}{R_{t}}
$$

Where $L_{s}$ is the stator inductance; $R_{t}$ is the stator terminal resistance.

Whilst the flux is decaying, the speed of the motor also steadily declines with time according to a mechanical time constant, which is the time required for the speed of a motor to reach $63.2 \%$ of its rated value for a fixed voltage [3]. This is achieved using the following equation:

$$
t_{m}=\frac{J_{m} * R_{t}}{K_{t} * K_{e}}
$$

Where $J_{m}$ is the rotational inertia; $K_{t}$ is the torque constant and $K_{e}$ is the voltage constant.

As the frequency of the steadily decaying residual voltage changes, so does its phase with respect to the incoming constant supply voltage. The phase of the residual voltage changes to a point where it is completely out-of-phase with the supply voltage whilst maintaining a non-zero magnitude. The potential difference between the constant supply and the residual voltage magnitude on the stator plays a significant role in the magnitude of the inrush current and torque spikes. A worst-case scenario that has been established in literature states that the largest spike in the current and torque occurs when the magnitudes of the supply and residual voltage are similar and completely out-of-phase. If the residual voltage reaches $180^{\circ}$ phase shift and its magnitude has not reduced significantly, it is possible for the motor to see twice the terminal voltage [12]. 
While the motors in industry do not practically maintain a residual voltage similar in magnitude to the supply at the instant of reclosing, it is important to know the transient performance of the motor in order to determine when it is safe to restart after the moment of disconnect [13].

The peak inrush currents can hence be determined by the following equation [5], [14]:

$$
I_{\text {peak }}=\frac{V_{t}}{Z_{\text {stator }}}
$$

Where $V_{t}$ is the terminal voltage and $Z_{\text {stator }}$ is the equivalent stator impedance.

The developed mechanical torque can be found using the following set of equations [7]:

$$
\begin{aligned}
& Z_{t h}=\frac{j X_{m}\left(R_{s}-j X_{s}\right)}{R_{s}+j\left(X_{m}+X_{s}\right)} \\
& V_{t h}=\frac{X_{m}}{\left(X_{m}+X_{s}\right)} * V_{t} \\
& T_{\text {mech }}=\frac{V_{t h}^{2}}{\omega_{\text {synch }}\left[\left(R_{t h}+\frac{R_{r}}{s}\right)^{2}+\left(X_{t h}+X_{r}\right)^{2}\right]} * \frac{R_{r}}{s}
\end{aligned}
$$

Where $V_{t h}, Z_{t h}$ and $R_{t h}$ are the Thevenin voltage, impedance and resistance respectively.

\subsection{Reclosing transients in induction machines}

Torque and current transients are sensitive to the potential difference between the constant supply and decaying residual voltage. For any change in the potential difference that is 1 pu greater than the rated supply voltage, larger transient peaks for the torque and current are seen than at start-up [5]. Previous studies have largely focused on the reclosing of induction machines and this has been based exclusively on the principle of residual voltage magnitude and phase shift. Other studies from [12] have included the effects of saturation in the overall study together with the varying of a critical industrial load. Another study has attempted to cut down on the impact of the torque and current reclosing transients solely on the use of setting up a corresponding mathematical model which was then run through a simulation [3]. The key solution would be to find the exact calculation and determination of the phase shift and magnitude that would give the least peaking transients. This simulation case would then serve to highlight the feasibility of using this model in engineering application.

This particular study aims to focus on a practical approach to compare the severity of reclosing transients between standard and energy efficient machines. Furthermore, the study extends its scope by subjecting both types of machines to varying voltage unbalance to observe the effect of reclosing transients. The effect the voltage unbalance has on the power quality of the machines needed to be compared.

\subsubsection{Residual voltage}

Once an induction motor is disconnected from its supply, the remaining magnetic flux in the revolving rotor will continue to induce a voltage in the stator windings. When the motor is in a coasting transient state, the residual voltage slips in and out of synchronism with the constant supply at an increasing rate as it continues to decrease with time [15]. Large motors, in particular, are able to have time constants of 
several seconds and thus have the capability to become self-excited generators which can deliver substantial current at a voltage and frequency which is less than the supply parameters [15]. When the motor contact is open, the supply voltage remains the same and continues to run with the same frequency while the residual voltage decreases with a changing phase angle. This can be visualised using vectors to represent the supply and residual voltage as shown in Figure 9 and 10.

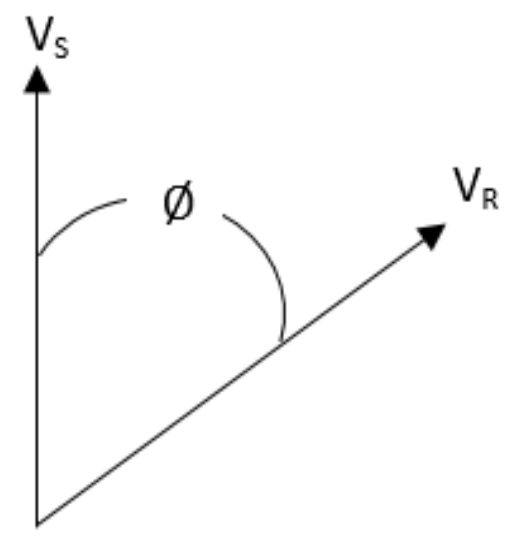

Figure 9: Supply and residual voltage vectors

Vectors $V_{S}$ and $V_{R}$ represent the supply and residual voltage respectively. $\emptyset$ represents the phase angle between the supply and the residual voltage. As the motor begins to slow down, the phase angle, $\varnothing$, increases. Figure 9 shows the phase angle at approximately $60^{\circ}$. If the motor is restarted at any point before it reaches zero speed, the total voltage applied to the motor is the difference between $V_{S}$ and $V_{R}$ [15].

The phase angle between the residual voltage and the system supply voltage changes with time since the induction motors speed is lower than the synchronous speed. As a result, the magnitude of the phasor voltage difference between the residual voltage and the supply can be much greater than the supply voltage which is applied initially when starting the motor [16].

If the phase angle, $\emptyset$, reaches $180^{\circ}$, as shown in Figure 10 , and the amplitude of $V_{R}$ has not decreased significantly, the vector difference between $V_{S}$ and $V_{R}$ could almost be twice the terminal voltage. It is important to note that the supply and residual voltage are not operating at the same frequency. 


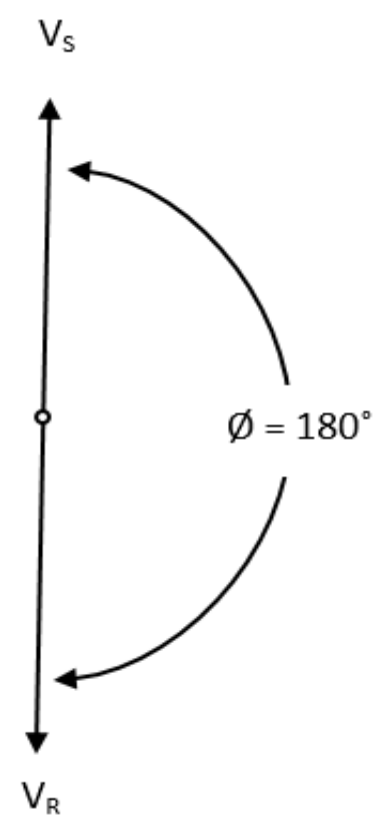

Figure 10: Supply and residual voltage vectors at $180^{\circ}$

The deceleration of the motor and the load combination can be given by the following equation:

$$
\alpha=\frac{-T_{\text {load }}}{J_{\text {total }}}
$$

Where $\alpha$ is the rotational acceleration of the motor shaft.

To determine the angle, $\emptyset$, between the supply voltage and the residual voltage, it is important to consider that when the motor is disconnected from the power supply, the continuing load will cause the motor to slow down [16]. Since there is no mass attached to the machine, the mass of the DC machine armature coupled to the induction machine is taken as the mass [16].

If the load torque is independent of the speed, or changes very little for the minor changes in speed which may result during a power interruption, then the deceleration may be assumed to be a constant [16]. The angle between the two phasors can be approximated by the equation below:

$$
\emptyset=\emptyset_{0}+t p\left[\left(\omega_{r o}-\omega\right)+\frac{\alpha t}{2}\right]
$$

The magnitude of the motor residual voltage is given by the following equation:

$$
\begin{aligned}
& V_{R}=V_{R o} e^{\frac{-t}{T_{0}}} \\
& T_{0}=\frac{X_{2}+X_{m}}{2 \pi f r_{2}}
\end{aligned}
$$

The magnitude of the resultant phasor voltage difference, $V_{\text {res }}$, between the power supply voltage, $V_{S}$, and the motor residual voltage, $V_{R}$, from the stator terminals can then be determined from the equation below: 


$$
V_{\text {res }}=\sqrt{\left(V_{R}-V_{S} \cos \emptyset\right)^{2}+\left(V_{S} \sin \emptyset\right)^{2}}
$$


Figure 11 shows the decay of both the PPEIM and SEIM after disconnect.

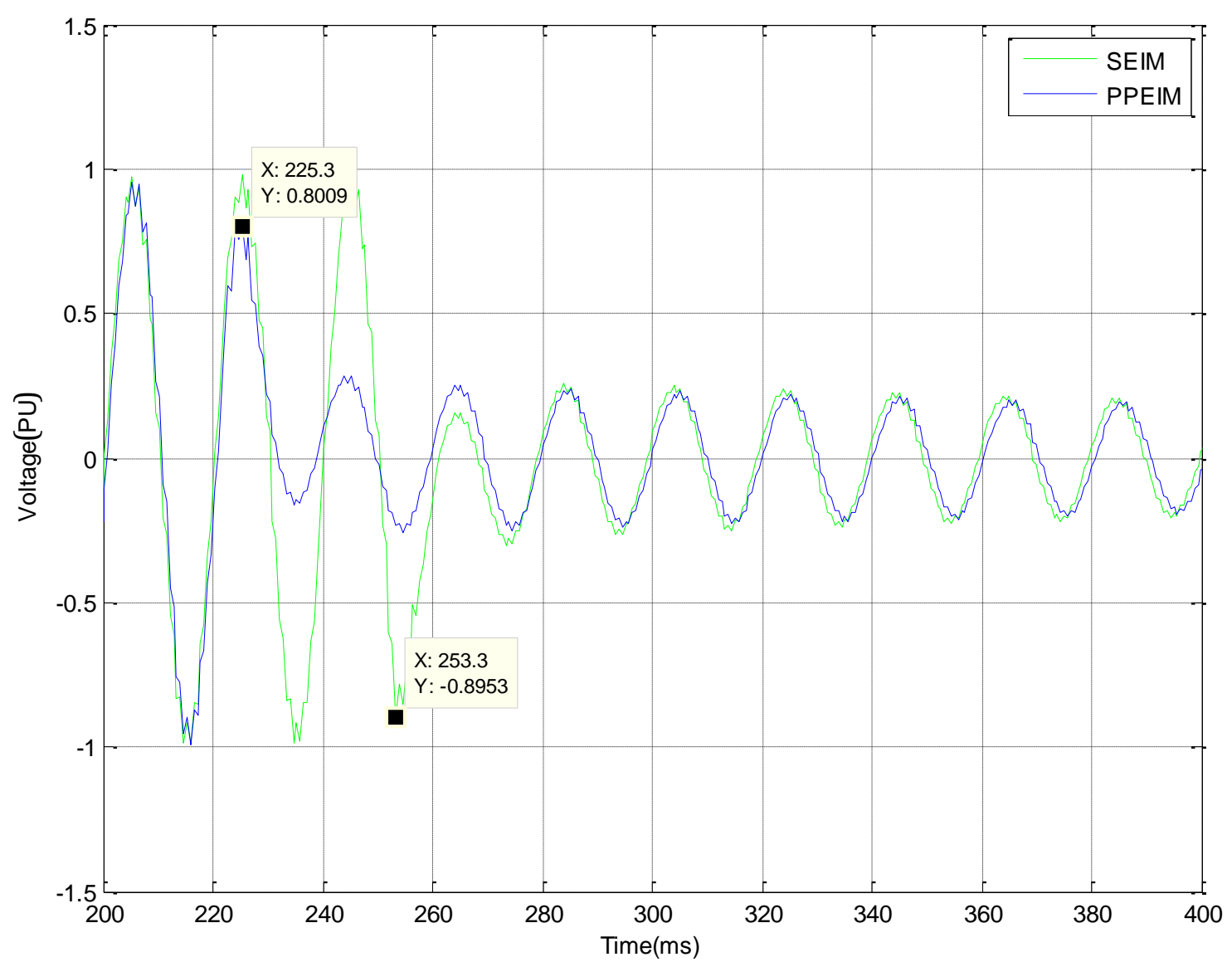

Figure 11: Residual voltage profiles after disconnect

The figure shows the residual voltage of both machines at disconnect and the decay in the subsequent cycles thereafter. It can be seen that the peak of the PPEIM at disconnect, $0.801 \mathrm{pu}$, is lower than that of the SEIM, $0.895 \mathrm{pu}$. The figure above also shows a clear decay in magnitude of the residual voltage as it loses synchronism with the supply voltage when the contactor is opened.

The prediction of the extent of the current and electrical torque which may result when the contactor is reclosed on an induction machine is based fundamentally on the determination of the magnitude of the resultant volts per hertz, $V_{\text {res }}$, between the supply and residual volts per hertz at the instant of reclosing. The ANSI Standard C50.41 specifies a limit on reclosing to cases where this value does not exceed 1.33 pu volts per hertz on the motor rated and frequency bases [16]. It is believed that, at the point of restart, the rated stator voltage should not be exceeded by the magnitude of the resultant volts per hertz if a machine should be restarted safely [14]. It is clear, from previous work, that the magnitudes of the inrush current and torque spikes are dependent on the phase and magnitude of the residual voltage.

At reconnect, the restarting inrush current transients could be at least twice the normal starting inrush values if the residual voltage has not decayed appreciably at $180^{\circ}$ phase shift [15].

\subsubsection{Current transient}

The potential difference between the residual voltage and the supply voltage that exists at the stator terminal, upon reclosing, will result in peaking stator currents that are larger than the starting currents 
[5]. The peaking value of the current transient occurs within the first cycle after reclosing of the machine occurs. Transient currents flowing in the stator and rotor circuits have ac and dc components that have an additive or subtractive effect on the contained fluxes [5], [17]. The peaking current is directly associated with a change in the magnetic field thus the interaction between residual magnetic field components can result in high peaking transient current [18].

Taking the vector difference between the supply voltage and the residual voltage and dividing by the stator leakage inductance will result in a good estimate of the magnitude of the transient current [11]. The equation below further expands on equation (5) in terms of the estimated current transient:

$$
I_{r s}=\frac{E_{r}-E_{S}}{X_{1}}
$$

In addition, if the flux has not decayed significantly i.e. $E_{r}=E_{s}$, with the supply voltage completely out of phase $\left(180^{\circ}\right)$ with the residual voltage on the stator, then the current transient would be:

$$
I_{r s}=\frac{2 E_{S}}{X_{1}}
$$

\subsubsection{Torque transient}

When the supply is reconnected, transient currents flow in the stator and rotor circuits [17]. The dc components of these currents interact with the trapped fluxes and this results in magnetic fields which are stationary and rotating with respect to the corresponding circuits. These magnetic field components interact with each other to produce a corresponding torque [17]. This is illustrated in Figure 12:

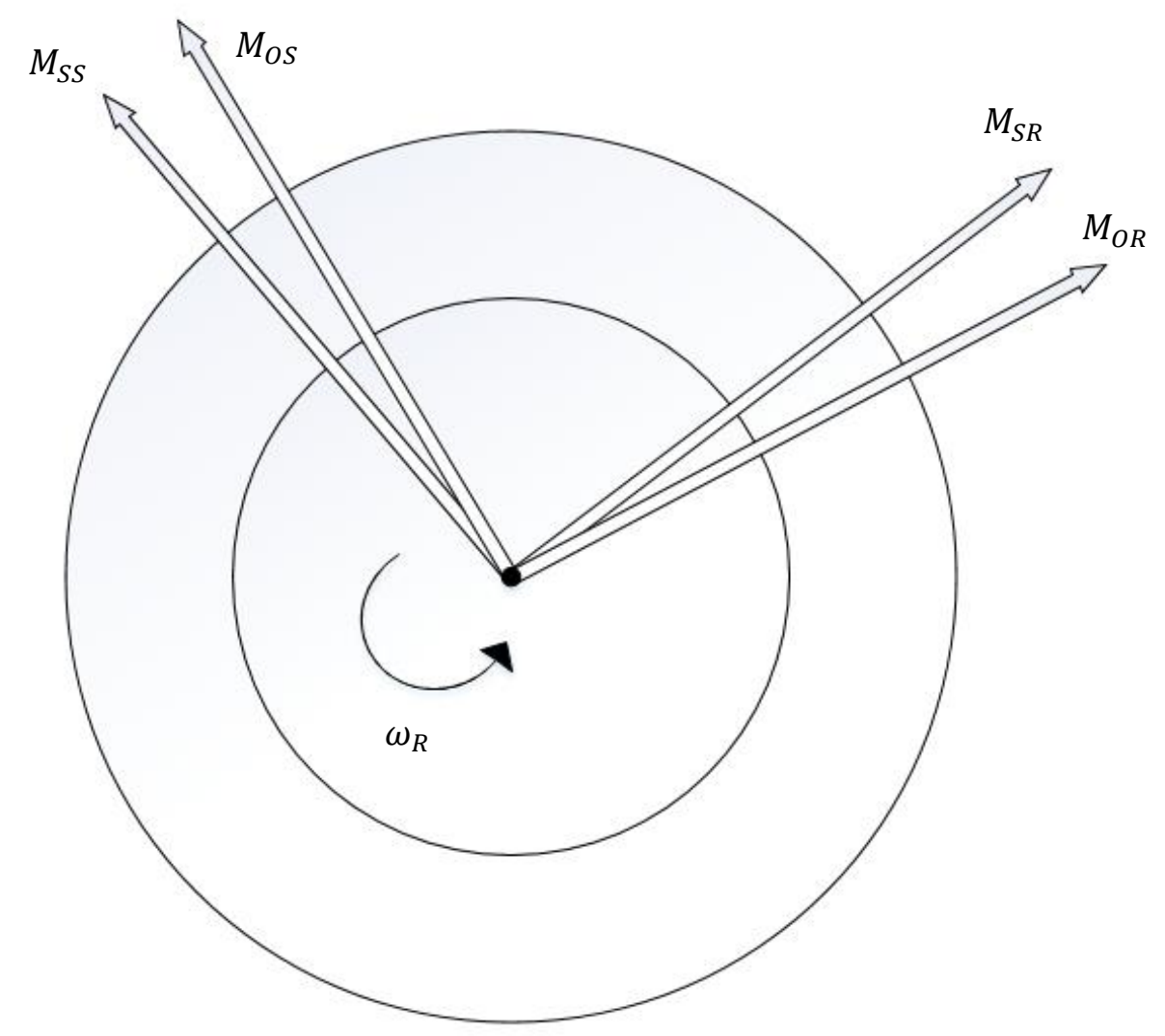

Figure 12: Various components of stator and rotor magnetic fields 
Where $M_{O S}$ is the stationary stator magnetic field; $M_{O R}$ is the stationary rotor magnetic field which rotates with rotor speed $\left(\omega_{R}\right) ; M_{S S}$ is the supply frequency stator magnetic field which rotates at synchronous speed $\left(\omega_{S}\right)$ and $M_{S R}$ is the slip frequency rotor magnetic field which rotates at synchronous speed $\left(\omega_{S}\right)$ [17].

The unidirectional, oscillating, slip frequency and speed frequency torque components is produced by the interaction of the stator and rotor stationary and rotating magnetic fields. These components all result in the torsional shaft torque [17]. The values of these components are large at the moment of reclosing and continue to decay with time. The absolute maximum value of the oscillating electromagnetic occurs within the first cycle after the point of reclosing [19]. Previous studies have shown that the worst-case conditions can result in an electromagnetic torque that has higher peaks than starting a motor from rest.

\subsection{Induction machine types}

\subsubsection{Squirrel cage motor}

Most three-phase induction motors are squirrel cage motors and the power ratings for these machines vary from one-third to several hundred horsepower [6]. These types of motors, rated one horsepower or above, are cheaper and are able to start heavier loads than single-phase motors [6]. A squirrel cage motor consists of a rotor which has a pair of end rings and conductor bars interconnecting the end rings. At least one end ring is provided with two insulating gaps to divide the end ring into two separate portions [20].

\subsubsection{Wound-rotor induction machines}

This type of induction motor is one in which the secondary winding is an insulated polyphase winding which is similar to the stator winding [21]. The wound-rotor motor is just a variation of the squirrel cage induction motor. The rotor windings terminate at the collector rings and access to the rotor circuit is obtained through stationary brushes being in contact with each other. Through this arrangement, additional resistors and contactors can be easily incorporated. Applications of this type of machine include high inertia loads, where the pull-out torque is required to be generated at almost zero speed and accelerate to full speed in a short amount of time [6]. Examples of these applications include hoist and crane operations.

\subsection{Differences between standard and energy efficient machines}

Premium plus efficiency induction machines have recently become more favoured to the standard types due to the need to improve energy savings [4]. Premium efficiency machines are built by re-designing the stator and rotor windings whilst still maintaining the standard design of a standard efficiency machine. With this in mind, motor manufacturers are constantly attempting to design new energy efficient motors which require higher quality materials and accurate motor designs [4]. Table 1 shows the structural characteristics of the SEIM and PPEIM: 
Table 1: SEIM and PPEIM structural characteristics

\begin{tabular}{|c|c|c|}
\hline & \multicolumn{2}{|c|}{ Machine Type } \\
\hline Characteristic & SEIM & PPEIM \\
\hline Magnetic Core & $\begin{array}{l}\text { Cheaper annealed steel which is vulnerable } \\
\text { to temperature conditions [4] }\end{array}$ & $\begin{array}{l}\text { Higher grade silicone steel which is } \\
\text { more robust }\end{array}$ \\
\hline Stator Copper Loss & $\begin{array}{l}\text { Smaller slots therefore produce lower } \\
\text { current. However, less saturated than } \\
\text { PPEIM [4] }\end{array}$ & $\begin{array}{l}\text { Larger slots in stator core which } \\
\text { reduces copper losses }\end{array}$ \\
\hline $\begin{array}{l}\text { Friction and } \\
\text { Windage Losses }\end{array}$ & $\begin{array}{l}\text { More heat losses thus larger cooling fans } \\
\text { needed leading to higher windage losses [4] }\end{array}$ & Reduced windage and friction losses \\
\hline Stray Load Losses & $\begin{array}{l}\text { Smaller air gaps thus less varied power } \\
\text { factor [4] }\end{array}$ & $\begin{array}{l}\text { Larger air gaps thus larger } \\
\text { magnetizing current }\end{array}$ \\
\hline Cast Iron Casing & Inferior heat dissipation [4] & $\begin{array}{l}\text { Casing with a larger number of ribs to } \\
\text { increase surface area and therefore } \\
\text { better heat dissipation }\end{array}$ \\
\hline
\end{tabular}

\subsubsection{Magnetic core}

Changing the quality of the lamination steel of the core stack is a proven method of improving the efficiency of an induction machine [4]. This means that a machine with less magnetic material tends to have a higher permeability and, therefore, lower losses. Premium steel is a good example of these since it combines low specific core losses with high permeability [22].

\subsubsection{Stator copper loss}

The losses experienced by an induction machine are caused largely by the finite resistance in the stator winding experiencing a given current [4]. Using larger slots, as is the case with PPEIMs, in the stator core will result in a reduction of the copper losses. However, the larger slots do result in a reduction of the volume of the magnetic circuit, which causes it to saturate and thus, increases the iron losses [23]. This can be avoided in high efficiency designs by increasing the length of the magnetic core. Furthermore, the use of multi-tiered end-windings have aided in the reduction of the amount of inactive and loss producing copper [23].

\subsubsection{Rotor slip loss}

Initiatives have been undertaken to achieve superior efficiency while maintaining high starting torque with low current. One such initiative is to use finite element techniques and iterative processes to develop new rotor slot shapes which comply with the prioritised performance specifications [23]. Previous work has shown that a reduction in the rotor slip losses using the techniques mentioned has led to motor efficiency gains of up to $1 \%$ without any detrimental effects on the starting performance [23].

\subsubsection{Friction and windage losses}

PPEIMs are designed, in principle, with reduced motor windage and friction losses. This results in a flatter efficiency curve against loading conditions and this results in higher efficiencies at loads exceeding the 50\% - 75\% nominal full load range [4]. Energy efficient motors are known to produce less 
heat than standard motors and therefore, smaller cooling fans are required to reduce the friction and windage losses [22]. In addition, using hybrid bearings that have ceramic balls instead of steel balls may further reduce bearing losses. Previous studies show that these types of bearings run at cooler temperatures and offer a longer life than the conventional deep-groove ball bearings [24]. Bearing manufacturers are working on non-contact and lower friction bearing seals which serve to reduce friction losses and wearing effects. Ceramic balls used in antifriction bearings may reduce losses, reduce lubrication intervals as well as "self-healing" properties if any contamination occurs in the bearing [24].

\subsubsection{Stray load losses}

The stray load losses of a motor can be reduced by increasing the air gap. This can, however, lead to a larger magnetising current in energy efficient machines which increases the power factor of the motor [4]. The stray load losses can be minimised by the skew of the stator and rotor. As a result, however, starting torque difficulties and electrical noise can occur [4], [25].

\subsubsection{Cast iron casting}

IEEE 841 motors utilise cast iron housings that are finned for better heat dissipation. Increased conductivity on the outer housing is achieved by incorporating a fully rounded outer diameter of the stator lamination stack [4], [24].

\subsubsection{Permeability}

Permeability, $\mu$, is a material property that describes the ease with which a magnetic flux is established and it is defined as the ratio of flux density, $B$, and the magnetic field strength, $H$ [7]. This is shown by the equation below:

$$
\mu=\frac{B}{H}
$$

The equation (18) above describes the slope of the B-H curve at any given point on the hysteresis loop. The slope of the hysteresis loop informs us about the material that is being magnetised. The typical B-H curve is shown in the figure below:

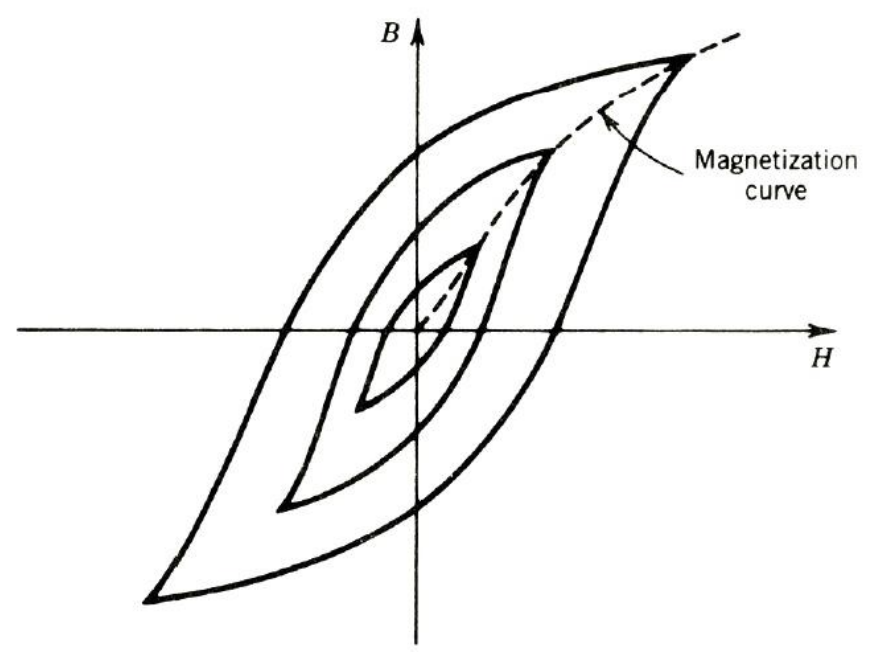

Figure 13: Magnetisation and hysteresis loop [7]

Material with a wider hysteresis loop have:

- Lower permeability

- Higher retentivity 
- Higher coercivity

- Higher reluctance

- Higher residual magnetism [7]

Material with a narrower hysteresis loop have:

- Higher permeability

- Lower retentivity

- Lower coercivity

- Lower reluctance

- Lower residual magnetism [7]

Residual magnetic fields are affected by the permeability, which is related to the carbon content and alloying of the material. The standard efficiency machines are built with material that has higher carbon content and, therefore, a lower permeability than energy efficient machines. Thus, the standard machines retain more magnetic flux and incurs higher losses. The energy efficient machines are built with higher grade silicone steels in order to reduce the losses and maintain a higher permeability [4], [26].

Due to this higher permeability, it means that the energy efficient machines have a lower retentivity. Retentivity is associated with the ability of a coil to retain its magnetism when current has stopped flowing [27]. Due to this, it is expected for a PPEIM to have a lower residual flux and therefore a lower residual voltage at disconnect.

\subsection{Dynamic modelling}

Symmetrical components can be used to better analyse induction motor transients on a per-phase basis [4]. Developed in 1918 by Charles L. Fortescue, the symmetrical components theory manages to convert any poly-phase unbalanced system into individual systems. This is essentially converting an unbalanced three-phase network into two balanced systems (positive and negative sequence) with a zero sequence component [28].

The dynamic modelling shown below is applicable to both squirrel-cage and wound rotor induction machines [29]. James W. Kolodziej offers a detailed derivation as well as transformation of the equations that result in the dynamic model of the induction machine [30]. The dynamic model of an induction machine is obtained by transforming the stator voltages and currents according to the following equations:

$$
\left(\begin{array}{l}
V_{0} \\
V_{+} \\
V_{-}
\end{array}\right)=\frac{1}{3}\left(\begin{array}{ccc}
1 & 1 & 1 \\
1 & a & a^{2} \\
1 & a^{2} & a
\end{array}\right)\left(\begin{array}{l}
V_{a} \\
V_{b} \\
V_{c}
\end{array}\right)
$$

Where $a=e^{j \frac{2}{3} \pi}[4]$

In a similar manner, the $\mathrm{ABC}$ network can be regained using the matrix shown in equation (2) below:

$$
\left(\begin{array}{l}
V_{a} \\
V_{b} \\
V_{c}
\end{array}\right)=\left(\begin{array}{ccc}
1 & 1 & 1 \\
1 & a^{2} & a \\
1 & a & a^{2}
\end{array}\right)\left(\begin{array}{l}
V_{0} \\
V_{+} \\
V_{-}
\end{array}\right)
$$


Where $V_{0}, V_{+}$, and $V_{-}$are the zero, positive and negative sequence voltage components respectively.

\subsubsection{Clarke transform}

A three-phase stator or rotor voltage, current and flux linkage can be expressed according to its stationary reference frame on the stator side. It can also be expressed according to its rotating reference frame when referring to the rotor side based on the rotor electrical speed, $\omega_{r}$ [31]. A generic equation for this transformation is shown below:

$$
\left[\begin{array}{l}
x_{d} \\
x_{q} \\
x_{0}
\end{array}\right]=\frac{2}{3}\left[\begin{array}{ccc}
1 & -\frac{1}{2} & -\frac{1}{2} \\
0 & \frac{\sqrt{3}}{2} & -\frac{\sqrt{3}}{2} \\
\frac{1}{2} & \frac{1}{2} & \frac{1}{2}
\end{array}\right]\left[\begin{array}{l}
x_{a} \\
x_{b} \\
x_{c}
\end{array}\right]
$$

Where $x$ represents the stator or rotor side voltage, current or flux-linkage.

\subsubsection{Park transform}

The d-q reference frame can also be obtained from the Park transform using the $a, b, c$ variables and the equation is shown below [32]:

$$
\left[\begin{array}{l}
x_{d} \\
x_{q} \\
x_{0}
\end{array}\right]=\frac{2}{3}\left[\begin{array}{ccc}
\cos (\theta) & \cos \left(\theta-\frac{2 \pi}{3}\right) & \cos \left(\theta+\frac{2 \pi}{3}\right) \\
\sin (\theta) & \sin \left(\theta-\frac{2 \pi}{3}\right) & \sin \left(\theta+\frac{2 \pi}{3}\right) \\
\frac{1}{2} & \frac{1}{2} & \frac{1}{2}
\end{array}\right]\left[\begin{array}{l}
x_{a} \\
x_{b} \\
x_{c}
\end{array}\right]
$$

Where $\theta=\omega t$.

\section{$2.7 \quad$ Voltage unbalance}

Voltage unbalance is a typical power quality issue in industrial power systems due to many reasons which may include: monophasic loads, non-transposed lines open-delta transformers amongst others [33]. Numerous authors have studied the causes and effects of voltage unbalance in order to specifically determine its allowable levels. These authors include Fortescue [34] who has proposed the first factor to quantify either voltage or current unbalances as the ratio of negative and positive components. Recently, there are several factors that are used to measure voltage unbalances, of which the relevant ones include the Voltage Unbalance Factor (VUF), the Percent Line Voltage Unbalance (LVU) and the Complex Voltage Unbalance Factor (CVUF) [33].

The LVU is defined as the maximum deviation of an RMS line voltage from the average of the RMS line voltage and it only requires RMS quantities whereas the VUF and CVUF are calculated as the ratio of the positive sequence line voltage to the negative sequence line voltage. The VUF considers only the magnitude while the CVUF includes both the magnitude and the angle [33]. Recent works have proposed analytical methods to calculate the VUF and CVUF only using the line RMS voltages and, therefore, the major advantage of LVU has been eclipsed [33]. During the last 20 years, numerous authors have studied the effects of voltage unbalance on induction motors. In [35], the author, Lee, compares the efficiency, power factor and loss increment for eight different experimental unbalance cases including under-and overvoltage scenarios [33]. 
Observing transients in the presence of voltage unbalance presents a power quality issue which can potentially worsen the reclosing problem. When electrical supply issues such as voltage fluctuations, voltage unbalance and harmonics occur, they can have a significant effect on the motor efficiency [36]. Voltage unbalance occurs when the rms magnitude of the voltages or phase angles between the adjacent supply voltages in a three-phase system are not equal [36].

Voltage unbalance is defined according to four main definitions and can be expressed in different percentages depending on which definition is used [4]. The three main definitions which are commonly used are found below:

\subsubsection{National electrical manufacturers association (NEMA)}

NEMA defines the degree of unbalance as the ratio of maximum voltage deviation from the average line voltage to the average line voltage and is also referred to as the line voltage unbalance rate (LVUR) and its equation is as follows:

$$
\begin{aligned}
& \% L V U R=\frac{\text { Max Voltage Deviation from Avg Line Voltage }}{\text { Avg Line Voltage }} * 100 \\
& =\frac{\operatorname{Max}\left[\left|V_{a b}-V_{a v}\right| ;\left|V_{b c}-V_{a v}\right| ;\left|V_{c a}-V_{a v}\right|\right]}{V_{a v}} * 100
\end{aligned}
$$

Where, $V_{a v}=\frac{V_{a b}+V_{b c}+V_{c a}}{3}$

The NEMA definition only requires the magnitudes of the line voltages and excludes the phase angles [4]. This, therefore, makes it an easier method to use simply due to the fact that a digital multi-meter can be used to take measurements. It is also this main reason why the NEMA definition is widely used in industry rather than others [4].

\subsubsection{Institute of electrical and electronic engineers (IEEE)}

The IEEE voltage unbalance is defined in a similar manner as the NEMA definition but it, however, uses the phase voltage unbalance rate [37], [38]. The equation is given by:

$$
\begin{aligned}
& \% P V U R=\frac{\text { Max Voltage Deviation from Avg Phase Voltage }}{\text { Avg Phase Voltage }} * 100 \\
& =\frac{\operatorname{Max}\left[\left|V_{a}-V_{a v}\right| ;\left|V_{b}-V_{a v}\right| ;\left|V_{c}-V_{a v}\right|\right]}{V_{a v}} * 100
\end{aligned}
$$

Where, $V_{a v}=\frac{V_{a}+V_{b}+V_{c}}{3}$

Just like the NEMA case above, the phase angle information is omitted since only the magnitudes of the phase voltages are considered. PVUR is suitable to the field measurements because its calculations involve only the magnitudes of the three phase voltages [39]. 


\subsubsection{IEC (True definition)}

The IEC represents the "true definition" of voltage unbalance and it is calculated as the ratio of the negative sequence voltage component to the positive sequence voltage component [4], [40]. The threephase supply will need to be transformed into the two-dimensional symmetrical sequence components. The equation can be found below:

$$
\% V U F=\frac{\left|V_{n \mid}\right|}{\left|V_{p}\right|} * 100
$$

Where $V_{n}$ and $V_{p}$ are the negative and positive sequence voltages respectively. These two-dimensional components are obtained by transforming the three phase components according to the matrix equation found above. This is the only definition that takes into account the magnitudes and angles of the voltage components [36], yet, in most cases, only the magnitude is considered.

\subsubsection{Per-phase equivalent circuit model}

The equivalent circuit parameters are based on the IEEE and IEC definitions [4]. They are derived from the no load and blocked rotor test and the equivalent circuit is a single-phase representation of a star or delta connected induction machine [41]. All parameters are referred to the stator side.

The positive sequence equivalent circuit has a shunt resistance, $R_{f e}$, which represents the core losses at rated voltage [4]. The stator resistance, $R_{S}$, and the stator leakage reactance, $X_{S}$, are shown in the in the figure below to the left of the magnetising reactance, $X_{m}$. The rotor resistance, $R_{r}^{\prime} / s$, and the rotor leakage reactance, $X^{\prime}$, are found to the right of the magnetising reactance [4].

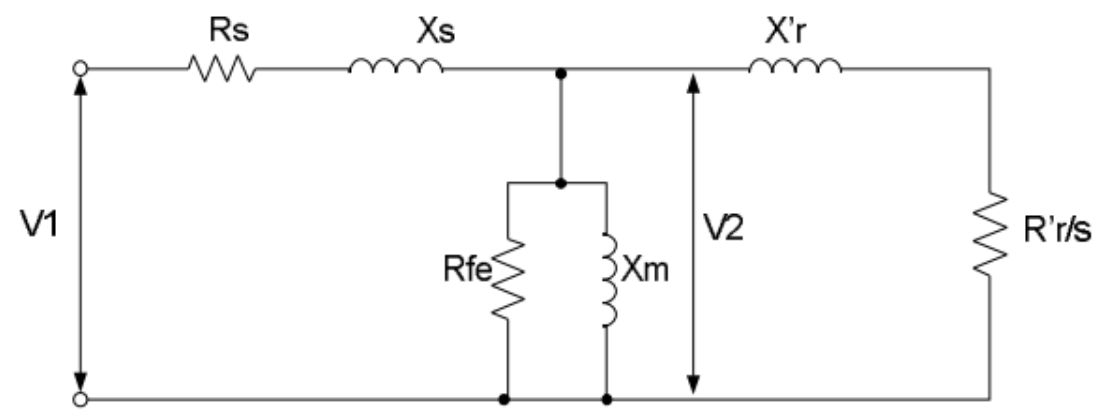

Figure 14: Per-phase positive sequence equivalent circuit [4]

The negative sequence equivalent circuit is similar in form to the positive sequence circuit. The only differences are the fact that the voltages and currents are negative sequence values and the slip is at $2-$ $s$ [4]. The diagram of the negative sequence circuit is found in Figure 15:

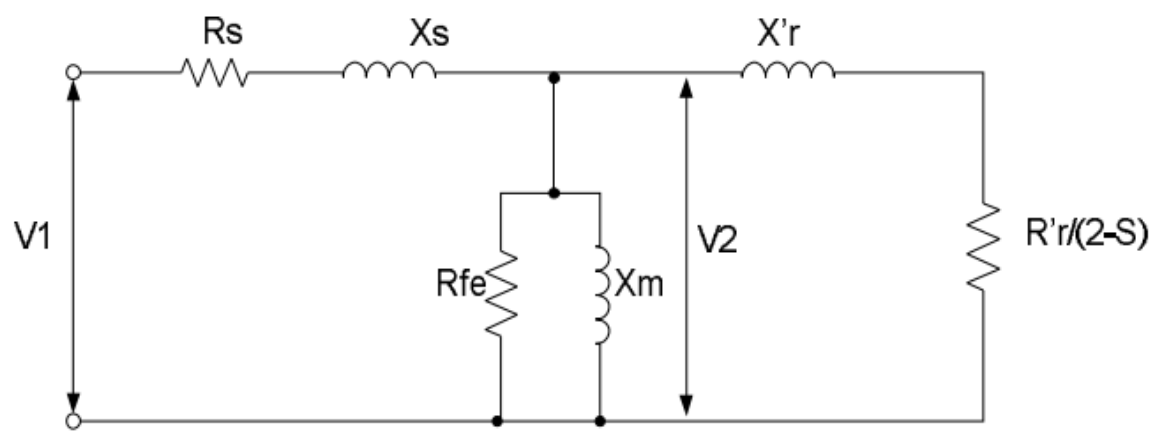

Figure 15: Per-phase negative sequence equivalent circuit [4] 


\subsubsection{Effects of voltage unbalance}

Voltage unbalance occurs when the RMS magnitude of the voltages or phase angles are not equal [36]. Voltage unbalance results in positive and negative sequence components and machines experiencing it undergo detrimental effects. An unbalanced three-phase voltage supply connected to a motor causes the motor to draw unbalanced currents which can be several times the voltage unbalance [4]. Depending on the variations in design and manufacturing of the machine, there can be varying degrees of current unbalance. The current unbalance can be as high as nine times the voltage unbalance for certain energy efficient machines [4], [22].

Furthermore, the impact of voltage unbalance can be seen on industrial load performance and often results in adverse economic consequences. The unbalance condition causes the negative sequence of the voltage to superimpose on the positive sequence which results in overheating, derating, inefficiency, power factor, torque pulsation and pulsation in the peak current [39]. In Figure 16, the cycle of unbalance from the generating side to the consumer side. 


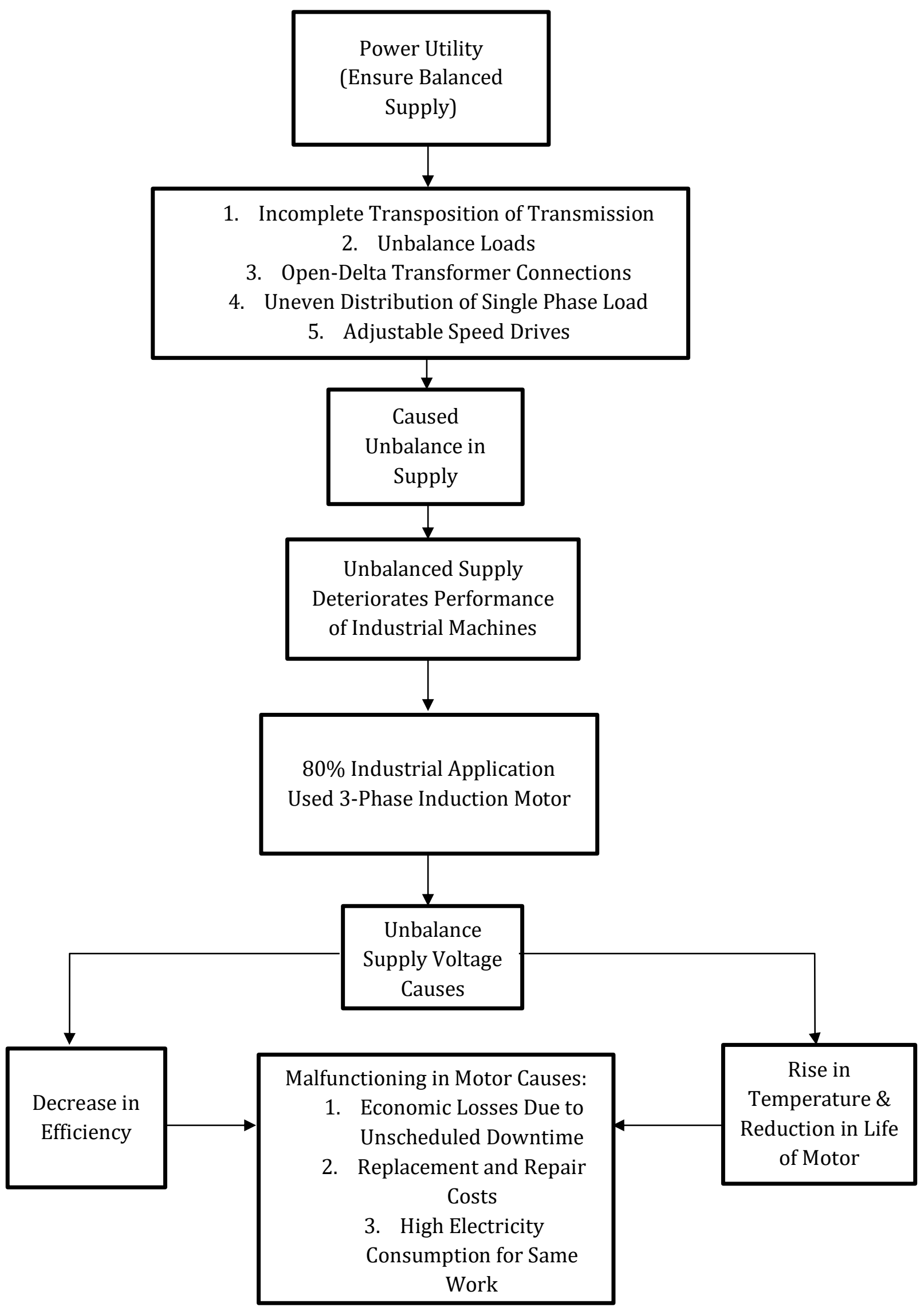

Figure 16: Voltage unbalance implications in induction machines [39] 
The positive sequence gives the desired torque while the negative sequence produces an air gap flux which results in a reverse torque that opposes the positive sequence torque [36]. What results is a behaviour of the induction machine resembling two machines which rotate in opposite directions with the positive sequence voltage at slip, $s$, and the negative sequence voltage rotating at slip, $2-s$ [40]. Another article states that the interaction of these opposing fields produces pulsating electromagnetic torque and velocity disturbances which result in increasing losses, stresses and noise in the machine [42].

It is a known fact that there is a higher reduction in the negative sequence impedance in energy efficient machines due to the lower slip. As a result, there is an increase in negative sequence currents under voltage unbalance [4]. The additional current unbalance can lead to additional heating of the rotor and hence, an increase in the vibration of the motor [4].

Figure 17 shows the positive and negative sequence torque components of an induction motor that is undergoing voltage unbalance.

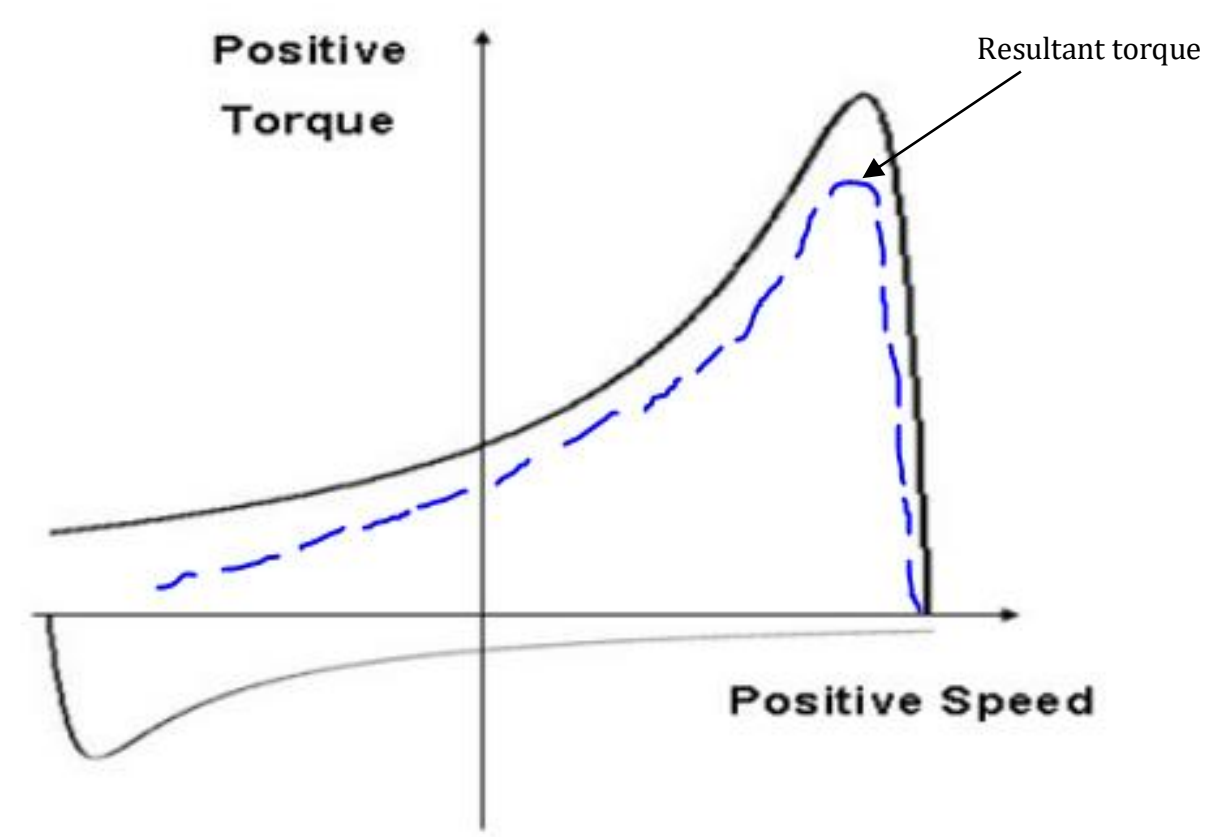

Figure 17: Positive and negative sequence torques under voltage unbalance [36]

From Figure 17, it can be clearly seen that the resultant torque-speed curve is reduced. The reduction of peak torque will compromise the ability of the motor to ride through voltage dips and sags [36]. Furthermore, due to the motor taking a longer time to speed up, the thermal model of the motor changes and this can lead to a decreased service life [36]. If the motor is fully loaded, it is forced to operate at a higher slip and this results in higher rotor losses and thus, a higher heat dissipation.

Due to the energy-efficient machines having a lower negative sequence impedance, they will experience a larger current unbalance as a result of voltage unbalance. This leads to a larger percentage reduction in the developed torque than the standard efficiency motors. If motors continue to experience voltage unbalance whilst under operation, then there will be a decrease in efficiency due to an increase in the current [4], [43]. 
The equation below shows the reduction in mechanical power due to the flow if the negative sequence current:

$$
P_{m}=I_{r p}^{\prime 2} * R_{r p}^{\prime} *\left(\frac{1-s}{s}\right)-I_{r n}^{\prime 2} * R_{r n}^{\prime} *\left(\frac{1-s}{2-s}\right)[\mathrm{W}]
$$

Where $I_{r p}^{\prime 2}$ and $I_{r n}^{\prime 2}$ are positive and negative sequence rotor currents respectively [4].

The total torque is expressed as follows:

$$
T_{m}=I_{r p}^{\prime 2} * R_{r p}^{\prime} *\left(\frac{1}{s \omega_{0}}\right)-{I^{\prime}}_{r n}^{2} * R_{r n}^{\prime} *\left(\frac{1}{(2-s) \omega_{0}}\right)[\mathrm{Nm}]
$$

Where $\omega_{0}$ represents the synchronous speed in radians per second [4]. Both equations 35 and 36 show that an increase in the negative sequence currents will result is a reduction in the power as well as the developed torque. 


\section{Experimental Set-up}

The laboratory set-up, instrumentation and testing methods for the two efficiency classes of the induction machines will be discussed in this section. The experimental tests for start-up and reclosing were conducted for a three-phase, four-pole star-connected, $7.5 \mathrm{~kW}$ Standard Efficiency Induction Motor (SEIM) and Premium Plus Efficiency Induction Motor (PPEIM) which were procured from the same vendor. Numerous tests were conducted at rated, unbalanced over- and undervoltage supply conditions on each motor and averages were taken to get a more representative sample. The instantaneous voltages, currents, torque, speed, power and frequency were measured using the Yokogawa WT1800 Power Analyser. The experimental set-up is shown in the following figure:

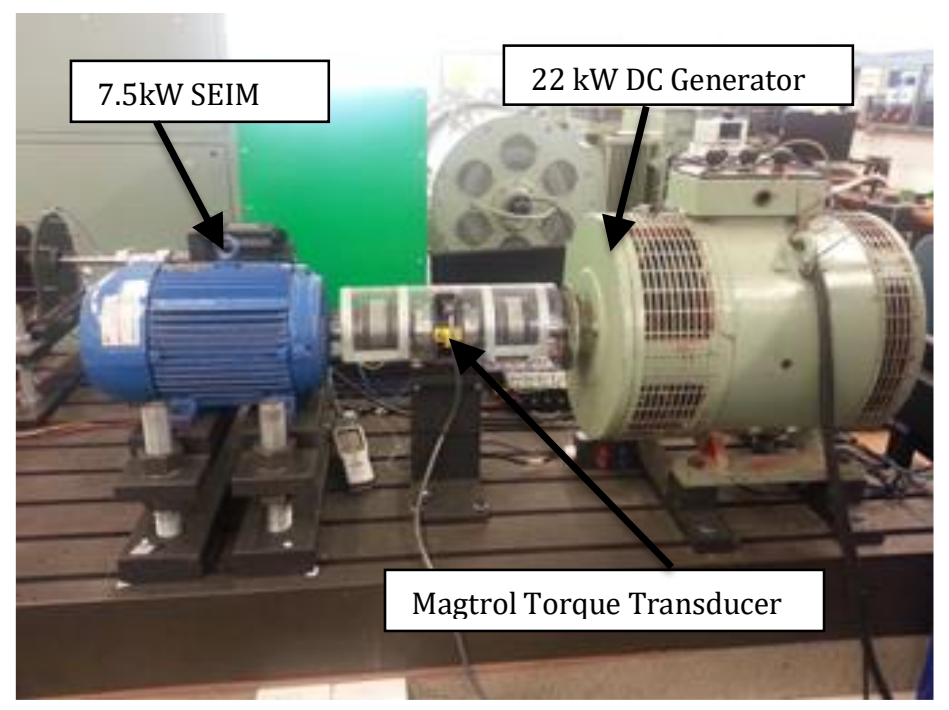

Figure 18: 7.5 kW experimental rig

The ratings for the SEIM and the PPEIM are shown below:

Table 2: SEIM and PPEIM ratings for a wye connection

\begin{tabular}{|l|l|l|}
\hline & Rating & PPEIM \\
\hline Parameter & SEIM & 690 \\
\hline Voltage(V) & 690 & 50 \\
\hline Frequency (Hz) & 50 & 8.06 \\
\hline Current (A) & 8.58 & 1465 \\
\hline Speed (rpm) & 1455 & 7.5 \\
\hline VA (kW) & 7.5 & 0.86 \\
\hline Power factor $(\cos \theta)$ & 0.84 & 1.15 \\
\hline Service factor & 1 & Class H \\
\hline Insulation & Class F & \\
\hline
\end{tabular}

The ratings in Table 2 are for a star-connected machine. Both machines were star-connected yet they were run at a terminal voltage of $400 \mathrm{~V}$. 
The SEIM and PPEIM were coupled to a separately excited DC Machine, which served as the load and the torque was adjusted by controlling the armature current. Both machines were connected to the threephase supply and the signals were captured using the Yokogawa WT1800 Power Analyser. The power analyser has the following properties:

- 1602 samples per frame

- 2 ms time interval per sample

- Linked to the Magtrol TM312 in-line torque transducer to measure the speed and torque (coupled to the motor in operation with a 15 horsepower (HP) DC motor). It is a $0.1 \%$ accuracy class transducer and is rated at $200 \mathrm{Nm}$ with a $100 \%$ overrated capability [4]

When dealing with large rotating electrical machinery, the definitive industry standards in the United States and Canada are the IEEE (Institute of Electrical and Electronic Engineers) and the NEMA (National Electrical Manufacturers Association) standards. The standards used will vary depending on the country but these standards are often a reflection of the IEC (International Electrotechnical Commission). In essence, the IEC standard is, by definition, the international standard and most companies model and purchase induction machines according to this standard [44]. However, to model torque and current performance as well as constructional features, this study adheres to the IEEE or NEMA standard.

Both machines are run under no load conditions. It was decided that the star connection be used as opposed to the delta due to the starting currents in a delta connection being potentially up to 3 times higher than steady state values. This also aided in obtaining the per-phase equivalent circuit parameters which are displayed below:

Table 3: Equivalent circuit parameters

\begin{tabular}{|l|l|l|}
\hline & Values \\
\hline Parameter & SEIM & PPEIM \\
\hline$R_{s}(\Omega)$ & 0.6889 & 0.595 \\
\hline$R_{r}(\Omega)$ & 0.6282 & 0.59 \\
\hline$L_{s} ; L_{r}(\mathrm{mH})$ & 4.34 & 12.7 \\
\hline$L_{m}(\mathrm{mH})$ & 108 & 433 \\
\hline$J_{m}\left(\mathrm{~kg} \cdot \mathrm{m}^{2}\right)$ & 0.0465 & 0.0528 \\
\hline
\end{tabular}

Table 4: Starting scheme and synchronous speed

\begin{tabular}{|l|l|}
\hline Type of Starter & Wye star-delta run \\
\hline Synchronous speed (rpm) & 1500 \\
\hline
\end{tabular}




\section{$3.1 \quad$ The $22 \mathrm{~kW}$ test rig}

All tests were conducted while making use of the already constructed $22 \mathrm{~kW}$ test rig.

\subsubsection{Power supply system}

The power supply system used consisted of a main unit that was connected to the grid. This unit also included a three-phase internal variac which was used for voltage unbalance. The image of this unit is shown in Figure 19.

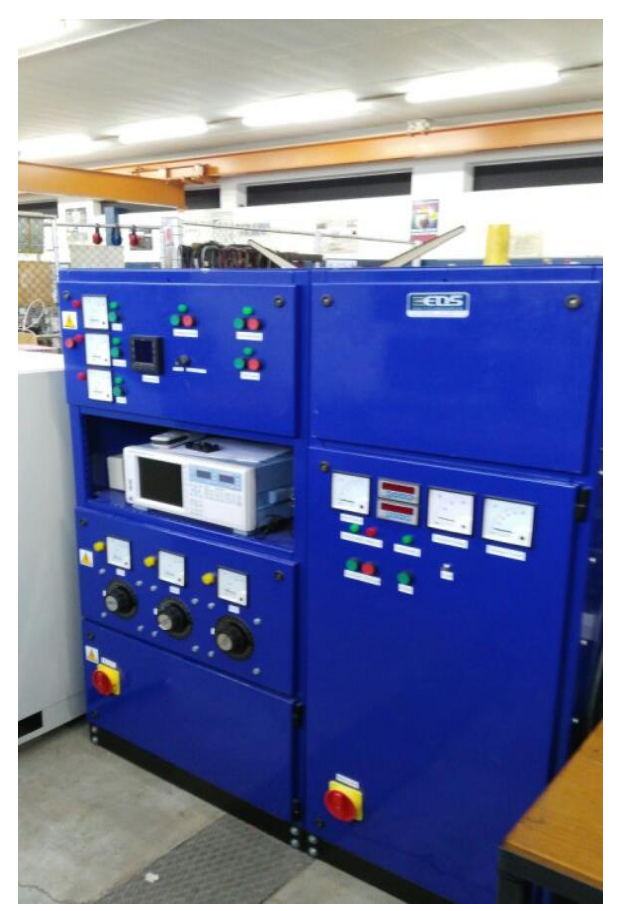

Figure 19: Power supply unit

\subsubsection{Magtrol torque transducer}

An inline TM 312 torque transducer was used for torque and speed sensing. The output value of the measured torque is shown as an analogue DC signal with a \pm 5 volt deflect [45]. The measuring system is based on two concentric cylinders shrunk on each side of the shaft's deformation zone [4]. Accompanying these is are two concentric coils attached to the housing. The cylinders have rows of slots that rotate with the shaft inside the coils. An alternating current is then usually applied to the primary coil at a frequency of $20 \mathrm{kHz}$.

If no torque is applied, the slots on the two cylinders do not overlap. If a torque is applied, then the deformation zone experiences an angular deformation which results in the slots overlapping [4]. As a result, a torque-proportional voltage is on the secondary coil and the built-in electronic module outputs an analogue voltage of $\pm 5 \mathrm{~V}$. This shows that the transducer uses a non-contact differential in order to deduce the torque. The rotor speed is taken from one of the open collector pins as the speed is read from an optical sensor on a toothed wheel. The electronic conditioner outputs a signal that is proportional to the speed of the rotor [4].

\subsubsection{Yokogawa power analyser}

A three-phase Yokogawa WT1800 Precision Power Analyser was connected in series with the supply as well as the induction machine being tested. It is able to capture the instantaneous line voltages and 
currents being fed into the machine. It contained six power input channels and the torque and speed signals from the Magtrol inline transducer were read by the device. The analyser is also capable of sampling at a frequency rate of $16-32 \mathrm{kHz}$ for a sample period of 100 milliseconds [45]. A figure of the power analyser is shown below.

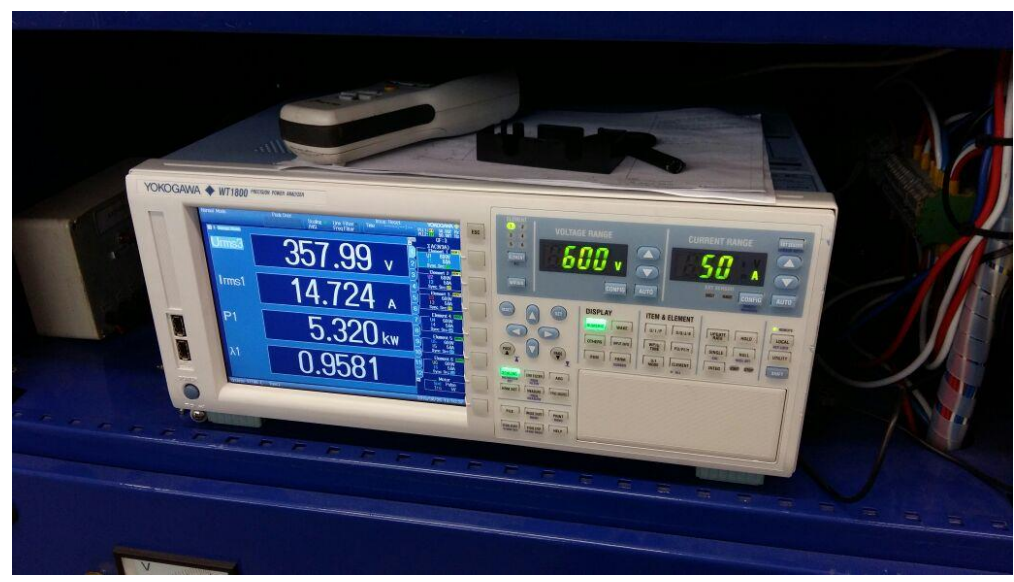

Figure 20: Yokogawa digital power analyser

The configuration for the Yokogawa's connection to the induction machine is shown in Figure 21. A computer was connected to the power analyser and it was used to capture the test data. The computer was also installed with WT Viewer so that the data could be easily displayed on-screen. The speed and torque from the Magtrol transducers are also displayed on the WT Viewer and the power analyser together with the power, voltage and current. The output power is obtained through the torque and speed measurements [4].

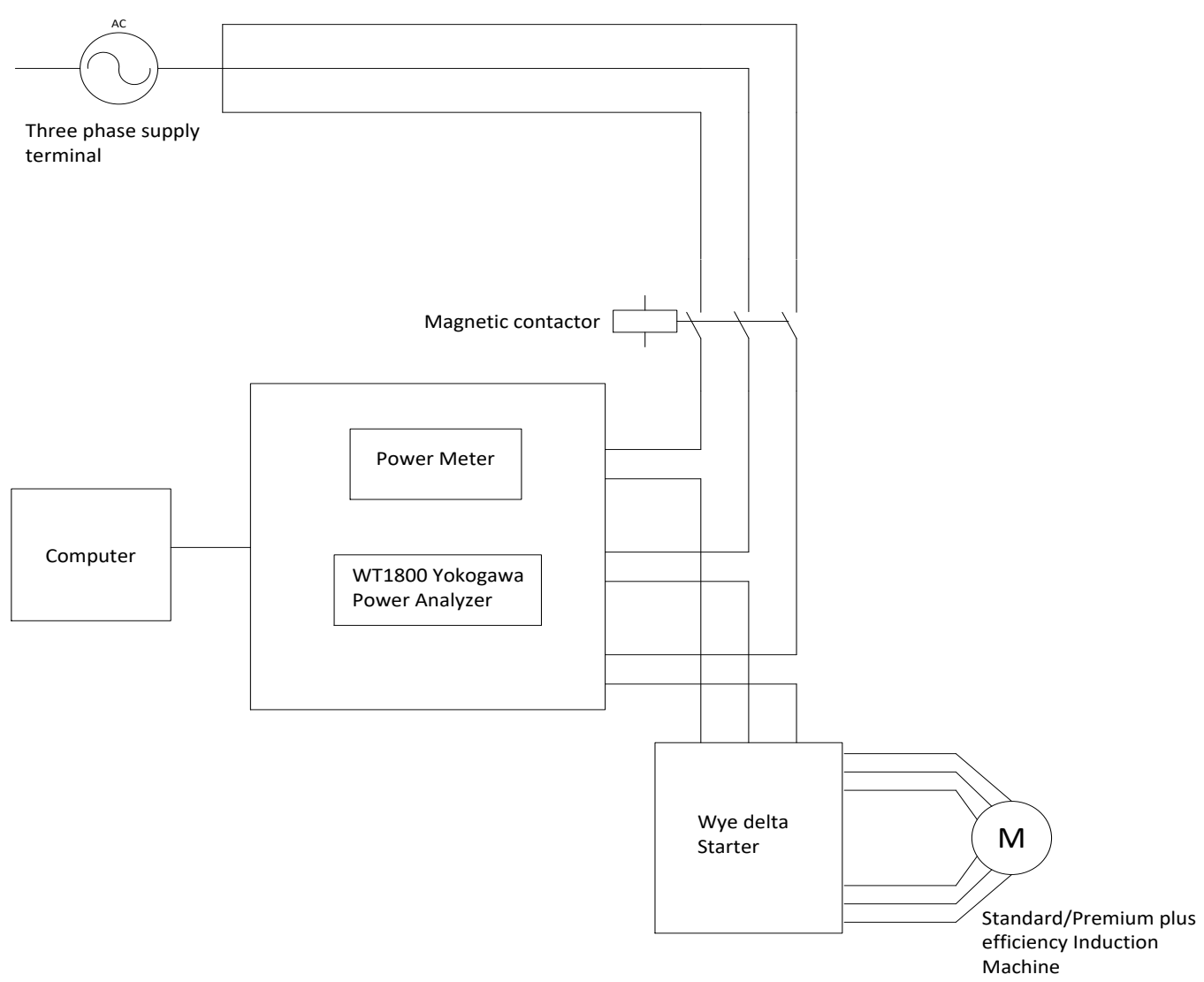

Figure 21: Experimental set-up [5] 


\subsubsection{Winding resistance measuring tool}

A galvanometer was used to measure the stator resistance and it is regarded as one of the most accurate methods of measuring it. An image of the galvanometer used is found in Figure 22.

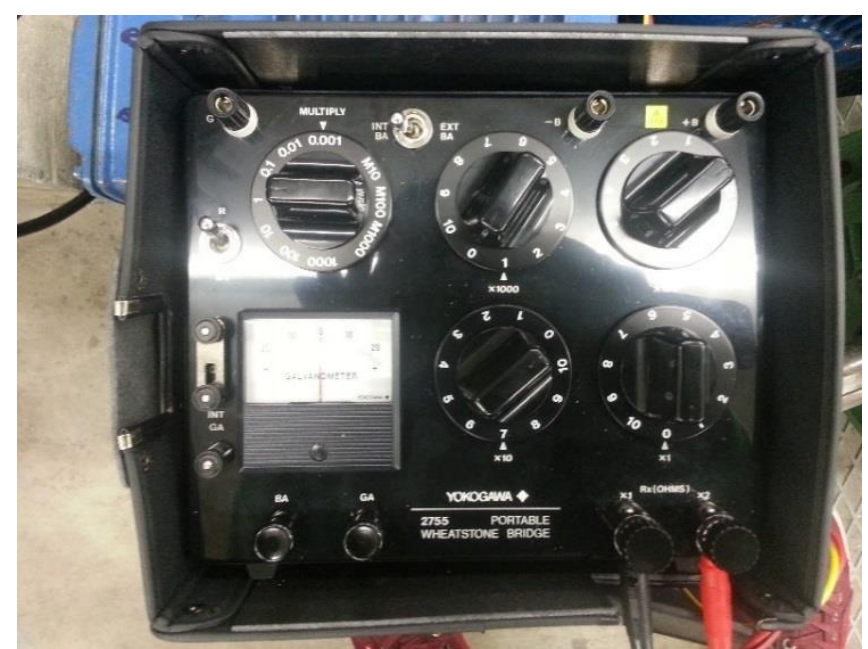

Figure 22: Galvanometer for winding resistance measurement

Galvanometers are made from a Wheatstone bridge with four resistance branches, a voltage source and a meter [4]. In the bridge circuit, three known resistances are compared with an unknown resistance in order for zero current to reflect on the meter [46]. Figure 23 below shows a typical circuit diagram of a Wheatstone bridge.

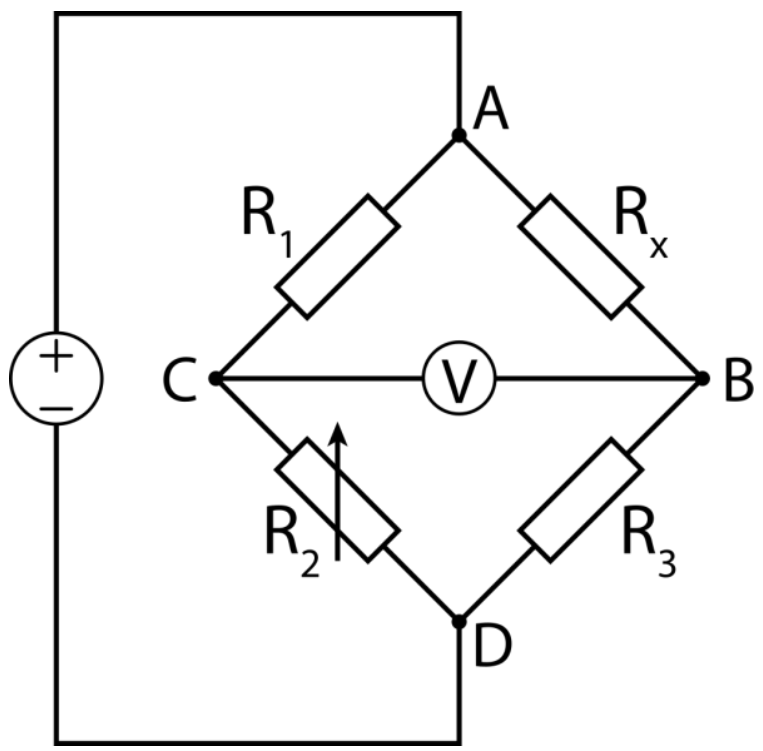

Figure 23: Wheatstone bridge circuit diagram [4]

The stator resistance was measured according to Figure 24: 

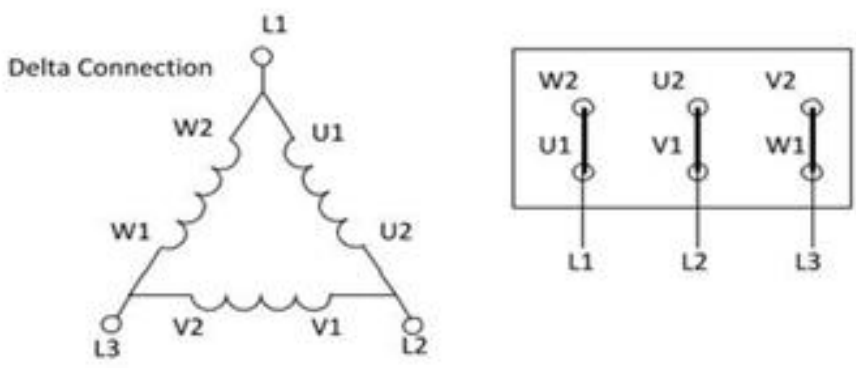

Figure 24: Stator resistance wiring arrangement [6]

Due to the delta connection of the stator resistance at the terminals, the resistance measured for each phase is shown in Figure 24. The leads of the galvanometer were placed on the ' $U$ ' terminals in the diagram to get the corresponding 'a' phase resistance. This was repeated for the remaining terminals to obtain the ' $b$ ' and ' $c$ ' resistances respectively.

An average of the resistances was calculated to obtain the stator resistance:

$$
R_{s}=\frac{R_{a}+R_{b}+R_{c}}{3}
$$

\subsection{Testing procedure}

\subsubsection{No load test}

The no load test gives information about the exciting current and the rotational losses. This test was conducted by applying a three-phase balanced voltage on the stator terminals with the load completely detached from the rotor at a rated frequency of $50 \mathrm{~Hz}$. The line-to-line voltage, line current, power and frequency were recorded and these all served to assist in the calculation of the stator leakage reactance and magnetizing reactance [4].

The no load resistance is obtained using the following equation:

$$
R_{N L}=\frac{P_{N L}}{3 * I_{P}^{2}}
$$

Where $I_{P}^{2}$ is the square of the phase current and $P_{N L}$ is the no load power.

The no load impedance and reactance is obtained using the following equations:

$$
\begin{aligned}
& Z_{N L}=\frac{V_{p}}{I_{p}} \\
& X_{N L}=\sqrt{Z_{N L}^{2}-R_{N L}^{2}}
\end{aligned}
$$

Where $V_{p}$ is the phase voltage.

\subsubsection{Blocked rotor test}

The locked rotor test gives information about the leakage impedances [7]. For this test the rotor of the induction machine was locked to prevent it from moving whilst a three-phase balanced voltage, under the same rated frequency of $50 \mathrm{~Hz}$, was applied to the stator terminals. A variac was used to raise the voltage to a point where the rated current was reached. As was the case for the no load test, the line-toline voltage, line current, power and frequency were recorded in order to calculate the stator and rotor reactance and resistance. 
The blocked rotor resistance, impedance and reactance are obtained using the following equations:

$$
\begin{aligned}
& R_{B R}=\frac{P_{B R}}{3 * I_{p}^{2}} \\
& Z_{B R}=\frac{V_{p}}{I_{p}} \\
& X_{B R}=\sqrt{Z_{B R}^{2}-R_{B R}^{2}}
\end{aligned}
$$

Where $P_{B R}$ is the blocked rotor power. To determine the stator and rotor reactance, $X_{S}$ and $X_{r}^{\prime}$, the following calculation was made:

$$
\begin{aligned}
& X_{S}+X_{r}^{\prime}=X_{B R} \\
& X_{S}=X_{r}^{\prime}=\frac{X_{B R}}{2}
\end{aligned}
$$

To calculate the magnetising reactance, the no load reactance was subtracted from the stator reactance as follows:

$$
X_{m}=X_{N L}-X_{S}
$$

The rotor resistance was calculated as:

$$
R=R_{B R}-R_{S}
$$

A more accurate calculation of $R_{r}^{\prime}$ is recommended by the IEEE. The blocked rotor resistance, $R_{B R}$, is the sum of $R_{S}$ and an equivalent resistance, $R$, which is the resistance of the $R_{r}^{\prime}+j X_{r}^{\prime}$ branch as is seen below:

$$
R=\frac{X_{m}^{2}}{R_{r}^{\prime 2}+\left(X_{r}^{\prime}+X_{m}\right)} * \mathrm{R}_{\mathrm{r}}^{\prime}
$$

But if $X_{r}^{\prime}+X_{m} \gg R_{r}^{\prime}$, then

$$
\begin{aligned}
& R=\left(\frac{X_{m}}{X_{r}^{\prime}+X_{m}}\right)^{2} * \mathrm{R}_{\mathrm{r}}^{\prime} \\
& \therefore \mathrm{R}_{\mathrm{r}}^{\prime}=\left(\frac{X_{r}^{\prime}+X_{m}}{X_{m}}\right)^{2} * \mathrm{R}
\end{aligned}
$$

The resulting per-phase equivalent circuit is shown in Figure 25. 


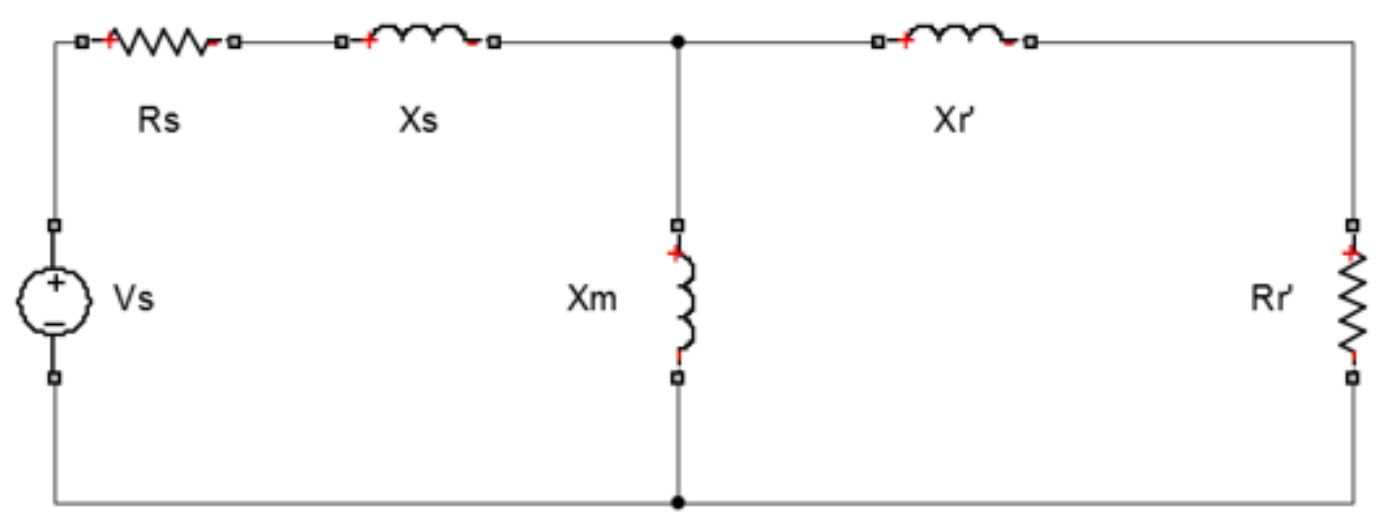

Figure 25: IEEE per-phase equivalent circuit

\subsubsection{Starting a motor from rest}

This experiment was done with the aim of studying the behaviour of the SEIM and PPEIM when they are started form rest and comparing the results with restarting the machines when they are coasting in a transient state.

For the start-up process, a number of steps were conducted which started with the switching on of the AC main supply. The isolator was manually switched on as seen in Figure 18, which then supplied power to the motor being tested. The Magtrol TM312 torque transducer captured the torque and speed readings in order to transmit them to the power analyser, which was already capturing the stator voltage and current readings from the terminals. Once the machine was switched on, a 500ms update time was required before the data could be captured on the WT Viewer. For each test, $1000 \mathrm{~ms}$ worth of data was captured before it was plotted using MATLAB R2013a.

\subsubsection{Restarting a motor in a coasting transient state}

The experiment was done with the aim of studying the behaviour of both machines as they are started while they decelerate in a transient state.

For the restart process, a large sample of results were collected, initially, to get the phase shift of the residual voltage between 0 to $90^{\circ}$, with the worst case being the $90^{\circ}$ phase shift. The same process was carried out for the phase shift of the residual voltage between 90 to $180^{\circ}$, with the worst case being the $180^{\circ}$ phase shift. The test for each phase shift was conducted by opening and then reclosing the contactor within the open circuit time constant. Each time the contactor was reclosed, the WT Viewer captured a frame of the data to visually assess the phase shift. An update time of $500 \mathrm{~ms}$ was required by the WT Viewer after each capture.

Each capture was carefully analysed in order to obtain the closest match to the required phase shift and the ten best samples were averaged in order to get a better representative sample. For each test, $1000 \mathrm{~ms}$ worth of data was captured before it was plotted using MATLAB R2013a. For the restart tests specifically, the plots for residual voltage, transient stator current, transient electromagnetic torque and speed of each motor were captured and analysed before a comparison was made. 


\subsubsection{Simulation results of the PPEIM and SEIM}

A representative circuit model of the PPEIM and SEIM was implemented using a MATLAB SIMULINK environment. The simulations were run in order to determine ideal results for the restart effects on the induction machine. This enables a comparison to be done between experimental and simulated results which would highlight the deviations of the actual results from the ideal conditions.

\section{i. $\quad$ SIMULINK models}

Both the PPEIM and SEIM were modelled using an asynchronous machine block on SIMULINK. This block is capable of implementing a three-phase wound rotor, squirrel cage or double squirrel cage induction motor modelled in a dq reference frame (rotor, stator or synchronous). For this study, a squirrel cage motor was modelled and the stator and rotor windings were connected in wye to an internal neutral point.

The circuit diagram model used for both induction machines can be found in Figure 26:

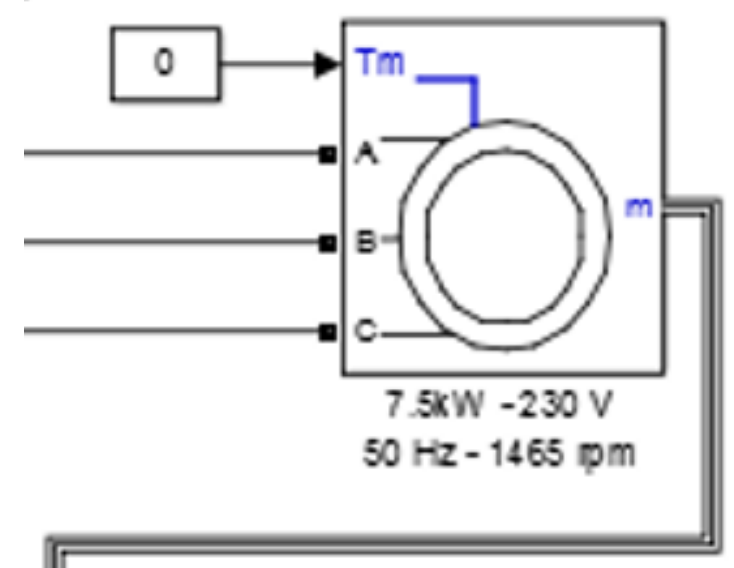

Figure 26: SIMULINK model for PPEIM and SEIM

\section{ii. $\quad$ Residual voltage decay profiles}

The following residual voltage profiles were obtained for the decay of the residual voltage of both the PPEIM and SEIM using the SIMULINK model. The examples shown are for the $180^{\circ}$ phase shift of the residual voltage. 


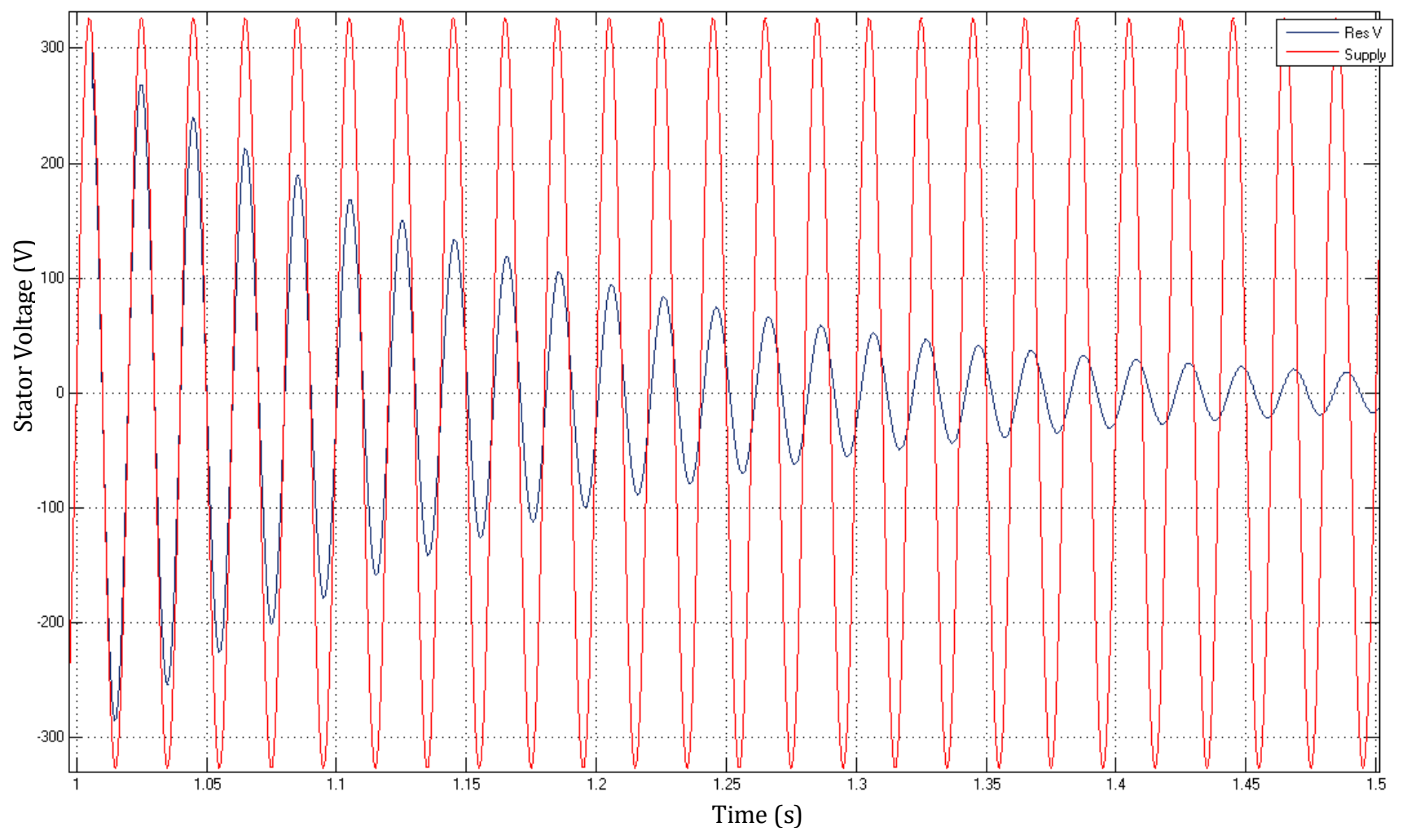

Figure 27: SEIM per-phase residual voltage decay

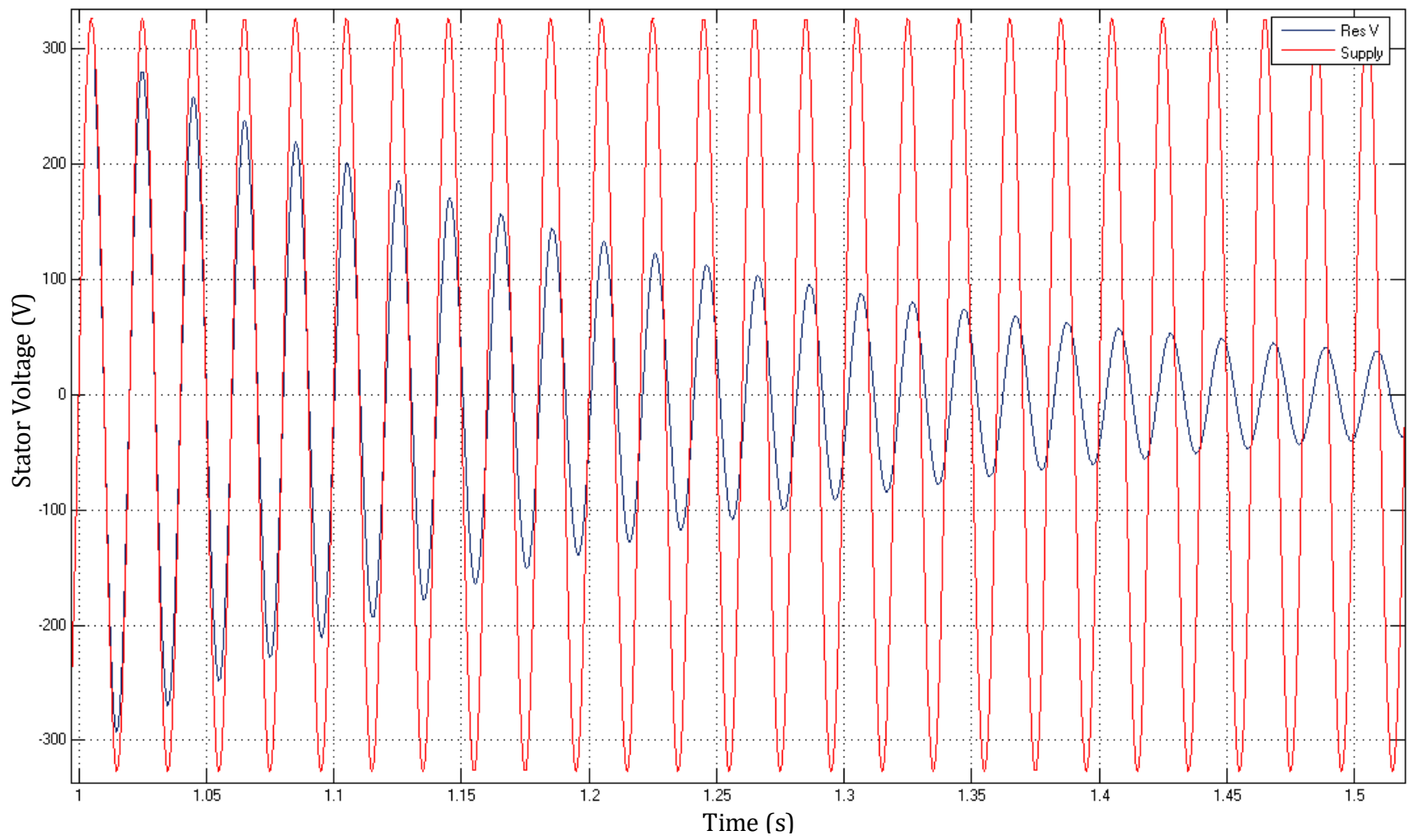


Figure 27 and 28 show that, from the point of disconnect, the PPEIM shows a slower decay in the residual voltage compared to the SEIM. The higher inertia of the PPEIM enables it to maintain a higher speed and, therefore, a higher residual voltage than the SEIM until the $180^{\circ}$ phase shift.

\section{iii. Current transients}
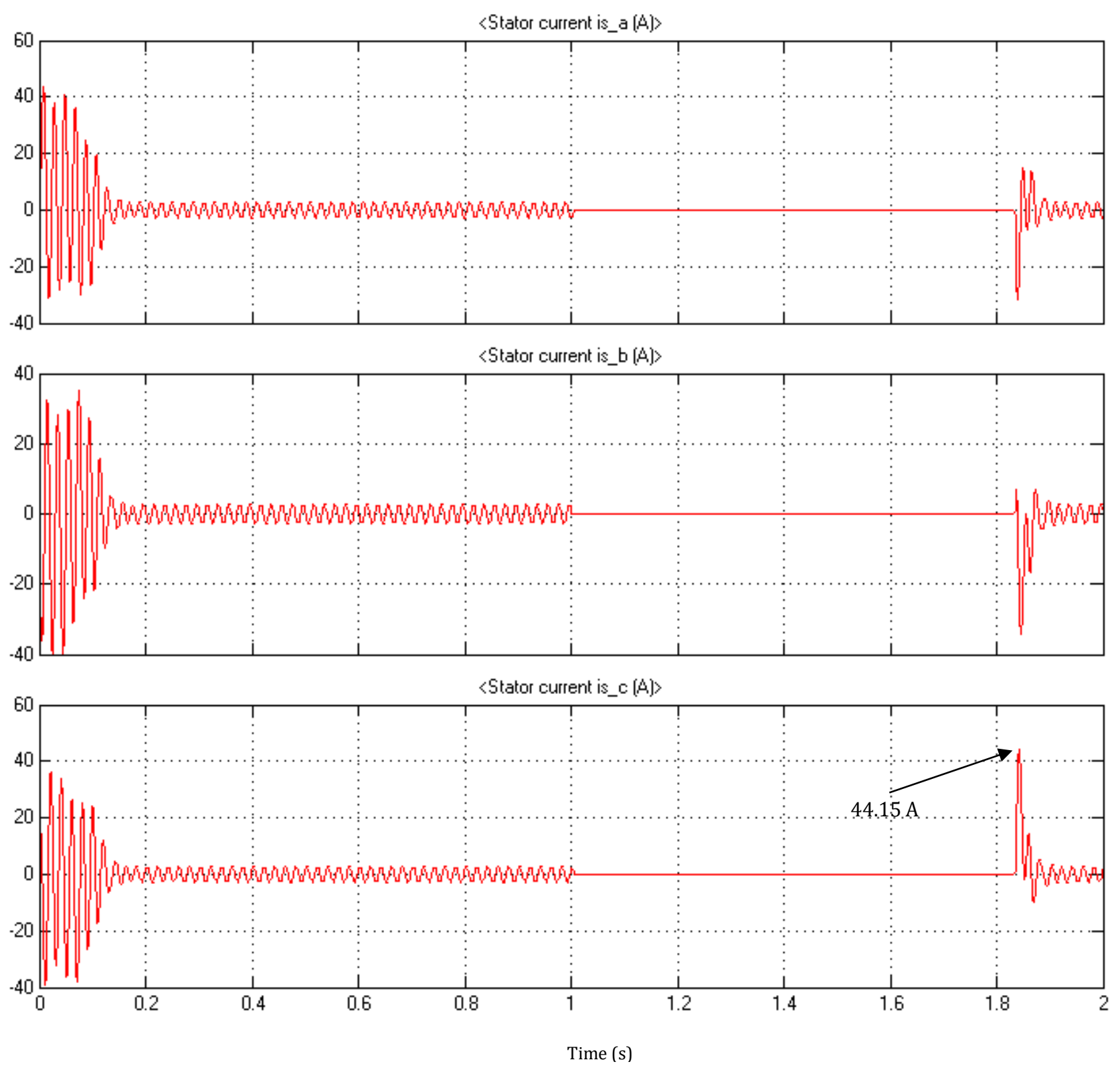

Figure 29: SEIM current transient response - 180 degrees phase shift 

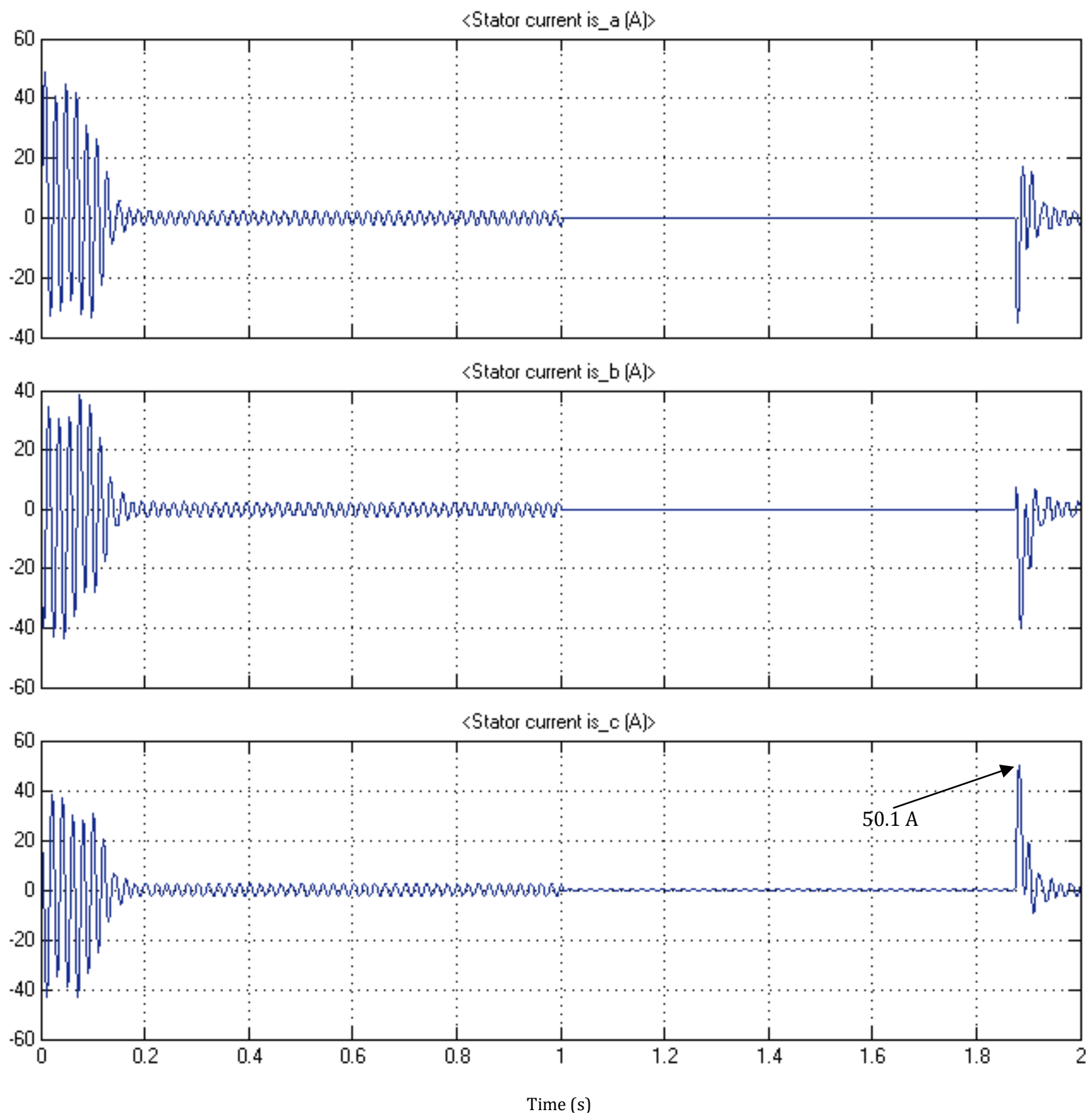

Figure 30: PPEIM current transient response - 180 degrees phase shift

The per phase stator current responses can be seen in Figure 29 and 30. The highest current spike occurs at phase $\mathrm{C}$ for the SEIM at a peak of $44.15 \mathrm{~A}$, whereas the PPEIM reaches a highest peak of $50.1 \mathrm{~A}$ for phase $\mathrm{C}$. This yields a difference of $6.2 \mathrm{~A}$, which is not exceedingly significant yet it highlights the expected outcome of the PPEIM having a larger peaking current transient than the SEIM. 

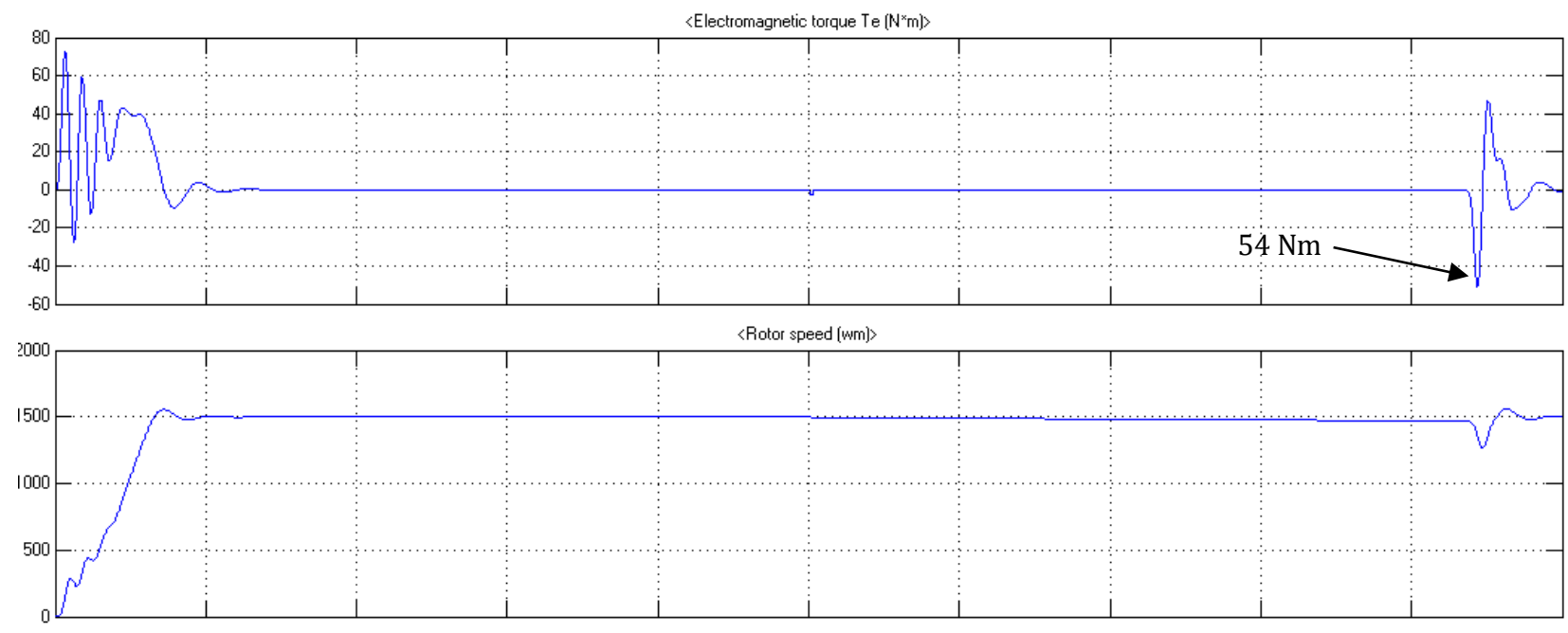

Time (s)

Figure 31: PPEIM SIMULINK torque \& speed transient response - 180 degrees phase shift
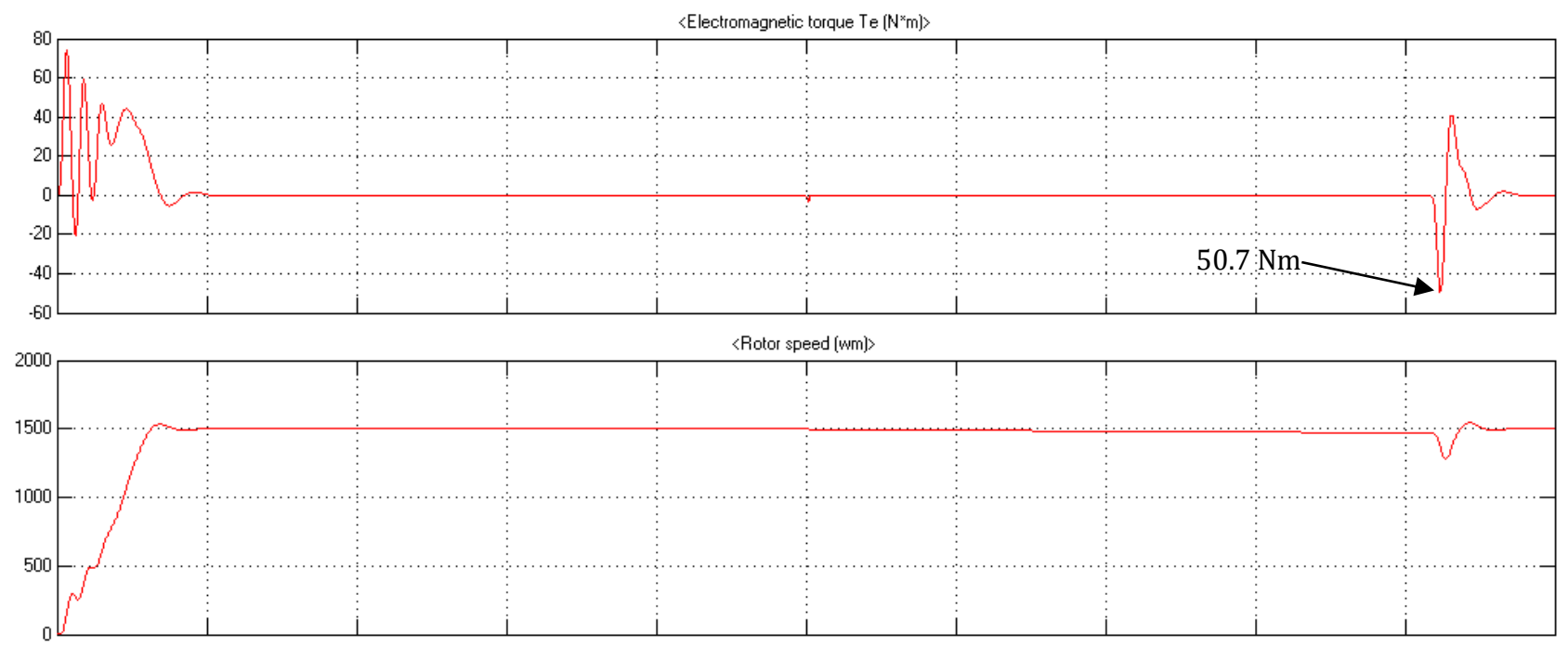

Time (s)

Figure 32: SEIM SIMULINK torque \& speed transient response - 180 degrees phase shift

The load on the torque for the simulations was set to zero. The torque response of the PPEIM, 54 Nm, was found to be higher than the SEIM, $50.7 \mathrm{Nm}$. This is expected since the current response of the PPEIM was higher in Figure 30. It is clear from these results that the time required to attain the desired phase shift has an influence on the magnitude since the speed of the machines slows down. Therefore, it is the purpose of this study to observe these relationships and compare the findings to the practical behaviour of the motors. 


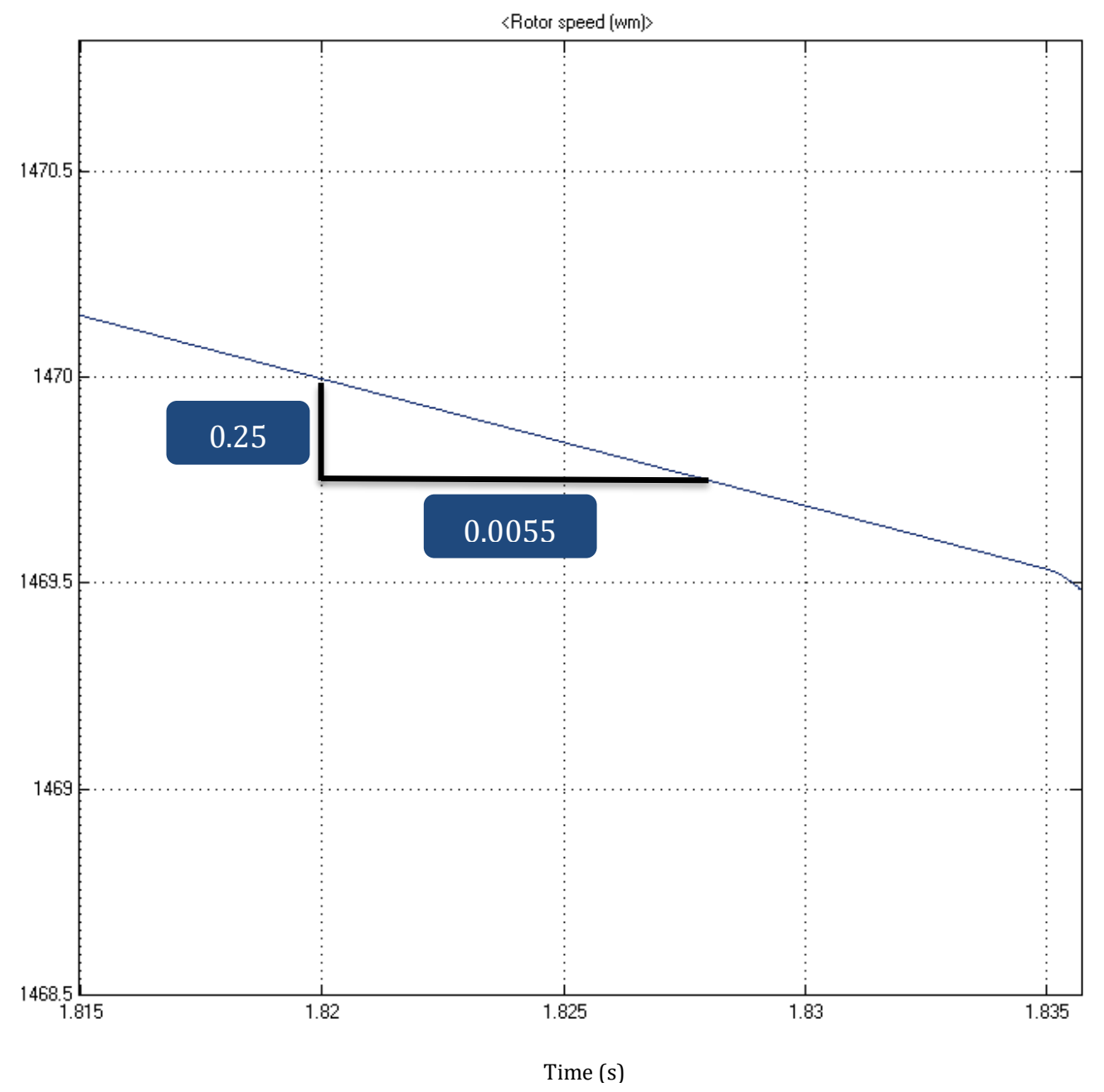

Figure 33: Detailed view of SEIM rotor speed decay - 180 degrees phase shift

A closer look at the decay of the speed profile shows that the SEIM in Figure 33 shows a slightly faster decline in the rotor speed than the PPEIM in Figure 34. This is illustrated by the SEIM having a sharper gradient of speed decay than the PPEIM for the $180^{\circ}$ phase shift of the residual voltage before the motor is restarted. The gradient of the PPEIM is at a value of $33 \mathrm{rpm} / \mathrm{s}$ and the gradient of the SEIM is $45 \mathrm{rpm} / \mathrm{s}$. This signifies a difference in the way in which the two machines decrease in speed after the point of disconnect, with the SEIM experiencing a faster decay. This difference is highlighted further in the experimental results in Chapter 4 where it can be seen that the speed of the rotor has an influence on the decay of the residual voltage magnitude and hence, the resulting transient current and torque. This can be mainly attributed to the higher inertia of the PPEIM $\left(0.526 \mathrm{~kg} \cdot \mathrm{m}^{2}\right)$ compared to the SEIM $(0.465$ kg. $\mathrm{m}^{2}$ ). 


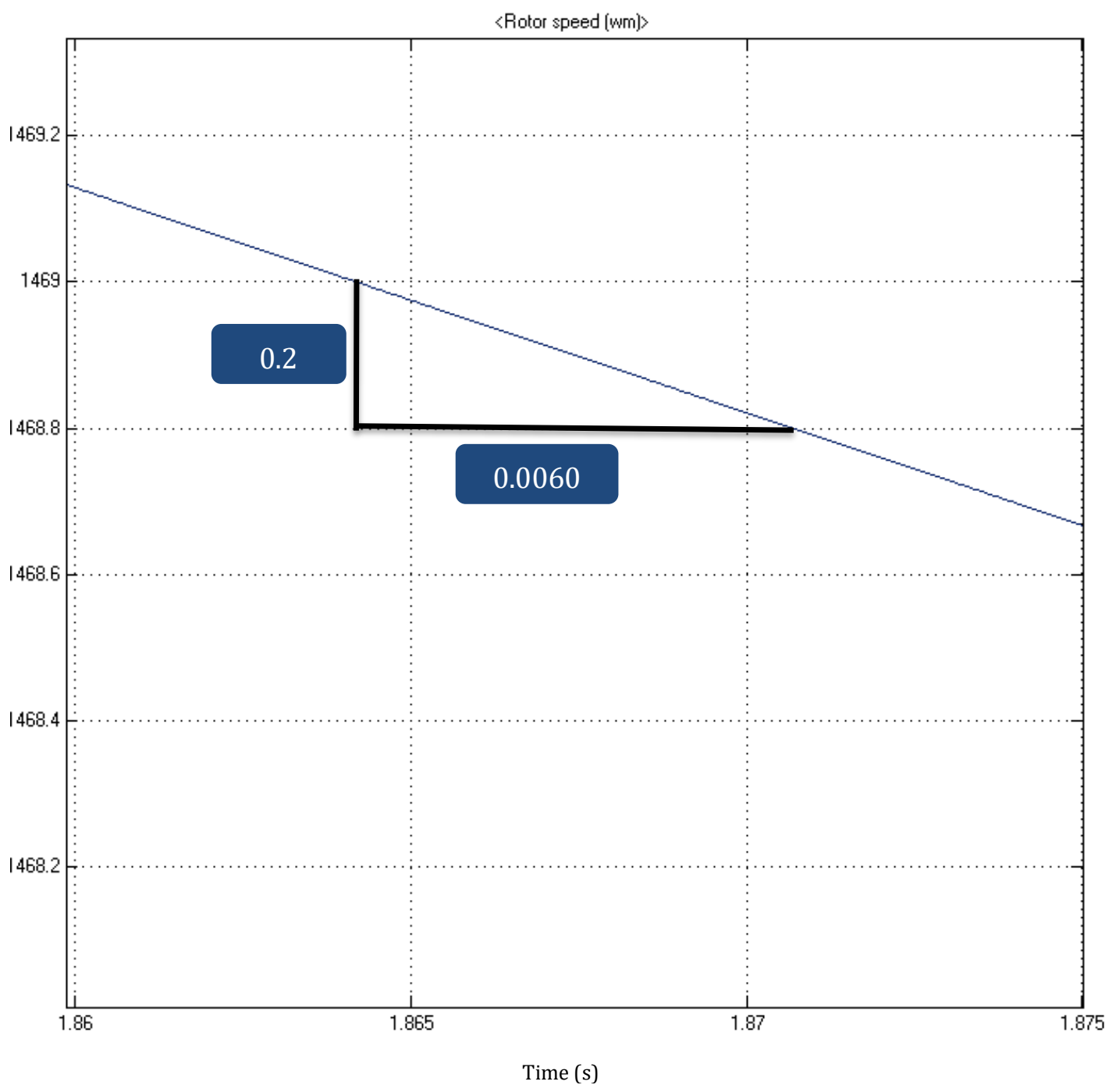

Figure 34: Detailed view of PPEIM rotor speed decay - 180 degrees phase shift

Observing the disconnect profiles for both machines, it can be seen that the SEIM has a higher residual voltage peak after disconnect than the PPEIM. This is illustrated in Figures 35 and 36: 


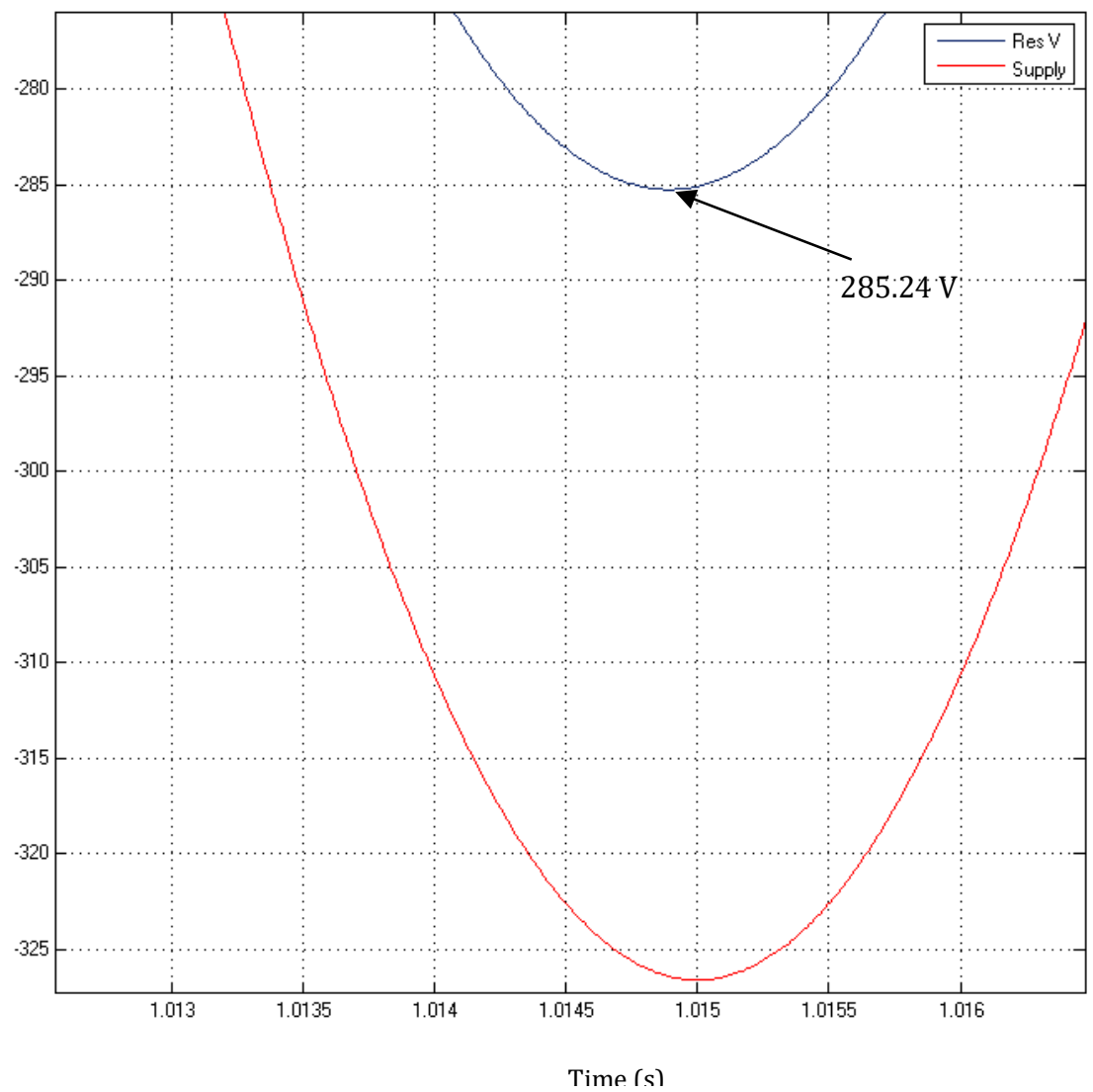

Figure 35: Detailed view of SEIM residual voltage peak after the point of disconnect

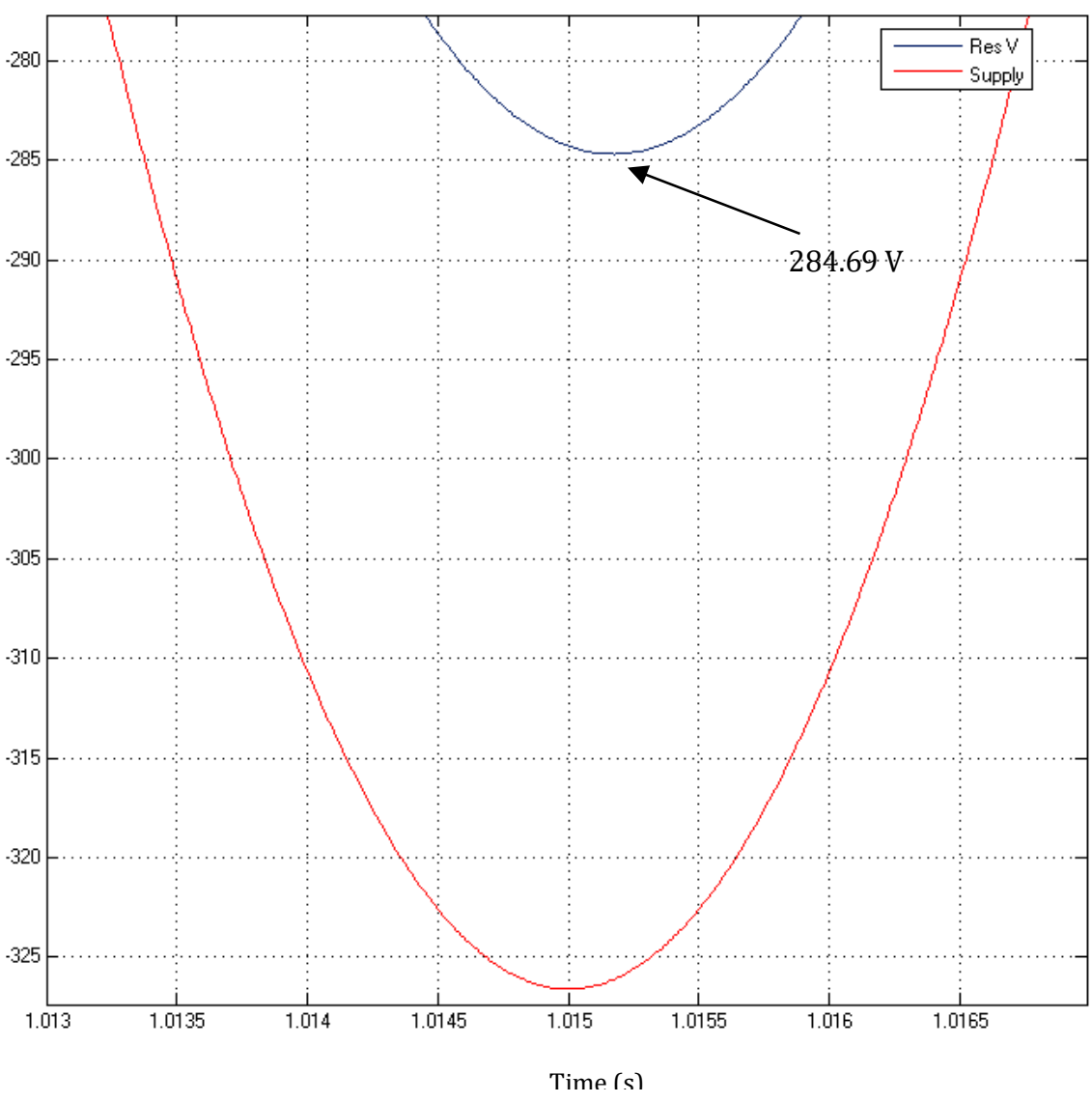

Figure 36: Detailed view of PPEIM residual voltage peak after the point of disconnect 
An observation of Figure 35 and 36 shows that the SEIM has a higher residual voltage peak just after disconnect at a magnitude of $285.24 \mathrm{~V}$ than the PPEIM which has a magnitude of $284.69 \mathrm{~V}$. From this, it can be established that the MATLAB SIMULINK induction machine model does take the residual flux that remains after disconnect into account. It will be seen in the experimental results later in chapter 4 that the SEIM does have a larger residual voltage just after the point of disconnect than the PPEIM. This is due to the higher retentivity and residual magnetism that the SEIM has based on the lower-grade silicon steel used in its manufacture. 


\section{Validation of results and discussion of balanced induction machine transients}

This chapter presents the validation of the results for the rated voltage start-up and restart tests. It also deals with the impact of the tests on the current and torque transients of induction motors. The important factors that play a role in the residual voltage decay of both machines before they are restarted are presented. Numerous experimental trials were run for the start-up and restart tests to obtain an exhaustive amount of data. This assisted greatly in observing trends which gave a better analysis of how the shift in phase and change in magnitude of the residual voltage affected the current transients

A comparison is made between the PPEIM and SEIM in terms of the current and torque transient response. The experiments were carried out for 4 conditions. These included, start-up conditions and restart conditions with a $0^{\circ}, 90^{\circ}$ and $180^{\circ}$ phase shift of the residual voltage relative to the supply. Initially, the machines were operated under rated, steady state conditions in order to obtain the base values. These values were used to characterise the results for easier analysis, interpretation and comparison between the two machines [5].

The values in this section will be presented as per-unit [pu] quantities. Table 5 shows the base values for the motors run under a star wye connection. The base values for the voltage and current were the rated peak phase magnitudes whereas the rated values were used for the torque and the speed.

Table 5: Induction motor base values

\begin{tabular}{|l|c|c|c|c|}
\hline Type of motor & Voltage [V] & Current [A] & Torque [Nm] & Speed [rpm] \\
\hline Premium plus efficiency & 318.43 & 11.3 & 49.3 & 1465 \\
\hline Standard efficiency & 318 & 12.13 & 49.3 & 1455 \\
\hline
\end{tabular}

\subsection{Start-up from rest}

The use of a direct-on-line (DOL) starting method can result in the current and electromagnetic torque of a motor having very large peaks before settling in steady state when compared with a star-delta starter. At start-up, there is no residual voltage to further impact on the current and torque magnitudes and the effect is exclusively due the supply terminal and the stator impedance [5]

Due to such effects, a reduced voltage starter is utilised for the motors being assessed. The starter used is a star-delta starter and it operates by initially starting the motor in a star connection, which reduces the voltage by a factor of $\frac{1}{\sqrt{3}}$. This factor therefore reduces the starting current and torque by two-thirds [47].

For the start-up case, the same voltage is applied to both machines. Only the current and torque transients will be presented and discussed in the following section. 
The start-up current and torque profiles are shown in Figure 37:

$i$.

Per-phase current

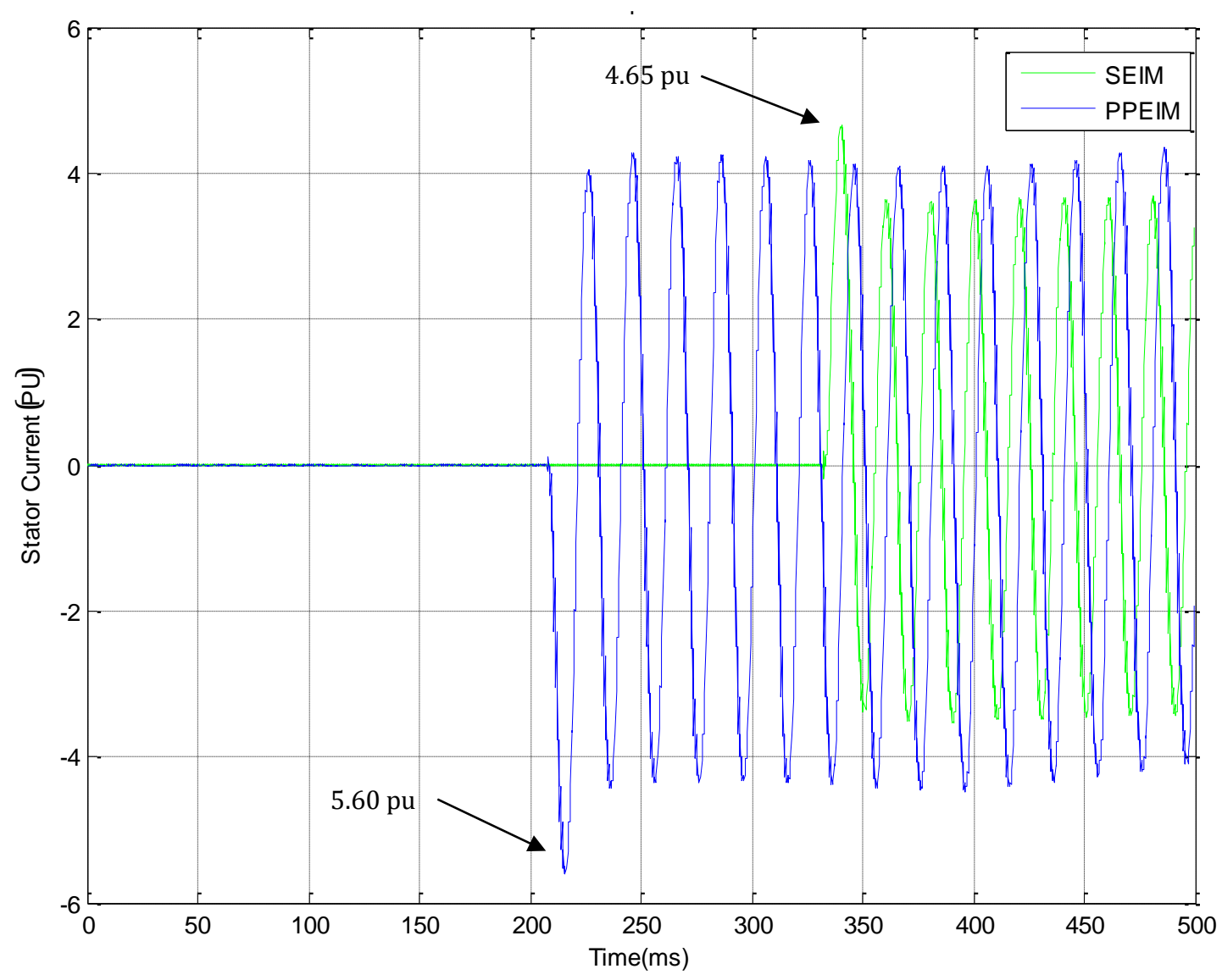

Figure 37: Rated per-phase start-up stator current

When an induction motor is started, large inrush currents occur. Ordinarily, during the initial half-cycle, the inrush current spike is at its highest and is much larger than the normal rated current. After the initial half-cycle, the motor starts to rotate and the start-up current begins to subside. Once the motor reaches steady state speed, the current would have reached its operating value which should be below its rated value [4].

Upon the connection of a three phase supply voltage to the terminals of a motor, only the impedance of the stator limits the current drawn. There is no residual voltage in the system, thus there is no remaining flux to oppose the current [4]. Due to the PPEIM having a lower resistance, it will typically draw a larger per unit current spike at start-up. The average locked rotor current of an SEIM can rise up to five or six times the rated current. For PPEIMs, the starting currents can be as high as eight times the rated value [4].

This start-up current spike can last for a few cycles for a small motor such as the $7.5 \mathrm{~kW}$ induction machine but may last for several seconds for larger motors depending on the load inertia, since motors in industry will often be loaded [4]. Due to the PPEIM having a larger current at start-up, this can have an adverse effect on the protection system that is connected to the motor and this will be especially true for much larger machines in industry. 
From Figure 37, it can be seen that the inrush currents that appear during the first period of the startup process are prominently large but are lowered immediately in the next cycle. The figure shows spikes of $5.60 \mathrm{pu}$ for the PPEIM and $4.65 \mathrm{pu}$ for the SEIM. This shows that the starting current can indeed rise up to over three to four times the rated value for a star-delta start-up procedure as has been stated in [13]. The same article also states that this is a reduced value as the start-up transients can potentially rise to six to eight times the rated value in the case of DOL starting.

The sustained transient of roughly 4 pu (for the PPEIM) can be seen before the machine comes to a no load steady state. However, this is not a worst-case scenario for start-up since a delta-star starter is used as opposed to a DOL start-up method [13], thereby reducing the supply voltage. A high current amplitude has the potential to damage the switch powers of electrical components connected to the terminals, with inverters being a prime example [48].

The large starting current and subsequently sustained transient, as seen in Figure 37, can potentially cause the voltage supply to dip during this period which can be hazardous to the other machines connected to the same grid [13]. Essentially, voltage distortions and variations in supply amplitude may cause power quality issues. Both these phenomena can be grouped together to be termed as voltage sags. Voltage sags often have varying effects on sensitive equipment. A larger emphasis needs to be placed on motor protection as a result, especially with the case of a fast reconnection to the same or alternate supply [49].

ii. Torque

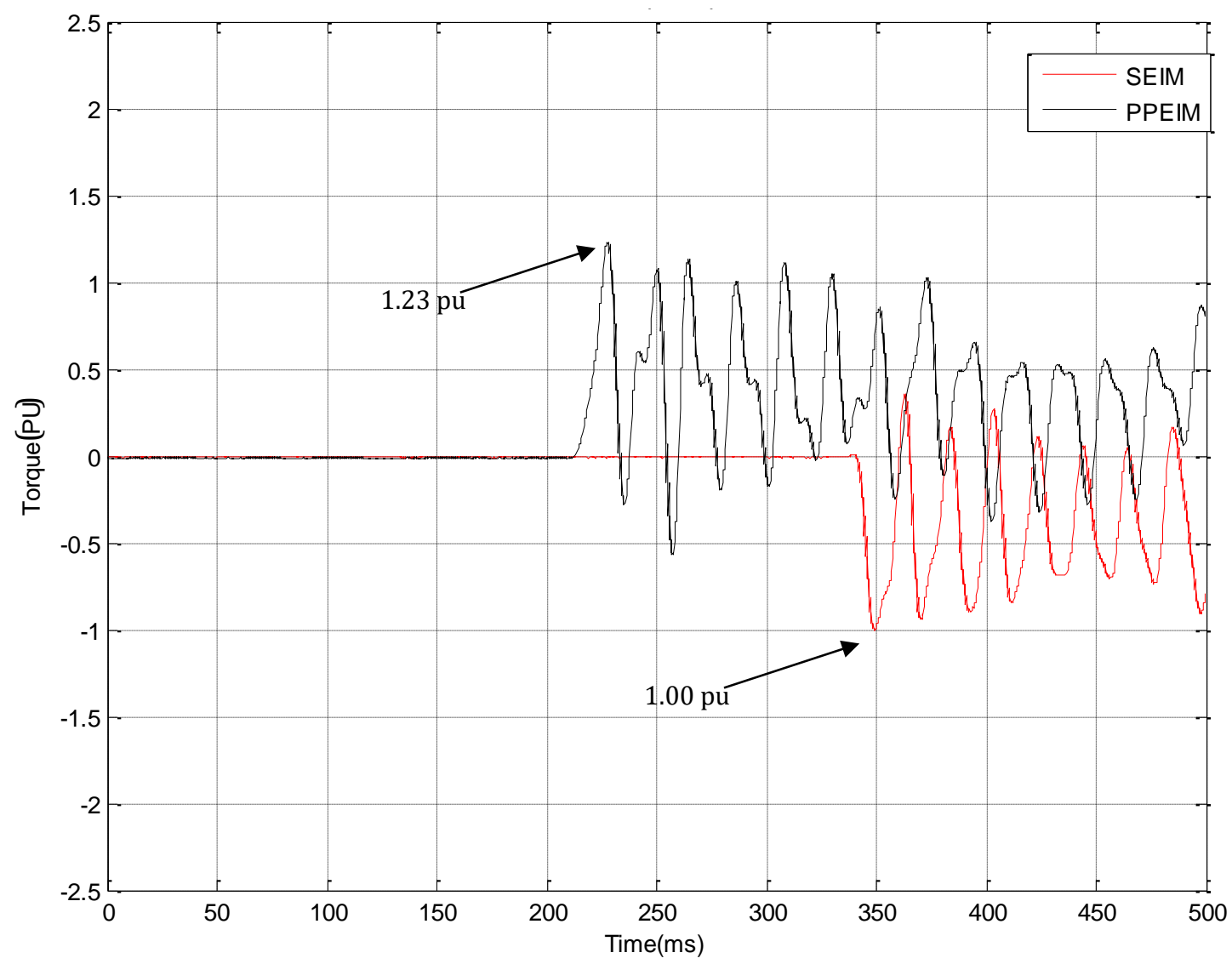

Figure 38: Rated start-up torque 
The start-up torque has values of $1.23 \mathrm{pu}$ and $1.00 \mathrm{pu}$ for the PPEIM and SEIM respectively as has been presented in Figure 38. There is a difference of 0.23 pu between the two machines. This difference in torque transients will be seen to increase when restarting the machines at different phase shifts of residual voltage and this is due to the fact that at start-up, it is only the impedance that determines the starting transients. The PPEIM has a stator impedance of $0.59 \Omega$ while the SEIM has a stator impedance of $0.69 \Omega$. Later in the chapter, it will be seen how the presence of residual voltage will have varying effects on the current and torque transients depending on when the machine is reconnected.

One thing to note in Figure 38 is that the torque transient does not spike significantly. This is a similar pattern to the start-up current where the transient is sustained for several cycles before it dies down.

\subsection{Restart when coasting to standstill}

As an electric motor has its contactors reclosed, the effects that are experienced are due to the variation in frequency, magnitude and phase of the residual voltage. Improper reclosing of the contactors will result in undesired transients that cause large current and torque. This can result in supply voltage instability, a switching off of the supply, shattering of the windings, insulation and bearings of the motor as well as the disturbance of the normal production process in a factory [3].

It is for this reason that careful analysis needs to be done at the point of reclosing. It has been stated before that the safe reclosing time is when the residual voltage is $33 \%$ of the supply voltage [30]. However, the studies found in Pathom et al have shown that this criterion is ineffective since large magnitudes of torque and current transients may still appear after the residual voltage decay has decreased below 33\%. The magnitude and phase of the residual voltage relative to the constant supply voltage determines the resulting current and torque transient peaks. The results for three phase shifts are presented in this analysis of reclosing transients. The magnitude is a consequence of the time required to achieve a desired phase shift, given the mechanical time constant. For the deemed worstcase scenario, attempts were made to reclose the contactor within the open circuit time constant of the motors concerned.

If the magnitudes of the machines are the same and only phase shifts are considered, much larger potential differences would be experienced between the supply and residual voltage as the phase shift with a maximum at $180^{\circ}$. For experimental results, the time required to attain the desired phase shift also has an effect on the magnitude since the speed of the machine is decreasing. Later in the chapter it will be seen, through experimental results, how the speed influences the magnitude of the residual voltage.

\subsubsection{Restart for $0^{\circ}$ phase shift}

For the restart tests, the per-phase residual voltage, current and developed torque is presented. With respect to each machine, the restart is executed while the residual voltage is in phase with the constant supply. This point of reconnect occurs sooner than the cases with larger phase shifts, therefore the magnitude of the residual voltage is higher than the other cases, since the speed of the machine is also greater. Furthermore, the potential difference between the constant supply and stator residual voltage is expected to be the least. This statement has a more significant bearing if the magnitudes of the supply and residual voltage are the same.

Figure 39 shows a single phase of the residual voltage relative to the supply voltage as the contactor is opened and reclosed. This is shown for the SEIM. 


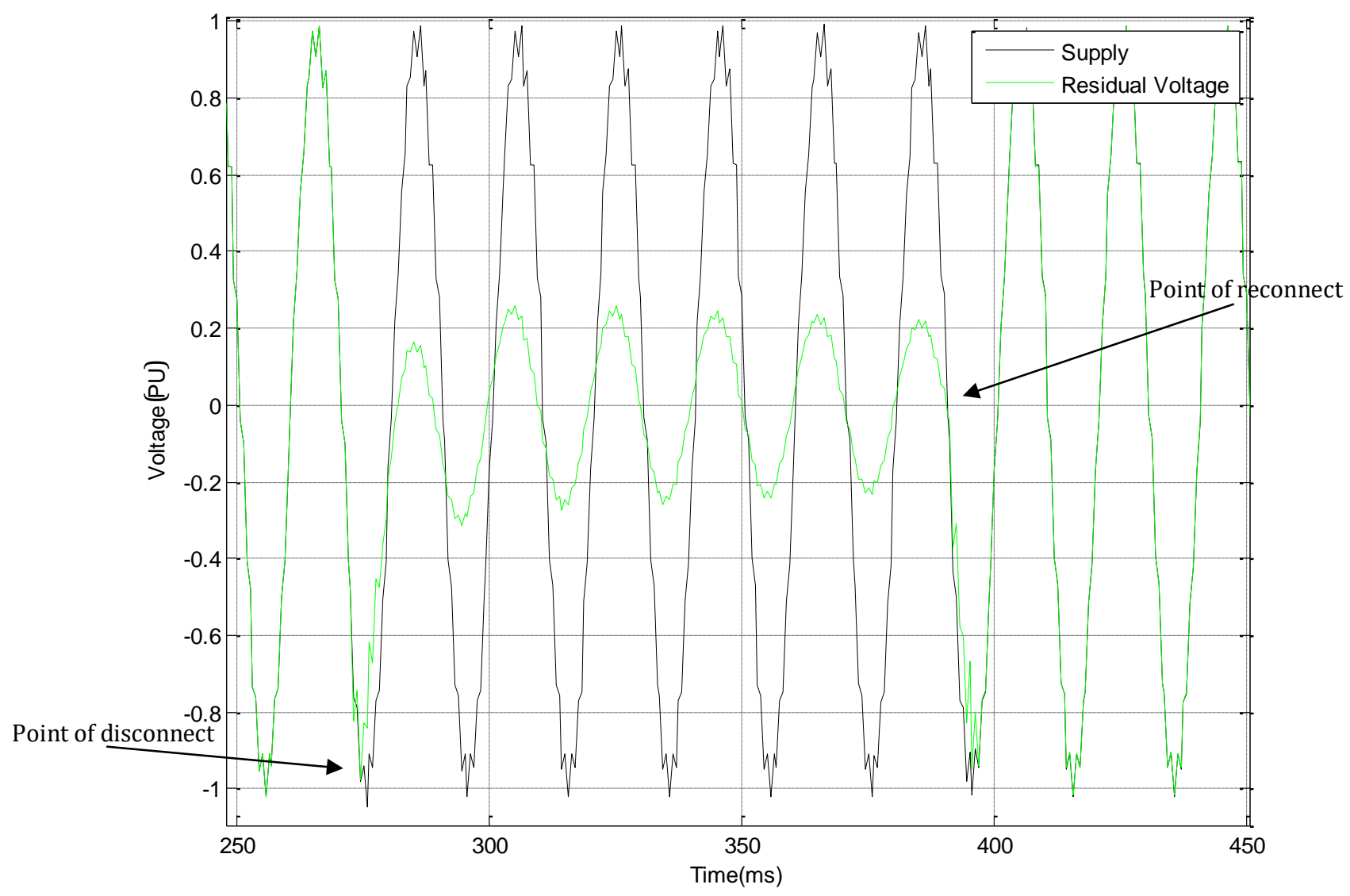

Figure 39: $0^{\circ}$ Per-phase supply voltage vs. residual voltage [SEIM]

Figure 39 shows that the residual voltage and supply have a similar phase at the last peak before the point of reconnect. The point of interest for the residual voltage is the last peak before restart. This offers a valuable point of reference for the residual voltage in the subsequent tests since it plays a significant role in the magnitude of the peak current and torque transients. 


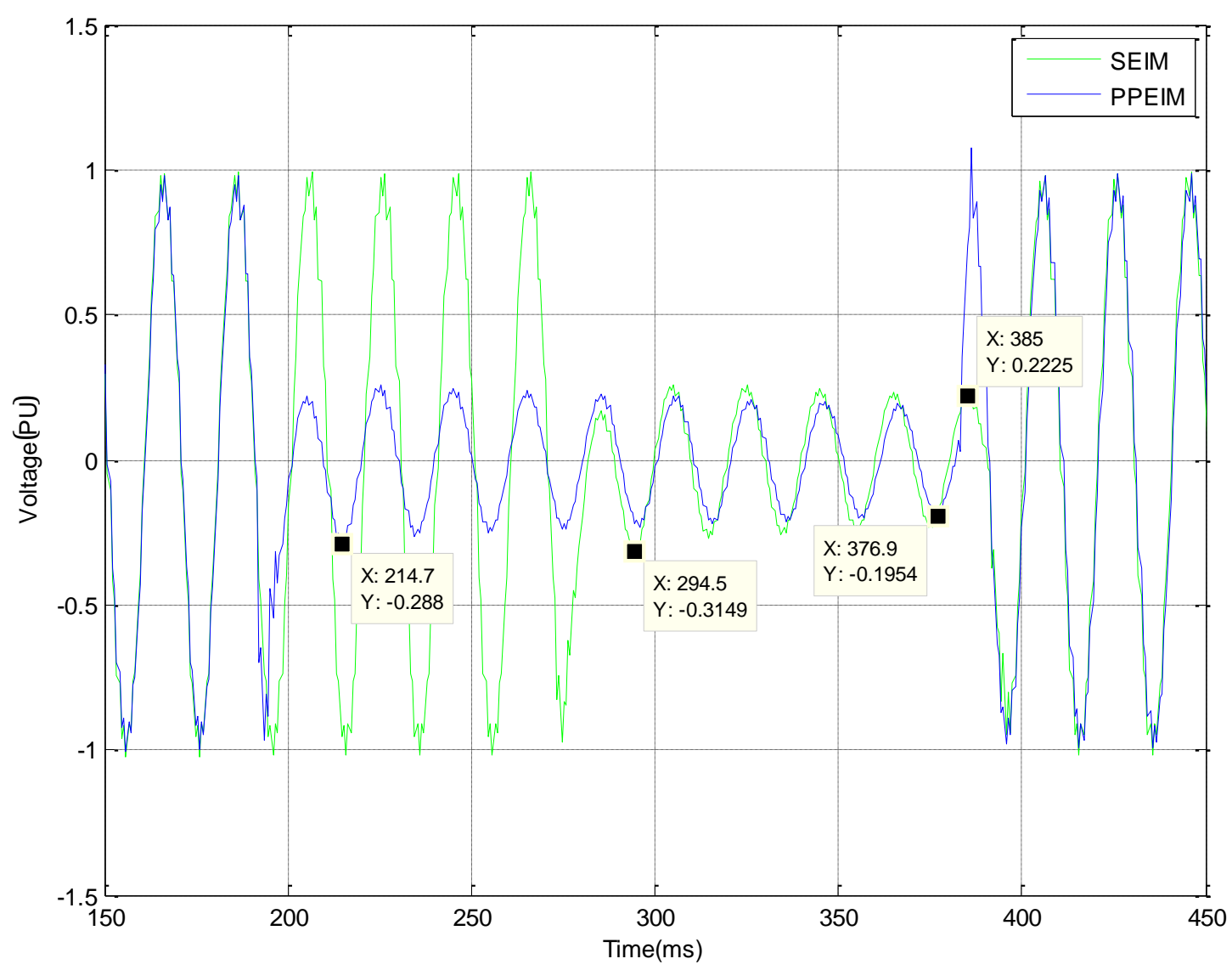

Figure 40: Per-phase residual voltage - 0 degrees phase shift

From Figure 40, it can be seen that the first peak from the point after disconnect is higher for the SEIM than for the PPEIM, which was expected based on the poorer permeability of the SEIM. This is shown in Figure 40 where the second peak after the point of disconnect has $0.29 \mathrm{pu}$ and $0.32 \mathrm{pu}$ for the PPEIM and SEIM respectively. Due to the PPEIM having a higher permeability, it therefore has a lower retentivity. Thus, it has a lower ability for its coil to retain its magnetism once the current supply has been interrupted. It is for this reason that the PPEIM shows a lower residual voltage in the first cycle after the point of disconnect. This can also be associated with the lower residual flux remaining in the PPEIM.

In addition, the difference in the number of cycles before the point of reconnect highlight the fact that the PPEIM takes several cycles longer than the SEIM to get to the required phase shift. This will be explained further in the chapter. 
ii.

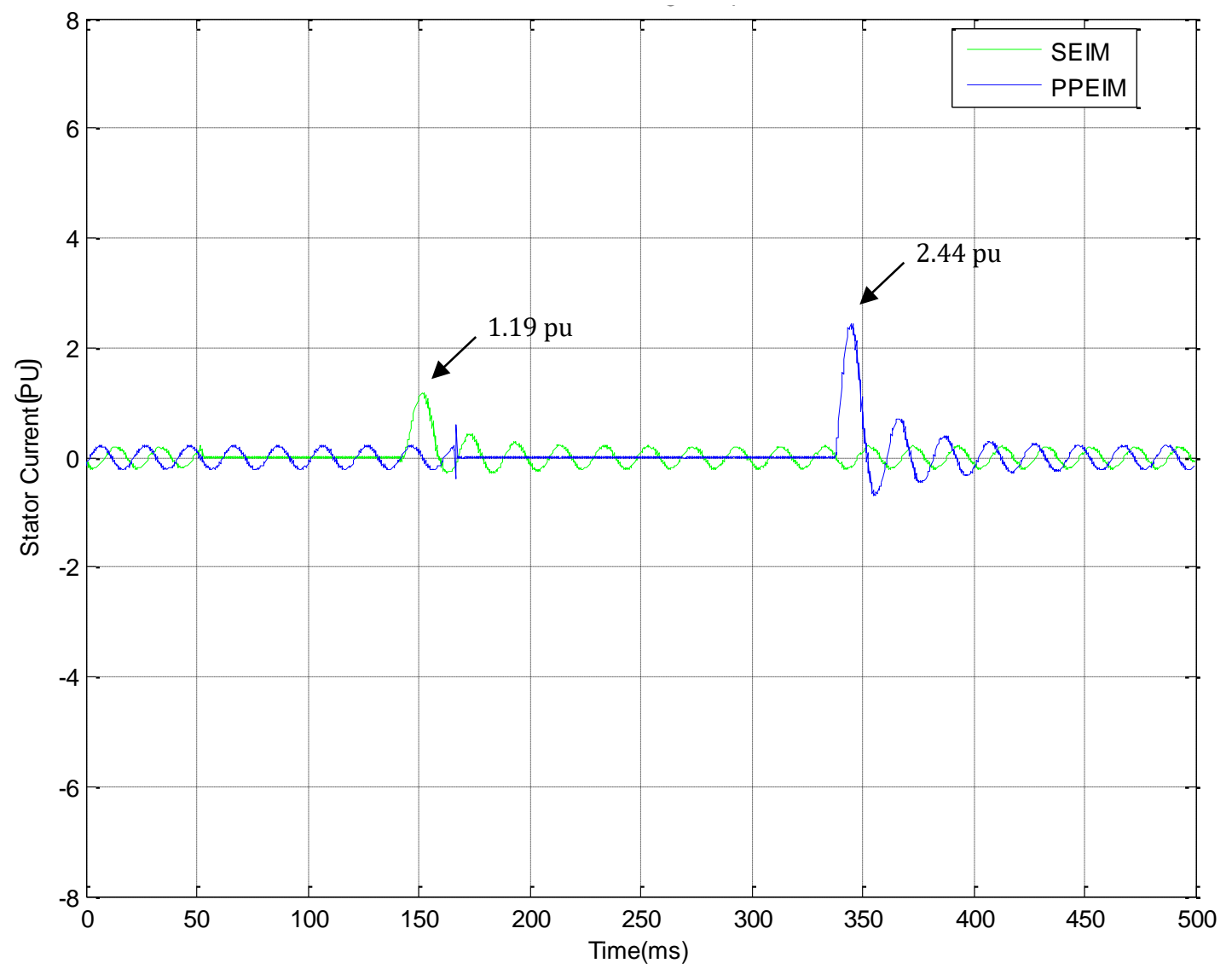

Figure 41: Per-phase stator current - 0 degrees phase shift

In Figure 41, it can be seen that the per-phase stator current spike is less than the start-up case. For the start-up case, the stator current transient had a value of $4.65 \mathrm{pu}$ and $5.60 \mathrm{pu}$ for the SEIM and PPEIM respectively.

Comparing these values to Figure 37, a reduction is observed for both machines with a result of $1.19 \mathrm{pu}$ and 2.44 pu for the SEIM and PEIM respectively in Figure 41. It is clear that the presence of a large residual voltage in this scenario reduces the potential difference and hence, reduces the current transients. The supply voltage and the residual voltage are in phase with each other and thus the resultant voltage, or potential difference, is at a minimum.

It can be seen that the PPEIM experiences a larger current transient spike than the SEIM. This large difference can be attributed to the PPEIM having a lower stator impedance than the SEIM since the potential difference between the supply and the voltage is not significant. 


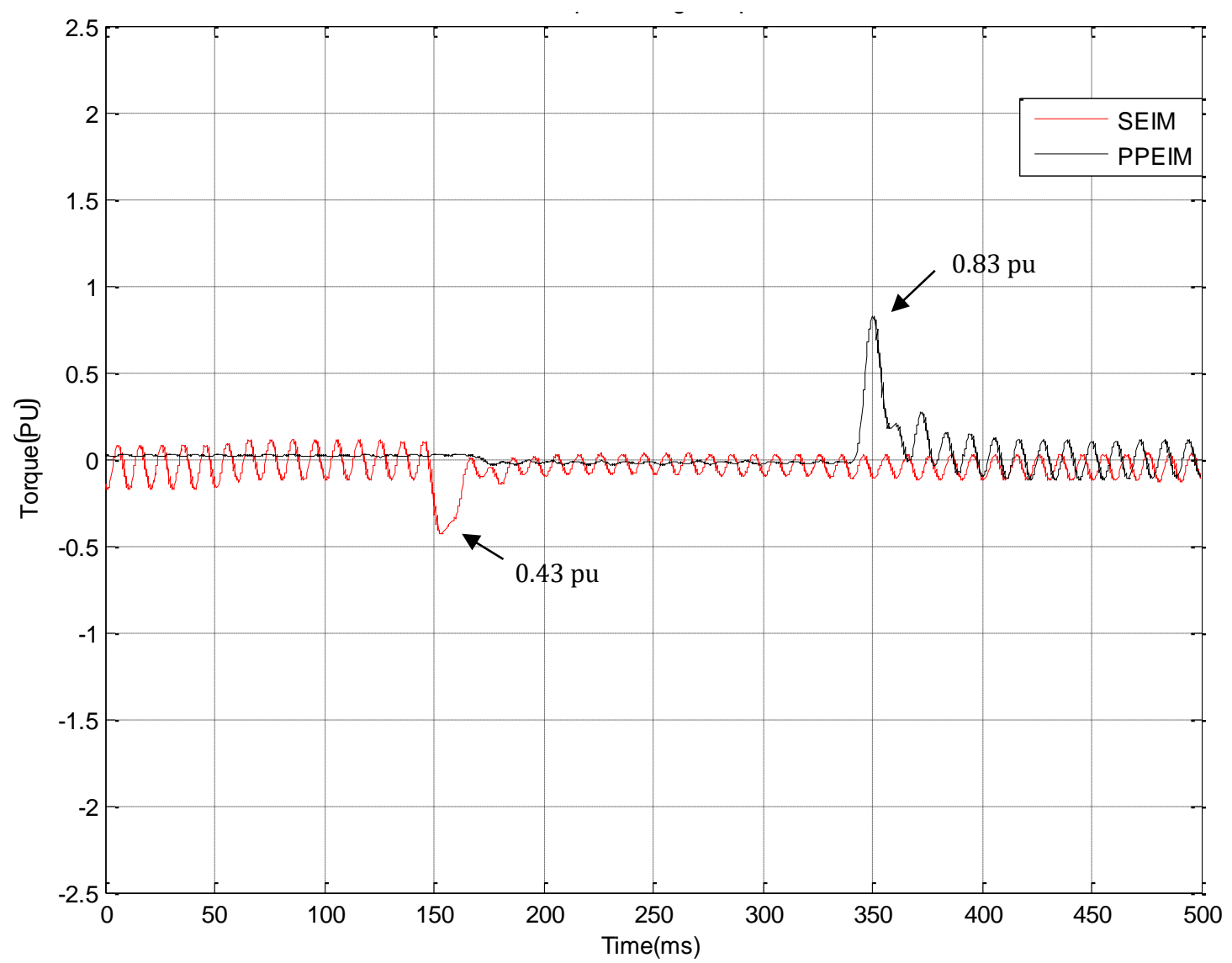

Figure 42: Torque - 0 degrees phase shift

Observing the torque in Figure 42, it can be seen that the PPEIM has a larger spike, $0.83 \mathrm{pu}$, than the SEIM which is at $0.43 \mathrm{pu}$. It should also be noted that the torque experienced in this test is less than the start-up case (1.00 pu for SEIM and 1.23 pu for PPEIM). It should also be noted that the difference in torque between the two machines is larger for this case than at start-up. At start-up, the torque difference between the two machines is 0.23 pu whereas for the $0^{\circ}$ phase shift, the torque difference is $0.40 \mathrm{pu}$. The torque difference has increased by $74 \%$ from the start-up case to the $0^{\circ}$ phase shift case.

It then becomes clear that the potential difference between the supply and residual voltage plays an important role in the magnitude of the current and torque transients. The latter cases for the $90^{\circ}$ and $180^{\circ}$ phase shift further highlight this and it can be seen that the larger the magnitude of the potential difference between the supply and the residual voltage, the larger the transients will be.

\subsubsection{Restart for $90^{\circ}$ phase shift}

For this test, the residual voltage was allowed to decay further until the per-phase residual voltage had shifted by $90^{\circ}$ from the reference supply.

\section{i. $\quad$ Residual voltage}

Figure 43 shows a single phase of the residual voltage relative to the supply voltage as the contactor is reclosed. This is shown for the SEIM. 


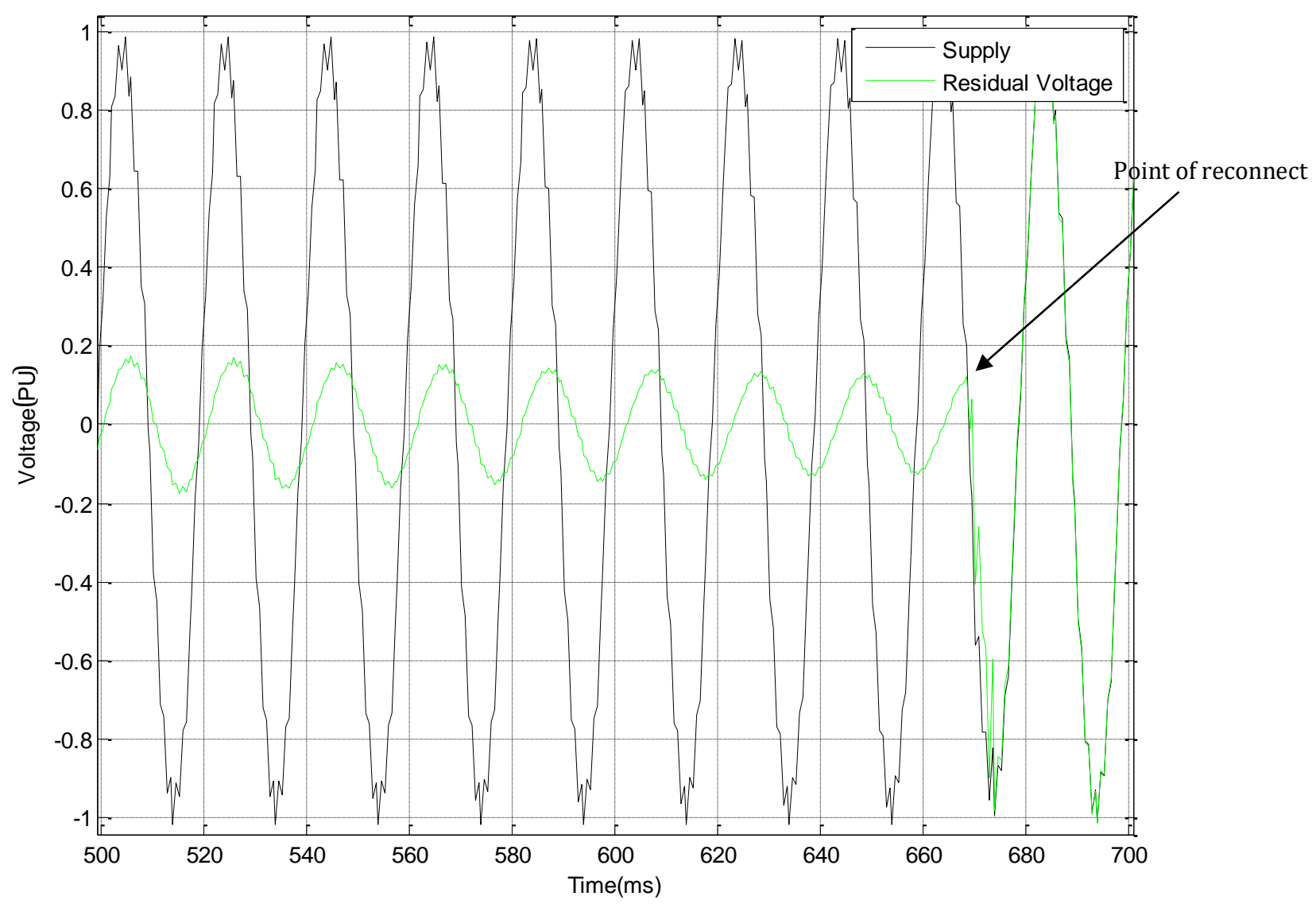

Figure 43: $90^{\circ}$ Per-phase supply voltage vs. residual voltage [SEIM]

A $90^{\circ}$ analysis was considered in order to compare and verify the impact that the phase shift has on the current and torque transients. Numerous tests were run in order to get an average value for the residual voltage magnitude at this particular section of the study.

A comparison of the typical restart profiles for a $90^{\circ}$ phase shift in residual voltage is shown in Figure 44: 


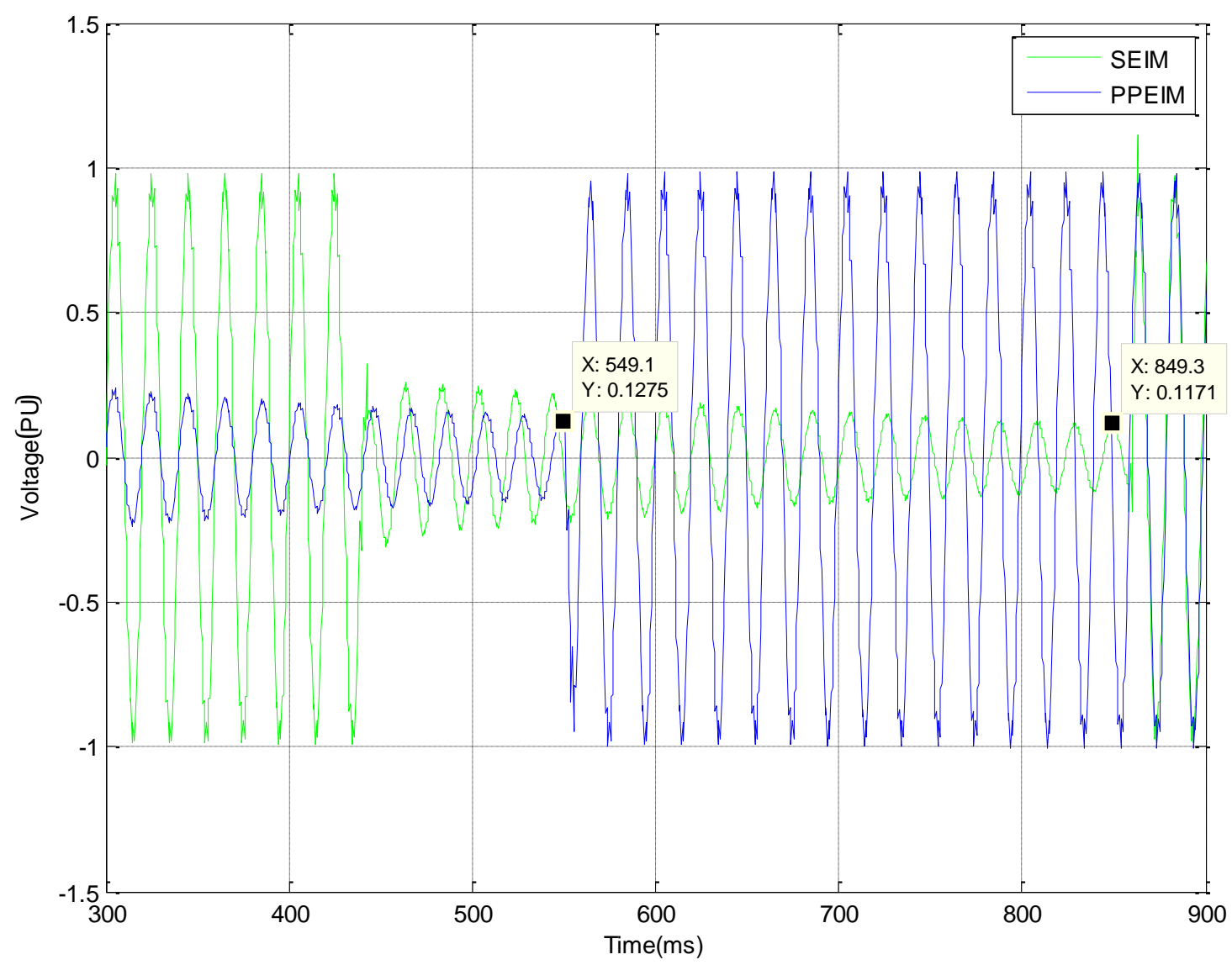

Figure 44: Per-phase stator residual voltage - 90 degrees phase shift

Figure 44 shows that the residual voltage is now at a lower peak per unit magnitude $(0.127$ pu for PPEIM and $0.117 \mathrm{pu}$ for the SEIM) than the $0^{\circ}$ phase shift case $(0.195 \mathrm{pu}$ for PPEIM and $0.222 \mathrm{pu}$ ) seen in Figure 29 above. This reduction is a result of allowing more time for the residual voltage phase to achieve a $90^{\circ}$ phase shift. As a result, the potential difference has increased for each machine due to a further reduction in the residual voltage. Thus, a larger peak current and torque spike is expected.

\section{ii. $\quad$ Current}

The per-phase transient current response is shown in the Figure 45. 


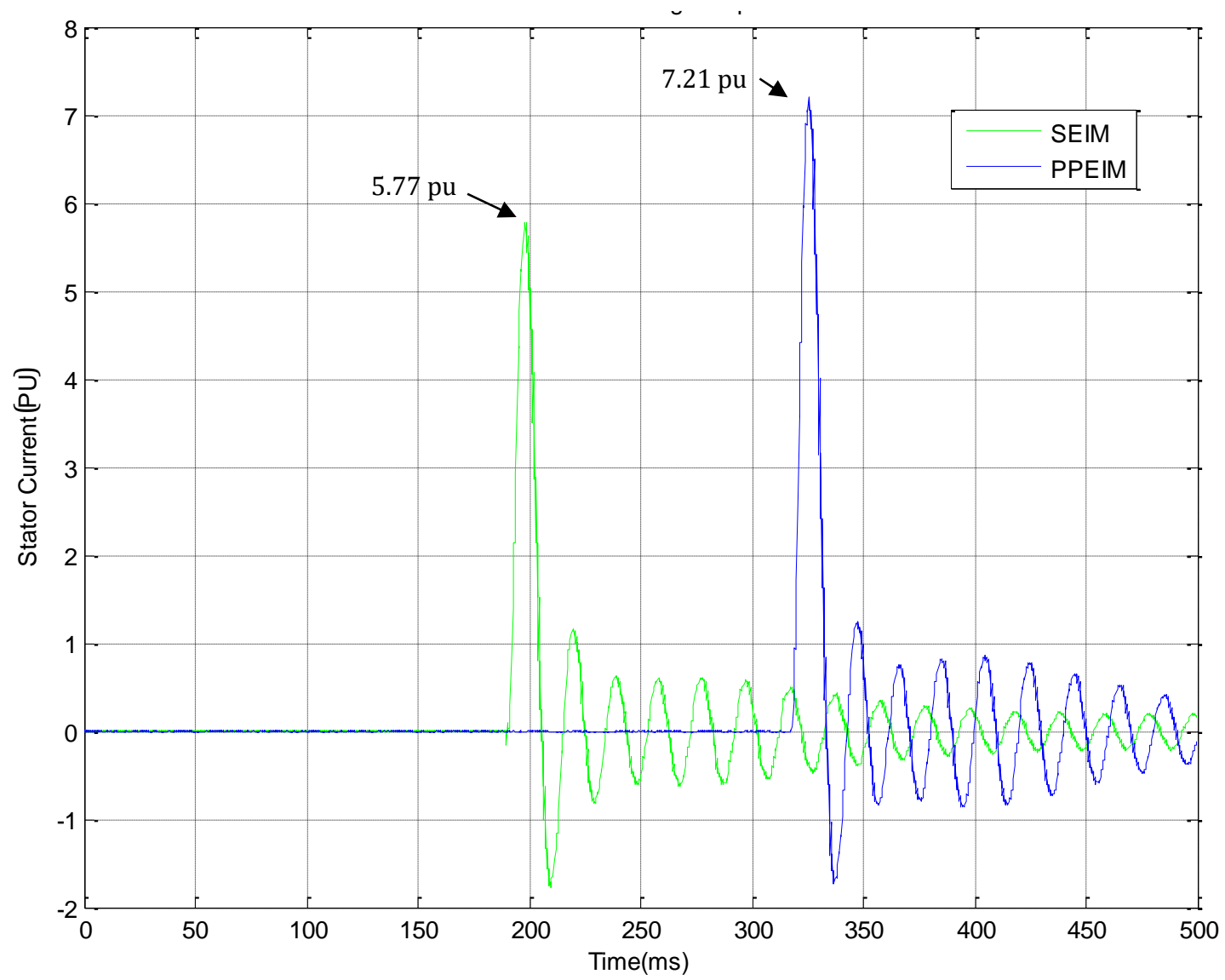

Figure 45: Per-phase stator current - 90 degrees phase shift

From Figure 45, it can be seen that the current spikes are higher than the $0^{\circ}$ case for each machine. It can also be seen that the PPEIM attains a higher overall current spike (7.26 pu) than the SEIM (5.77 pu). Generally, a larger current amplitude will lead to a higher torque response and thus, the larger the concussion on the rotor will be [3]. Conversely, the lower the current amplitude, the lower the impact of the developed torque will be and a slighter concussion of the rotor will be experienced. 
iii.

\section{Torque}

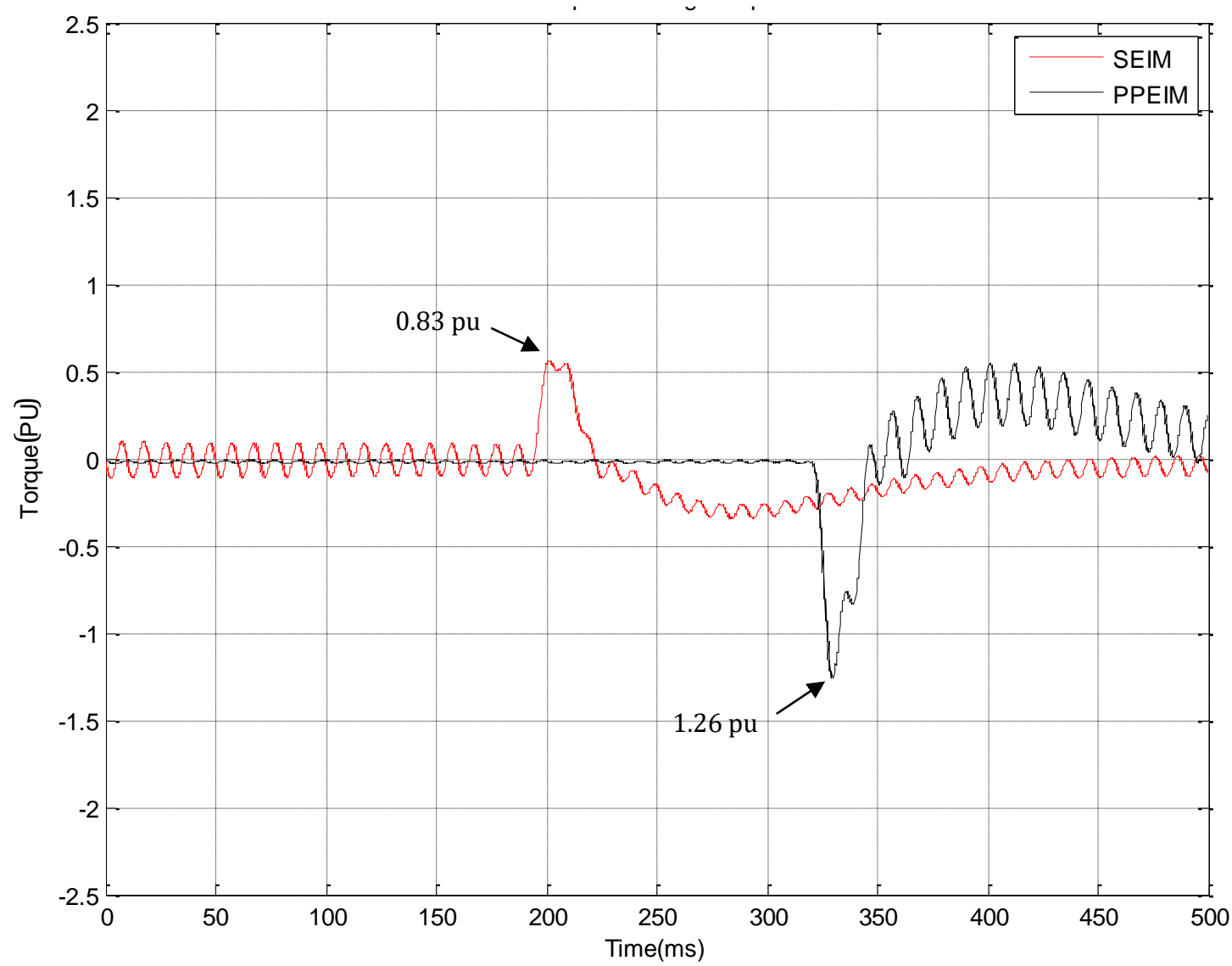

Figure 46: Torque - 90 degrees phase shift

The torque in Figure 46 shows a 52\% increase for the PPEIM (from 0.83 pu to $1.26 \mathrm{pu}$ ) while the SEIM experienced a $30 \%$ increase (from 0.43 pu to $0.56 \mathrm{pu}$ ) in torque spikes from the $0^{\circ}$ phase shift case. In addition, the PPEIM maintains a larger torque than the SEIM due to the larger current transients seen in Figure 36. It is evident that the PPEIM is more susceptible to the mechanical concussions associated with restarting torque transients as the potential difference between the supply and the residual voltage increases.

\subsubsection{Restart for $180^{\circ}$ phase shift}

This section covers the $180^{\circ}$ phase shift restart tests and the resulting current and torque transient spikes. The lowest per-phase residual voltage is expected due to the extended amount of time allowed for it to decay. Furthermore, since the residual voltage is $180^{\circ}$ out-of-phase with the constant incoming supply, the largest potential difference is expected for each machine. Due to this fact, the largest current and torque transients are also expected.

Figure 47 shows a single phase of the residual voltage relative to the supply voltage of the SEIM as the contactor is reclosed when the phase shift reaches $180^{\circ}$. 


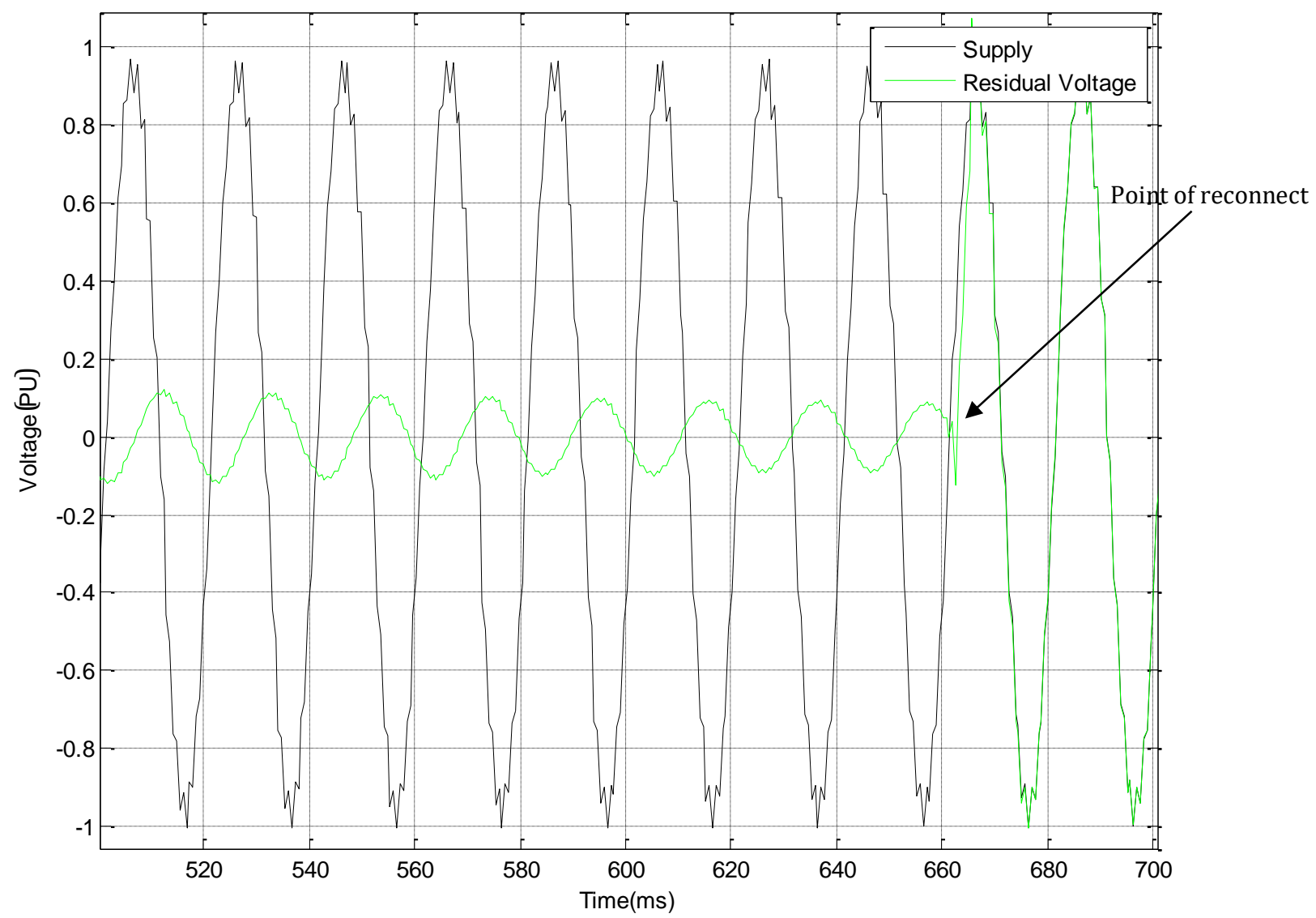

Figure 47: $180^{\circ}$ Per-phase supply voltage vs. residual voltage [SEIM]

\section{i. Residual voltage}

A comparison of the typical restart profiles for a $180^{\circ}$ phase shift in residual voltage are shown in Figure 48 between the SEIM and the PPEIM: 


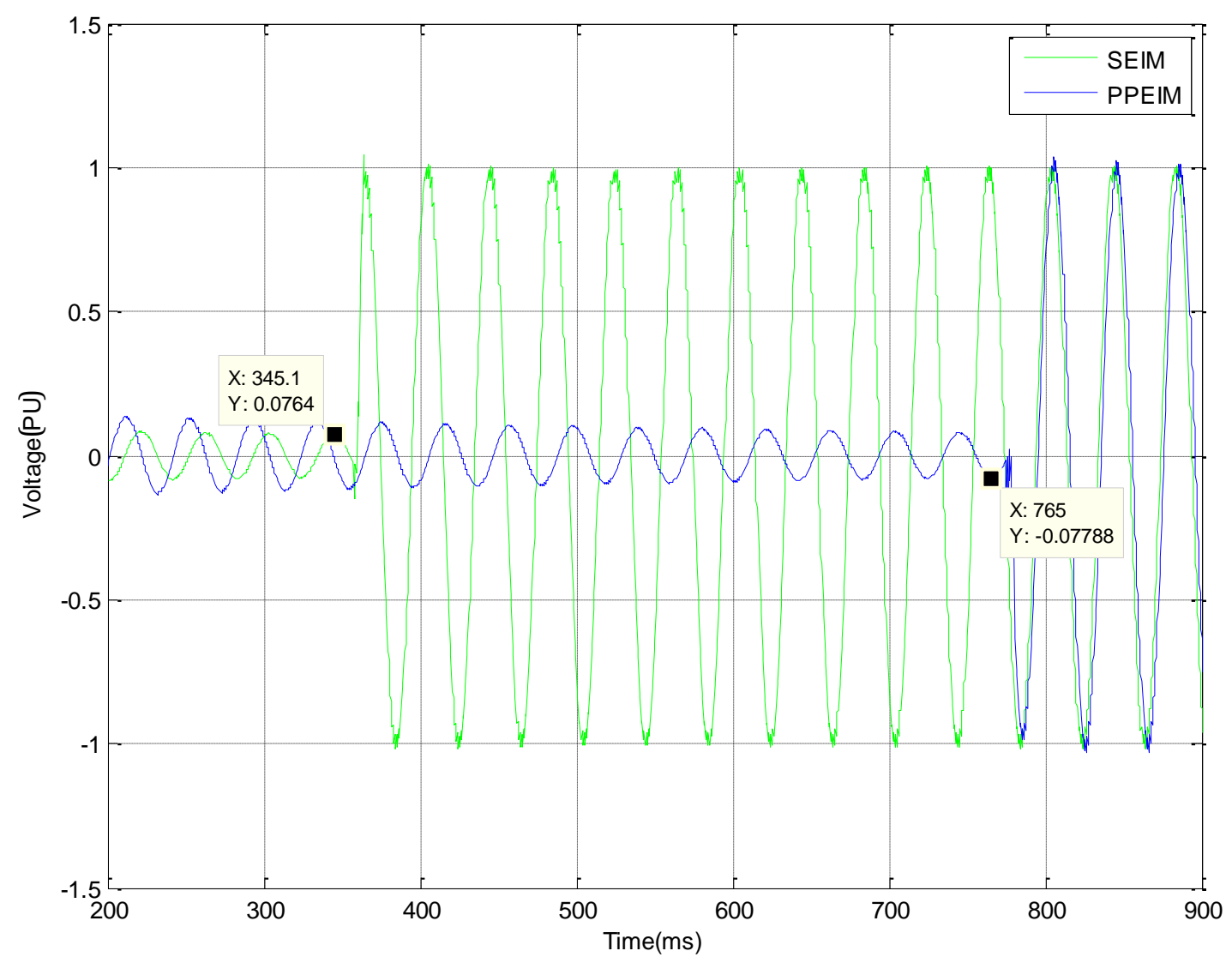

Figure 48: Per-phase residual voltage - 180 degrees phase shift (a)

It is important to note that the residual voltage of the PPEIM is higher than the SEIM. The traces in Figure 48 indicate that the PPEIM will therefore have a slightly larger potential difference than the SEIM just before restart. For instance, phase A shows a 0.00148 pu difference in the last residual voltage peaks before restart. However, as it is seen in Figure 49, the PPEIM exhibits a current spike that is almost 1.4 times larger than the SEIM. 
ii.

Current

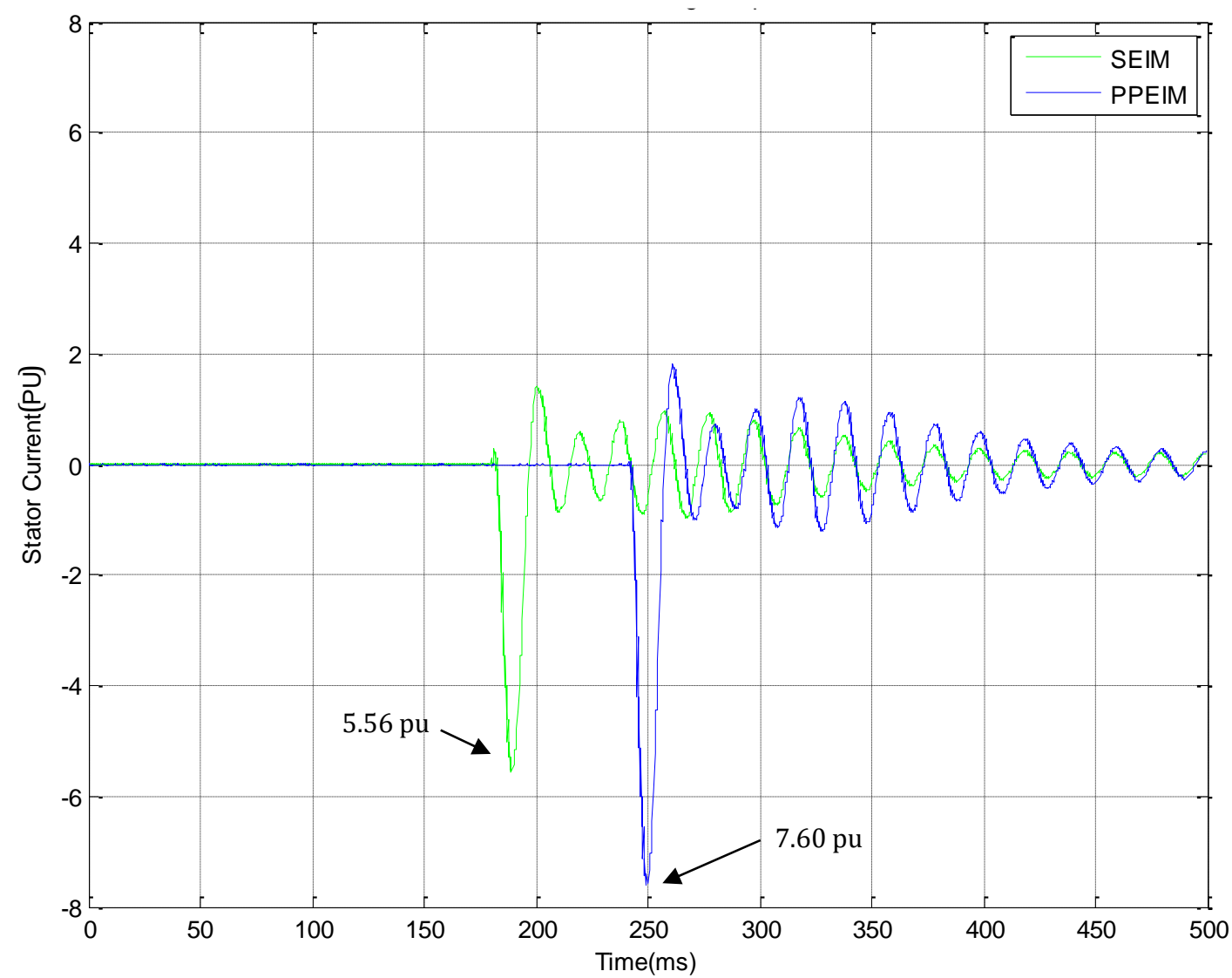

Figure 49: Per-phase stator current - 180 degrees phase shift

The largest possible transient spike for the current in this test is seen in Figure 49 with the PPEIM peaking at $7.60 \mathrm{pu}$ and the SEIM peaking at $5.56 \mathrm{pu}$. The PPEIM still maintains a higher current transient spike than the SEIM and both machines experience the largest current peaking transients for this phase shift due to the magnitude of the potential difference being at its largest value. This shows that while the residual voltage is steadily decaying, the potential difference is at its greatest when the supply is reapplied at $180^{\circ}$ phase shift. This is due to the fact that as the machine reaches $180^{\circ}$ and is reconnected, an effective terminal voltage larger than that experienced at start-up will occur [12].

Furthermore, the findings attained from the worst-case scenario of induction motor restart in the simulations are validated. The peaking current transients were higher for the PPEIM (50.1 A) than for the SEIM (44.15 A) which were also seen earlier in Figure 29 and 30. 
iii.

Torque

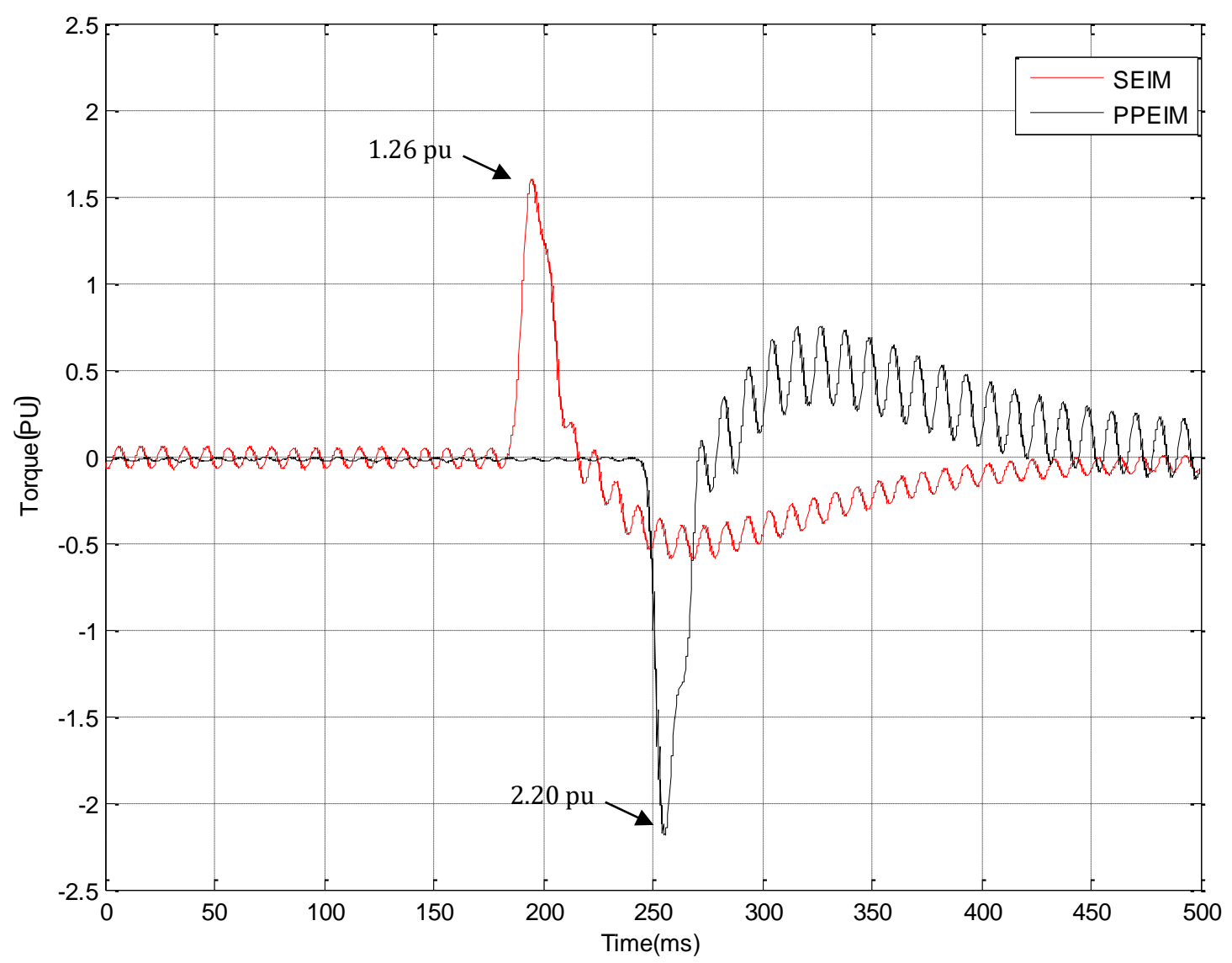

Figure 50: Torque - 180 degrees phase shift

The major difference is clearly seen for the $90^{\circ}$ to $180^{\circ}$ case, where a $75 \%$ and $185 \%$ increase in torque transient spikes in seen for the PPEIM (from $1.26 \mathrm{pu}$ to $2.20 \mathrm{pu}$ ) and SEIM (0.56 pu to $1.60 \mathrm{pu}$ ) respectively. The largest torque spike occurs for the $180^{\circ}$ phase shift. Since it is deemed the worst-case scenario, the largest potential difference and, by extension, the lowest residual voltage, is seen here before reconnect. Thus, the largest current and the largest torque transient occurs as expected. In Figure 50 , the same trend is seen as the previous cases where the restart torque is larger for the PPEIM than the SEIM.

The current and torque transient spikes for both machines last momentarily for the restart cases. While the current does not have a severe effect in terms of heating in the winding, the momentary torque, however, can have serious mechanical damage to the windings [11]. The PPEIM experiences a restarting torque which is over 2 times larger than the rated value which indicates that it will experience additional mechanical stress which can be detrimental over a prolonged period of time [13] compared to the SEIM.

The following tables highlight the per-unit magnitudes of the current and torque spikes for the figures shown above. The potential difference between the peak supply and residual voltage magnitude peak just before restart is also shown. The magnitudes of the residual voltage are taken from the last peak observed before the point of reconnect as has been shown in Figures 40, 44 and 48.

The results in Tables 8 and 9 show that the peak current and torque values increase with an increasing phase shift between the supply and residual voltage even though the residual voltage is decaying in magnitude for each of the phase shifts. 
Table 8: PPEIM experimental results

\begin{tabular}{|l|l|l|l|l|}
\hline & $\begin{array}{l}\text { Potential Difference } \\
(\mathrm{PU})\end{array}$ & Current (PU) & Torque (PU) & Speed (rpm) \\
\hline Start-Up & 1.02 & 5.60 & 1.23 & $\mathrm{n} / \mathrm{a}$ \\
\hline $0^{\circ}$ & 0.805 & 2.44 & 0.83 & 1485 \\
\hline $90^{\circ}$ & 0.873 & 7.21 & 1.26 & 1462 \\
\hline $180^{\circ}$ & 1.078 & 7.60 & 2.20 & 1456 \\
\hline
\end{tabular}

Table 9: SEIM experimental results

\begin{tabular}{|l|l|l|l|l|}
\hline & $\begin{array}{l}\text { Potential Difference } \\
(\mathrm{PU})\end{array}$ & Current (PU) & Torque (PU) & Speed (rpm) \\
\hline Start-Up & 0.99 & 4.65 & 1.00 & n/a \\
\hline $0^{\circ}$ & 0.778 & 1.19 & 0.43 & 1494 \\
\hline $90^{\circ}$ & 0.883 & 5.77 & 0.56 & 1468 \\
\hline $180^{\circ}$ & 1.076 & 5.56 & 1.60 & 1453 \\
\hline
\end{tabular}

It is evident that from the results that the PPEIM experiences a higher transient torque spike than the SEIM for every test. It is also evident that the current and torque spikes increase as the phase displacement varies from $0^{\circ}$ to $180^{\circ}$ with the $180^{\circ}$ case showing the largest torque spike with values of $2.20 \mathrm{pu}$ and $1.60 \mathrm{pu}$ for the PPEIM and SEIM respectively. Observing the potential difference, it can be seen that the magnitude of the residual voltage at the point of reconnect influences the magnitude of the current and torque transients. The transients are larger for the PPEIM which experiences the larger potential differences at the worst case of $180^{\circ}$. It should also be noted, however, that the potential difference for the PPEIM and SEIM are not significantly different for the worst case.

The PPEIM experiences the larger effect of the two machines for every phase shift. This is influenced not only by the smaller stator impedance but by the speed of the PPEIM as it decays at a slower rate than the SEIM after disconnect. This is due to the fact that the PPEIM has a higher rotational inertia and mechanical time constant than the SEIM which would mean that the PPEIM would naturally take a longer time to wind down after disconnect. This means that there would be a less significant decay in the residual voltage of the PPEIM, which has resulted in the largest residual voltage once the machine has reached $180^{\circ}$ phase shift. The worst-case scenario of the $180^{\circ}$ phase shift is indicated by the largest torque transients experienced by both machines.

These spikes are larger than those experienced under start-up conditions for their respective machines. The difference between the machines can be attributed to the fact that the PPEIM has a higher residual flux in the windings at reconnect and a higher speed as well as a lower stator impedance. The relationship between the current, torque, speed and residual flux are complicated according to Wang et al [3]. However, it is important to look at each of the factors that influence the restarting transients individually in order to establish a dominating factor that better explains the differences between the 
PPEIM and SEIM. These factors which influence the outcome in this scenario can be found in the next section.

\subsection{Important factors in determining restarting transients in induction machines}

\subsubsection{Residual flux}

In the case of residual flux, it is expected for the SEIM to have a larger residual flux at disconnect due to the fact that it has a lower permeability than the PPEIM. From Figure 51, the markers indicate the typical peak values of the residual voltage after four cycles from the point of disconnect for a single phase.

Since both motors operate at similar speeds under no load, it can be stated that the larger peak residual voltage associated with the SEIM at disconnect $(0.315 \mathrm{pu})$ is attributed to the larger residual flux when compared with the PPEIM $(0.288 \mathrm{pu})$ at $0^{\circ}$ phase shift. At reconnect, the residual voltage peak value for the SEIM (0.223 pu) is also larger than the PPEIM (0.195 pu).

For the $90^{\circ}$ case, a steady decay is seen for both machines in Figure 51. The SEIM, having been tested at different times to the PPEIM, shows a larger peaking residual voltage profile from its point of disconnect until the point at which the PPEIM is reconnected at 274 ms. However, by the time the SEIM reaches the $90^{\circ}$ phase shift at $424 \mathrm{~ms}$ and is reconnected, it has a lower residual voltage peak (0.117 pu), than the SEIM $(0.144 \mathrm{pu})$.

A single-phase residual voltage profile before reclosing for a $90^{\circ}$ phase shift is shown:

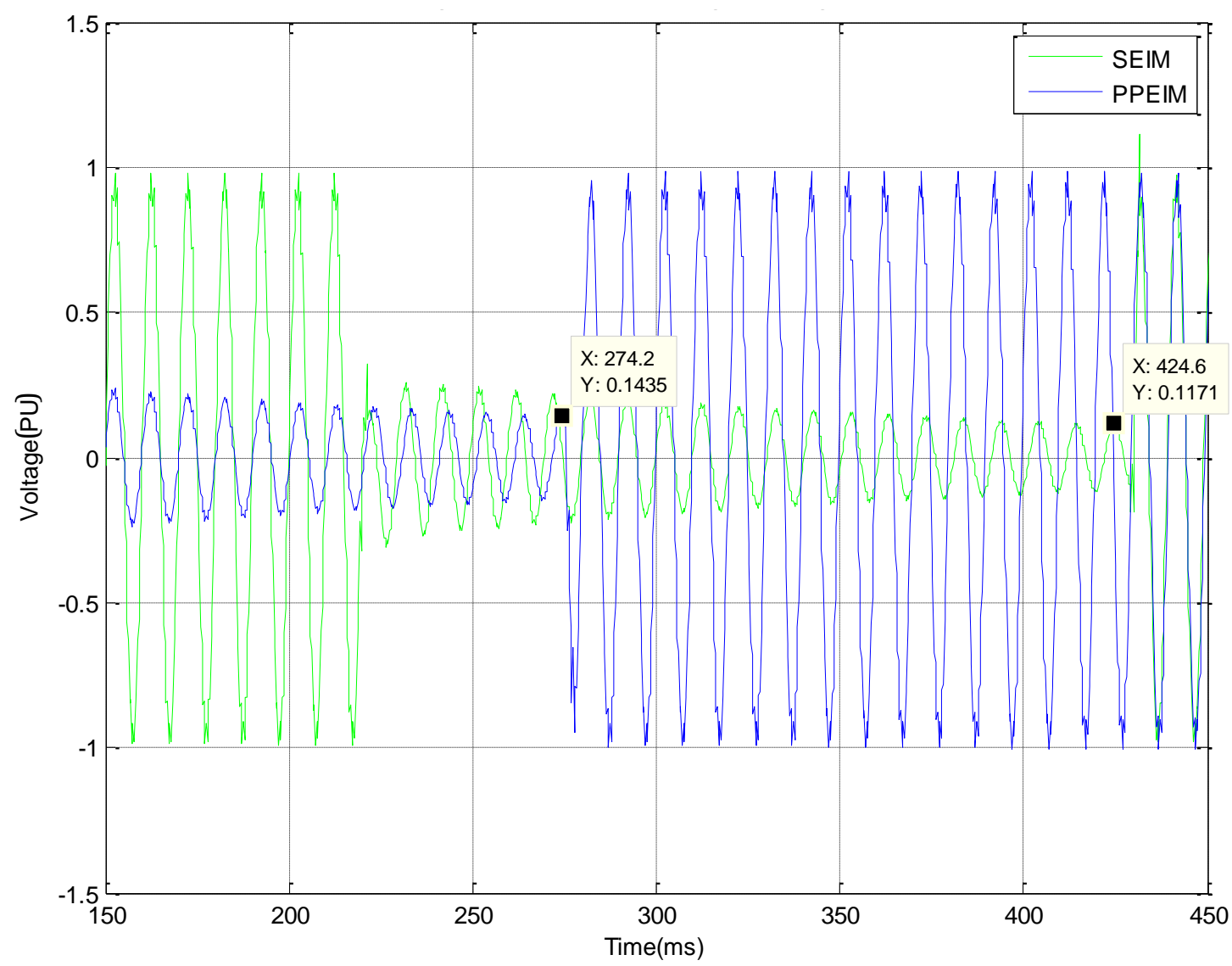

Figure 51: Per-phase residual voltage - 90 degree phase shift (b) 
For the $180^{\circ}$ case, a similar pattern to that of the $90^{\circ}$ phase shift is seen. The peak value for the residual voltage is higher for the PPEIM than the SEIM and remains so until their respective points of restart. Also, the time between the respective restart points is considerably shorter than for the preceding cases.

In this case, however, the PPEIM has a larger residual voltage peak ( $0.089 \mathrm{pu})$ just before restart than the SEIM (0.076 pu). This explains the larger potential difference, between the constant supply and stator residual voltage peak, for the PPEIM than the SEIM before restart. It should be known that the potential difference in this case is the addition of the last residual peak to the constant supply at the same point. This further supports the reasons behind the larger current and torque transient spikes shown earlier for the PPEIM as opposed to the SEIM.

Figure 52 shows the profile of the residual voltage at $180^{\circ}$ phase shift for both machines. Note that the potential difference between the residual voltage and the constant supply reaches its maximum for this test.

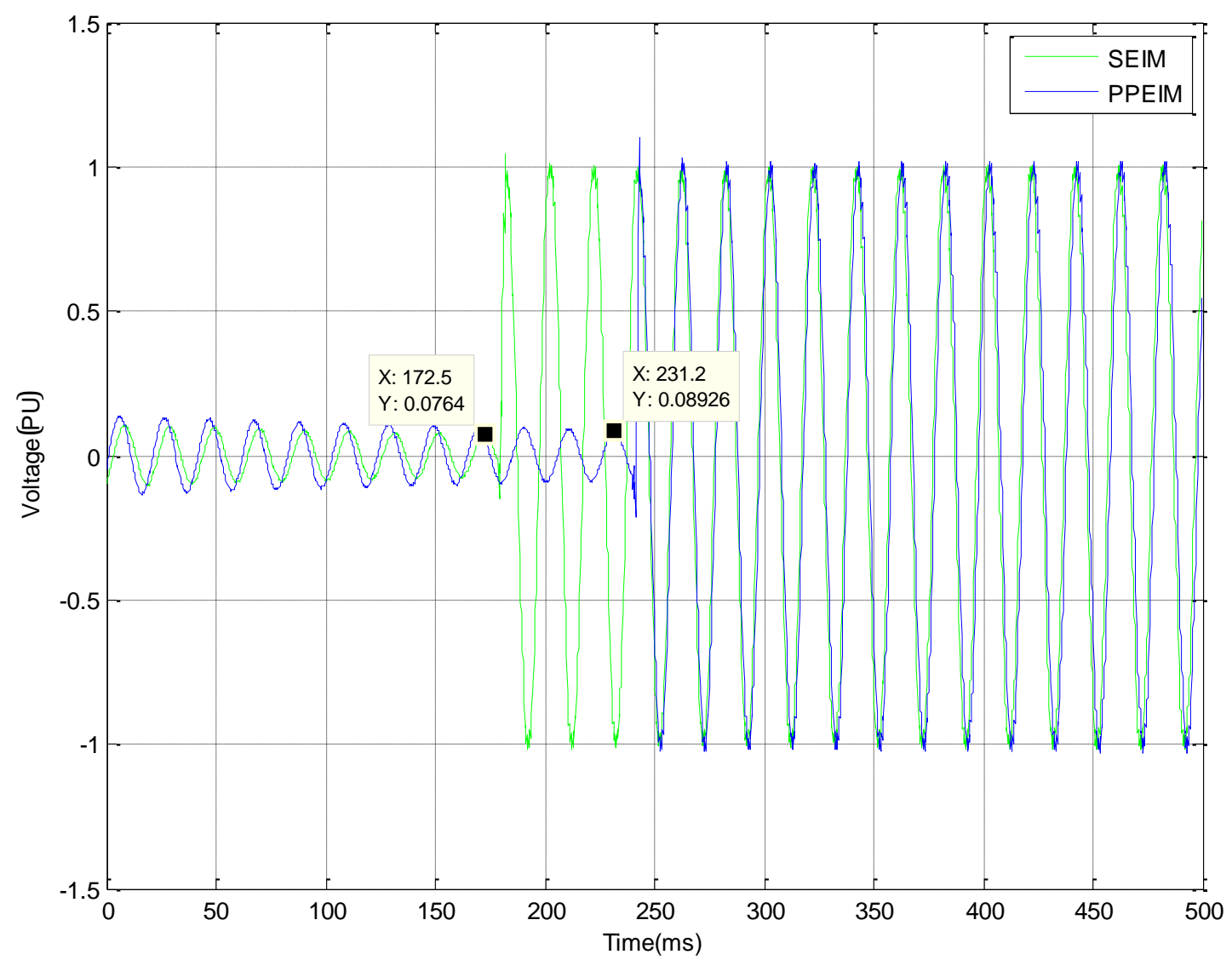

Figure 52: Per-phase residual voltage - 180 degree phase shift (b)

Though it can be seen that there is no significant difference in the peak residual voltage just before reconnect between the SEIM and PPEIM, it is important to note that the residual voltage magnitude is partly influenced by the speed of the machine and the residual flux. Even though the SEIM has a higher residual flux, the PPEIM has a higher rotor time constant and therefore the speed decays at a slower rate. This is evident in the $180^{\circ}$ phase shift since the residual voltage is higher for the PPEIM, since the speed at reconnect is higher. This is mainly attributed to the lengthier time required to acquire the $180^{\circ}$ phase shift compared to the $0^{\circ}$ phase shift, clearly showing the slower speed decay and therefore higher mechanical time constant for the PPEIM. 


\subsubsection{Speed}

The PPEIM runs at a higher rated speed (1465 rpm) than the SEIM (1455 rpm). For this set of experiments, however, the machines were run under no load conditions. Thus, both machines ran at speeds very close to the synchronous speed (1500 rpm). The rate of decay soon after disconnect has a bearing on the residual voltage magnitude, especially at points just before reconnect.

Considering the $0^{\circ}$ phase shift case, a large difference is seen between the PPEIM and SEIM. Both machines are given minimum time to decay. For the respective restart points of the SEIM and PPEIM, as shown in Figure 44, it can be seen that the PPEIM is restarted at a lower speed of $1474 \mathrm{rpm}$ in comparison to the $1483 \mathrm{rpm}$ of the SEIM. Due to the considerably higher speed for the SEIM at reconnect, a larger peak residual voltage is expected at restart for the SEIM than the PPEIM. This supports the higher residual voltage magnitudes seen for the SEIM compared to the PPEIM in earlier results.

The speed profile for the $0^{\circ}$ phase shift restart is shown in Figure 53:

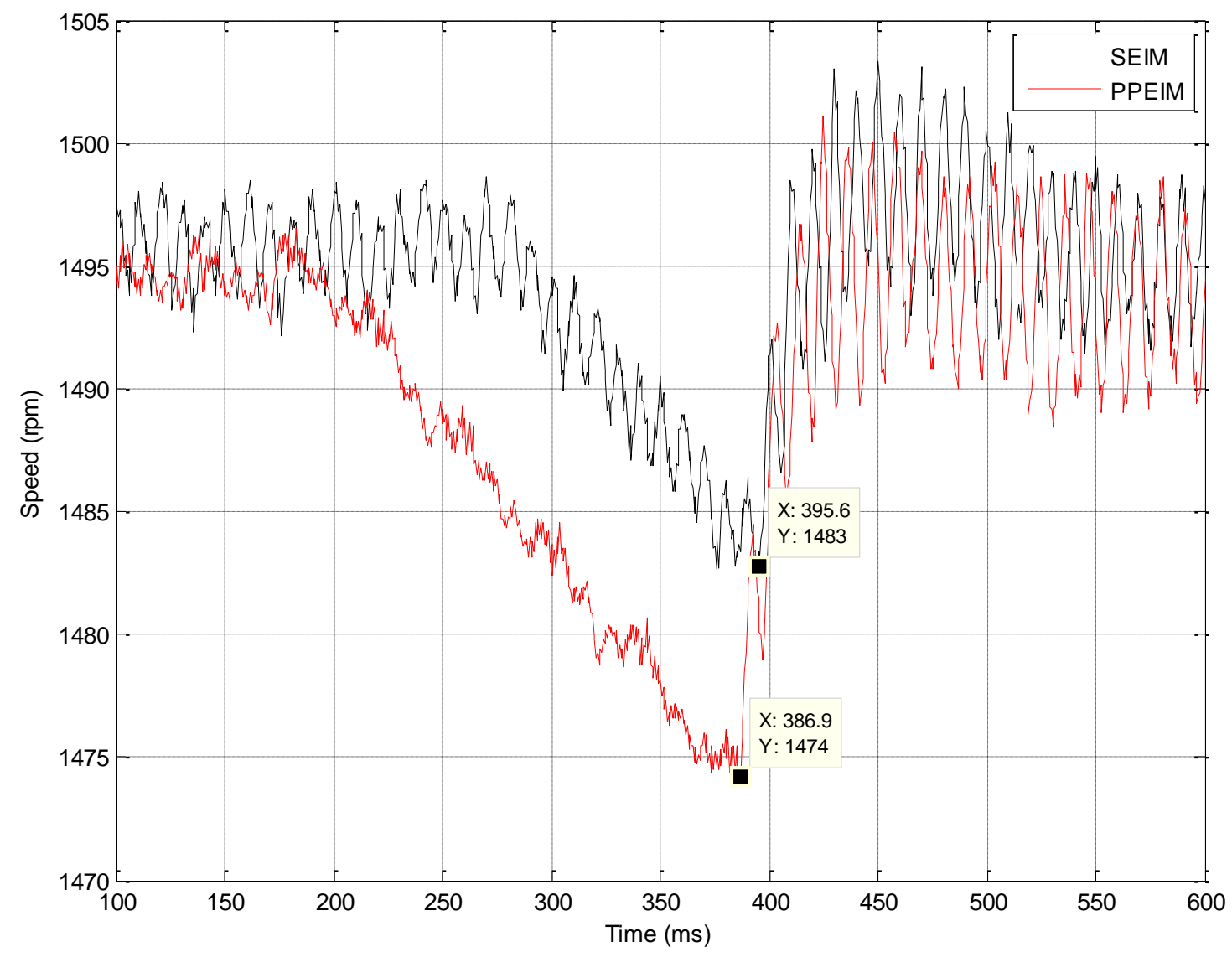

Figure 53: Speed transient - 0 degree phase shift

For the $90^{\circ}$ case, the speed of the SEIM is lower than the PPEIM at the respective points of restart. The two sample points shown in Figure 54 show that the PPEIM is restarted at a speed of $1463 \mathrm{rpm}$ for the PPEIM while the SEIM is at $1457 \mathrm{rpm}$. This supports the statement made earlier in [50] about the shaft speed affecting the magnitude of the residual voltage peak. A larger speed regularly results in a larger residual voltage magnitude if no electrical load is applied. With no electric load, the frequency will correspond to the shaft speed which drops due to friction, windage and, in some cases, a mechanical load [50]. 
However, due to the PPEIM residual voltage taking longer to reach the $90^{\circ}$ phase shift, the speed seen at the restart point for the PPEIM is slightly lower than that of the SEIM at its corresponding restart point. This is shown in Figure 54:

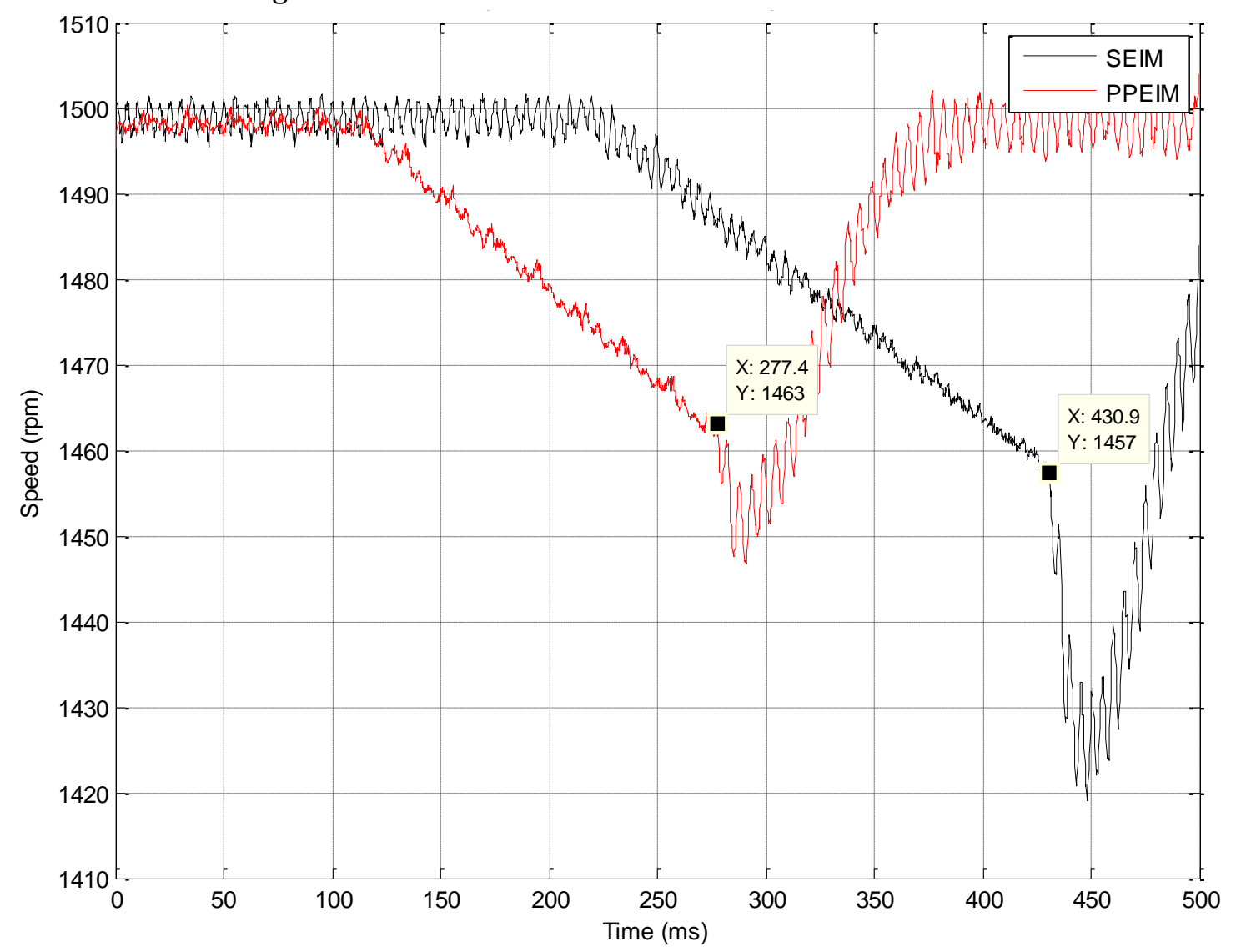

Figure 54: Speed transient - 90 degree phase shift

Due to a larger open circuit time constant, it takes longer for the voltage of the PPEIM to reach the 37\% of the rated voltage value than the SEIM. This translates well into the speed case seen in Figure 54. In Figure 52, it can be seen that the PPEIM is still at a higher residual voltage peak than the SEIM just before reconnect. This further highlights the fact that the rotor speed is proportional to the residual voltage as it decays in time, as stated in [50].

For the $180^{\circ}$ case, due to a larger residual voltage peak for the PPEIM seen earlier, a larger speed is expected at the point of restart for the PPEIM. There is no significant difference in the speed between the PPEIM (1458 rpm) and the SEIM (1454 rpm) but the expectation is met. Generally, as was the case with $90^{\circ}$, the PPEIM maintained a higher speed than the SEIM before the restart points of both machines. A further validation is made from the simulated results in chapter 3 which showed the speed of the PPEIM being higher than that of the SEIM just before the point of reconnect in Figures 35 and 36.

This is illustrated in Figure 55: 


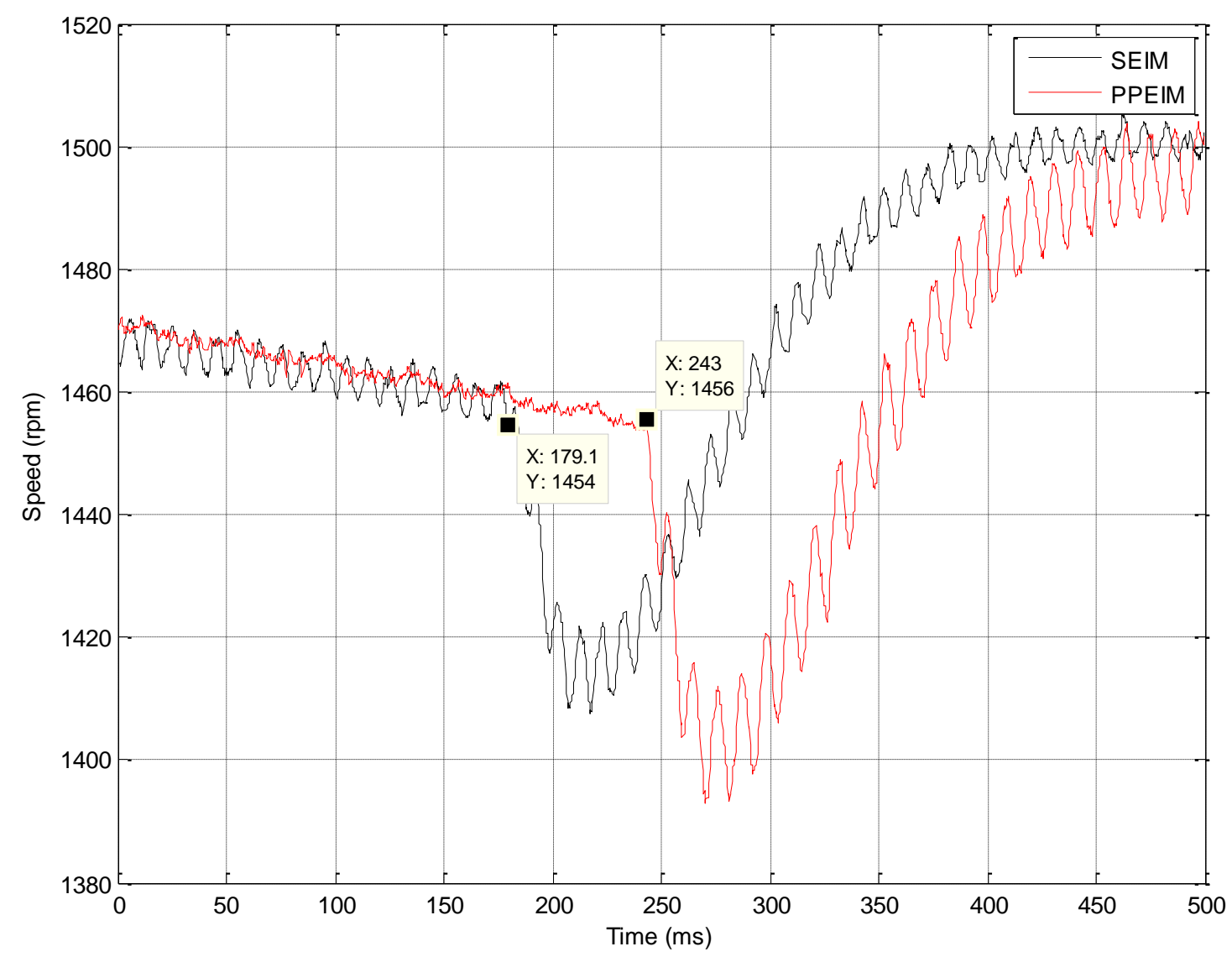

Figure 55: Speed transient - 180 degree phase shift

It is important to note that in this case, the speed of the PPEIM is higher at the point of reconnect which supports the fact that the residual voltage of the PPEIM would be higher and this would result in a slightly larger potential difference. Figure 55 shows that the difference in speeds between the two machines is negligible (2 rpm) at their respective points of restart. This however, does not necessarily explain the much higher current and torque spike for the PPEIM compared to the SEIM. The respective stator impedances of the two machines have to be taken into account.

\subsubsection{Stator impedance}

Standard efficiency machines have a higher winding resistance than energy efficient machines. Thus when a three phase voltage is applied to the stator terminals, the only impedance limiting the current is this impedance. At start-up, there is no residual flux, thus no residual voltage to oppose the flow of current [4]. Thus, the current and torque spikes are dependant solely on the impedance. Due to the PPEIM having lower impedance, a much higher starting current spike is expected and due to the larger current spikes seen for the PPEIM, a larger torque is observed for the same machine.

When restarting while coasting, there exists a residual flux which results in a residual voltage. The potential difference between the supply and residual voltage, together with the stator impedance, will influence the magnitude of the current and torque spikes. A larger potential difference results in larger current and torque transients. The PPEIM is worse in this regard since it experiences a larger potential difference and has a lower stator impedance. 


\subsubsection{Dominating factor}

A dominating factor can hence be established when it comes to determining which machine experiences the most detrimental transients. The information above has shown that the potential difference between the peak supply and the stator residual voltage magnitudes does have an impact on the current and torque transients for both machines. This potential difference varies as the magnitude and phase of the residual voltage changes with the worst-case scenario being the $180^{\circ}$ phase shift of the residual voltage where the potential difference is at its largest.

Immediately after the moment of disconnect, the machines remain rotating with a steadily decreasing speed. The residual voltage frequency was seen to decrease more sharply for the SEIM than the PPEIM. The residual voltage associated with the SEIM is higher at the point of disconnect yet it decreases more rapidly due to the lower rotor time constant compared to the PPEIM. However, in the tests conducted, the difference in magnitude between the residual voltages at the point of reconnect is marginal in comparison to the change in current and torque spike for a particular test condition. Therefore, there appears to be greater sensitivity to the stator impedance in determining the extent of the spike, however all factors need to be considered when assessing the potential risk, especially when examining large machines in industry.

Table 6: Factors associated with the motor design, which contribute to the spike in current and torque when restarting while coasting

\begin{tabular}{|l|c|c|}
\hline & SEIM & PPEIM \\
\hline $\begin{array}{l}\text { Rotor time } \\
\text { constant }\end{array}$ & $\times$ & $\checkmark$ \\
\hline Permeability & $\checkmark$ & $\times$ \\
\hline $\begin{array}{l}\text { Stator } \\
\text { Impedance }\end{array}$ & $\times$ & $\checkmark$ \\
\hline
\end{tabular}

Table 10 indicates the factors associated with the motor design, which would contribute to the spike in current and torque when restarting while coasting. The larger rotor time constant in the PPEIM would mean that the PPEIM frequency and speed takes longer to decay and thus, attains a higher residual voltage at the point of reconnect under the worst-case condition. The higher permeability of the SEIM suggests that the residual voltage at the point of disconnect is higher for the SEIM than the PPEIM. As both machines decay to the $180^{\circ}$ phase shift, the SEIM is now seen to have the lower residual voltage due to a slower decay in speed and lower rotor time constant.

It must be noted that there is no significant difference between the peak residual magnitudes of the two machines. For most of the tests, the potential difference is slightly higher for the PPEIM at each last peak just before the point of reconnect, which supports the larger torque and current spikes seen. However, the current and torque spikes observed between machines are consistently larger for the PPEIM even with a marginal difference in residual voltage magnitudes at different points of reconnect. This is supported by the fact that the PPEIM has a considerably lower resistance. Thus, a dominating factor for the larger transients seen in the PPEIM is, in fact, the stator impedance. 


\section{Impact of voltage unbalance on reclosing of SEIM and PPEIM}

This chapter deals with the impact of the start-up and restarting process on the current and torque transients of induction motors which experience unbalanced voltage conditions. The PPEIM and SEIM are both run under the same unloaded start-up and restart tests for rated, undervoltage and overvoltage with unbalance. The machines were tested for the $1 \%$ and $2 \%$ voltage unbalance and the results for the power quality issue are discussed in this section.

Previous studies have focused on the effects of voltage unbalance on induction motors from an analytical point of view and have accounted for the losses in the models. Other works have done experimental studies on the effects of voltage unbalance effects on induction machines using the CVUF method, including the segregation of the losses for motors with different NEMA designs [33]. This study, however, is done with the purpose of finding the effect of voltage unbalance on the transient operation of induction machines. The IEC method of calculating the percentage unbalance was used as the VUF conveys an improved physical version of the cause of unbalance and is more useful in the prediction and analysis of the effects of voltage unbalance on the motor [39].

An appreciable unbalance in the supply voltage in an induction machine leads to an unbalance in the associated current and torque [4]. The proceeding results will show the current and torque transient spikes that occur as a result of rated voltage unbalance as well as over- and undervoltage unbalance.

Both the PPEIM and SEIM were tested under the same voltage unbalance conditions. The unbalance was achieved by maintaining the magnitude of one of the phases at the rated voltage while equally raising and lowering the voltage magnitudes of the other two phases.

The unbalance measurements were taken in voltages ranging from a balanced condition ( $0 \%$ unbalance) to $2 \%$ unbalance for the start-up and the $180^{\circ}$ phase shift restart conditions. The input voltage was $400 \mathrm{~V}$ for the rated voltage case, $440 \mathrm{~V}$ for the overvoltage case and $360 \mathrm{~V}$ for the undervoltage case.

The results for the tests are shown in Table 11 for the SEIM and Table 12 for the PPEIM. 
Table 7: SEIM voltage unbalance

\begin{tabular}{|c|c|c|c|c|c|c|c|}
\hline & & \multicolumn{2}{|c|}{ Average Voltage } & \multicolumn{2}{|c|}{ 1\% Unbalance } & \multicolumn{2}{|c|}{ 2\% Unbalance } \\
\hline & & Torque & Current & Torque & Current & Torque & Current \\
\hline \multirow{3}{*}{ Start-Up } & $\begin{array}{l}\text { Average Rated } \\
\text { Voltage }\end{array}$ & 1.04 & 4.65 & 0.99 & 4.35 & 1.04 & 4.46 \\
\hline & Overvoltage & 1.31 & 5.04 & 1.28 & 4.95 & 1.22 & 5.11 \\
\hline & Undervoltage & 0.80 & 4.07 & 0.79 & 4.00 & 0.73 & 4.11 \\
\hline \multirow{3}{*}{$\begin{array}{c}\text { Restart } \\
180^{\circ}\end{array}$} & $\begin{array}{l}\text { Average Rated } \\
\text { Voltage }\end{array}$ & 1.84 & 5.82 & 1.77 & 5.60 & 1.74 & 5.65 \\
\hline & Overvoltage & 2.02 & 6.25 & 2.01 & 6.22 & 2.02 & 6.59 \\
\hline & Undervoltage & 1.48 & 5.18 & 1.46 & 5.19 & 1.52 & 5.26 \\
\hline
\end{tabular}

Table 8: PPEIM Voltage Unbalance

\begin{tabular}{|c|c|c|c|c|c|c|c|}
\hline & & \multicolumn{2}{|c|}{ Average Voltage } & \multicolumn{2}{|c|}{ 1\% Unbalance } & \multicolumn{2}{|c|}{ 2\% Unbalance } \\
\hline & & Torque & Current & Torque & Current & Torque & Current \\
\hline \multirow{3}{*}{ Start-Up } & $\begin{array}{l}\text { Average Rated } \\
\text { Voltage }\end{array}$ & 1.18 & 5.40 & 1.23 & 5.12 & 1.28 & 5.23 \\
\hline & Overvoltage & 1.48 & 5.88 & 1.41 & 5.54 & 1.45 & 5.61 \\
\hline & Undervoltage & 0.95 & 4.65 & 0.93 & 4.56 & 0.94 & 4.62 \\
\hline \multirow{3}{*}{$\begin{array}{c}\text { Restart } \\
180^{\circ}\end{array}$} & $\begin{array}{l}\text { Average Rated } \\
\text { Voltage }\end{array}$ & 2.42 & 7.11 & 2.43 & 6.80 & 2.33 & 6.61 \\
\hline & Overvoltage & 2.89 & 7.37 & 2.42 & 6.90 & 2.44 & 6.95 \\
\hline & Undervoltage & 1.95 & 5.85 & 1.77 & 5.91 & 1.81 & 5.98 \\
\hline
\end{tabular}

Both tables show that the current and torque transients respond to the magnitude of the voltage applied to the stator terminals. The input stator resistance of both machines remains the same and thus, the varying start-up and inrush restart current and torque first half-cycle peaks depends on the magnitude 
of the mains voltage applied [4]. It can be seen that the largest torque transients occur for the overvoltage case, followed by the average rated voltage and finally, the undervoltage case.

Both tables indicate that the start-up and restart peak torque values for voltage unbalance, for the $2 \%$ condition above, are, on average, lower than that of the average voltage transients for the balanced condition. This decrease in the transient torque peak from the balanced condition is expected since [36] states that a presence of voltage unbalance causes a negative sequence torque to exist due to the negative sequence voltage. This negative sequence voltage results in a flux in the airgap that rotates in the opposite direction to the positive rotating field. With the exception of non-linearity, the result is a superimposing of the two motors with one operating at a slip, s, while the other operates at a slip of 2-s [36]. As a result, there is a net reduction in torque and speed. The reduction of the peak torque compromises the ability of the motor to ride through voltage dips and sags. The transient effects of the resulting voltage sags can result in the triggering of the motors protection system [51]. Once a voltage dip occurs, the induction machine may stall and would not be able to reaccelerate sufficiently to drive a load upon restoration of the supply to a normal state [52].

The PPEIM experiences a larger deviation of torque transients than the SEIM. In a separate study, under steady state conditions for voltage unbalance, the current unbalance is expected to be between 2 to $5 \%$ higher for premium plus machines than standard motors [4]. Due to this, larger negative sequence currents are experienced by the PPEIM and thus, a larger reverse air gap torque is seen [4]. For the transient case, a similar pattern is seen where the PPEIM experiences a larger drop in the start-up and $180^{\circ}$ restart transients. This can be linked to the parameter differences between machines with the PPEIM having a higher permeability and more magnetic material [53]. When translating this to a scenario in industry, the PPEIM would experience a more difficult recovery from a voltage sag or dip when connected to a load.

In addition, even though the voltage unbalance in these cases is relatively small, it can have large implications on the mechanical component of induction machines. Voltage unbalance leads to current unbalance which then leads to heating issues, increased losses, vibrations, acoustic noise, decrease in torque as well as the shortening of the life of an induction motor [54]. Figure 56 shows the variation in the speed of the SEIM when it is restarted under rated voltage unbalance. This example is for the $180^{\circ}$ phase shift of the residual voltage with respect to the supply.

It can be observed that the ripple in speed is increased in the PPEIM case as well. Figure 57 shows the speed variation for the PPEIM at a $180^{\circ}$ phase shift of the residual voltage. 


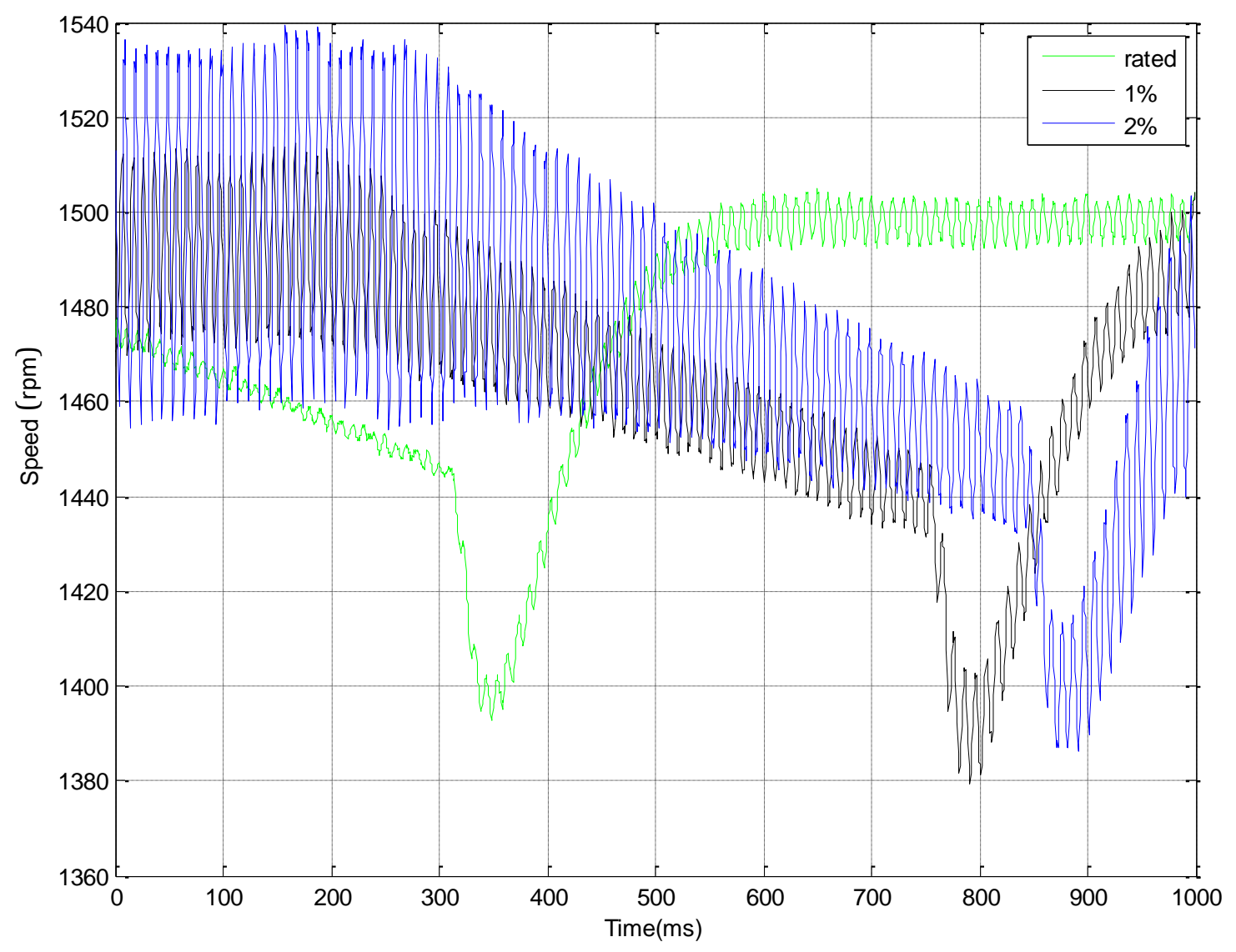

Figure 56: SEIM speed (rpm) for rated voltage unbalance at 180 degrees phase shift

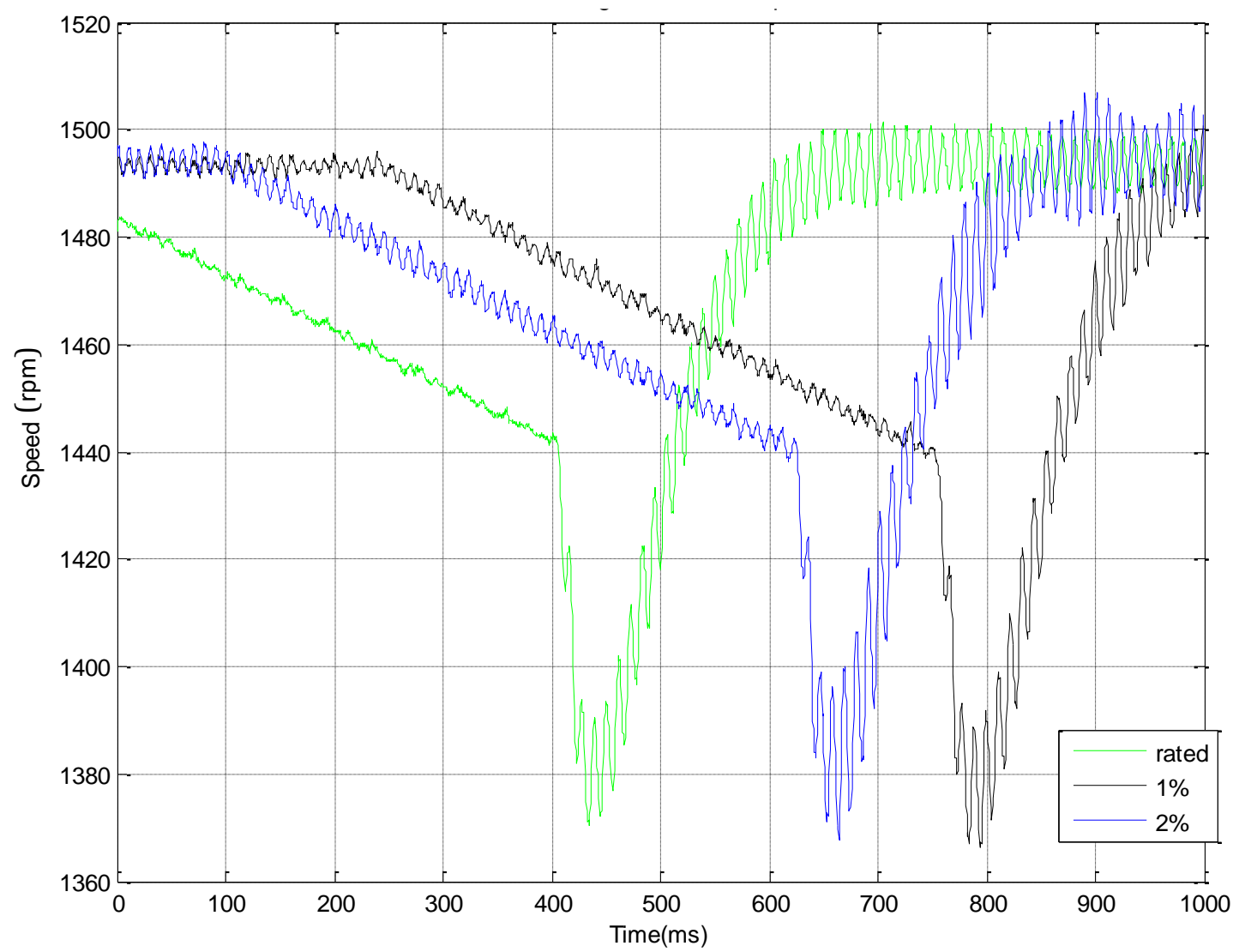

Figure 57: PPEIM speed (rpm) for rated voltage unbalance at 180 degrees phase shift 
It is evident from Figures 56 and 57 that both machines experience a larger degree of ripple in speed as the percentage voltage unbalance increases. However, it is clear that the SEIM experiences a significantly larger ripple effect due to the increased voltage unbalance. The degree of ripple experienced by the SEIM for such a small machine can mean that, in a practical case in industry, larger machines will inevitably experience an even worse ripple due to voltage unbalance. It is also well known that an unbalanced voltage results in an extra load to utilities and an extra charge to consumers. Thus, an increase in voltage unbalance factor will result in an increase in the magnitude of the current unbalance and torque unbalance [54].

Observing the torque, it can be seen that the voltage unbalance increases the ripple for both machines. Depending on the extent of the unbalance, the average torque is reduced considerably. Figure 58 and 59 illustrate the effect that an increasing voltage unbalance on a rated supply has on the SEIM and PPEIM.

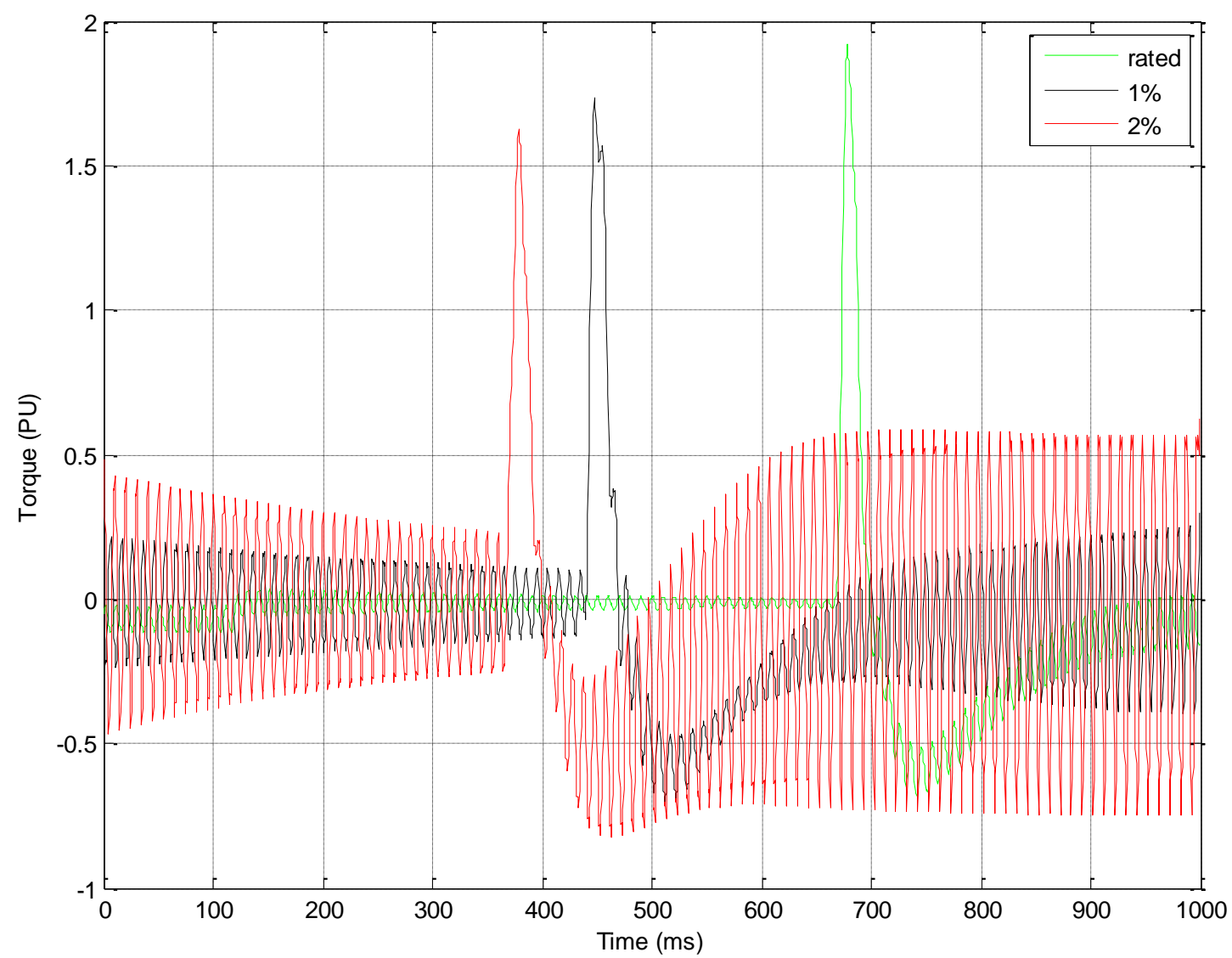

Figure 58: SEIM torque for rated voltage unbalance at 180 degrees phase shift 


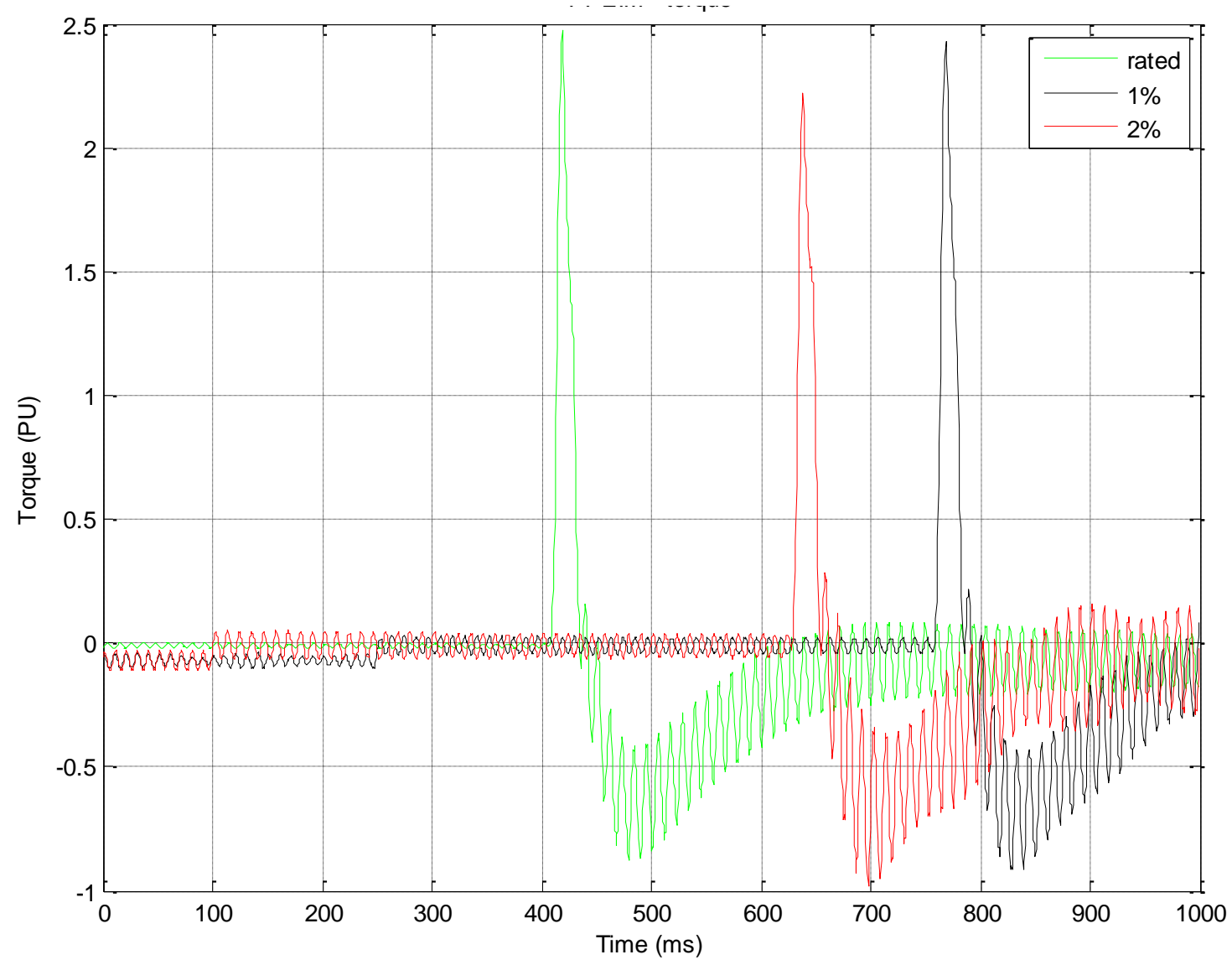

Figure 59: PPEIM torque for rated voltage unbalance at 180 degrees phase shift

From Figure 58 and 59, it can be seen that the peaking torque is gradually reduces as the percentage voltage unbalance increases. This validates a statement made by [54] which states that the average electromechanical torque is reduced by the presence of voltage unbalance.

Due to the induction machines undergoing voltage unbalance, a negative sequence current is induced and it, in turn, produces a backward rotating field. The interaction of the positive forward rotating field and the negative rotating field produces certain current harmonic components in the stator. These components interact with the main magnetic field and set a pulsating torque over the rotor which rotates with a frequency of $2 \mathrm{f}_{s}$ [42]. The pulsating torque incites an oscillation also in the rotor speed, as can be seen in Figure 56 and 57. In the cases of severely distorted voltage supply, the induction machines mechanical performance is heavily affected and a derating should be applied [42].

Furthermore, it can be seen that both the PPEIM and SEIM experience increasing degrees of torque ripple with the $2 \%$ voltage unbalance undergoing severe levels. It is important to note that, just as was the case with the speed, the PPEIM experiences torque ripple at a lesser extent than the SEIM. It is known that PPEIMs are designed principally with reduced windage and friction losses, stray load losses and stator copper losses [4]. The effects of voltage unbalance are known to cause additional iron and copper losses, which leads to temperature increases in the machines and hence, increased torque vibrations. The increased losses in electrical machines are directly dependent on subharmonics and higher frequency components [55]. As the motor becomes more unbalanced, the stator and rotor circuits experience significant increases in losses which cause excessive heating [56]. With the SEIM being constructed with higher losses than the PPEIM, it can be understood that the SEIM will experience more detrimental unbalance effects as far as speed and torque vibrations are concerned. In an industrial 
environment with larger, fully loaded machines, the SEIM would be exceedingly more susceptible to the stress and malfunctioning of mechanical parts due to the excessive speed and torque pulsations.

When observing the rated voltage, under- and overvoltage unbalance for the two machines, the profiles for the torque is as follows:

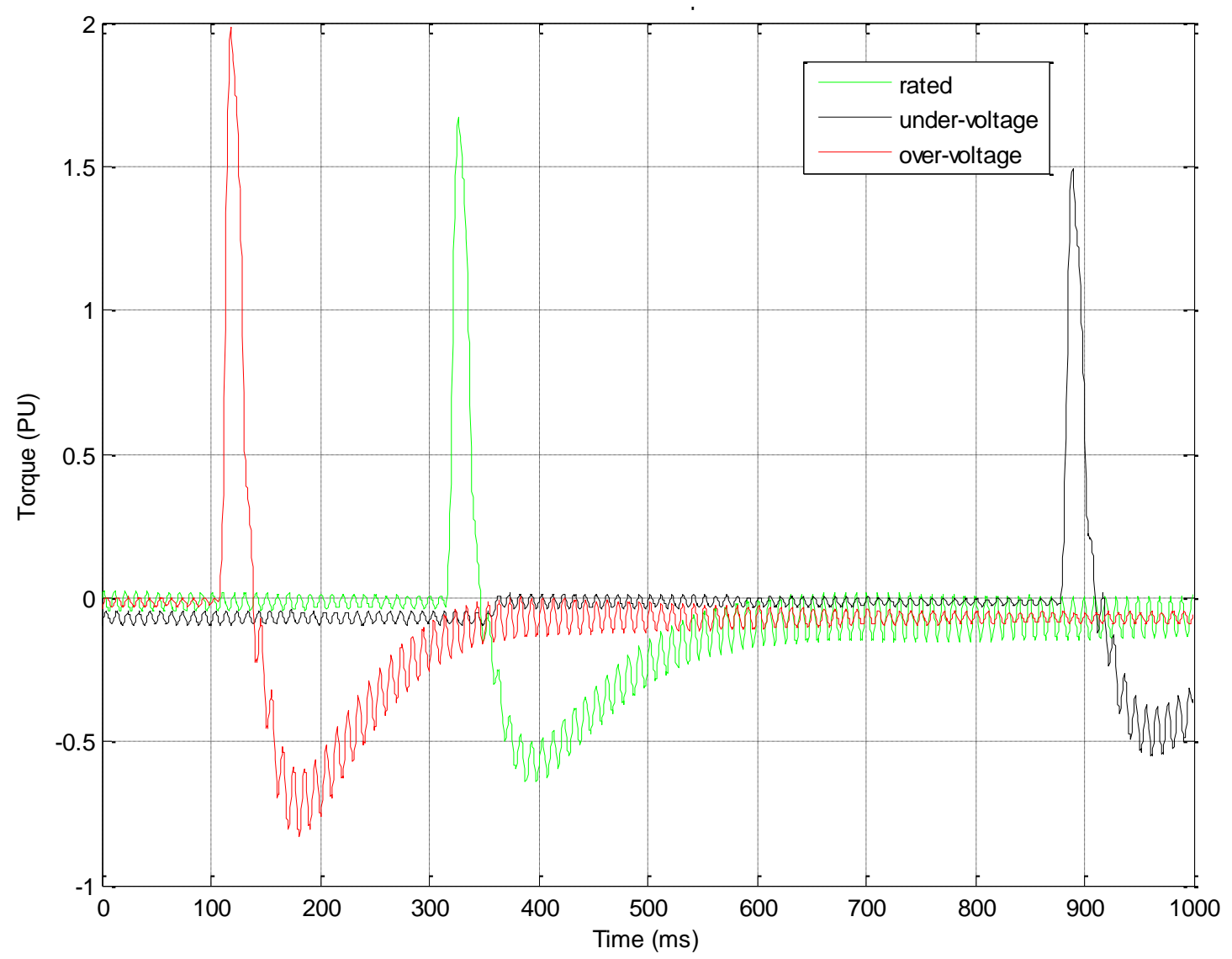

Figure 60: SEIM rated, under- \& overvoltage torque comparison

The torque profiles show that both the SEIM and PPEIM exhibit the highest peaking torque transients for overvoltage operation and the lowest transients for the undervoltage case. Since overvoltage unbalance is defined as the unbalance due to the positive sequence voltage being higher than the rated value [35], then Figure 60 and 61 validate this statement. 


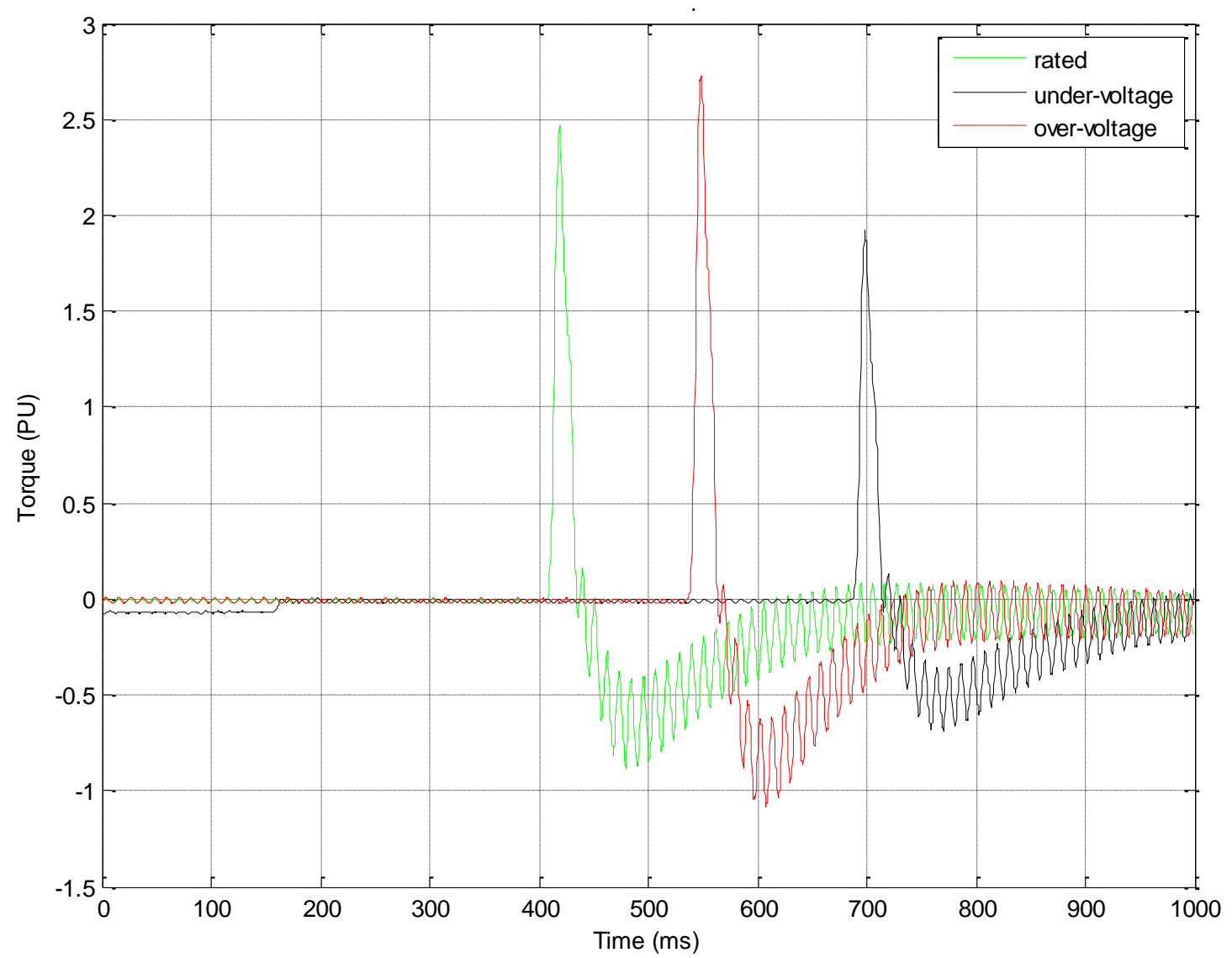

Figure 61: PPEIM rated, under- \& overvoltage torque comparison

During undervoltage conditions, it is important to know that there is a lower magnetisation of the core and hence, more line current is required to sustain the shaft power [4]. For the PPEIM in Figure 62, since the developed torque is proportional to the square of the voltage and the average voltage is lowered by $10 \%$ compared to the rated voltage, the motors developed torque has dropped by $22 \%$ from the nominal torque. Furthermore, an increase in the voltage unbalance factor within the undervoltage condition will cause a further reduction in the developed torque as is shown in Figure 62. 


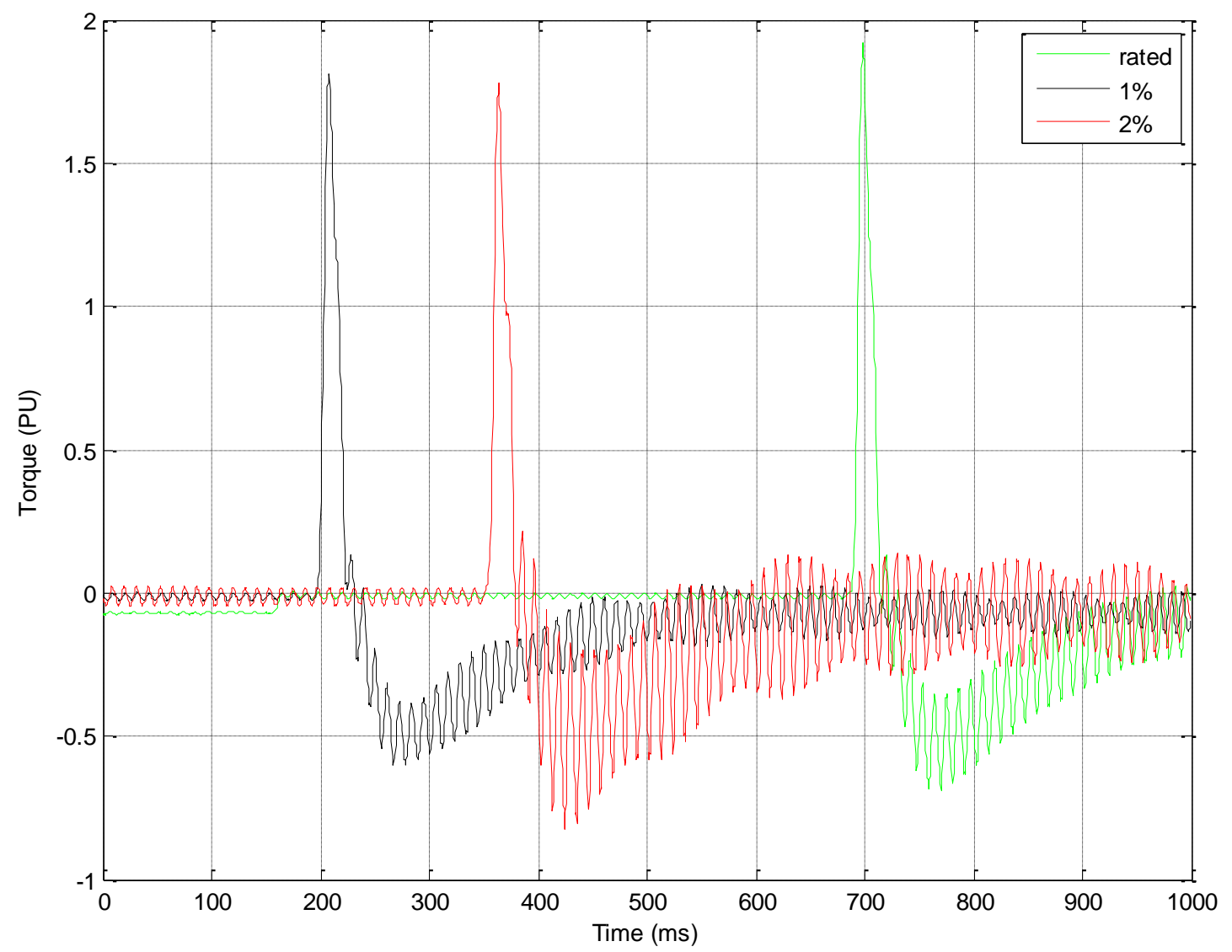

Figure 62: PPEIM undervoltage torque comparison between rated, $1 \%$ and $2 \%$ unbalance

A similar pattern is seen for the SEIM which undergoes undervoltage unbalance with varying degrees of voltage unbalance factor, as is seen in Figure 63. 


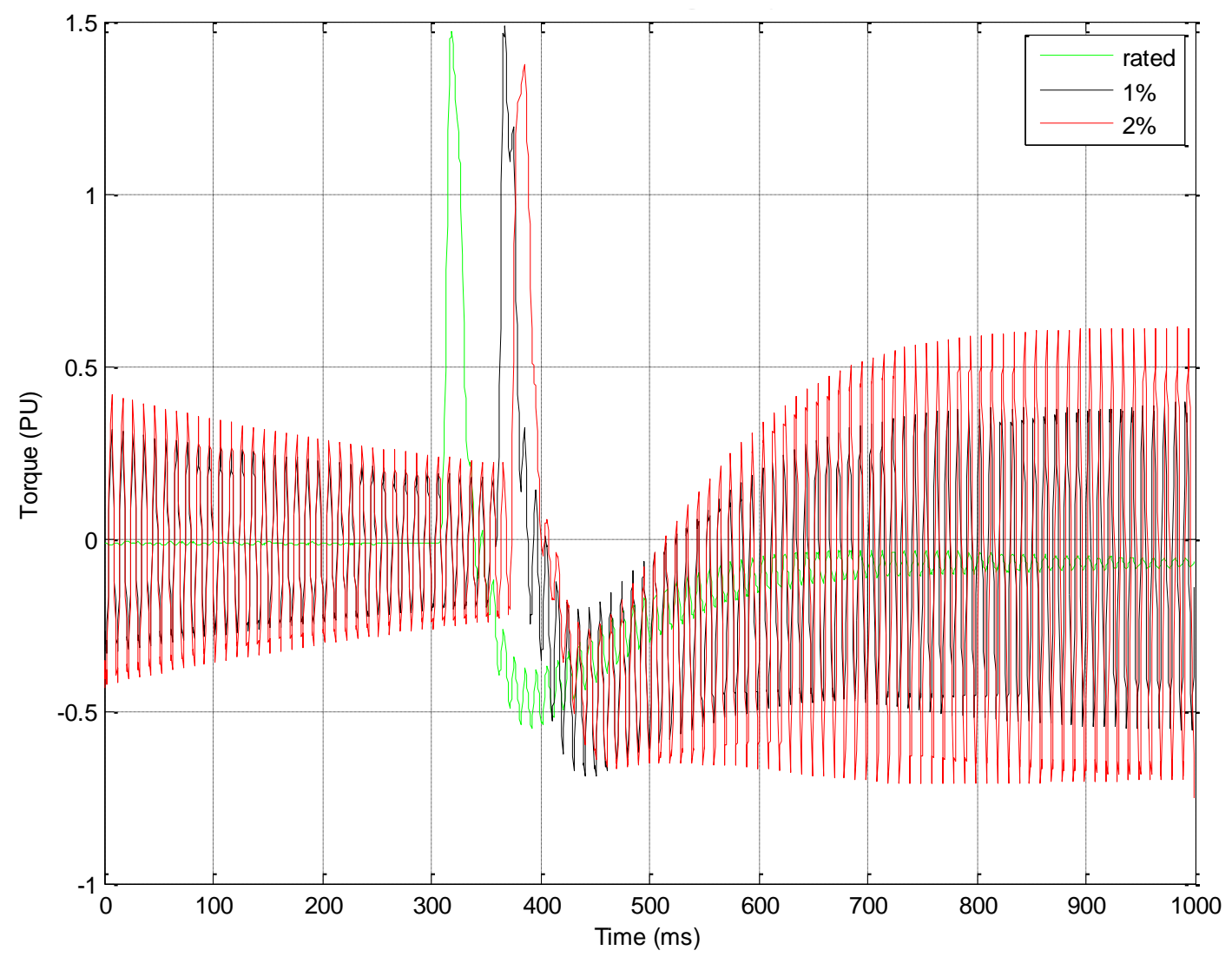

Figure 63: SEIM undervoltage torque comparison between rated, $1 \%$ and $2 \%$ unbalance 


\section{Conclusion}

This study described a detailed experimental investigation that was performed in order to compare the effects of restarting a coasting induction machine before it comes to rest and conducting the same experiment in the presence of voltage unbalance. Under both balanced voltage magnitudes as well as the unbalanced cases, the PPEIM and SEIM behaved differently.

The results show that restarting an induction motor before it comes to rest can lead to current and torque spikes higher than the rated values. The literature states that a possible worst-case scenario is achieved at the $180^{\circ}$ phase shift since the largest potential difference between the constant supply and the residual voltage exists. The experimental analysis of the results offered a validation of the simulated results and this contributed towards the realisation of the effects of transient restarting of the induction machines. The issue of how to prevent severe damage to the mechanical component of an induction machine, or alternatively, the serious reduction of the supply voltage caused by an overload as the induction machine is restarted after a disconnect comes up repeatedly [50]. The issue is a very prominent one due to the fact that tests on fully loaded machines in industry reflect up to 20 times the normal shaft torque as a result of out-of-phase restarting of induction machines. Included in these studies are reports of cracked foundations, broken shafts and frequent motor trip-outs which occur as a result of the same cause [50]. Furthermore, it is seen that the PPEIM experiences larger current and torque spikes than the SEIM.

With regards to the forces acting on the motors, it can be established that the high peaking currents can cause large rotational forces at the worst-case restart. Restarting the induction machine with a residual voltage that is out of phase with the supply and has experienced a minimal decay in magnitude can lead to very high peaking torque transients that can cause large rotational forces and vibrations [5].

Incidentally, it should be noted that induction machines in industry may not immediately show signs of distress due to the excessive torques which come as a result of out-of-phase restarting. However, due to repetitious restarting of the induction machines under these conditions, the damage will eventually show, especially for larger machines [50].

While the PPEIM offers improved efficiency due to reduced core losses, it is important to note that the PPEIM, under these restart conditions, is more susceptible to the detrimental effects of out-of-phase restarting. The results above aid to better investigate the trade-off between the:

1) phase relationships of the supply and residual voltage;

2) the magnitude of the residual voltage and

3) the stator impedance of the machine

It has been seen that at the point of disconnect, the SEIM had a higher residual voltage magnitude than the PPEIM based on the lower permeability and, therefore, a lower retentivity and higher instantaneous residual flux. The SEIM, however, has been seen to decay at a faster rate than the PPEIM. Thus, the phase relationship between the constant supply and the residual voltage of the SEIM changes faster than that of the PPEIM. Included in this is the fact that the PPEIM has a higher inertia and therefore its speed and, as a result, its residual voltage declines at a slower rate.

Due to this, the PPEIM ends up with a larger residual voltage at the worst-case scenario of $180^{\circ}$ phase shift. The difference in magnitude between of the residual voltage between the PPEIM and SEIM at the 
worst-case scenario is not that significant to justify the large difference in peaking torques between the machines. It would be safe to confirm that the potential difference between the supply and the residual voltage for both machines is a factor that cannot be looked at in isolation. It is for this reason that the stator impedance of the PPEIM can thus be established as a dominating factor in determining the difference in the outcome of the results seen in earlier chapters.

With respect to voltage unbalance, it can be concluded that both machines experience lower torque spikes for all the start-up and restart conditions under voltage unbalance compared to the balanced rated voltage restart. This is expected since the results from [57] show that an induction machine under a three-phase balanced condition has a larger peak starting transient torque than one which is under voltage unbalance. The unbalanced voltages cause the line currents to be unbalanced up to 10 times the voltage unbalance and, as a result, an induction motor connected to a generator or unbalanced grid can exacerbate the system unbalance [36]. Several papers include the thermal effects of the unbalance operation on induction machines. However, in this study, the thermal results were not experimentally attained as the main focus was on transient restarting of the induction machines.

The overall effect of the system unbalance is reduced efficiency as well as a reduction in the lifespan of the machine. There are some significant power quality issues that are prevalent with the PPEIMs. The PPEIM is more susceptible to unbalance effects due to a larger negative sequence air gap torque being developed during the transient periods. In industry applications, the unbalanced currents would cause unbalanced voltage drops over the line impedances and thus, worsen the voltage unbalance at the terminals of induction machines [36]. While it can be confirmed that the average torque does experience a reduction in the average peaking torque with increasing unbalance, it can be seen that the differences between the magnitudes are not significantly high. Figures 49, 50, 52 and 53 highlight this observation.

From the above findings, it is evident that there some other significant differences in the way that standard and energy efficient induction machines respond to abnormal voltage conditions. It can be concluded that the SEIM does not experience as large a reduction in the developed torque when considering the effect of an increasing voltage unbalance factor compared to the PPEIM. On the other hand, it can also be noted that the PPEIM is less tolerant to the excessive amount of torque and speed ripple than the SEIM. For the exact same amount of increasing voltage unbalance factor (from $0 \%$ to $2 \%$ ) applied on both machines, the SEIM experienced a significantly greater amount of ripple in its mechanical characteristics compared to the PPEIM.

As the unbalance in the voltage source can cause excessive losses, heating, vibration and torque pulsations, its detection is very important. As a result, the efficiency and average output torque would decrease and the ripple would increase enough to destroy the mechanical component of an induction motor, according to [54]. Based on the findings herein, it can be affirmed that under voltage unbalance the industrial induction machine stands to experience a deteriorated performance. When a machine experiences a high degree of voltage unbalance, a derating of the machine is required in order to prevent the performance of the machine being heavily affected. The derating of the machine is strongly dependent on the harmonic content of the voltage waveform in both magnitude and order [42]. 


\section{Recommendations}

Based on the conclusion drawn, the analysis above shows that the magnitudes of torque and current peaks due to out-of-phase reclosing can be associated with the frequency and residual flux trapped in the air gap after disconnect. The comparison study between the PPEIM and SEIM show that the PPEIM is more susceptible to the effects of out-of-phase restarting, including the case when the supply is under voltage unbalance conditions. The following recommendations are made:

- A residual voltage phase detector should be developed in order to detect and avoid the event of out-of-phase reclosing. Coupled with this should be the development of an automatic mechanism to reclose the contactor when a minimum phase difference is detected.

- When conducting further research, the induction machine connected in a wye connection should be run at the rated value of $690 \mathrm{~V}$ line-to-line so that a more precise representation of the current and torque transient magnitudes can be obtained.

- Further research should involve the building and implementation of a dynamic (DQ) model in order to better simulate the current and torque transients.

- Suggestions can be made to premium efficiency motor manufacturers to design the stators to have a higher resistance so as to minimise the current and torque transients experienced for these types of machines.

- For this study, only two types of induction machines were taken into consideration and these were the PPEIM and SEIM, both having the size of $7.5 \mathrm{~kW}$. Additional, larger machines (such as a $15 \mathrm{~kW}$ rating) should have been tested in order to get a more representative sample of the application in industry. This would lead to a more comparative study as the degree of severity of the peak current and torque transients at out-of-phase reclosing would have been observed as the sizes of machines got larger.

- The start-up and restart tests should be run under loaded conditions. Furthermore, a change in the load should be tested to see which motor, between the premium plus and standard efficiency machine, would be more susceptible to the resulting transient current and torque spikes. This same exercise should be conducted for voltage unbalance.

- The magnitudes of the transient current and torque spikes are dependent on the magnitude of the residual voltage. To better illustrate this, the transient analysis of a simple resistor-inductor (RL) circuit should be implemented and compared to experimental results. Modelling the RL circuit with an ideal switch and a single AC source, a similar set-up to the per-phase equivalent circuit of an induction machine can be achieved.

- A method of limiting the transient current and torque transients should involve testing with the use of relays (automatic transfers). The following recommendations should be made when it comes to applying relays at reclosing [50]: 
- Motor undervoltage protection must be a time delay type

- Motor undervoltage relays must have lower drop-out voltage and longer time at zero volts than undervoltage relays initiating transfers

- To ensure co-ordination, the transfer initiating undervoltage relay, motor undervoltage relays and residual voltage relay should all be connected across the same phase

- Another solution would be to measure the relative voltage between the supply and the residual voltage in order to prevent reclosing depending on the magnitude of the relative voltage. This will allow for reclosing within certain periods when the phase angle difference and the residual voltage is below a determined value [12].

- A fully digital power supply should be utilised to apply voltage unbalance more effectively. The variacs used in the current power supply did not serve to offer accurate variations in voltage across the different phases. The power supply should also be able to reach the $690 \mathrm{~V}$ rated lineto-line voltage for a wye-connected induction machine. This will give a fully representative value for the peak current and torque transients that occur.

- A comprehensive study was done on the transient torque and current when restarting the standard and energy efficient induction machines under voltage unbalance. However, a more detailed investigation should have been conducted by taking the motor efficiency and power factor into account.

- Voltage unbalance will typically lead to an increase in temperature and, as a result, shorten the lifespan of the motor [35]. The article by Lee [35] states that a given value of the voltage unbalance factor may correspond to at least eight voltage unbalance cases yielding different temperature rises. To ensure reliability and a safe operation of the induction motor undergoing voltage unbalance, it is important to derate the machine. Furthermore, the derating curve and the temperature rise curve should take the positive sequence voltage into account to achieve this end. Another article [58] states that as per NEMA guidelines, operating a motor for any length of time at a voltage unbalance greater than $5 \%$ is not recommended. The temperature would rise very quickly to a point where protection from damage would be impractical. A protection method according to the NEMA standard would be reduce the motors output load in order for it to tolerate the extra heating casued by the unbalance [58].

- For this study, only the unbalance in the voltage magnitude was considered. A broader study should involve unbalance in the voltage phase, magnitude and a combination of both parameters. According to [54], a certain degree of torque pulsation can be expected and can be compared to the case when voltage and phase unbalance are considered. 


\section{References}

[1] G. G. Richards and M. A. Laughton, "Limiting induction motor transient shaft torques following source discontinuities," Energy Conversion, IEEE Transactions On, vol. 13, (3), pp. 250-256, 1998.

[2] R. Nailen, "Motor inrush current: what does it really mean?" Elect.App.Mag, pp. 56-60, 1986.

[3] Aiyuan Wang, Zhihao Ling and Wenbo Liu, "Residual voltages analysis in reclosing process for induction machine," in Intelligent Control and Automation, 2008. WCICA 2008. 7th World Congress On, 2008, pp. 4785-4788.

[4] A. L. Van Wyk, M. A. Khan and P. Barendse, "Impact of over/under and voltage unbalanced supplies on energy-efficient motors," in Electric Machines \& Drives Conference (IEMDC), 2011 IEEE International, 2011, pp. 1380-1385.

[5] S. Gumede, "Effects of Motor Restart Before Coasting Down to Zero Speed," (Electronic), Oct, 2012.

[6] R. Parekh, "AC Induction Motor Fundamentals," Microchip Technology Inc, 2003.

[7] P. C. Sen, Principles of Electric Machines and Power Electronics. John Wiley \& Sons, 2007.

[8] P. S. Rao, G. S. Rao and K. Vasudevan, "Electrical Machines II," 2011.

[9] Y. Akiyama, "Induction motor residual voltage," in Industry Applications Society Annual Meeting, 1990., Conference Record of the 1990 IEEE, 1990, pp. 24-29.

[10] L. Yu and K. N. Wong, "Open and short circuit behavior of induction motors," in Industrial Applications Society, 36th Annual Petroleum and Chemical Industry Conference, 1989, pp. 35-40.

[11] M. McCulloch, "The Effect of Voltage Dips On Induction Motors," vol. DPI Binder Rev 1.0, 1980.

[12] J. Reynaud and P. Pillay, "Reclosing transients in induction machines including the effects of saturation of the magnetizing branch and a practical case study," Energy Conversion, IEEE Transactions On, vol. 9, (2), pp. 383-389, 1994.

[13] V. Cohen, "Induction motors-protection and starting," Elektron Journal-South African Institute of Electrical Engineers, vol. 12, pp. 5-10, 1995.

[14] S. S. Mulukutla and E. M. Gulachenski, "A critical survey of considerations in maintaining process continuity during voltage dips while protecting motors with reclosing and bus-transfer practices," in Transmission and Distribution Conference, 1991., Proceedings of the 1991 IEEE Power Engineering Society, 1991, pp. 266-272.

[15] J. D. Gill, "Transfer of motor loads between out-of-phase sources," IEEE Trans. Ind. Appl., (4), pp. 376-381, 1979.

[16] R. H. Daugherty, "Analysis of Transient Electrical Torques and Shaft Torques in Induction Motors as a Result of Power Supply Disturbances," IEEE Power Engineering Review, vol. PER-2, (8), pp. 55-55, 1982.

[17] A. Shaltout and M. Al-Omoush, "Reclosing torques of large induction motors with stator trapped flux," IEEE Transactions on Energy Conversion, vol. 11, (1), pp. 84-90, 1996. 
[18] S. Dahal, P. Attaviriyanupap and Y. Kataoka, "A Study on Influence of Induction Motor Model on Power System Stability," [B] 電力・エネルギー部門電力技術研究会, 2008.

[19] J. Faiz, M. Ghaneei and A. Keyhani, "Performance analysis of fast reclosing transients in induction motors," IEEE Trans. Energy Convers., vol. 14, (1), pp. 101-107, 1999.

[20] G. E. Whellams, "Squirrel cage induction motors," US 4393344 A, 12 July 1983, 1983.

[21] J. C. Andreas, Energy-Efficient Electric Motors, Revised and Expanded. CRC Press, 1992.

[22] F. Parasiliti et al, "Three-phase induction motor efficiency improvements with die-cast copper rotor cage and premium steel," in Proceedings of SPEEDAM'04 Symposium, 2004, .

[23] D. Walters, I. Williams and D. Jackson, "The case for a new generation of high efficiency motorssome problems and solutions," in Electrical Machines and Drives, 1995. Seventh International Conference On, 1995, pp. 26-31.

[24] J. Malinowski, J. McCormick and K. Dunn, "Advances in construction techniques of AC induction motors: Preparation for super-premium efficiency levels," IEEE Trans. Ind. Appl., vol. 40, (6), pp. 16651670, 2004.

[25] W. Cao et al, "Experimental uncertainty in estimation of the losses and efficiency of induction motors," in Industry Applications Conference, 2006. 41st IAS Annual Meeting. Conference Record of the 2006 IEEE, 2006, pp. 441-447.

[26] A. H. Bonnett, "Understanding Efficiency in Squirrel-Cage Induction Motors," Industry Applications, IEEE Transactions On, vol. IA-16, (4), pp. 476-483, 1980.

[27] (01/01/2016). Magnetic Hysteresis. Available: http://www.electronicstutorials.ws/electromagnetism/magnetic-hysteresis.html.

[28] G. C. Paap, "Symmetrical components in the time domain and their application to power network calculations," IEEE Transactions on Power Systems, vol. 15, (2), pp. 522-528, 2000.

[29] P. S. Barendse, Design and Implementation of Variable Speed Wind Energy Induction Generator Systems for Fault Studies, 2004.

[30] J. W. KOLODZIEJ, Induction Motor Torque during Fast Bus Transfers, 2012.

[31] A. Tapia et al, "Modeling and control of a wind turbine driven doubly fed induction generator," IEEE Transactions on Energy Conversion, vol. 18, (2), pp. 194-204, 2003.

[32] P. Pillay and R. Krishnan, "Modeling, simulation, and analysis of permanent-magnet motor drives. I. The permanent-magnet synchronous motor drive," IEEE Transactions on Industry Applications, vol. 25, (2), pp. 265-273, 1989.

[33] J. Rengifo et al, "Experimental evaluation of the voltage unbalance in the efficiency of induction motors," in 2017 IEEE Workshop on Power Electronics and Power Quality Applications (PEPQA), 2017, pp. 1-6.

[34] C. L. Fortescue, "Method of symmetrical co-ordinates applied to the solution of polyphase networks," Proceedings of the American Institute of Electrical Engineers, vol. 37, (6), pp. 629-716, 1918. 
[35] Ching-Yin Lee, "Effects of unbalanced voltage on the operation performance of a three-phase induction motor," IEEE Transactions on Energy Conversion, vol. 14, (2), pp. 202-208, 1999.

[36] A. Dexters, W. Deprez and R. Belmans, "The effect of practical operation conditions on the performance of induction machines," Proceedings of CIRED 2007, pp. 4, 2007.

[37] Anonymous "IEEE Standard Test Procedure for Polyphase Induction Motors and Generators," IEEE Std 112-1991, pp. 0_1, 1991.

[38] W. Deprez, "Energy Efficiency of Induction Machines: A Critical Assessment (Energie efficiëntie van inductiemachines: een kritische beoordeling)," 2008.

[39] A. A. Chauhan, "Importance of unbalance supply estimation for power quality assessment and power system reliability," in 2015 4th International Conference on Reliability, Infocom Technologies and Optimization (ICRITO) (Trends and Future Directions), 2015, pp. 1-6.

[40] P. Pillay, P. Hofmann and M. Manyage, "Derating of induction motors operating with a combination of unbalanced voltages and over or undervoltages," IEEE Trans. Energy Convers., vol. 17, (4), pp. 485-491, 2002.

[41] A. Siddique, G. Yadava and B. Singh, "A review of stator fault monitoring techniques of induction motors," IEEE Trans. Energy Convers., vol. 20, (1), pp. 106-114, 2005.

[42] F. Babaa et al, "Condition monitoring of stator faults in induction motors: Part I- analytical investigation on the effect of the negative voltage sequence." in 2007 International Aegean Conference on Electrical Machines and Power Electronics, 2007, pp. 205-210.

[43] L. Refoufi, H. Bentarzi and F. Dekhandji, "Voltage unbalance effects on induction motor performance," in Proceeding of the 6th WSEAS Int. Conf. on Simulation, Modelling and Ottimization. Portugal, 2006, pp. 112-117.

[44] R. N. Bickford, "Comparison of IEC and IEEE/NEMA standards for rotating electrical machines," in Conference Record of 1999 Annual Pulp and Paper Industry Technical Conference (Cat. no.99CH36338), 1999, pp. 109-118.

[45] C. S. Gajjar, "Non-intrusive efficiency estimation of induction machines under various power supplies," Non-Intrusive Efficiency Estimation of Induction Machines Under various Power Supplies, 2013.

[46] K. Hoffmann, Applying the Wheatstone Bridge Circuit. HBM, 1974.

[47] J. Larabee, B. Pellegrino and B. Flick, "Induction motor starting methods and issues," in Record of Conference Papers Industry Applications Society 52nd Annual Petroleum and Chemical Industry Conference, 2005, pp. 217-222.

[48] Y. A. Chapuis and D. Roye, "Direct torque control and current limitation method in start up of an induction machine," in 1998 Seventh International Conference on Power Electronics and Variable Speed Drives (IEE Conf. Publ. no. 456), 1998, pp. 451-455.

[49] J. C. Gomez et al, "Behavior of induction motor due to voltage sags and short interruptions," Power Delivery, IEEE Transactions On, vol. 17, (2), pp. 434-440, 2002.

[50] A. R. Kelly, "Relay response to motor residual voltage during automatic transfers," American Institute of Electrical Engineers, Part II: Applications and Industry, Transactions of The, vol. 74, (4), pp. 245-252, 1955. 
[51] L. Guasch, F. Corcoles and J. Pedra, "Effects of symmetrical and unsymmetrical voltage sags on induction machines," IEEE Transactions on Power Delivery, vol. 19, (2), pp. 774-782, 2004.

[52] J. Das, "Effects of momentary voltage dips on the operation of induction and synchronous motors," in Industrial and Commercial Power Systems Technical Conference, 1989, Conference Record. 1989, pp. 79-86.

[53] S. Choudhury et al, "Impact of Skin Effect For the Design of a Squirrel Cage Induction Motor on its Starting Performances," International Journal of Engineering Science and Technology (IJEST), vol. 4, (1), pp. 362-366, 2012.

[54] S. Sahu et al, "Unbalanced voltage effects and its analysis on an induction motor," in 2017 International Conference on Innovative Mechanisms for Industry Applications (ICIMIA), 2017, pp. 263268.

[55] S. X. Duarte and N. Kagan, "A Power-Quality Index to Assess the Impact of Voltage Harmonic Distortions and Unbalance to Three-Phase Induction Motors," IEEE Transactions on Power Delivery, vol. 25, (3), pp. 1846-1854, 2010.

[56] A. von Jouanne and B. Banerjee, "Assessment of voltage unbalance," IEEE Transactions on Power Delivery, vol. 16, (4), pp. 782-790, 2001.

[57] Li Wang and Lih-Shyh Liu, "Analyses of unbalanced voltages on startup transients of a threephase induction motor using EMTP MODELS," in Power Engineering Society Winter Meeting, 2000. IEEE, 2000, pp. 308-312 vol.1.

[58] P. Pillay, P. Hofmann and M. Manyage, "Derating of induction motors operating with a combination of unbalanced voltages and over or undervoltages," IEEE Trans. Energy Convers., vol. 17, (4), pp. 485-491, 2002. 


\section{Appendix}

\subsection{MATLAB code used to extract peak torque values}

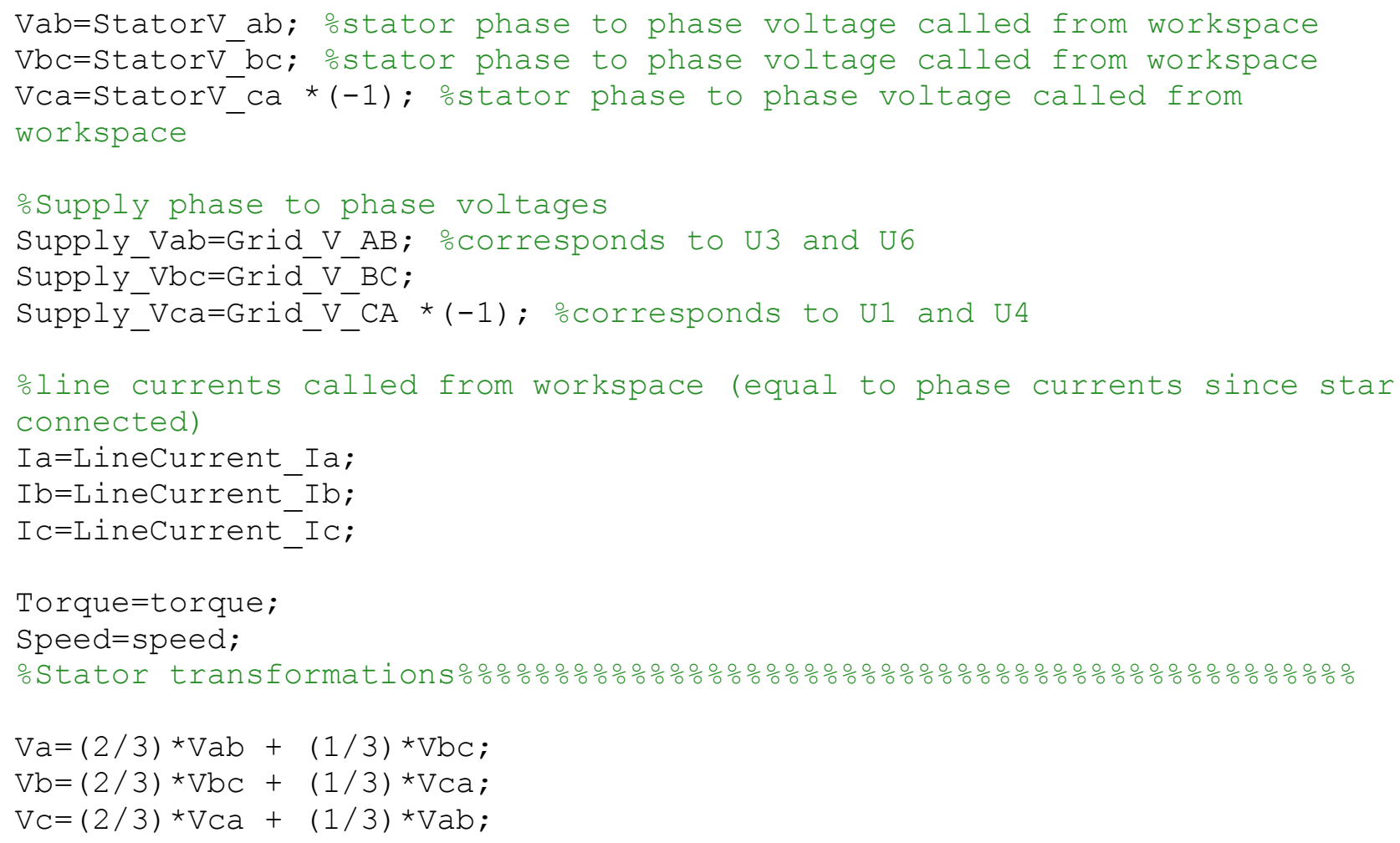

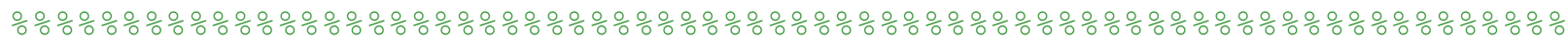

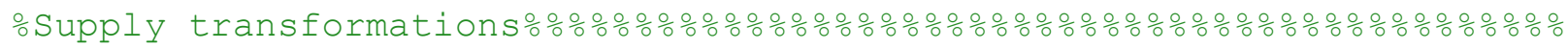

Va_supp $=(2 / 3) *$ Supply_Vab $+(1 / 3) *$ Supply_Vbc;

$\mathrm{Vb} \_$supp $=(2 / 3) *$ Supply_Vbc $+(1 / 3) *$ Supply_Vca;

Vc_supp $=(2 / 3) *$ Supply_Vca $+(1 / 3) *$ Supply_Vab;

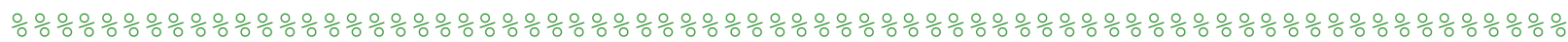

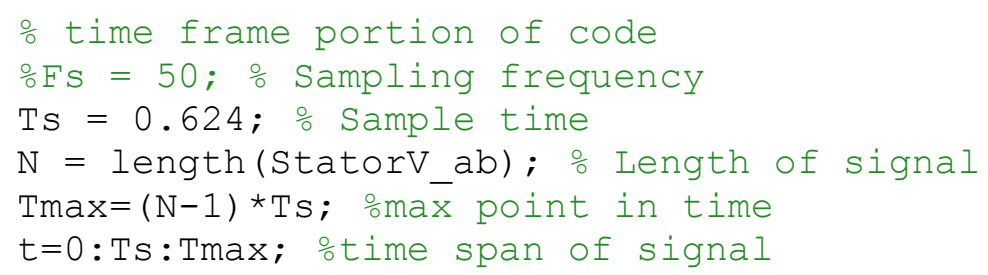


Torque_SEIM=49.3;

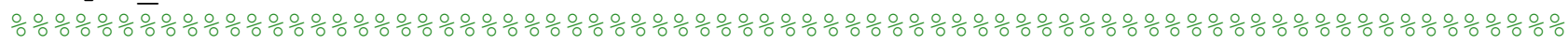

$\therefore$ PPEIM

Voltage $1=318.43$;

Current $1=11.3$;

Torque $1=49.3$;

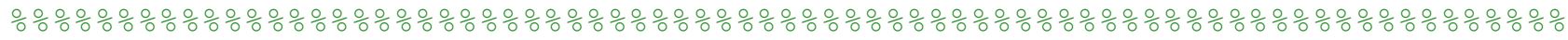

Va_supp_final=smooth (Va_supp/Voltage1);

Vb_supp_final=smooth $\left(\mathrm{Vb} \_\right.$supp/Voltage 1$)$;

Vc_supp_final=smooth $\left(V_{c}{ }_{-}\right.$supp $/$Voltage 1$)$;

Va final=smooth (Va/Voltage 1$)$;

$\mathrm{Vb}$-final=smooth (Vb/Voltage 1$)$;

$\mathrm{VC}_{\text {_final }}=\operatorname{smooth}(\mathrm{VC} / \mathrm{Vol}$ tage 1$)$;

Ia_final=smooth (Ia/Current 1$)$;

Ib final=smooth (Ib/Current 1$)$;

Ic_final=smooth (IC/Current 1$)$;

torque_final=smooth (Torque/Torque1);

Potential_Diff_A=Va_supp_final-Va_final;

Potential_Diff_B=Vb_supp_final-Vb_final;

Potential_Diff_C=VC_supp_final-Vc_final;

figure o create new figure

plot (t,torque_final)

xlabel ('Time (ms)');

ylabel ('Torque PU');

olegend('Supply V','Phase A Stator V','Potential Difference')

title ('Rated Voltage 180 degree Restart')

grid on 


\subsection{Start-up experimental results}

\subsubsection{Per-phase currents}

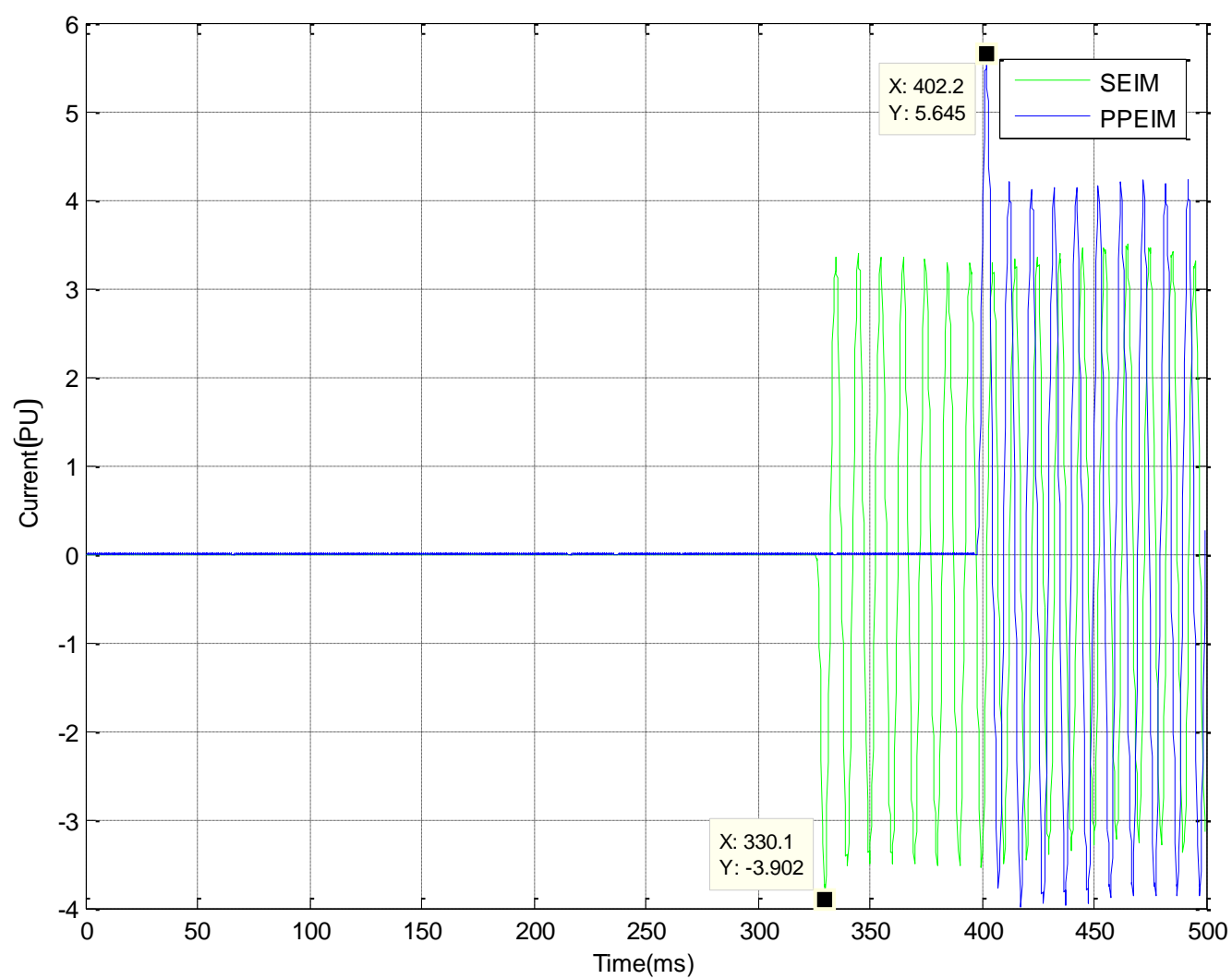

Figure 64: Rated phase A start-up current

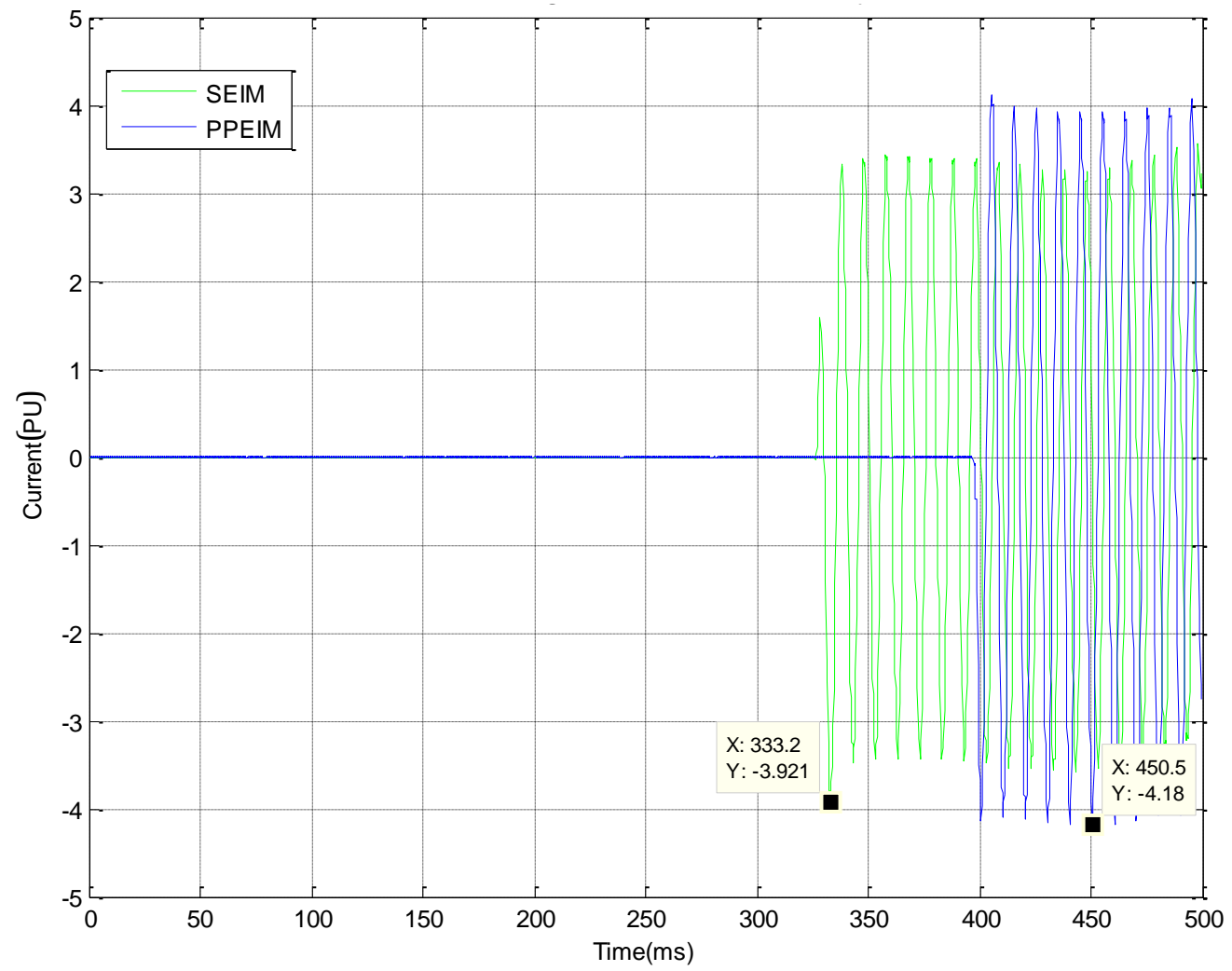

Figure 65: Rated phase B start-up current 


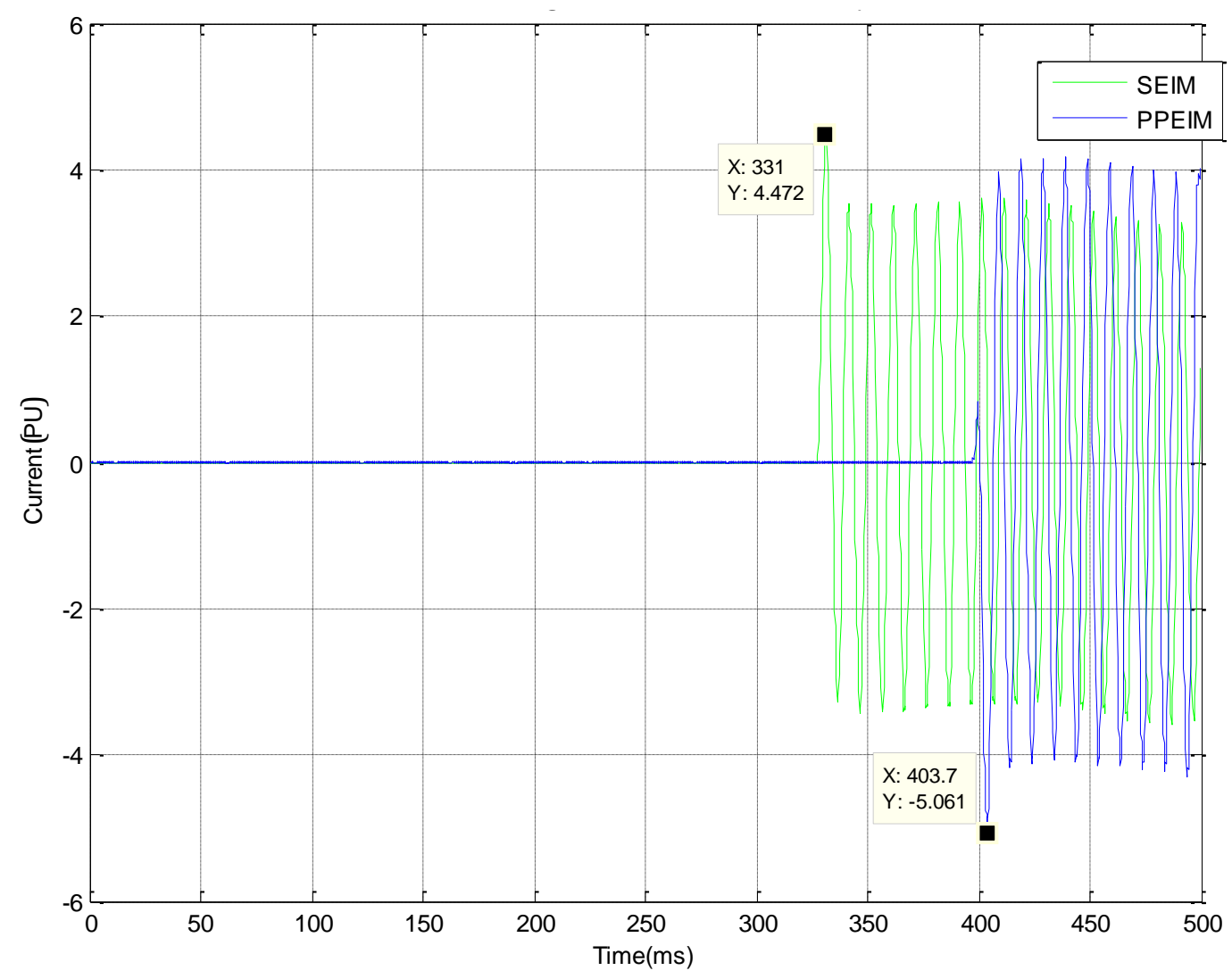

Figure 66: Rated phase C start-up current

\subsubsection{Torque}

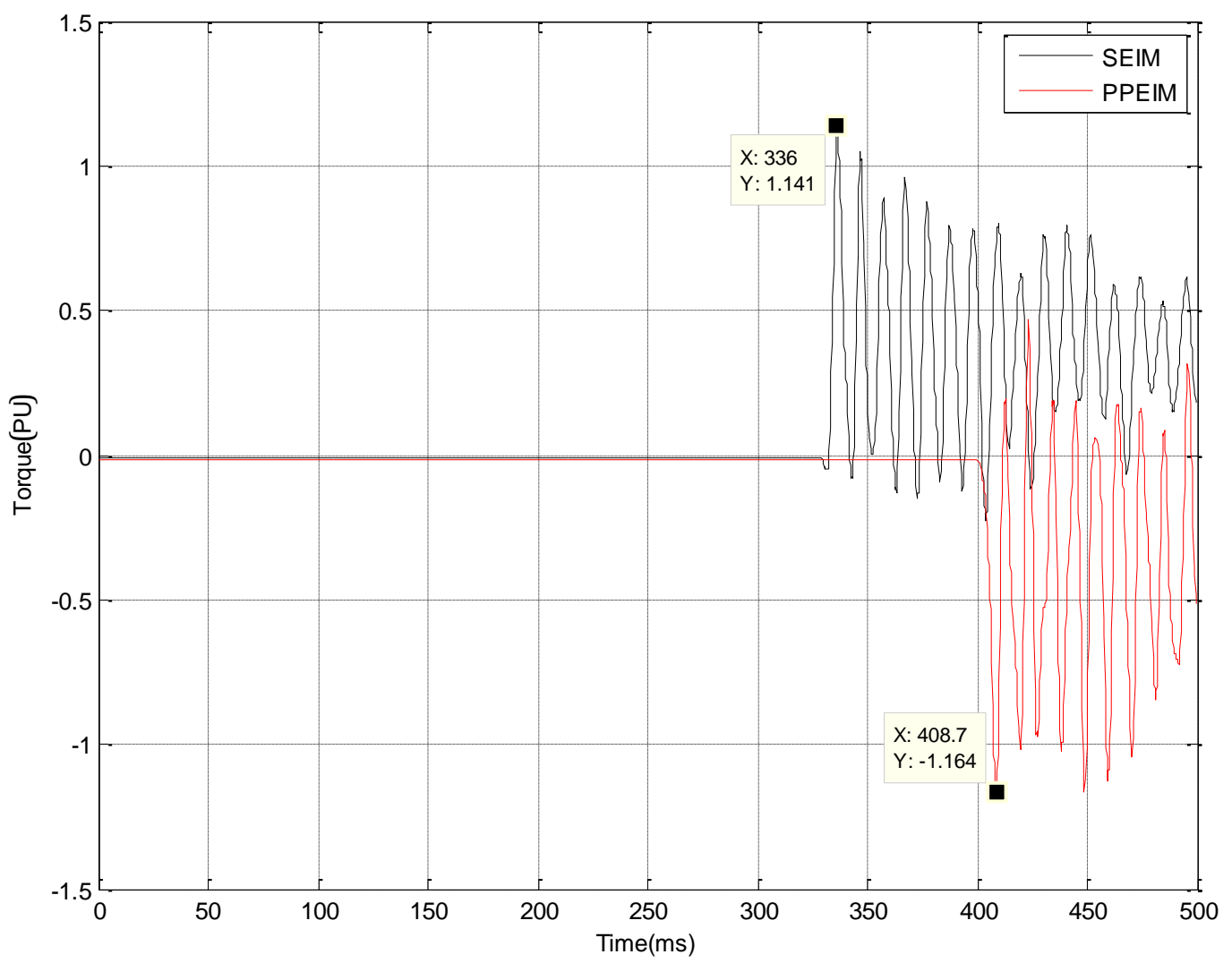

Figure 67: Rated start-up torque 


\subsection{Restarting experimental results}

\subsection{1 $\quad 0^{\circ}$ phase shift}

i. $\quad$ Residual voltage

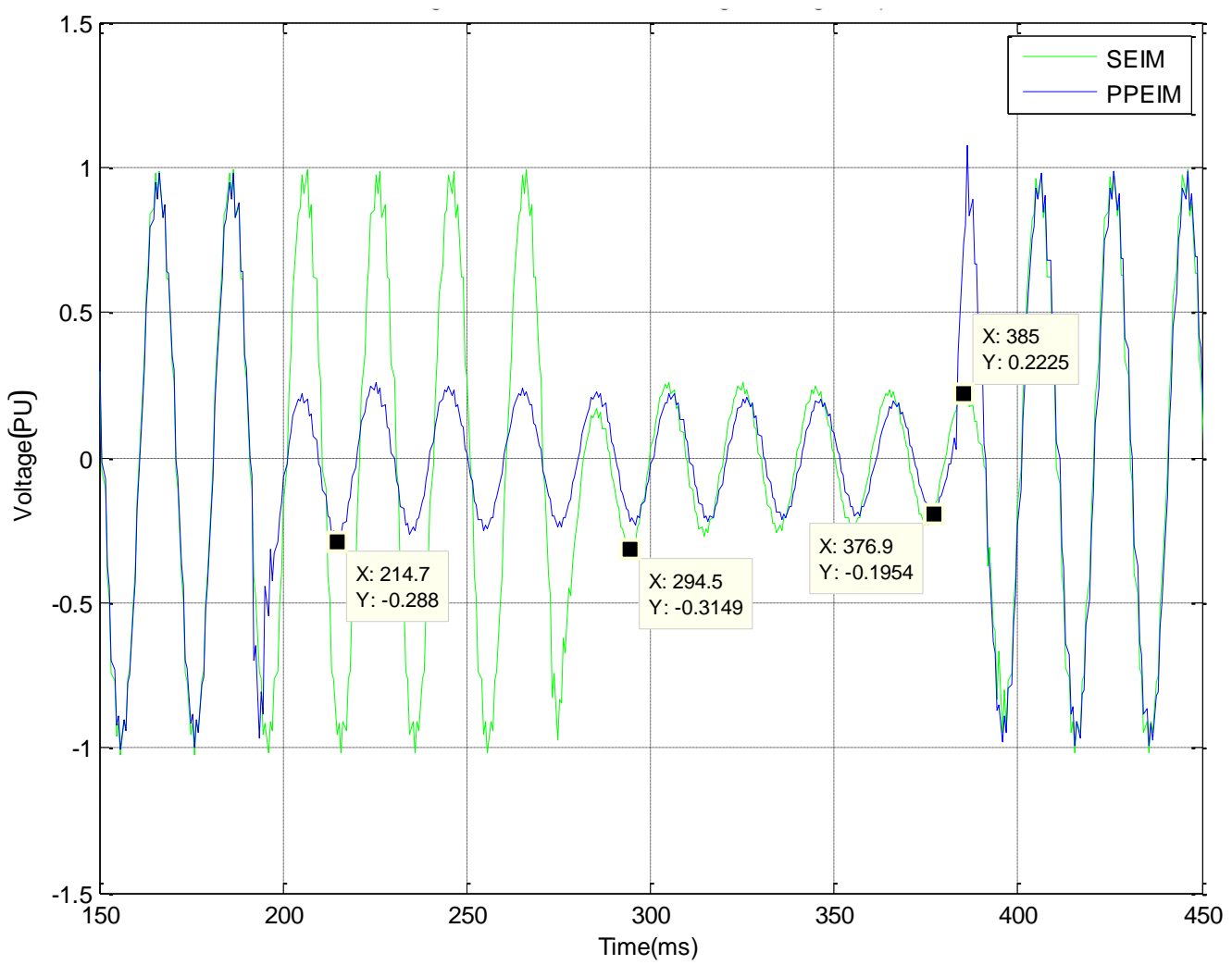

Figure 68: Phase A residual voltage - 0 degrees phase shift

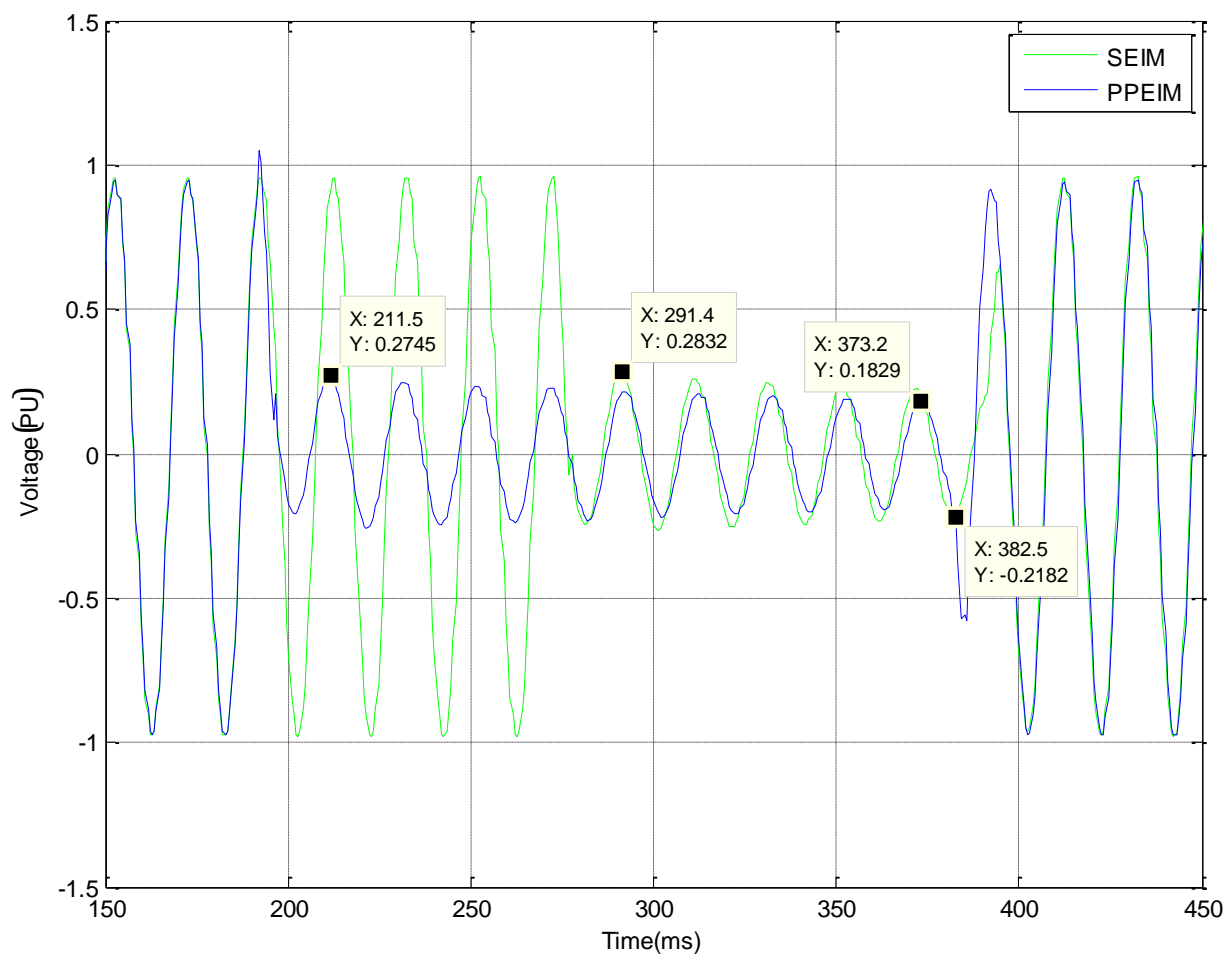

Figure 69: Phase B residual voltage - 0 degrees phase shift 


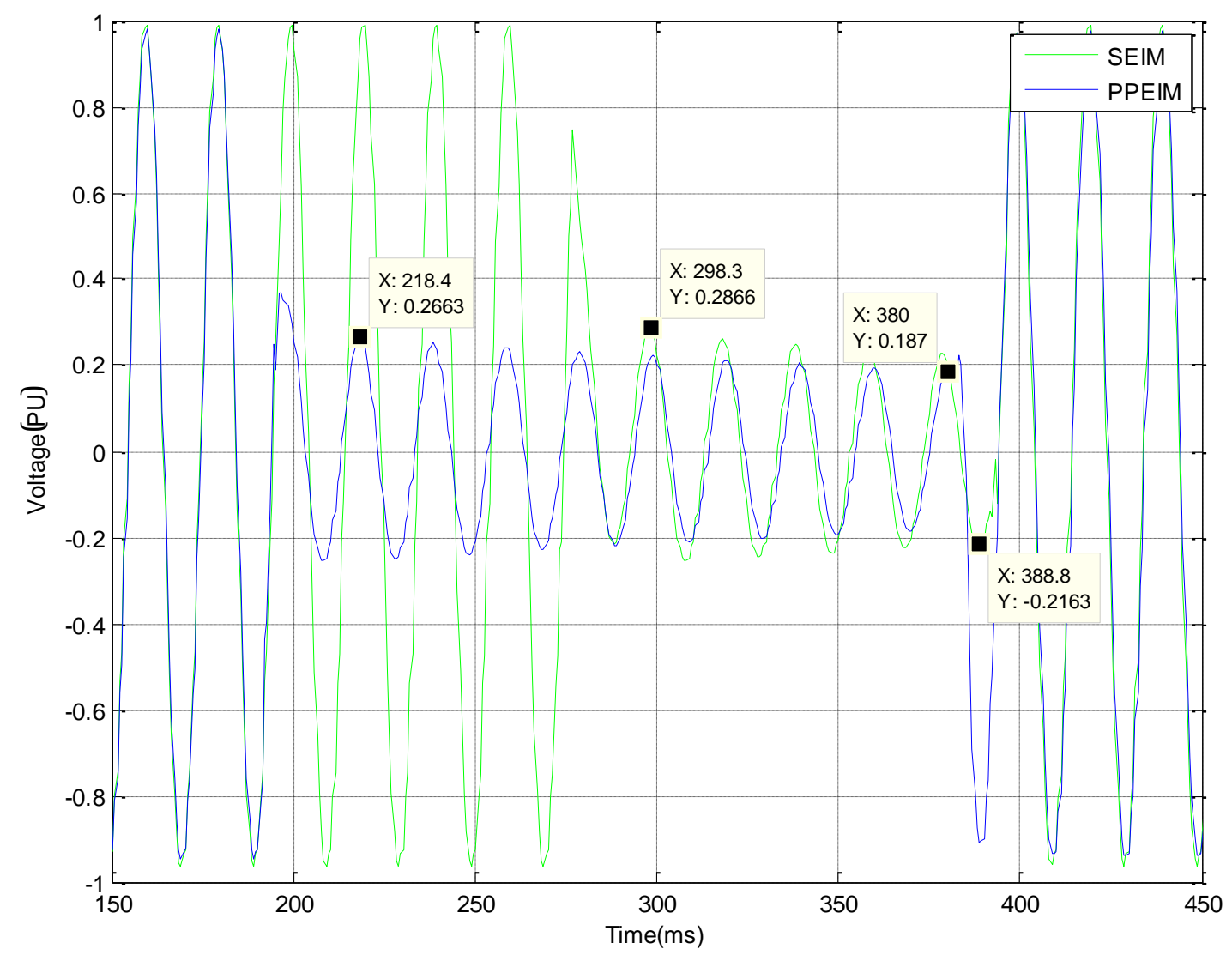

Figure 70: Phase $C$ residual voltage - 0 degrees phase shift

ii. Current

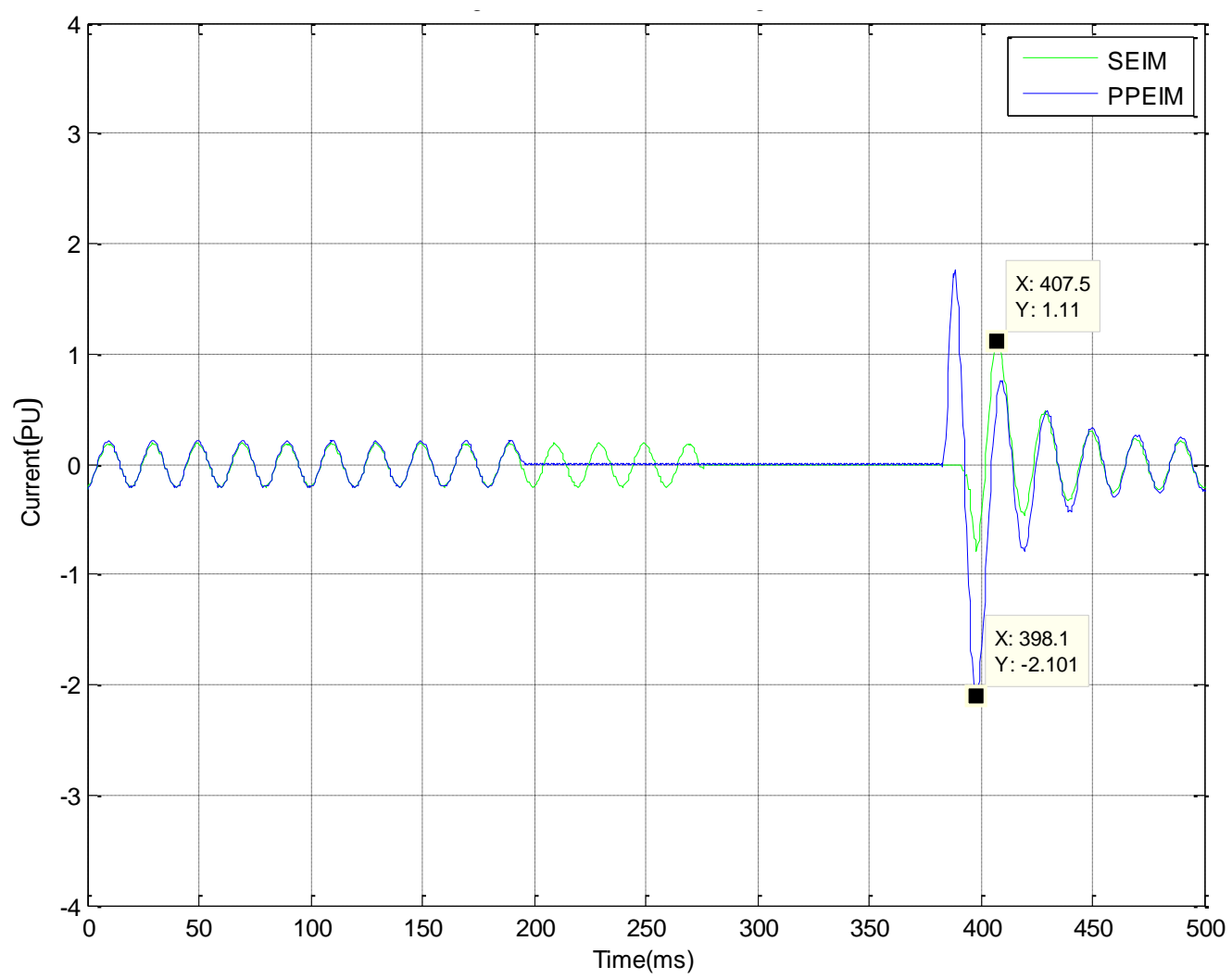

Figure 71: Phase A stator current - 0 degrees phase shift 


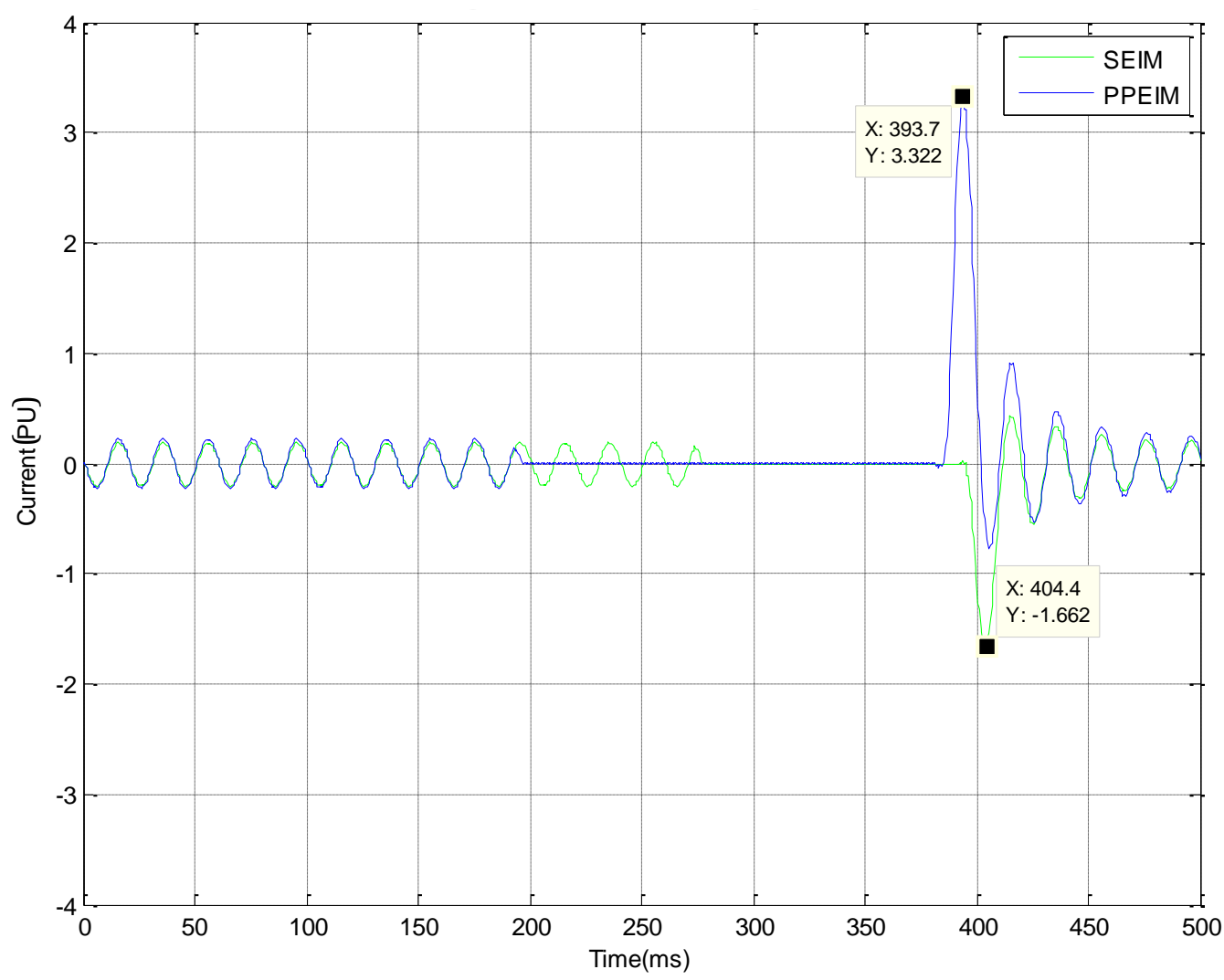

Figure 72: Phase B stator current - 0 degrees phase shift

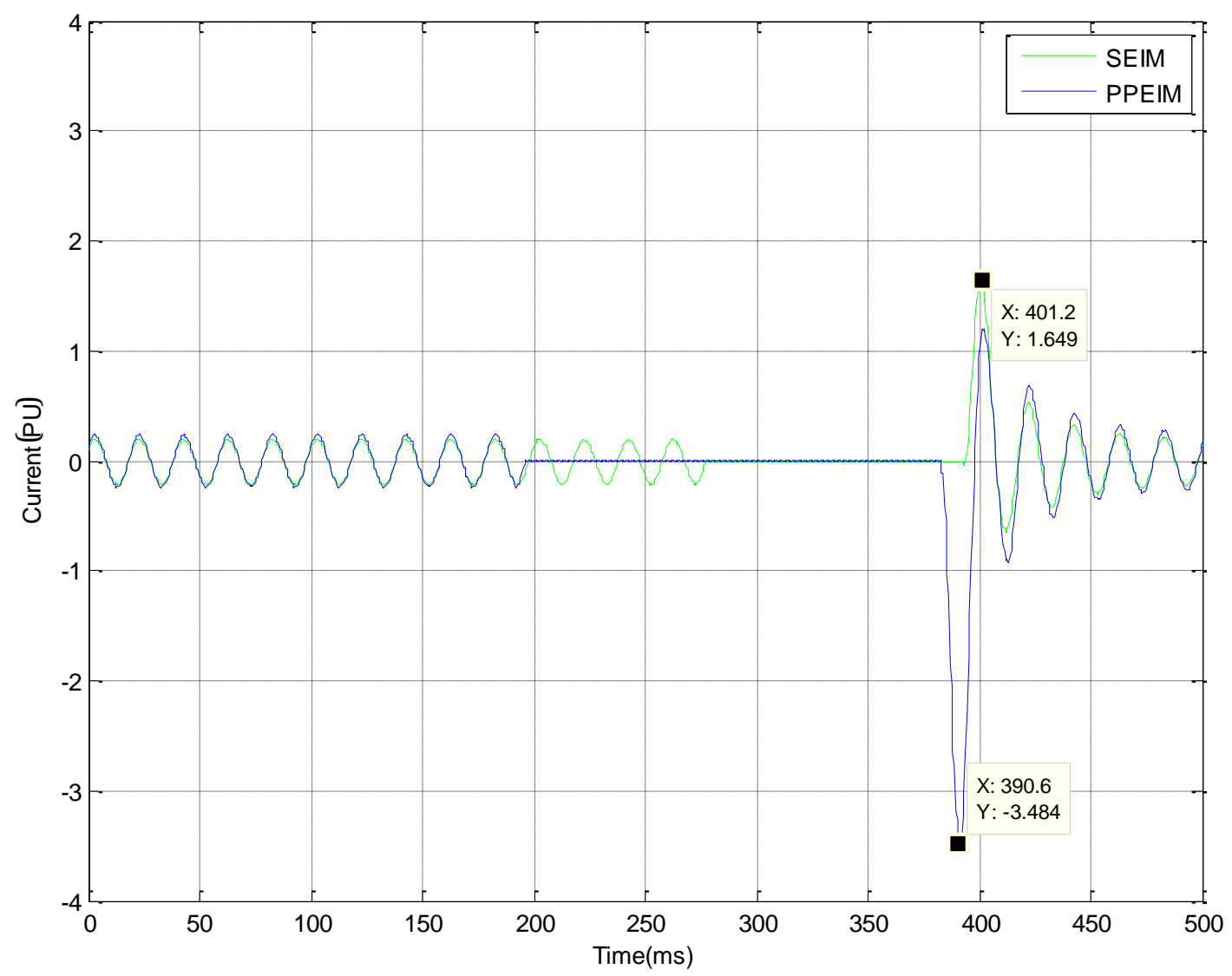

Figure 73: Phase C stator current - 0 degrees phase shift 
iii.

Torque

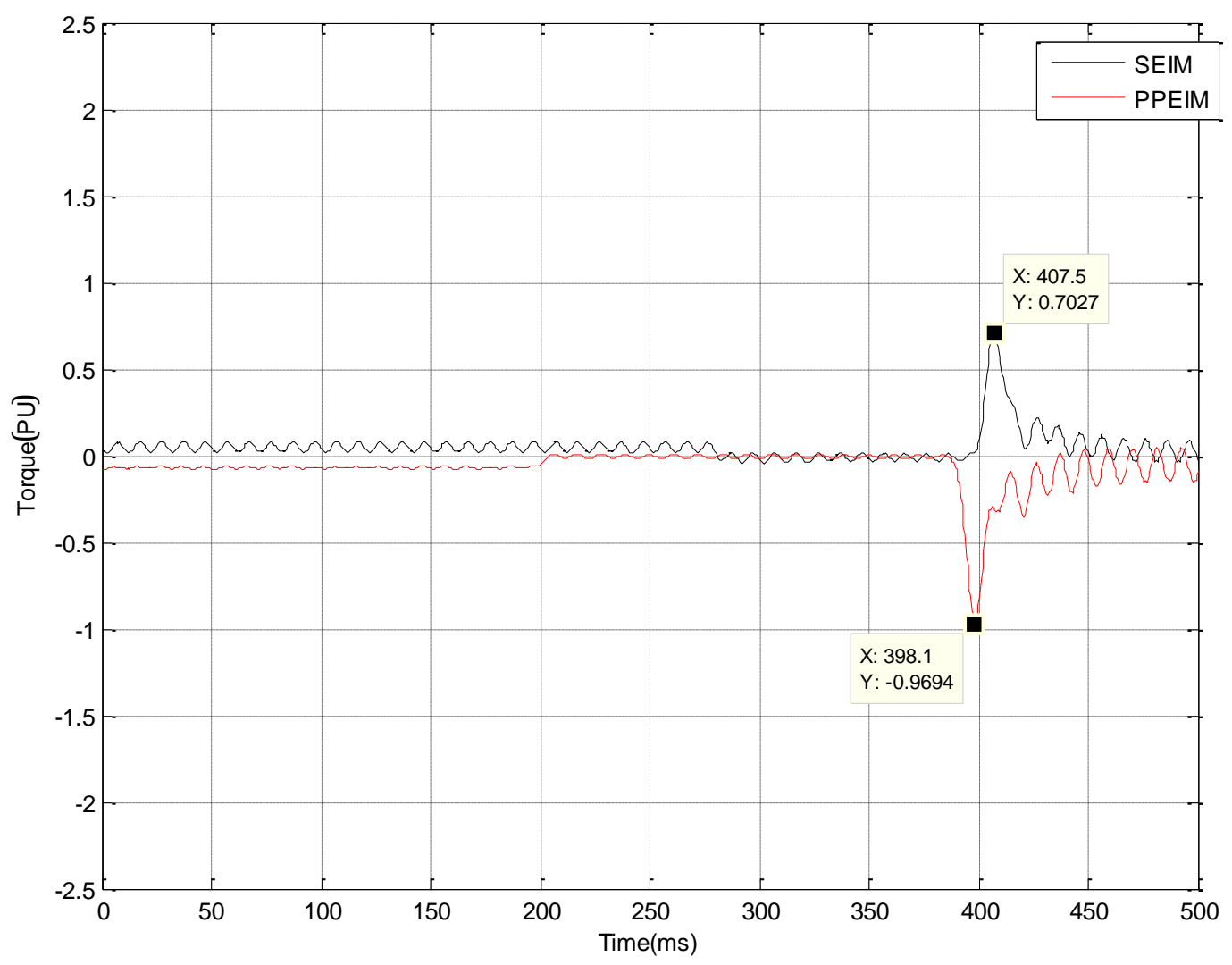

Figure 74: Torque - 0 degrees phase shift 
9.3.2 $\quad 90^{\circ}$ phase shift

i. $\quad$ Residual voltage

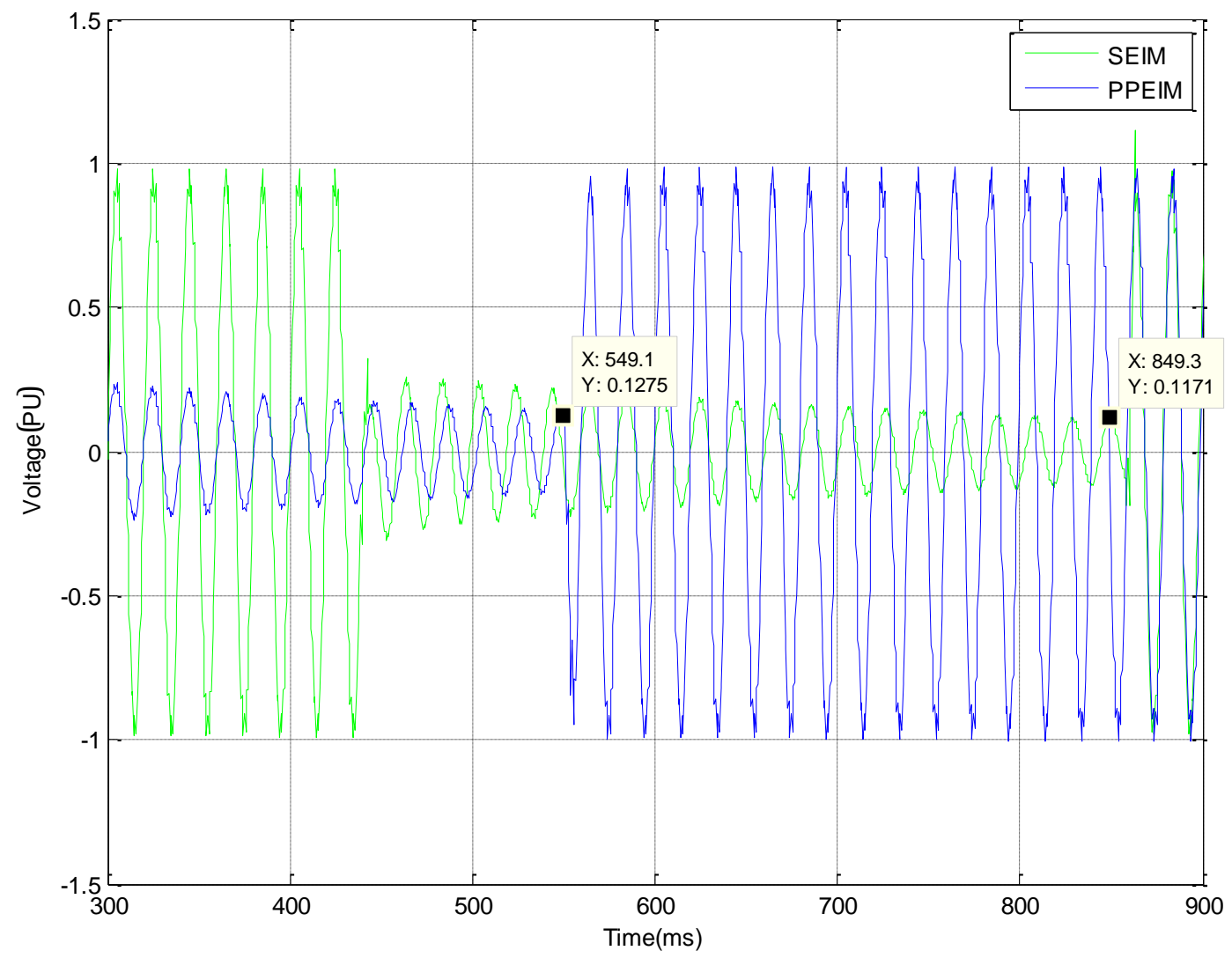

Figure 75: Phase A residual voltage - 90 degrees phase shift

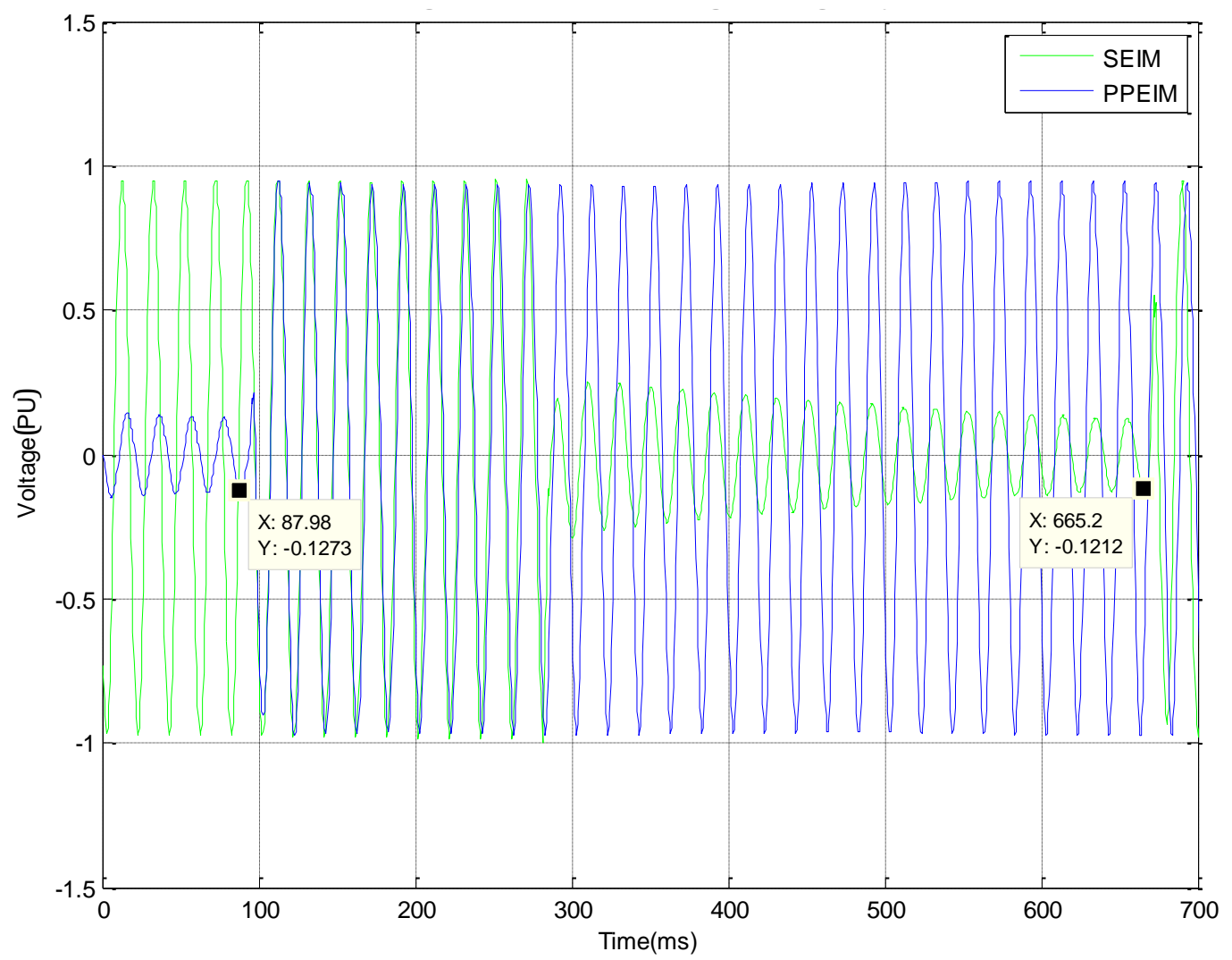

Figure 76: Phase B residual voltage - 90 degrees phase shift 


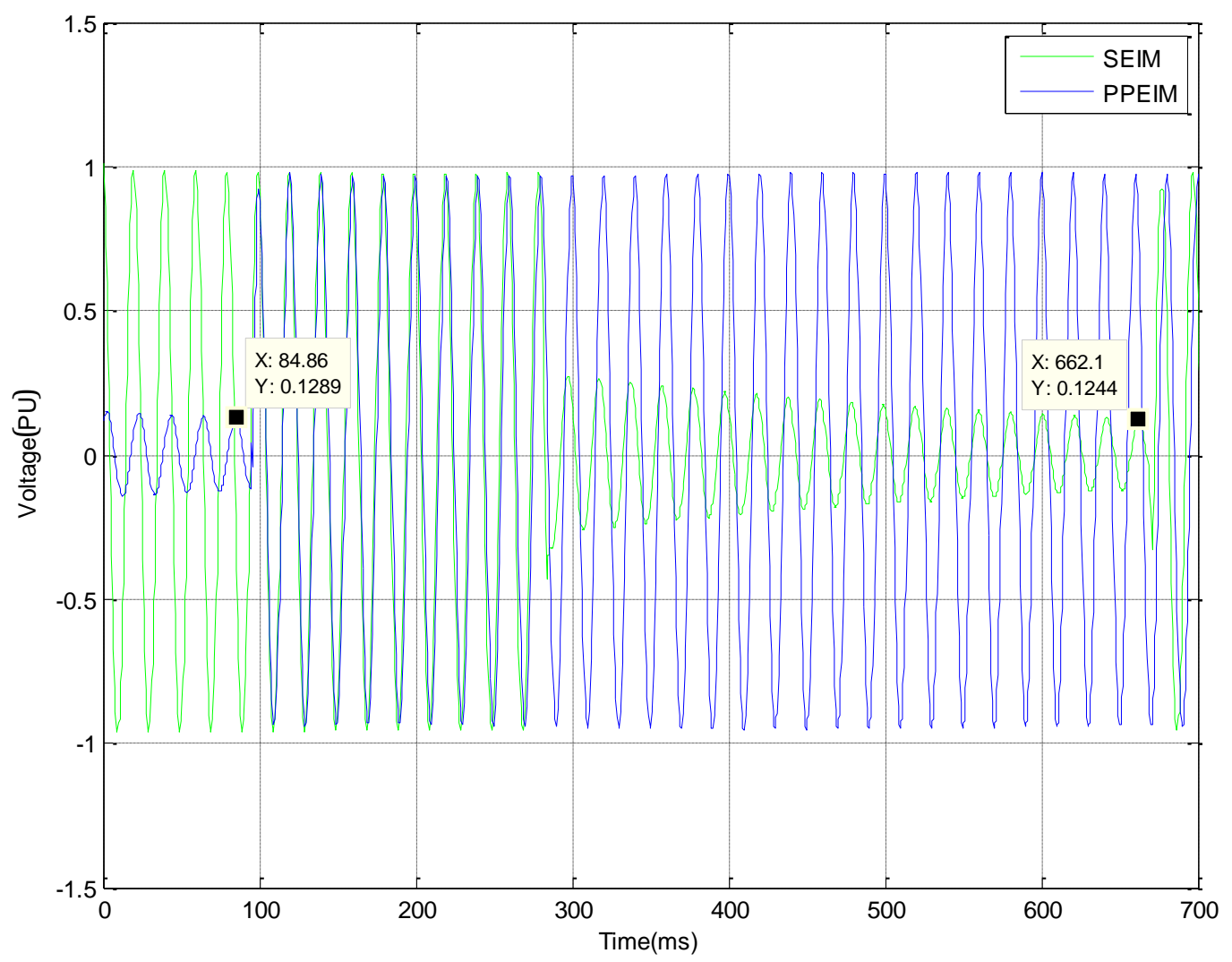

Figure 77: Phase C residual voltage - 90 degrees phase shift

ii. Current

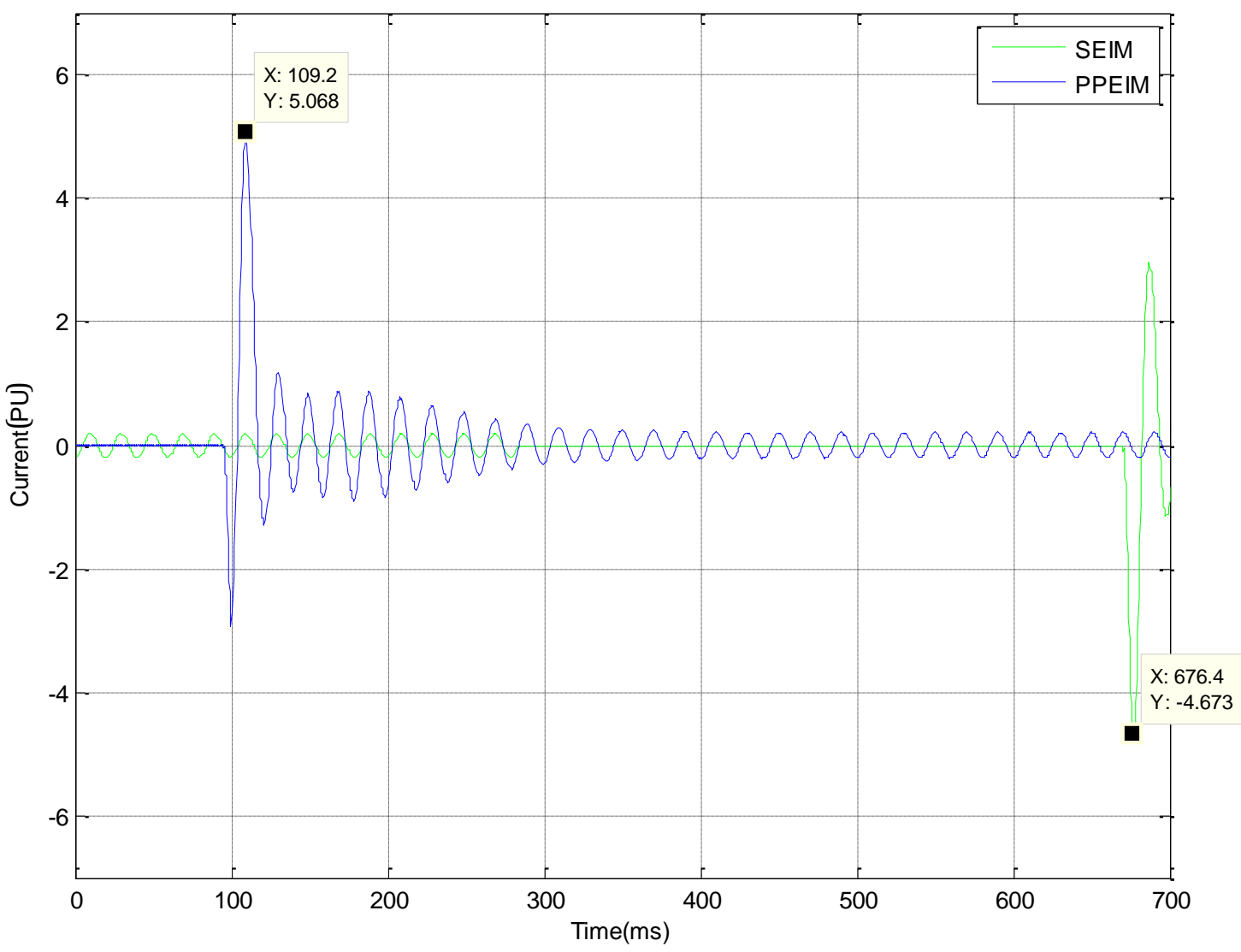

Figure 78: Phase A stator current - 90 degrees phase shift 


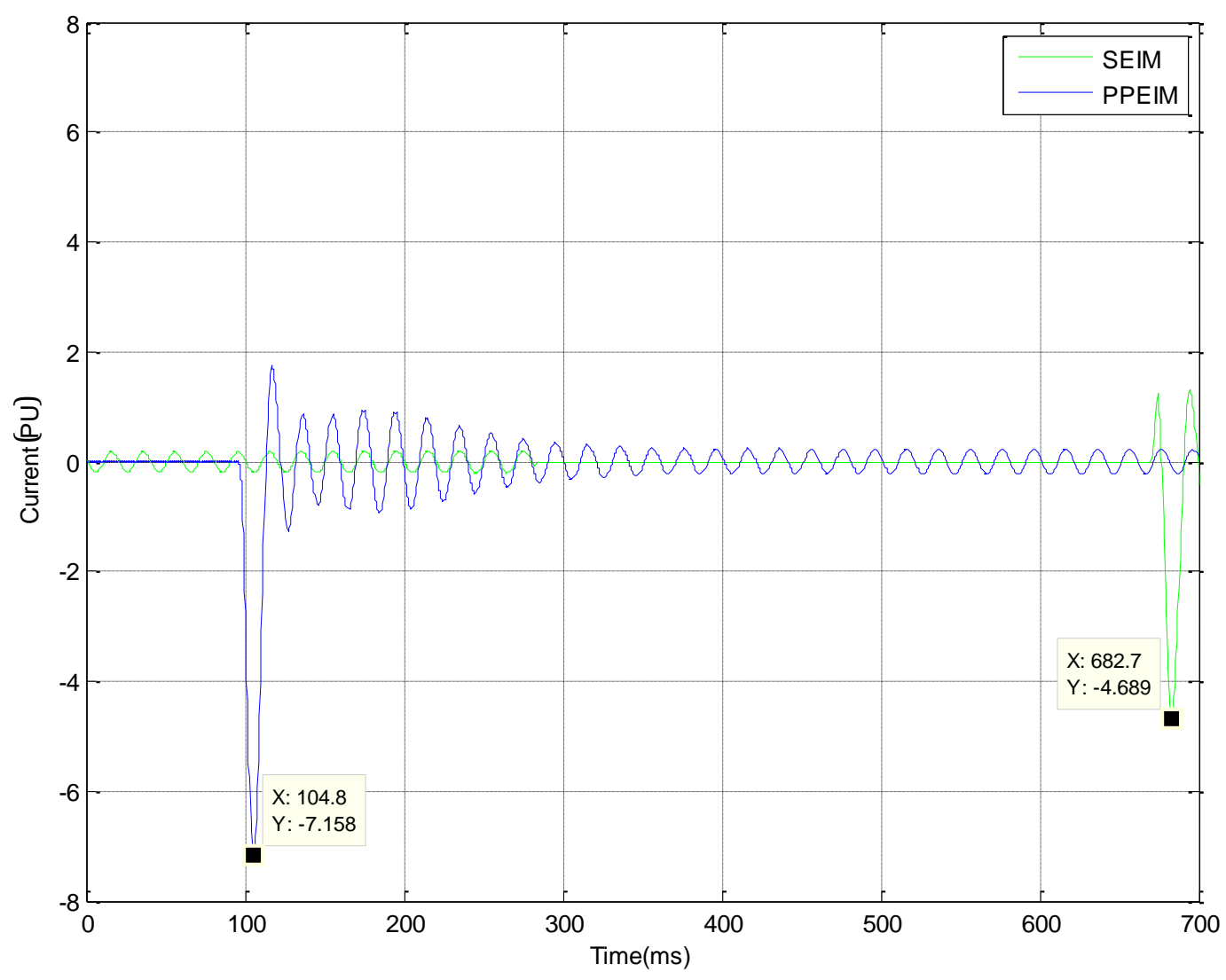

Figure 79: Phase B stator current - 90 degrees phase shift

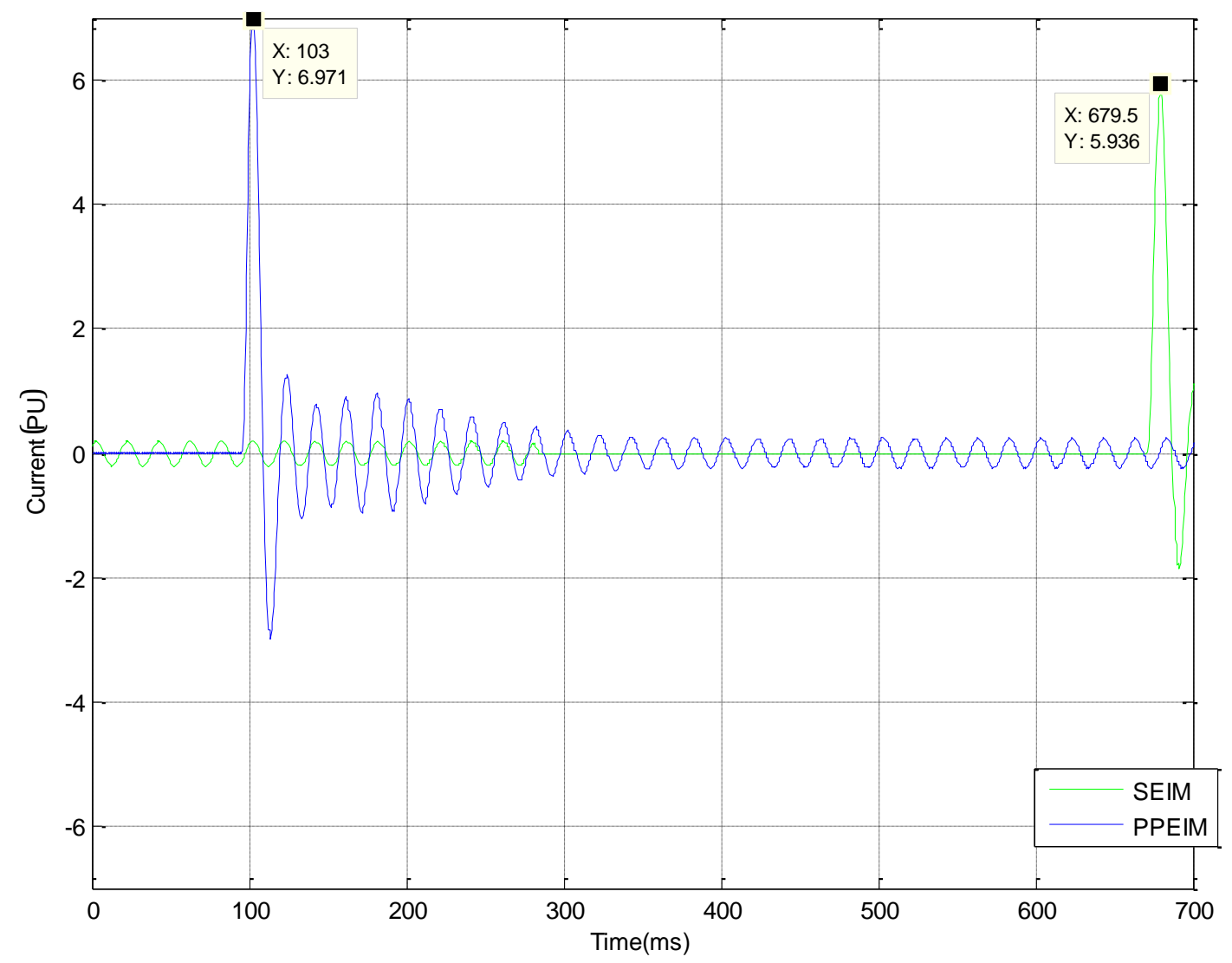

Figure 80: Phase C stator current - 90 degrees phase shift 
iii.

Torque

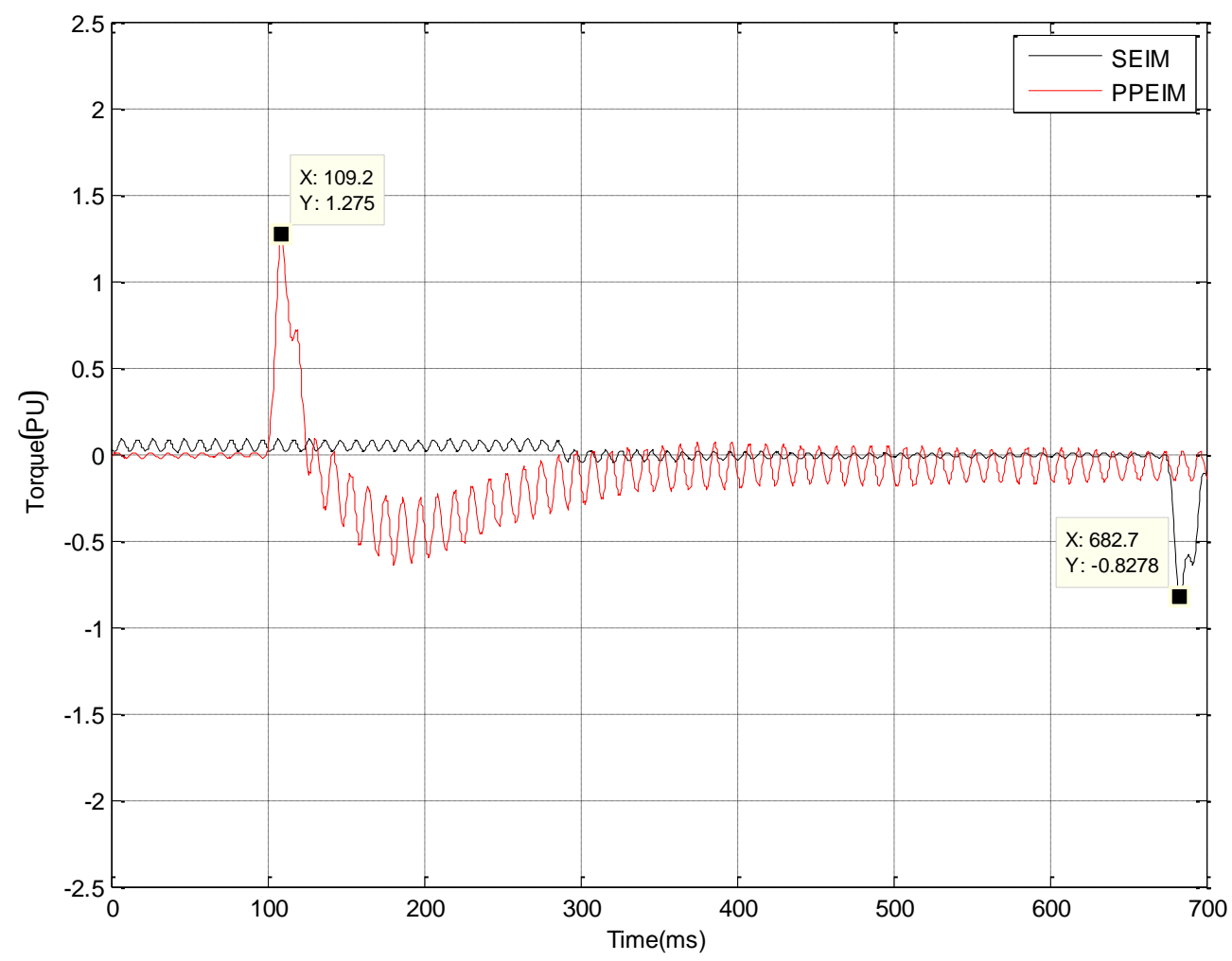

Figure 81: Torque - 90 degrees phase shift

\subsection{3 $\quad 1^{\circ} 0^{\circ}$ phase shift}

i. Residual voltage

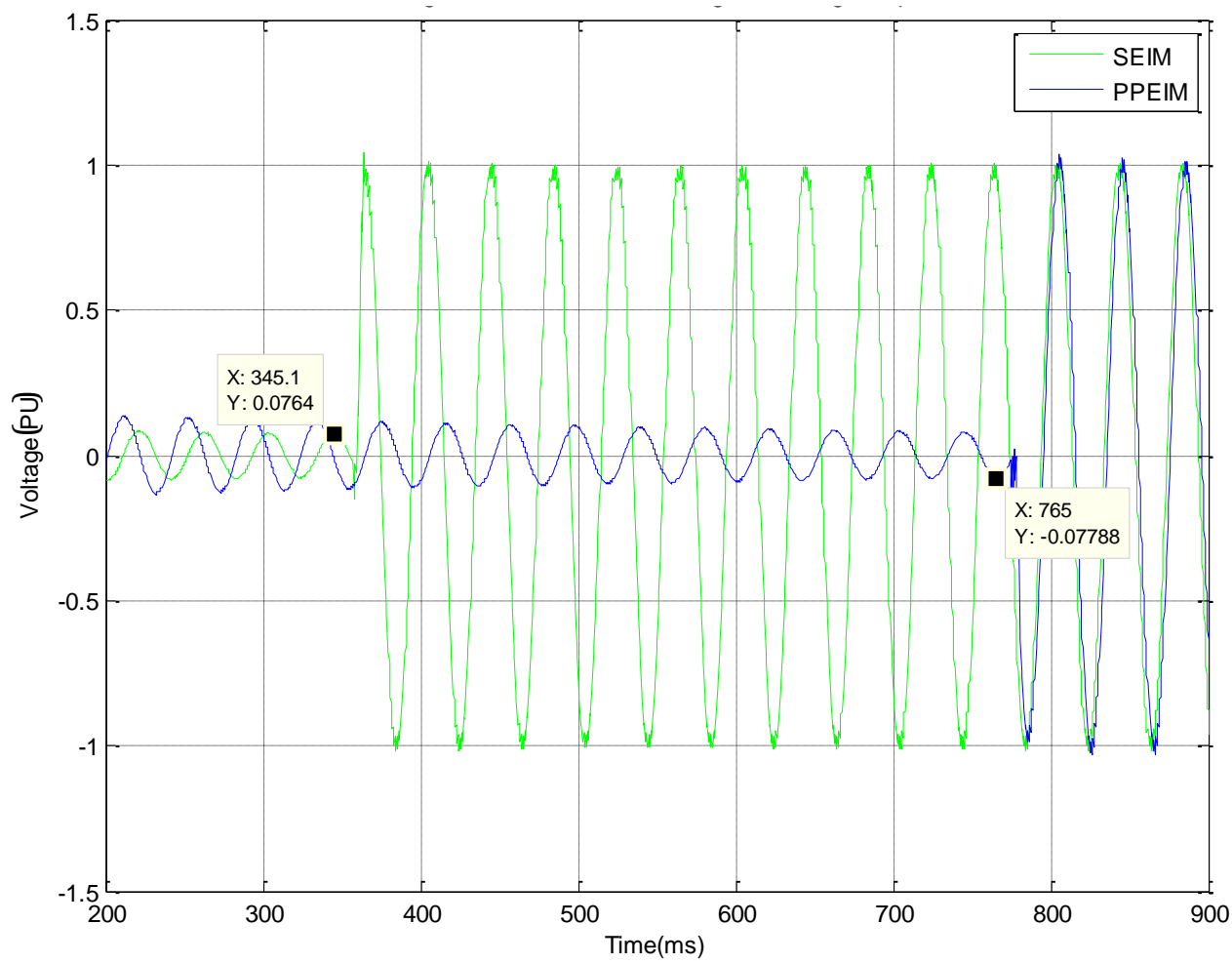

Figure 82: Phase A residual voltage - 180 degrees phase shift 


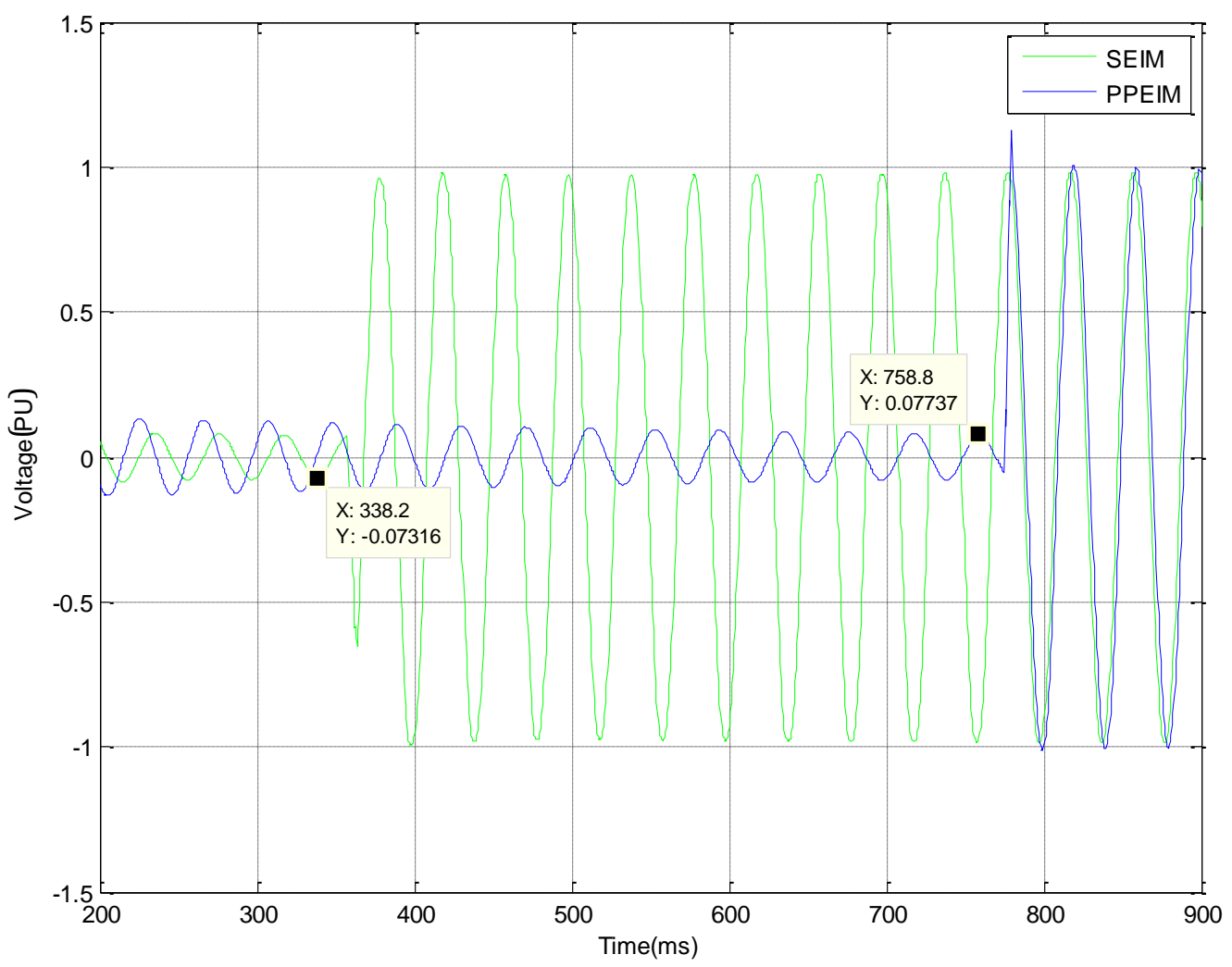

Figure 83: Phase B residual voltage - 180 degrees phase shift

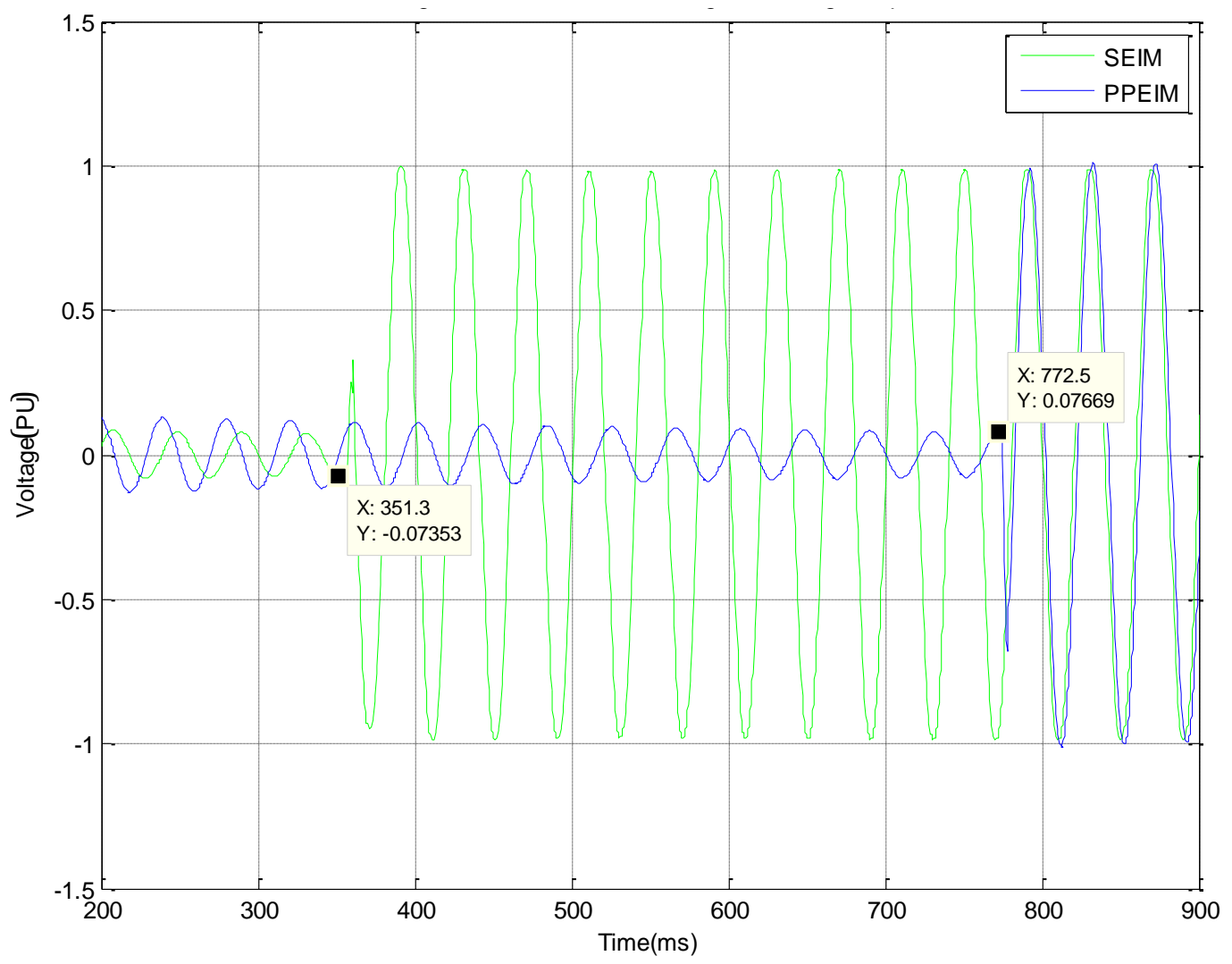

Figure 84: Phase $C$ residual voltage - 180 degrees phase shift 


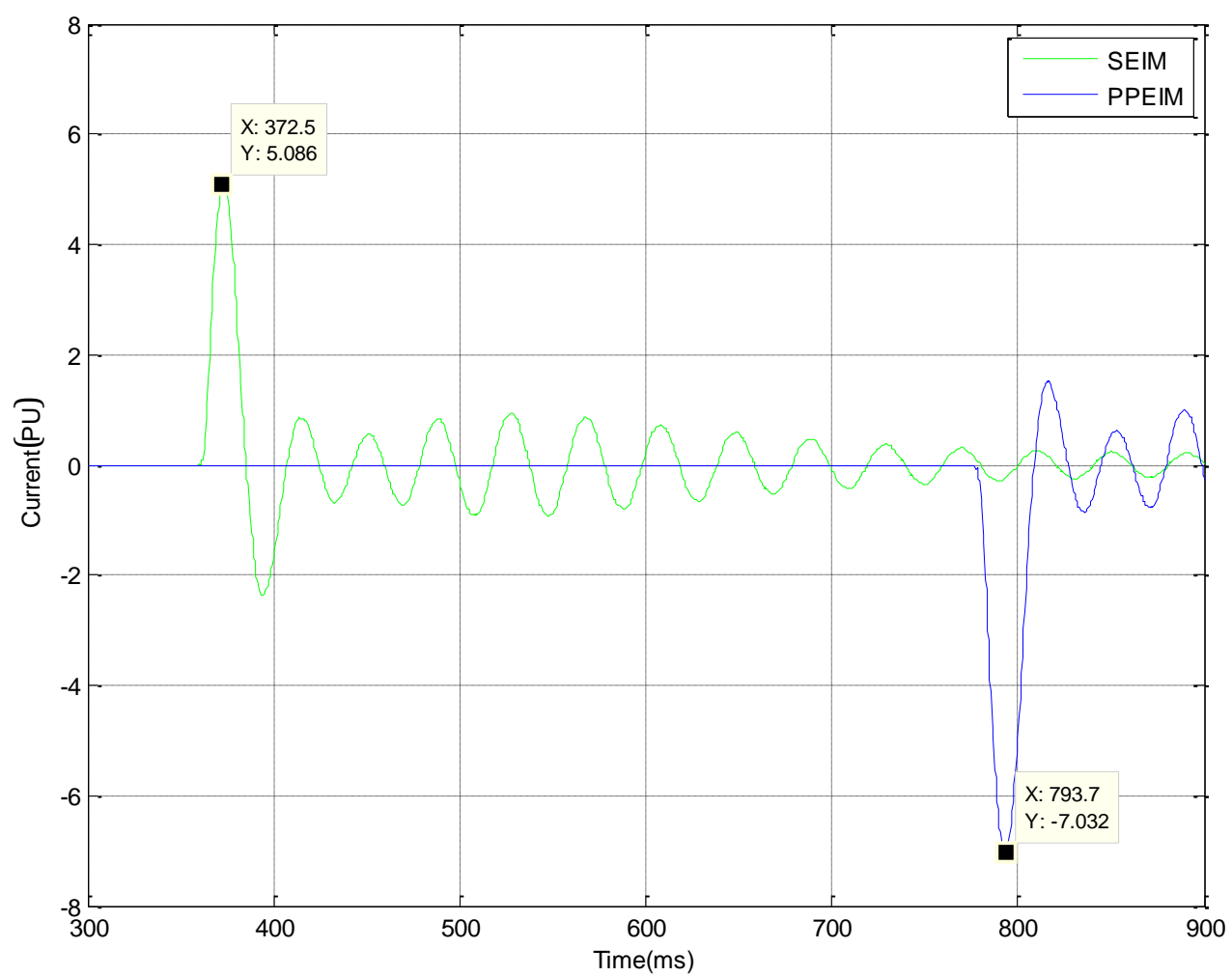

Figure 85: Phase A stator current - 180 degrees phase shift

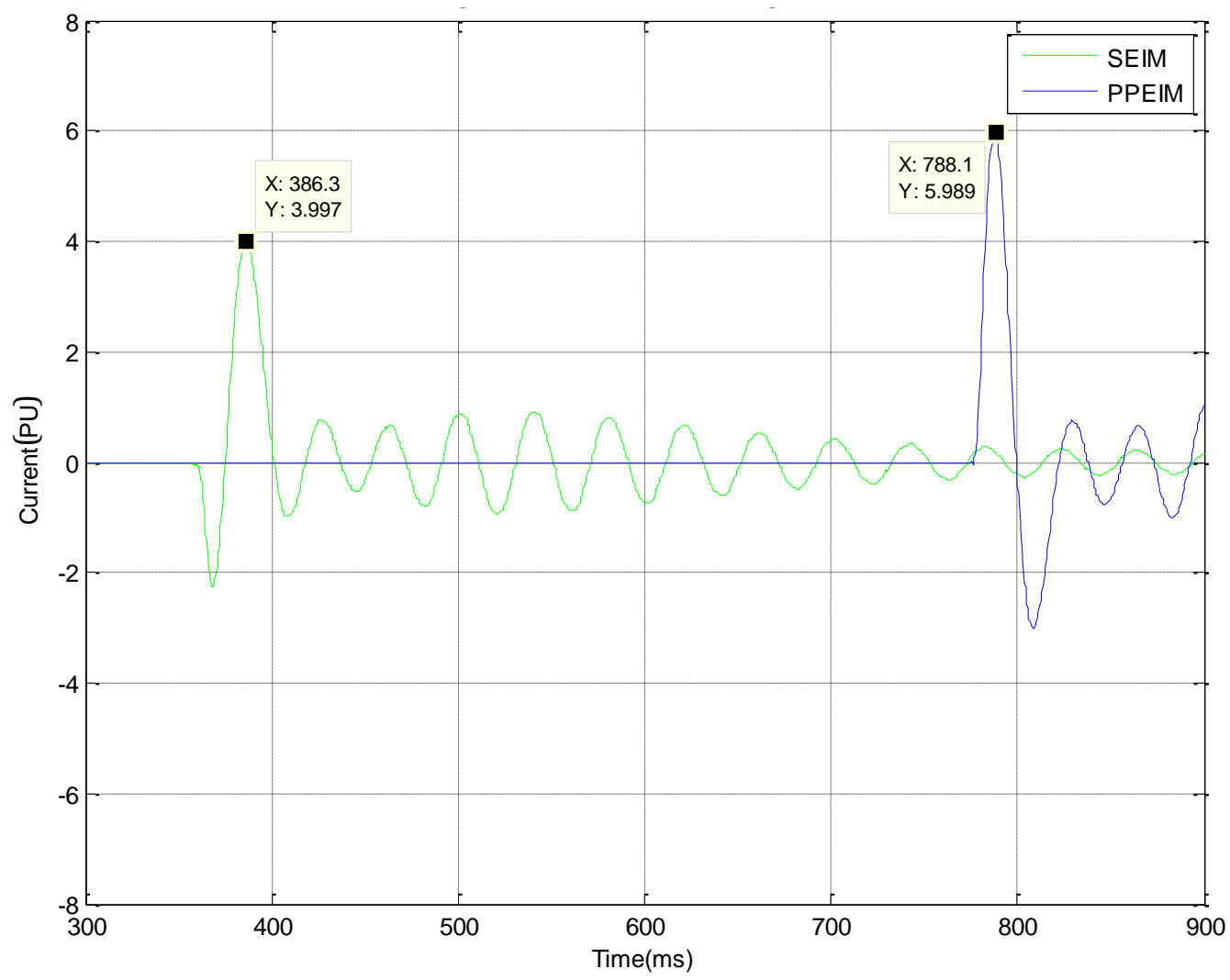

Figure 86: Phase B stator current - 180 degrees phase shift 


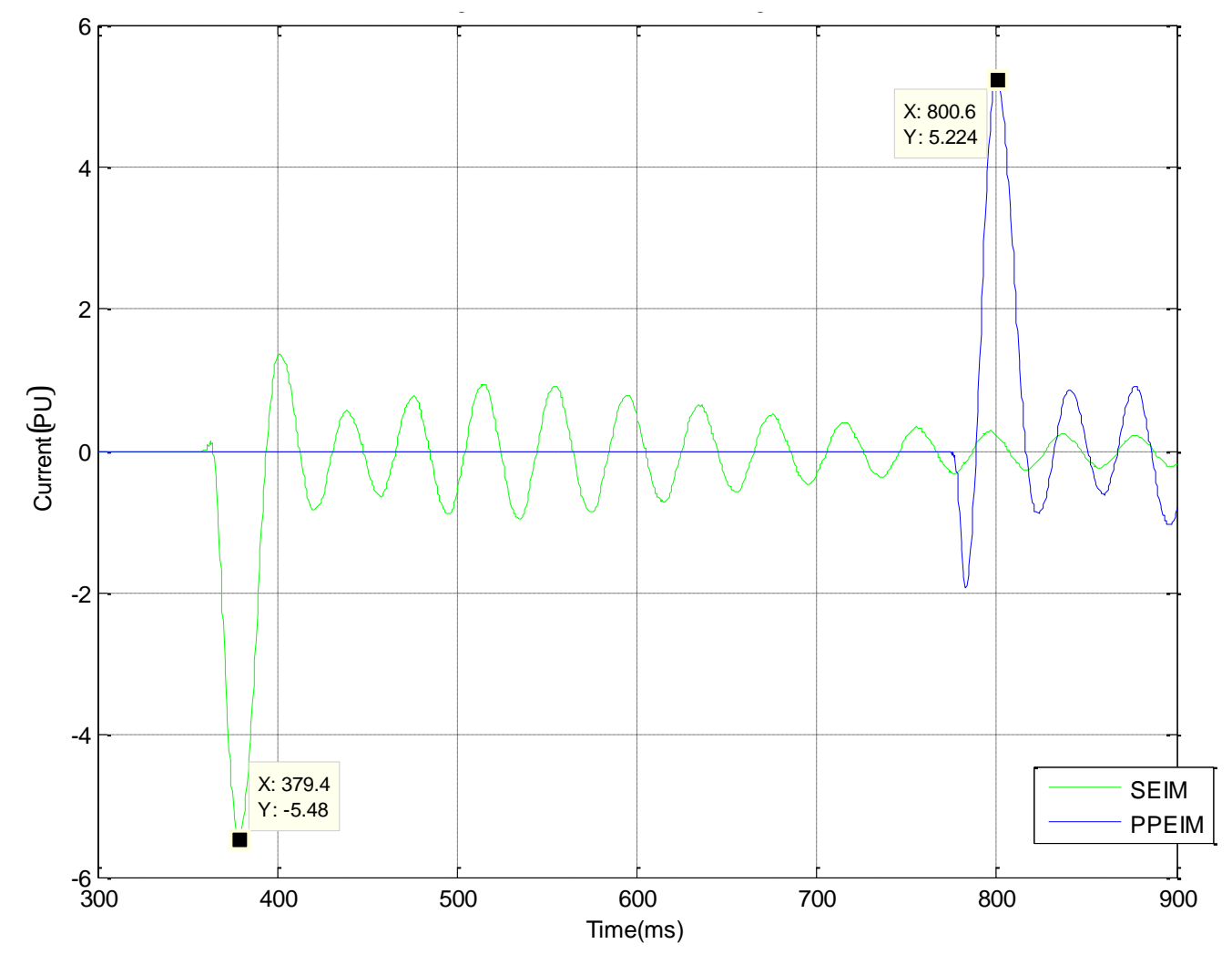

Figure 87: Phase C stator current - 180 degrees phase shift

iii. Torque

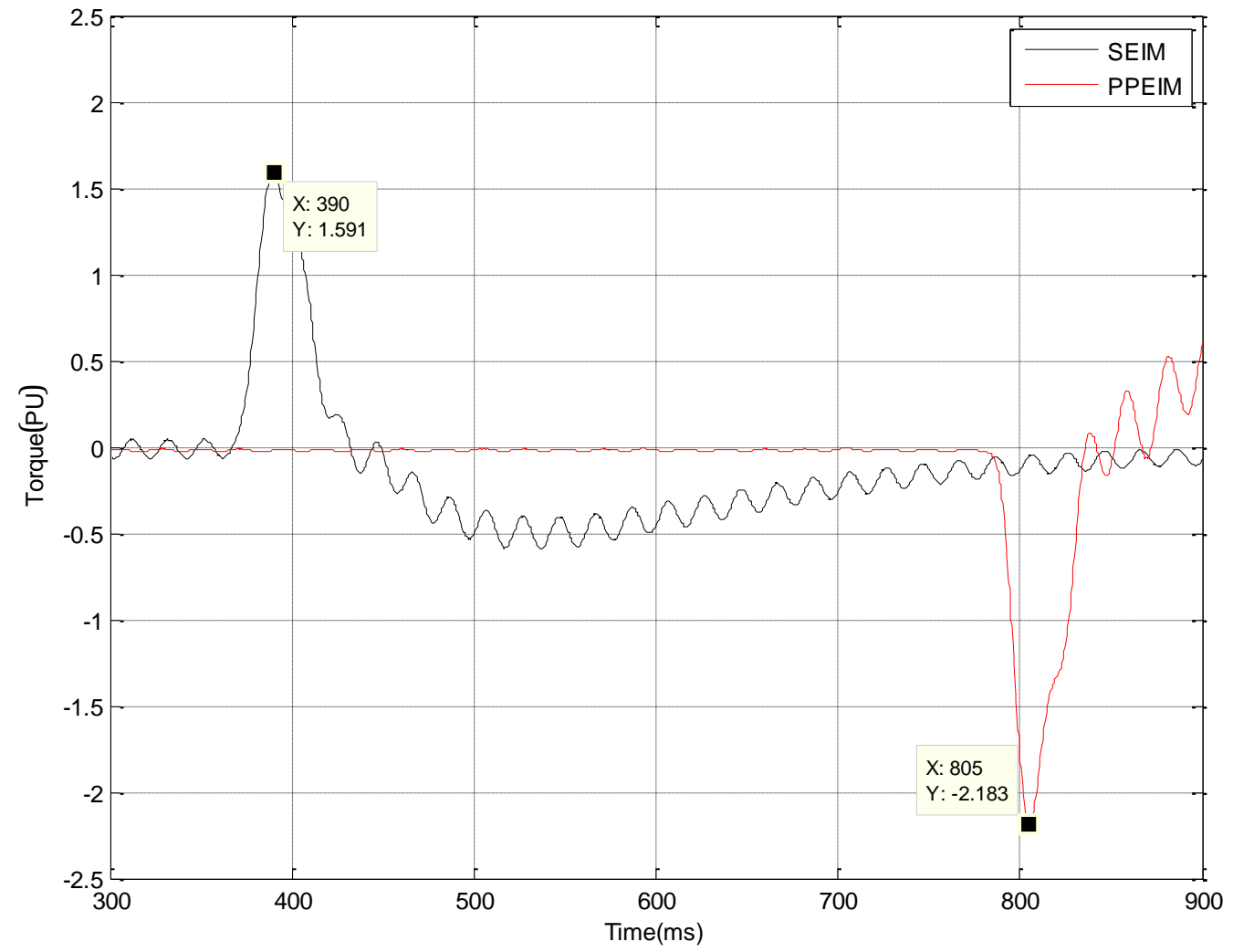

Figure 88: Torque - 180 degrees phase shift 